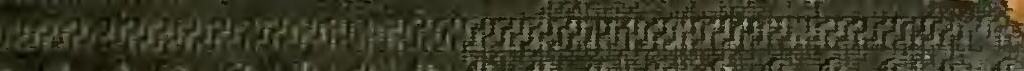

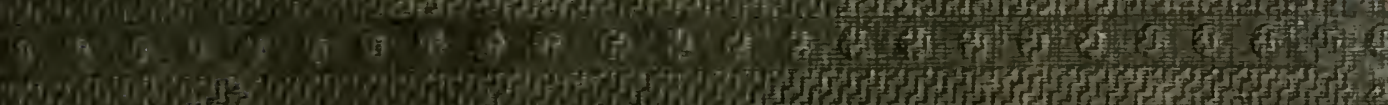

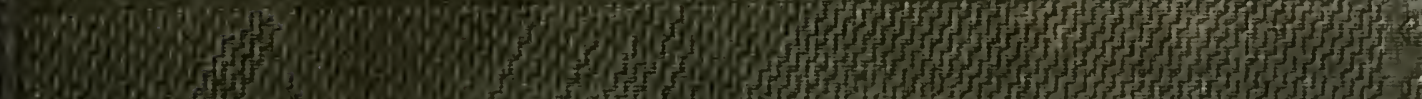
2013 $s_{3}$

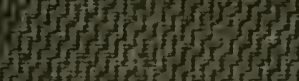




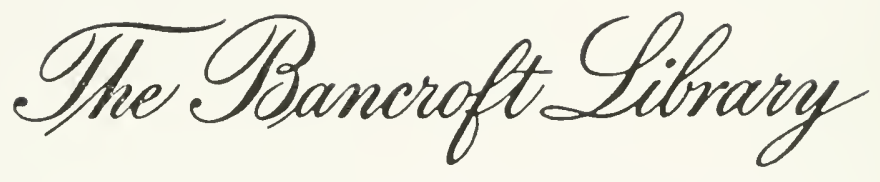

University of California - Berkeley

Gift of

Dr. \& Mrs. John C. Craig 


AN ACCOUNT

OF THE

\section{CULTIVATION AND MANUFACTURE \\ OF \\ TEA \\ I N C H I N A.}


LONDON :

Srotriswoode and SHaw, New-strect-Siquare. 


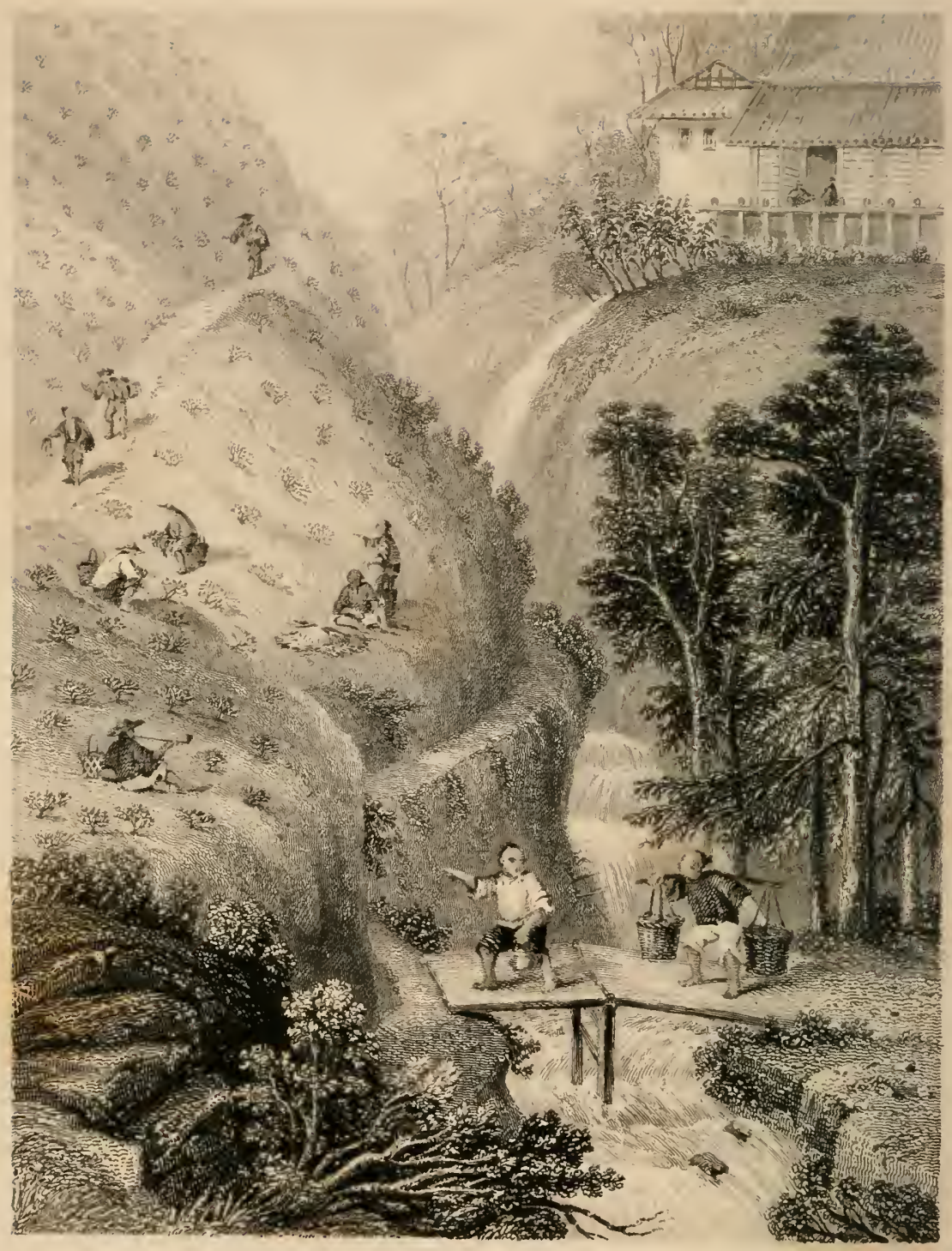




\title{
AN ACCOUN'T
}

OF THE

\section{CULTIVATION AND MANUFAC'TURE}

\author{
Or \\ $\mathrm{T} \mathrm{E} \mathrm{A}$. \\ I N C H I N A :
}

DERIVED FROM PERSONAL OBSERVATION

DURING AN OFFICIAL RESIDENCE IN THAT COUNTRY FROM 1804 TU 1826 ;

And illustrated ly the best Authoritiss, Chinese as well as European:

พITH

REMARKS ON THE EXPERIMENTS NOW MAKING

TOR THE INTRODUCTION OF THE CULTURE OF TIL TEA TREE IN other PARTS OF THE WORLD.

BY

SAMUEL BALL, EEQ.

LATE INSPECTOR OF TEAS TO THE HON, UNITED EAST INDIA COMPANY IN CHINA.

\section{ONDON :}

PRINTED FOR

LONGMAN, BROWN, GREEN, AND LONGMANS, PATERNOSTER-ROW. $18+8$. 
Digitized by the Internet Archive in 2008 with funding from Microsoft Corporation 


\section{SIR GEORGE THOMAS STAUNTON, BART. M.P. LL.D. F.R.S. \&c. \&c.}

IN TESTIMONY OF SINCERE REGARD AND ESTEEM,

\section{THIS VOLUME IS INSCRIBED}

BY

his obliged AND AtTACHed FRIEND AND SERVANT THE AUTHOR. 


\section{PREFACE.}

In laying before the public the following pages on the Cultivation and Manufacture of 'Tea in China, I have been actuated by a hope of dispelling some of the prevalent errors and misconceptions with which this subject has hitherto been involved; but mainly by a desire of supplying to the cultivator a desideratum, long and ineffectually sought, in aid of those attempts which are now in progress for the cultivation of the tea tree, on an extended scale, in British India, and other parts of the world.

The immediate aim, then, of this book is utility rather than amusement; and yet the general reader in turning over its pages may unexpectedly find his attention arrested by matter not altogether devoid of interest to him; while such as are stimulated by the gratification of a natural curiosity to seek some acquaintance with the modes of manipulating the fragrant leaf which "smokes as an infusion on our tables," may possibly find something which may instruct as well as amuse. At all events they will meet with a rational answer to a 
question frequently discussed at the tea-table, namely, "In what consists the difference between black and green tea ?" To the wholesale and retail dealer, if the task has been fairly executed, each page ought to have its interest; and the merchant will find, on reference to the heads of chapters, more than is promised by the title-page, on subjects regarding price, and other topics of trade. For the chemist some experiments are detailed, and a novel theory is submitted for further development from his science, as to a change in the constituents of black tea, which is traced to a process of manipulation previous to roasting, on which its darkness and redness of colour in leaf and infusion, as well as flavour, is supposed to depend. In the development, however, of this theory, I must claim the indulgence of the man of science, a character to which I make no claim.

The highly responsible and laborious official duties of my appointment under the East India Company, left me little leisure for literary pursuits during the season of activity at Canton; and during the recess at Macao, it must be acknowledged that $I$ found the enervating effects of a hot climate on a northern constitution indispose both body and mind to much exertion. It must also be confessed that the extreme retirement of my former life in China, with the absence of communion with literary and scientific men, as well as an imperfect supply of books, were great drawbacks 
to any preparation for appearing before the public as an author.

Still, having by labour, perseverance, and longcontinued exertion, expressly directed to this subject, collected something which may be useful, and seeing no probability of the same being obtained in a more effectual manner, and exhibited under more attractive forms, I feel induced, with an absence, however, of all pretension, to bring that something forward.

It will be seen by dates incidentally adverted to, that the facts, and most of the materials of this work, were established and collected thirty years ago. As regards the processes of manipulation, they were at all times noted down by me during the performance of the several stages of the process. These facts, as well as other materials, were derived from conversation with growers and manipulators from the tea districts; from written documerts furnished by Chinese; from published works in the same language diligently sought out; and also from correspondence with a Spanish missionary long resident in the province of Fokien. These were all put into their present form full twenty years ago, and were read to one or two friends during my residence in China. They have since that time received very little alteration, either in arrangement or expression.

They were not, however, so arranged with any view to immediate publication: on the contrary, I 
am too sensible, even at the present moment, of their great imperfection; but this arises not from any want of perseverance or diligence on my part, but from the peculiarly unfavourable situation in which foreigners were formerly placed at Canton. They were thus disposed as the best mode of recording and keeping together, in an intelligible form, the facts and materials I had collected. It was my wish to try some experiments on other leaves, which I have since done, as subservient to the development of the particular theory which I then entertained, and which I believe I have now successfully established.

On my return to England circumstances induced me to lay aside for a time my investigation relative to this subject. In the year 1839 the publication of the Parliamentary Papers on the "Tea Cultivation" at Assam attracted my attention, and directed my thoughts once more to this pursuit.

Since this period I have systematically and regularly pursued my inquiries, but for a long time without much success. No more publications issued from the India press relative to the cultivation of tea. Mr. Bruce's report of the manufacture of black tea is minutely and well described, but it contained nothing novel to me. My endeavours to obtain information from Java were equally fruitless; I consulted M. Guillemin's account of the cultivation of tea at the Brazils; and also Von Siebold's 
work on Japan, but altogether without advantage as regards the processes of manipulation.

Muldēr's excellent analysis of tea, though it did not determine points on which I sought instruction and confirmation of my own views, was nevertheless of the highest importance in directing my thoughts in the right channel; and to this paper and also to Liebig's Chemistry of Agriculture, I am indebted for the means of working out the theory concerning black tea, which I now place before the reader.

But it was not till the year 1844, when I received from a very old friend, Mr Bletterman, formerly chief of the Dutch Establishment at Canton, Mr. Jacobson's Handbook on the cultivation of tea at Java, that I found my own views so far confirmed, and my information such as to justify me in bringing my labours to a close. It will be seen by the large extracts in the form of notes, which I have subjoined to some chapters, how much I am indebted to this useful work.

It is unnecessary here to particularize what parts of my work were written in China, and what since; the subjects sufficiently explain themselves, and will be for the most part intelligible to the reader.

It has not formed any part of my plan to make quotations except from original sources; but I cannot pass over in silence the excellent work written by Dr. Lettsom; nor the able chapters on this subject contained in Dr. Royle's work on the 
"Botany of the Himalayan Mountains;" and in his "Productive Resources of India." It would be unjust to this able and scientific author to say that I had derived no assistance from these valuable works.

For the translation of Mr. Jacobson's treatise, written in the Dutch language, I am indebted to $\mathrm{Mr}$. Bruggermeyer, principal clerk to Messrs. Hofman and Schenk of the city of London. This work was published at Batavia in 1843 in three volumes. The first is an epitome of the other two. It is now under translation by Mr. Frith in Bengal*; but unless that gentleman translates the other two volumes, he will convey a very imperfect idea of the merits and matter of the work itself. The second and third volumes consist of 587 pages. I have made an abstract of them through an oral translation, and have compressed them into about eighty pages, having, as I believe, seized on all the material points. The notes given will enable the reader to judge how this task has been performed.

For a translation of Von Siebold's chapter on Tea, contained in his "Nippon," and for Mulder's analysis, I have been indebted to friends.

The plates belonging to this work were engraved from drawings made by Mr. J. W. Archer from Chinese sketches. The two views of the "Inner

* See Journal of the Agricultural and Horticultural Society of India, vol. v. parts 3 and 4. 
Range" of the Bohea Mountains were engraved by Mr. James Willmore, A. R. A., and the figures manipulating tea by Mr. Mason Jackson. They were executed con amore, and do credit to these able artists: and I avail myself of this mode of expressing my obligations to these gentlemen for the able and skilful manner in which they have preserved the spirit and character of the originals, while reducing them to the rules of art.

In conclusion, I would only observe that if this work should in any degree accomplish the objects for which it has been undertaken, I shall not regret the time and labour which I have devoted to its execution.

London, Dec. 30. 1847. 



\section{CONTENTS.}

\section{CHAPTER I.}

Discovery and early history of the tea tree in China-Introduction and gradual improvements of the processes required in its manipulation - Geographical distribution of the tree in China - Its extensive use, and mode of using it in China -At Japan - Von Siebold's opinion, that the tea tree was originally introduced into China from Corea, examined Proved to be indigenous - Identity of Assam tree doubtful - Extensive geographical distribution of the Chinese tree.

Page 1

\section{CHAP. II.}

Climate of China influenced by monsoon winds - No wet and dry season as in India-Quantity of rain at Canton - At Peking - Increase of temperature and humidity great from March to May - Temperature at Peking - At Canton - In the green and black tea countries - Foo-chew-foo-AmoyFrost severe but not continuous - Ice preserved through the summer - Temperature of Shang-hai - Chusan - Great variation of temperature principally in winter-Daily variation small - Climate generally salubrious - Tea tree exposed to great differences of climate-Climate most suitable

\section{CHAP. III.}

Black tea - Districts where the best kinds are found and cultivated - What situations are the most favourable - Exposure and nature of the soil - Accounts given in Chinese works By European missionaries - The various opinions as to the most suitable soil examined-Attempt to reconcile some 
of these differences - Soil the most suitable - Analysis of tea soils from China and Japan

Page 40

CHAP. 1V.

Culture - Accounts given in Chinese works - By European missionaries - Plantations seen by Mr. Gordon at Amoy Cultivation of green tea different from black - Mode practised in Japan - In Java

\section{CHAP. V.}

Time of gathering - Three gatherings - Difference of quality of the gatherings - Only young succulent leaves fit for tea - Mode at Java

\section{CHAP. VI.}

Manipulation previously to roasting - Mode described by a Chinese-Exposure or non-exposure to sun-Expedients adopted in rainy weather - Description of the several processes - Fragrance, none in fresh leaves - Developed by manipulation - Personal observation of the several processes - Redness of the leaf

\section{CHAP. VII.}

Roasting and final drying of the leaves - Two processes Roasting vessels and stoves described - Mode of roasting - Mode of rolling - Process of 'Ta-ching - Final drying - Stoves and instruments used - Mode of drying - Markets established - Packing of the tea at the village of Sing-csun - Remarks on the processes of manipulation - Variations in the mode of manipulation-Observations on the modes described by Mr. Fortune - Some teas wholly manipulated in the sun-Experiments on this mode, and deductions therefrom

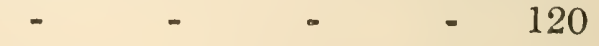

\section{CHAP. VIII.}

Manipulation of Pekoe, Caper, Nao-csee, and Long-csin teas The scenting of tea - Bohca tea-Originally brought from 
the tea country unmanipulated-Attempts to procure it manipulated - Size of chests found too large for inland carriage - Brought by sea - Also large quantities of Congou - Jealousy of Chinese government at this innovation Imperial edict prohibiting the shipment by sea from the port of Foo-chew-foo - Importance of this port - Doubts regarding the port examined and answered - Mode of roasting and drying Bohea tea at Canton - Brick-tec - Its form and manipulation - Its extensive use in Mongolia Description of a fête at Ourga - Caravans of this tea frequently fallen in with by travellers - Employed as a circulating medium - As money at horse races, feats of strength, and archery - Establishments of tea houses across the desert of Gobi frequent - Extensive use in Tibet - Mode of preparation for use throughout central Asia - Mixed with butter and flour, and churned - Capt. 'Turner's opinion of it - Mr. Manning's opinion - Teapots employed highly ornamented - Tea of Bisahar - - _ n - Page 154

\section{CHAP. IX.}

Green tea - The Hyson shrub is the Singlo shrub improved by cultivation - Gathering and manipulation - Roasting vessels described - Mode of manipulation of Hyson tea - Colour not factitious - Manipulation continued-Assortment of leaves into gunpowder, Hyson, Hyson skin, and young $\mathrm{H}_{y s o n}$ by sifting and winnowing - Twankay tea - Mode of manipulation described by a Chinese - Factitious colouring of green tea - Experiments to determine on what the peculiar colour of green tea depends - Factitious colouring of green tea continued - Mr. Warington's examination of this subject - Experiments with steam - Observations on the use of machinery as abridgments of labour - - $\quad 206$

\section{CHAP. X.}

Heat employed in the manipulation of tea in China - at Java - Absorption of heat by the leaves limited by evaporation Proved by experiment - Cause of leaves not burning Amount of heat regulated according to the succulency of the 
leaves - Heat employed at Java too low for green teaDifficulty in determining the requisite amount of heat Temperature recommended - Used at Java - Mode of measuring it liable to error _ _ _ n $\quad$ Page 246

\section{CHAP. XI.}

Review of P. :Mulder's analysis of tea-Colour of black tea not due to high temperature - Black tea not dried at a higher temperature than green - Gunpowder tea dried at the highest point of the scale of temperature, and Pekoe tea at the lowest -The red or brown colouring matter of black tea not due to high drying - The term black a misnomer - Analysis of tea - Odorous principle derived from a volatile oil - Developed in coffee by high temperature - The red or brown colouring matter of black tea in leaf and infusion traced to chemical causes - Other parts of the analysis reconciled with the preceding theory - Flavour dependent mainly on manipulation - Recapitulation of the modes of manufacturing black and green tea - Difference of quality of tea traced to various causes$$
-
$$

270

\section{CHAP. XII.}

Observations on the botanical and specific difference of teaOpinion of the Chinese, soil the only cause of difference Analogous cases in other vegetable productions - No difference at Java - No certainty that we possess true specimens of the black and green tea shrub of commerce - The Thea Bohea a Canton plant - The Assam plant doubtful as to species Examination of the grounds on which botanists have established a specific difference - Opposed to actual observation at Japan, Java, and the Brazils - Probably only one species but several varieties - All botanical difference destroyed in the course of packing - Probability that superior shrubs do exist in the Bohea and Hyson districts, the effect of long and careful cultivation

307.

\section{CHAP. XIII.}

Introduction of the cultivation and manipulation of tea into India - Supposed low rate of wages in China, and great 
cost of production examined - Mode of living of the Hindoo cultivator - Of the Chinese cultivator - Comparative rate of wages in the two countries - Sketch of the trade under the East India company - Effects on price since the abolition of the charter-Great profits of the Hong merchant - Expense of transport of tea from the tea country to Canton and Foochew-foo compared - Cost of tea at its seat of growth - Cost to the European at Canton - At Foo-chew-foo-Price with which the cultivator will have to compete-Cost of production at Assam - Kamaon - Java and the Brazils.

Page 333

APPENDIX 


\section{ERRATA.}

Page 91. note, line 3., for "Ting Hing " read "Tien Hing." 273. line 6., for "higher "read "high."

324. line 13., for "at Japan "read "in Japan." 


\title{
AN ACCOUNT
}

OF THE

\section{CULTIVATION AND MANUFACIURE}

\author{
OH \\ I'EA IN CHINA.
}

CHAPTER I.

DISCOVERY AND EARLY IIISTORY OF THE TEA TREE IN CHINA INTRODUCTION AND GRADUAL IMPROVENENTS OF THE PROCESSES REQUIRED IN ITS MANTPULATION-GEOGRAPHICAL DISTRIBUTION OF THE TREE IN CHINA - ITS EXTENSIVE USE, AND MODE OF USLNG IT IN CHINA - AT JAPAN — VON SIEBOLD'S OPINION, THAT THE TEA TREE WAS ORIGINALLY INTRODUCED INTO CHINA FROI COREA, EXAMINED - PROVED TO BE INDIGENOUS-IDENTITY OF ASSAX TREE DOUBTFUL-EXTENSIVE GEOGRAPHICAL DISTRIBUTION OF THE CHINESE TREE.

THe origin of the use of tea, as collected from the works of the Chinese, is traced to the fabulous period of their history; not, however, so much from the vanity of assigning to it a high antiquity, as to a kind of courtesy sanctioned by ancient usage and oral tradition, which ascribes the dis- 
covery of numerous medicinal plants, and of tea among the rest, to the Emperor Shin Nong*, esteemed as the inventor of agriculture, and author of physic: - for the Chinese themselves admit their chronology of this period to be defective, and that they have no authentic histories prior to the time of Yao and Shun. $\dagger$ It nevertheless is a common practice among empirics, even at the present day, to ascribe the discovery of their several nostrums to the Emperor Shin Nong, though all such pretension is treated as fabulous; and, with respect to tea in particular, receives no sanction from the more recent Chinese accounts of the history of that tree.

The earliest authentic account of tea, if any thing so obscure and vague can be deemed authentic, is contained in the She King, one of the classical works of high antiquity and veneration among the Chinese, and compiled by their renowned philosopher and great moralist Confucius.t This work, however, contains no more than the following obscure expression which is considered by the Chinese commentators as having an allusion to tea"Who says the $\mathrm{Tu}$ is better, it is sweet as the Csy." Now, we learn from other authorities, as well as from the standard dictionary of the country, published with the sanction of the Em-

* B. C. 3254 .

$\dagger$ 1. c. 2357 , see translation of Du Halde, vol. i. page 143, note. $\ddagger$ Born 550 в.c. 
peror Cang $\mathrm{Hi}$, that $\mathrm{Tu}$ 紫 was the ancient mode of writing Cha 算, and that both characters were used indifferently in so remote a period as that of Han, and down to the time of Lo. yu*, who lived in the Tang dynasty; when the character $\mathrm{Tu}$ fell into disuse, and the term Cha was substituted in lieu of it. This author wrote a short and interesting treatise on tea, to which we shall again refer.

In the Kuen Fang Pu, a work on natural history, there is a treatise called the Cha Pu, which is the most elaborate account of tea $I$ have met with. In this treatise, under the article "Ancient History of Tea," an absurd story is related of the discovery of this tree in the Tsin dynasty. $T$ Then follow others of an equally uninteresting nature, and of the same and subsequent periods; when mention is made of its being used as a medicine on the recommendation of a priest of the sect of $\mathrm{Fo}$, by the Emperor Ven Ty t, who established the dynasty of Suey, from which time its use as a

* A.D. 780 .

$\dagger$ In the reign of Yuen Ty in the dynasty of 'Tsin (A.D. 217), an old woman was accustomed to proceed every morning at daybreak to the market-place, carrying a cup of tea on the palm of her hand. The people bought it eagerly; and yet, from the break of day to the close of evening, the cup was never exhausted. The money received she distributed to the orphan and the needy beggar frequenting the highways. The people seizcd and confined her in prison. At night she flew through the prison window with her little vase in her hand.

$\ddagger$ A.D. 584 . 
beverage became generally known. The same work contains an allegory on tea, which ascribes its discovery and introduction to Imperial notice in the Heu Han dynasty * ; but it is designedly too full of poetical anachronisms to be deemed of any weight or authority. Nor does the author of this work attach much importance to such fables, nor even to accredited authorities which place the discovery of the use of tea so early as the Heu Han dynasty; for he distinctly states, in a short preface to this treatise, "That though tea is inclucled in Shin Nong's $\uparrow$ account of aliments, yet it was first used as a beverage in the reign of Suey Ty, or Ven Ty, and acknowledged good, though not much esteemed; but from that time, and during the dynasty of Tang $\$$, it gained in reputation, and was abundant in that of Sung $\$$, being esteemed and used everywhere."

The preface here alluded to is immediately followed by the Cha Kin, written by the learned personage Lo-yu, already mentioned, who lived in the dynasty of Tang, which is perhaps the most ancient authentic description of tea contained in the Chinese annals; and as it also treats of the qualities and effects of this plant, the reader may not be unwilling to know what this writer says on a subject which has occasioned such a diversity of
* A.D. 221 to 279.
$\dagger$ в. C. 3254 .
t A.D. 618 to 906
$\S$ A.v. 960 . 
opinion in Europe, and some even in China. After eulogising its fragrance and flavour, he observes "It tempers the spirits, and harmonises the mind: dispels lassitude, and relieves fatigue: awakens thought, and prevents drowsiness: lightens or refreshes the body, and clears the perceptive faculties." Again, in the allegory alluded to, one of the emperors of the Han dynasty is made to say, "The use of it grows upon me surprisingly : I know not how it is, but my fancy is awakened and my spirits exhilarated as if with wine." The learned author Lo-yu then proceeds to state, that — "All tea is gathered in the second, third, and fourth moons. The leaves must not be gathered in rainy, or even in cloudy weather, but when it is fair and clear. Bruise and pat them with the hands; roast them over a fire (poey); pack and close them up. In this manner tea is prepared; and there are a thousand and ten thousand. different kinds." Then follow other remarks and frivolous comparisons not very intelligible - at least to me. It is obvious, from the preceding account, that the Chinese were well acquainted with tea at this period; and we also find from other authorities that during the reign of Te Tsong, in the same dynasty, the consumption of tea was already so considerable as to attract the notice of government as an advantageous subject for impost. It is stated as a matter of history in the Kaung-moo, an abridged history of 
China, that a duty on tea was first levied in the fourteenth year of that reign.* In the dynasty of Sung $\uparrow$ the duty was again increased, and tea was first sent up as tribute, or as an annual offering to the emperor. It must also be noticed, that the Arabian travellers who passed into China in the ninth century $\$$ speak of tea as the common beverage of the country.

Now, from the reign of the Emperor Ven Ty, who founded the dynasty of Suey, in whose reign the author of the Cha $\mathrm{Pu}$ ascribes the first use of this plant as a beverage to that of Te Tsong, in the dynasty of 'Tang, when the first duty was levied, two centuries had elapsed; a period of time abundantly sufficient for its introduction into general use. This would place its origin as a beverage in the sixth century of the Christian era; and to pursue this inquiry further, in order to elicit the truth from the mass of confused and apparently contradictory evidence contained in the Chinese works on tea, would require a research which the subject cannot be deemed to merit. We shall therefore conclude, that although this plant may have been known to the Chinese so early as the third and fourth century of the Christian era, and occasionally resorted to as a medicine, yet, agreeably to the author of the Cha $\mathrm{Pu}$, its use as a beverage was not known prior to the sixth century; that it be-

* A. $1783 .+$ A. D. $969 .+$ A. 19.850. 
came abundant in the seventh and eighth, and general over the empire in the ninth century.

If the origin of the use of tea is involved in much obscurity, it may readily be imagined that the early mode of manipulation is not less so. The subject, however, being one of little interest, we shall here adopt the opinion of the author of the allegory before alluded to, - that tea was originally made into the form of cakes. Both prior and subsequent to the time of Lo-yu, allusion is made to this form among the early notices of tea; and also of these cakes being ground to powder, and used as an infusion, sometimes as a medicine, and sometimes at feasts and banquets; though when employed in early times at these entertainments, it always, perhaps, had some reference to its medicinal properties, as promoting digestion, or as stimulating the appetite. In the like manner camomile tea, and the Po-ul tea, are served in the present day at those tables, where a style refined and recherché is much studied. The writer has been present at an entertainment of this nature, where a strong infusion of camomile tea was served round after a numerous succession of dishes, constituting what may be called the first course, which had lasted more than an hour; and where, among other luxuries, the opium pipe was offered to such guests as were willing to enjoy it; but this was at a time when that fascinating but noxious 
drug, from its great cost, was used only by the rich and luxurious.

The only mode of manipulation spoken of in early times is by the agency of steam. The leaves were steamed, some say, to extract a bitter water from them, then rolled with the hands, or in cloths, and dried sometimes in the sun, and sometimes over a charcoal fire (poey). Whether the leaves were partially dried in the sun, or by fire, and then reduced to a powder to be formed into cakes; or whether they were preserved entire, and then rolled and moulded into the form of cakes or bricks, does not appear. One author, in speaking of La Cha*, says, "it is ground to powder and made into cakes, which are dried in the sun, but it is better to dry them over a fire." Another says, "the leaves are steamed, afterwards dried over a charcoal fire, and then reduced to a powder." By the first method, I understand that the leaves were kept entire, though formed into a cake; by the second, that the leaves were first reduced to a powder, and then formed into a cake. But it may be presumed that both these methods prevailed, since all these modes, forms, and even narnes, exist in the present day; as we shall further have occasion to notice.

That the mode of manipulation as it exists at the present time, where each leaf is preserved in

* It is doubtful whether the La Cha was made from the tea tree or a substitute. 
its individual state, also obtained at a remote period, there seems no reason to doubt. The commonly received opinion among the Chinese is, that it has prevailed from the time of Lo-yu; though we have no authority for this opinion, as far as I have been able to discover, beyond that of current belief and oral tradition. This learned personage does not speak of stcaming the leaves, as other early authors do; nor of forming tea into cakes, which modes constitute an important difference. Nor does he speak of rolling the leaves, which is doubtless an omission, or an error which has crept into the character or symbol used. Nor does he notice the process of chao (the roasting of the leaves in an iron vessel); but simply that of poey (the drying of the leaves over a charcoal fire). Neither do any of the early writers make use of the term chao. So that the method as described by Lo-yu in the Cha-kin, is simply that of beating and patting the leaves, and drying them over a charcoal fire; unless indeed, which is not improbable, the leaves were rolled either before or during the process of drying. Either of these modes would be sufficient to give the leaf its twisted form, as at present used: which form it is believed also prevailed at this remote period.

There can be no doubt that the Pekoe tea was early known to the Chinese, and was much esteemed by them. Indeed, they appear soon to have made the discovery that the young and suc- 
culent leaves were the best; or, as it is stated by them, that "the convoluted bud of the leaf is the best, and other leaves in proportion as least developed." It is obvious, also, that the bud of the leaf, from its natural compactness of form, would require no rolling, or formation into cakes, but was very likely to have been kept in its natural and individual state, as its different appellatives, bird's tongue, ear of corn, grey eye-brows, falcon's talons, and others, sufficiently indicate: and all these names are of ancient as well as of modern usc. Any imitation of this tea for purposes of fraud or commercial advantage, would soon lead to a general introduction of the manipulation into leaf, if found a superior method, as is universally acknowledged.

Nor is there any reason to suppose that these teas were not steamed like the rest, as this custom also prevails in the present day. The Long-csin tea of Che-kiang, and the Lien-czu-sin of Su-chao in Kiang-nan, and the Udsi tea of Japan, are examples of this mode of manipulation. These teas are green teas; but when the bud of the leaf is roasted and dried agreeably to the method practised in the Bohea country, it is a black tea, and is known under the general denomination of Pekoe tea.

The processes of chao and poey, that is, the roasting and drying of the leaves, as at present employed in the manipulation of tea, will be found fully 
explained under their respective articles. At what period these methods were introduced does not appear; but the superiority of these modes is acknowledged by the author of the Cha $\mathrm{Pu}$. The date of this work is not known to me. The author observes, on the manufacture of tea, that, "The leaves must be gathered just prior to the season of Ko-yu, picked clean, and heated with steam. When they change colour, spread them out, and fan off the steam with a fan; then roll and dry them over a charcoal fire (poey); and finally fold them up with the leaves of the Jo plant. It is said, that tea which is steamed in the first process is not so good as that which is roasted in an iron vessel (chao): and in the second process, that which is sun-dried is not so good as that which is dried over a charcoal fire (poey). So that which is first roasted in an iron vessel, and finally dried orer a charcoal fire is excellent." This latter method is the mode now adopted in the black tea districts for the preparation of the best teas.

Regarding the early geographical distribution and discorery of the tea plant, we again select the author of the Cha $\mathrm{Pu}$ as our guide. From this work we learn, that the tea plant, though spread over the "hills of note," was first discovered, or first attracted attention in the Vî-ye, or Bohea district (as Europeans have corrupted the name), in the province of Fo-kien. And this author, choosing to lend himself to fiction, partly from 
deference to certain prevailing popular opinions and tradition, and partly, perhaps, to give a greater éclat to his history, by connecting it with one of the most celebrated and stirring periods of the Chinese annals, has placed that discovery in the dynasty of Han.*

It is further remarked by the same author, and also by other authorities, that the tea plant was discovered in the Mong-shan district of the province of Szu-chuen in the reign of Te-tsongt: again, in the Singlo Hill, or green tea district of Kiang-nan, during the Sung dynasty $\$$ : and in very early times, though the precise age, perhaps, cannot be determined, it was found in the provinces of Fokien, Che-kiang, Kiang-nan, Kiang-sy, in the northern and southern divisions of Hooquong, and in Szu-chuen - every where among the hills or mountains.

Certain statistical works $\|$ and herbals also enumerate several places in all the provinces of the empire where tea is produced, as far north as Tang-chao-foo, in Shan-tong, $36^{\circ} 30^{\prime} \mathrm{N}$. lat.; as far south as Canton and Quong-sy, and as far east as the province of Yun nan. The Jesuit

* A.D. 221 to 279 .

† A. D. 780. So the Pen-csao-kiang-moo, and Kuen Fang Pu.

From the Moo-yuen-chy, a statistical work of that district.

$\S$ So the Pen-csao-kiang-moo.

\| The Pen-csao-kiang-moo, Kuen Fang Pu, Hoa-king, and others. 
missionaries also state, that tea grows in the province of Pe-chy-ly, though not in the immemediate vicinity of the capital; and all my inquiries on the subject tend to confirm that opinion. I was especially informed by the Père Amiot of the truth of this belief. Still the Chinese say, that the northern provinces of Pe-chy-ly, Shan-sy, Shen-sy, Shan-tong, and even Honan, are not favourable for the growth of tea. Bell states that he saw the tea plant in a garden at Peking, which appeared like a currant bush; but adds, "the climate about that capital being too cold for this shrub, there are only a few bushes of it found in the gardens of the curious." (Bell's Travels, p. 235.)

There can be no doubt that the tea shrub is very extensively cultivated in China; and the probability is, that every province, by means of its sheltered vallies, is enabled to contribute largely to its own domestic consumption. Still the ground allotted to the growth of this shrub, being commonly only such as is unproductive, hilly, or otherwise unprofitable, as the embankments of arable and cultivated ground; and as every part of the empire is not equally favourable to its growth, it has often been questioned, how far the use of this refreshing beverage is within the daily reach of the lowest order of the people. It is without doubt cxtensively used by all classes of the community, even the lowest, in some form or other, throughout this vast country; but it is equally certain, that 
innumerable other leaves are employed as substitutes by many people among the poorer class, as frequent experience shows. I examined many samples of such tea brought down to Canton by the gentlemen connected with Lord Amherst's embassy. Long lists of plants, moreover, are found in many of the Chinese herbals, to which the same term "tea" is applied; though the Chinese very well distinguish the true tea from its substitute, by observing, that the plants so used, "though they bear the name of tea, are not of the tea species." In fact, they use the term "tea" in a general sense as we do, to signify any infusion of leaves, as balm, camomile tea, and others.

Bell observes (Travels in China, pp. 297. 309.), that he went to a public tea house at Peking, where he saw many people drinking tea and smoking tobacco; and adds, that with a cash (about the tenth part of a penny English) a man can buy a dish of hot tea. The late Sir George Staunton also informs us, "That tea, like beer in England, is sold in public houses in every town, and along public roads, and the banks of rivers and canals; nor is it unusual for the burdened and wearied traveller to lay down his load, refresh himself with a cup of warm tea, and then pursue his journey." * It has already been observed, that the Arabian traveller's who entered China in the ninth century, speak of

* Lord Macartney's Embassy to Peking, rol. ii. p. 96. 
tea as the common beverage of the country, even at this early period; and all recent travellers furnish sufficient evidence of its general use in the present day. The wealthy Chinese simply infuse the leaves in an elegant porcelain cup, which has a cover of the same material; the leaves sink to the bottom of the cup, and generally remain there without inconvenience, though occasionally some may float or rise to the surface. To prevent this inconvenience, sometimes a thin piece of silver, of filagree or open work, is placed immediately on them. Where economy is necessary to be studied, the tea-pot is used. The wealthy Japanese continue the ancient mode of grinding the leaves to powder; and after infusion in a cup "it is whipped with a split bamboo, or denticulated instrument, till it creams*, when they drink both the infusion and powder, as coffee is used in many parts of Asia."

It may here be proper to remark that, on the authority of certain Japanese authors, a doubt has been raised by the Doctor Von Siebold, an intelligent botanist some time resident at Japan, as to the tea plant being indigenous in China. All are agreed that it is of exotic growth in Japan; and was introduced into that country from China, in the sixth century, agreeably to Kæmpfert, or

* Kampfer's Japan, Appendix, p. 15.; also, Manners and Clistoms of the Japanese in the Nineteenth Century, p. 187.

$\dagger$ Kompfer states (Japan, Appendix, p. 2.), that the tea plant was introduced into Japan from China in the year A.D. 519, by a prince of the name of Darma. It is remarkable that the Chinese 
the ninth century (which seems more probable) according to Von Siebold.* Both opinions are grounded on Japanese authorities. The latter author makes use of a very ingenious argument, based on the physical condition of the plant as exhibited at Japan, in further testimony of the truth of those historical accounts which affirm the tea plant to be of foreign introduction.

This intelligent author observes, that "the tea plant is found in the southern provinces of Japan, between the $30^{\circ}$ and $35^{\circ}$ of north latitude, growing abundantly along field-paths, way-sides, and ridges, as if. of spontaneous growth, and also planted in fields in unproductive ground: but on further advance towards the mountains it disappears." Hence, he assumes, perhaps judiciously, though not conclusively (the circumstances of climate being nearly the same), that the tea plant is an imported production at Japan. But the learned author seems to have confided too much in the

chronicles speak of a person of that name, describing him as a native of India, who visited China during the reign of Vû Ty, of the Leang dynasty, A.D. 543. He was in all probability a Fakir, and crossed over to Japan. During my residence at Canton, a devotee of this description visited that city, and came by sea.

* Mco-we, a Bonze, travelled into China, and brought back tea seeds from China. They were planterl on the hill of Toga-no-wo, in Jamasiro, about two leagues north-west of Mijako ; also at Udsi, a distriet of that province. (Japanese Eneyclopredia. IIak-buts-sin.) Another work states, "it was introduced A.D. 810." (Von Siebold's Nippon, part 6.) 
authenticity of those Japanese authorities, which state that the Chinese received the tea plant from Corea. It has already been shown, that even a tax was imposed on tea by imperial mandate, more than thirty years prior to the assumed date of its first introduction into China by the Coreans (A.D. 828). And if we adopt the same ingenious line of argument with reference to China, which the learned author has employed regarding Japan, the converse of his proposition will be proved; for the Chinese accounts all agree that the tea tree was first discovered where it is found growing in the present day-every where among the hills and mountains in the central provinces of the empire; and, consequently, is indigenous.

Recent, discoveries in Assam * also seem to justify the assumption, if nothing to the contrary be known, that it has spontaneously extended its growth along a continuous and almost uninterrupted mountainous range, but of moderate altitude, nearly from the great river the Yang-cse-

* Dr. Falconer considers the Assam tea tree to be a distinct species, and $\mathrm{Mr}$. M'Cleland a native product. This author concludes his interesting paper on the Assam tea plant in the following words : - "In this way, we derive from zoology additional aid in support of those views which the sister sciences afford, and are taught to look upon the tea plant in Assam, thus associated with the natural productions of Eastern Asia, not as an alien estranged from its own climate, but as an indigenous plant, neglected it is true by man, but in the full enjoyment from nature of all those peculiar conditions on which its properties will be found under proper management to depend." 
kiang to the countries flanking the south-western frontier of China, where this range falls in with, or, agreeably to the opinion of a well-informed and scientific author, Dr. Royle, forms a continuation of, the Himalaya range. But in those countries, as in every part of China, if found in the plains, or in the vicinity of habitations, and cultivated grounds, it may fairly be assumed that it was brought and propagated there by the agency and industry of man.

Hence it appears that the tea tree is not only indigenous in China, but that it is cultivated throughout the empire, in the northern climate of Pe-chy-ly, and the southern one of Quongtong; and that every province probably produces much of its own tea for common domestic purposes, though not for festive and ceremonial occasions. If there be any exceptions to this supposition, it may be the provinces of Pe-chy-ly, Shansy, and Shen-sy. It also grows at Japan, Corea, and the Le-kieu Islands, the island of Chusan, at Tonkin, and in Cochin-China. Thus it extends over the vast space of 28 degrees of latitude, and 30 degrees of longitude; and, consequently, is subject to great variations of heat and cold, and other differences of climate. 


\section{CHAP. II.}

CIMATAE OF CIINA INFLUENCED BY MONSOON WINDS-NO WET AND DRY SEASON AS IN INDIA-QUANTITY OF RAIN AT CANTON -AT PEKING-INCREASF OF TEMPERATURE AND HUMIDITY GREAT EROM MARCII TO MAY - TEMPERATURE AT PEKINGAT CANTON-IN THE GREEN AND BLACK TEA COUNTRIESFOO-CHEW-FOO - AMOY-FROST SEVERE BUT NOT CONTINUOUS -ICE PRESERVED THROUGII THE SUMMER-TEMPERATURE OF SIIANG-MAI - CHUSAN - GREAT VARIATION OF TEMPERATURE PRINCIPALLY IN WINTER-DAILY VARIATION SMALL-CLMMATE GENERALLY SALUBRIOUS-TEA TREE EXPOSED TO GREAT DIFFERLNCES OF CLMATE - CLIMATE MOST SUITABLE.

Tre climate of China is greatly influenced by the periodical winds termed monsoons, which are familiarly considered to prevail during six months of the year from the N. to N. E., and throughout the remaining portion from the S. to S. W. ; thus stamping the same general features on the climate of this extensive empire. The one is attended by cold, frost, and dryness, thus giving a check to vegetation; and the other by heat and moisture, stimulating its vitality in a high degree. These divisions of the year, however, can hardly be con. siclered as constituting a wet and dry season, similar to those of India ; for in China it rains throughout the year. Thus at Shanghai much rain and snow is said to fall in the winter season; and light passing showers are frequent at Canton and Nacao, as 
well as tropical rain during the S.W. monsoon; and though the quantity which falls during the N.E. monsoon is greatly disproportionate to that which descends in the S.W. monsoon, it nevertheless, on an average of seasons, equals the quantity which falls in the neighbourhood of London for the same period, from November to April inclusive. The quantity which falls at Canton is 11.11 inches; at Macao 13.58; and in London 10.28; whereas at Calcutta the quantity seldom reaches three inches.* Still, in a country bordering on the tropics, as Canton, this, from the activity of evaporation, together with the force and aridity of the northern wind, is comparatively a state of dryness.

The quantity of rain which falls at Canton and Macao during the S.W. monsoon, when the winds come charged with moisture from the sea, amounts to $67 \cdot 85$ inches; whereas during the N.E. monsoon, when the wind blows over the land, there falls, as already stated, 11.11 inches; thus making the total quantity 78.96 inches. $\uparrow$

But the annual quantity which falls at Peking is only 27.98 inches $\ddagger$, which is less than in England, though that capital is situated further south by sixteen degrees.

Hence it appears that the southerly winds, in

* See Bengal Asiatic Journal, 1836 to 1838.

$\dagger$ Kerr's Journal.

$\ddagger$ Annuaire Magnétique et Météorologique de l'Empire de Russie, anné 1842. 
their passage over this extensive empire, deposit the moisture with which they are saturated gradually and less copiously as they advance to the north, till finally both one and the other become exhausted as they reach Peking.

At Macao, from March to May the increase and varying relations of temperature and humidity are considerable; and the quantity of rain which falls during these months, agreeably to Mr. Beale's journal *, increases in a geometrical progression. Towards the end of March and beginning of April, the atmosphere becomes stagnant, warm, and close; mists and fogs cover the sea in the mornings, and sometimes in the day; the hygrometer attains its highest range of humidity, and the air being thus saturated with aqueous vapours, a considerable deposition of moisture is perceptible on the painted walls of houses and other surrounding objects.

The increasing heat, evaporation, and alternation of bright weather and light showers which now accompany the progress of spring in April, produce a warm humid state of atmosphere, the effects of which are apparent in the vast stimulus giren to vegetation. At length commence those tropical rains, accompanied with awful thunder and lightning; which precede the setting in of the S. W. monsoon early in May, and continue at intervals throughout that monsoon.

* Davis's "Chinese," second edition, p. 339. 
The central provinces of the empire participate in this state of atmosphere, and also in these renovating rains, but less copiously, and somewhat later. We learn from Fontaney that on arriving at I-cheu, in lat. $35^{\circ} 18^{\prime}$, on the 6 th of Nay, he could get no meat to buy, because the sale of it had been interdicted by the Mandarins of the city, in hopes to obtain rain from that sort of fast.* We find, also, in Monsieur Stanislas Julien's interesting "Résumé des principaux Traités Chinois sur la Culture des Mûriers et l'Education des Vers a Soie," that much rain is expected in Chekiang in April and May, "de peur que la pluie du troisième mois n'endommage l'écorce," \&c. p. 15. Again, p. 47.; "pour empêcher que les pluies du quatrième mois ne pénètrent le bois," \&c. Further, De Guignes states that while the Dutch embassy under Van Braam traversed this province in April, the winds veered to the south, and brought rain. $\%$ The green tea men also say that the winds become variable in April and May, and that the tea harvest commences between the 20th of April and the 5th of May. Again, "by the middle of April at Ning Po," says Mr. Fortune, "deciduous trees and shrubs were covered with leaves, barley was in full ear, and the oil plant (Brasica sinensis) was forming masses of golden yellow on the sides of hills and

* Du Halde, translation, vol. i. p. 50.

+ Voyage à Peking, tome iii. p. 147. 
on the plains, where the air was perfumed with the fragrance of its blossoms." * But north of Honan, or north of lat. $34^{\circ}$, the character of the rains and climate seems to partake more of that of extreme northern latitudes. Wheat, barley, buckwheat, maize, and millet, become the great staples of food in lieu of rice; and tropical products, as sugar and cotton, are cultivated with diminished success.

Regarding the temperature of China, it is remarked by Baron Humboldt, in his paper on Isothermal lines, that "the northern part of China, like the Atlantic region of the United States, exhibits excessive climates, and seasons strongly contrasted. At Peking, for example, where the mean temperature of the year is that of the coast of Brittany, the scorching heats of the summer are greater than at Cairo, and the winter as rigorous as at Upsal." (Brewster's Edinburgh Joumal.)

Situated nearly a degree south of Naples, this capital has her river's frozen over from the middle of November to the end of March $\uparrow$; and the average degree of the thermometer is under $20^{\circ}$ in the night during the winter months; and even in the day-time is below freezing point.f In summer it is generally above $80^{\circ}$, sometimes $90^{\circ}$. Humboldt gives the following as the result of five

* "Wanderings in China," p. 346.

$\dagger$ Du Halde states from the end of November to the midule of March, vol. i. p. 65., translation.

+ Staunton's Embassy, vol. ii. p. 338. 
years' observations at Peking, made at his request, by the Père Amiot, one of the last missionaries resident at that capital.

\section{Mean Temperature.}

$\begin{array}{lllll}\text { Winter } & - & -26^{\circ} \cdot 42 & \text { Warmest months } & -84^{\circ} \cdot 38 \\ \text { Spring - } & - & -56^{\circ} \cdot 30 & \text { Coldest months } & -24^{\circ} \cdot 52 \\ \text { Summer } & - & -82^{\circ} \cdot 58 & \text { Greatest variation } & -59^{\circ} \cdot 76 \\ \text { Autumn } & - & -54^{\circ} \cdot 32 & \text { Annual temperature } & 54^{\circ} \cdot 9\end{array}$

Oct. $13^{\circ}$ Cent. about $45^{\circ}$ Fahrenheit.

April $13^{\circ} .9 \quad " \quad 47^{\circ} \quad "$

Thus making a mean variation between the warmest and coldest months of $59^{\circ} 76^{\prime}$, and a mean temperature of $54^{\circ} 9^{\prime}$. The severity of the winter may also be judged of by the thickness of the ice, and the difficulty with which it melts. The Father Hyakinth states that "the rivers are covered with ice two or three quarter ells thick;" * and large solid blocks may be seen in the streets exposed for sale, or employed to cool the fruits of the vender during the great heats of summer, while the temperature in the shade is seldom below 80 degrees, and where every peasant and labourer may indulge in the luxury of his slice of iced water-melon for the third part of a penny. "Fish," says the Père Amiot, another missionary of the same name, "brought from the rivers of Leau-toung, are kept without salt in a frozen state for two or three months together. Every morning at sumrise the

* Denkwürdigkeiten über die Mongolie, p. 26. 
country in some districts of the province is subject to nitrous impregnations, and is as white as if a slight fall of snow covered the ground. The earth is frozen for three or four feet deep; and, once frozen, it does not thaw again till the end of March. This is sufficient," he observes, "to explain why the frost kills, in the vicinity of Peking, plants which Linnæus has raised in Sweden, which is nearly 20 degrees north of the Chinese capital."

(Mémoires concernant les Chinois, tome vi. p. 339.)

At Canton, which borders on the tropics, N. lat. $23^{\circ} 8^{\prime}$, and which is the most southern metropolitan city of the empire, as Peking is the capital and most northern one, the average degree of the thermometer is $53^{\circ}$ in the morning during the winter, and $82^{\circ}$ at noon during the summer.* The mean annual temperature may be stated at $71^{\circ}$, the mean range from $57^{\circ}$ to $84^{\circ}$, and the extreme range from $29^{\circ}$ to $94^{\circ} . \dagger$ The mean of four journals kept at Canton and Macao by Messrs. Bletterman, Beale, and Kerr (a respectable and intelligent gardener, sent out by Sir Joseph Banks), for a series of Jears, and Mr. Colledge's Journal for one year, given in the Canton Register for 1838, furnish a mean temperature for the four seasons as follows :

Winter, 58; Spring, 71; Summer, 83; Autumn, 75; Annual mean, $71_{\frac{\pi}{10}}$.

* Sir George Staunton's manuscript Journal.

$\dagger$ †err's Journal, and Davis's "Chinese," second edition, p. 339. 
It is not exaggeration to say that every year the rice fields in the neighbourhood are frozen for a few days, and that ice the thickness of a crown piece is occasionally seen carried through the streets for sale. From the middle of December to the end of March, Europeans are clad in their winter garments, and their houses are furnished with carpets, curtains, and fires. Nor is the thermometer a correct index of the intensity of the cold as regarding our sensations, owing to the force and dryness of the wind.

Should this degree of cold appear extraordinary in a country bordering on the tropics, it must be remembered that the northern winds, which prevail during five or six months of the year, come sweeping over the frozen arid steppes of Mongolia, and extend their influence throughout the China Sea to within five degrees of the equator. The intermediate provinces of the empire, being in many parts mountainous, with ranges running parallel with the monsoons, besides being greatly intersected by extensive rivers and lakes, some of which are occasionally frozen in the winter, must necessarily tend to keep up and support the cold now generated in more northern regions. Thus we find that the mountains which separate the two provinces of Quong-tong and Kiang-sy, though situated only three degrees from the tropics, and of moderate altitude, are occasionally covered with snow in the winter season. Indeed, on some oc- 
casions, though rare, snow has been known to fall in the streets of Canton. Thus we read in the Canton Register, that "on the morning of the 8th February, 1836, the roofs of the houses of that city were covered with snow, which had fallen in the night." The snow lay two inches deep. A similar fall of snow was remembered to have taken place about forty-six years previously, in the fiftyfifth year of the reign of Kien-Long.

In the centre of these two extremes, Peking and Canton, and between the latitude $23^{\circ}$ and $33^{\circ} \mathrm{N}$., the tea plant was found indigenous at a remote period of the Chinese history. This comprises the central, as well as the most populous and flourishing provinces of the empire, and includes that part most suitable to its growth, and where it is found to flourish in the present day. In this division of the country, between $\mathrm{N}$. lat. $27^{\circ}$ and $31^{\circ}$ are also situated the districts connected with the foreign trade, whence the greater part of the tea most esteemed by the Chinese is also procured for their home consumption. These districts are, however, places of little note, remote from great eities and highways, and untrodden, perhaps, by Europeans, except, indeed, by those great and able men who were employed in early times in framing those highly valuable maps which we possess in the present day. Thus it is not possible to furnish any thing more than vague and general ideas of the meteorological state of this part of the country; 
but, in the absence of all scientific details, a few general observations and facts may not prove unacceptable to those whose views may be directed to the introduction and cultivation of the tea tree in other parts of the world.

In the green tea country, situated in the district of Whey-chew-fu, N. L. $29^{\circ} 58^{\prime} 30^{\prime \prime}$ in the province of Kiang-nan, the northern winds begin to prevail, the Chinese say, in September. In October persons in easy circumstances begin to clothe themselves in their fur dresses; and in November the winter (or rather, perhaps, the N.E. monsoon) regularly sets in; when the young tea shrubs are said to be bound round with wisps of straw, to prevent them from being broken or injured by the wind and snow which falls in the winter season. The severity of winter, however, is not felt before December. From this time until March the weather continues cold; frost frequently prevails, and snow occasionally: water freezes in the house: but the Chinese houses are badly put together; windows and doors are roughly fitted ; in fact they are built for hot weather, not for cold. The Chinese defend themselves against cold by an additional quantity and different quality of clothing: their houses being thus much exposed to every change of temperature, a little tea accidentally left in a tea-cup over-night in any of the rooms will occasionally be found frozen in the morning. If we may rely on the statements of the Chinese (and recent accounts seem to confirm 
them), snow is sometimes two or three feet deep on the plains, and several inches thick on the housetops. In cloudy weather it may thus remain on the plains for ten days together; but soon melts on the re-appearance of the sun. They further state that excessive cold is injurious to the plant; some are occasionally killed, and others injured and checked in their growth, by frost and snow. They add, however, that this part of the country is not subject to such sudden changes of temperature as are experienced at Canton. In April and May the winds begin to veer to the southward, and bring occasional showers; but the south-west monsoon does not set in steadily before the end of May, or beginning of June. In this latter month the great rains commence. In July the summer regularly sets in, and the intensity of the heat is equal to that of Canton.

The Bohea country, in Fokien, differs little from the Hyson districts in point of temperature. The tea men describe the cold as less severe; and the fall of snow, as well as the thickness of the ice, as somewhat less. Indeed it is a mountainous district, with sheltered vallies, fenced in and protected from cold north-easterly and north-westerly winds by the lofty and continuous range of mountains which forms the barrier between this province and those of Chekiang and Kiangsee. December and January are considered the coldest months. It is said that the Kieu-kio-kee, a shallow stream which 
winds about the Bohea mountains, is annually frozen over. Here vagrants are seen ranging themselves along the most frequented parts, begging alms, and exciting the compassion of passengers by strewing paddy-husk on the ice, to prevent slipping. The summer is as hot as at Canton; though the mornings and evenings are sometimes sufficiently cold to render a Ma-qua-czu (a kind of spencer) necessary in traversing the hills.

I shall now subjoin an extract from a letter received from the aged and reverend Father Carpina, at this time the vicar-general of the province, and long resident in the eastern part of it, to whom I am also indebted for an account of the range of the thermometer, and much valuable information concerning the tea tree. He states, in answer to some questions put to him, that "The tea shrubs were neither injured, nor the harvest retarded by the cold of 1815, notwithstanding there fell in the month of February four spans (about thirty-three inches English) of snow in Fo-gan, lat. $27^{\circ} 4^{\prime} 48^{\prime \prime}$, and six spans (forty-nine inches) in Ning-te; so that the covers to the indigo plants, strongly fixed to protect them from the frost, sun, and wind, gave way under the weight of snow. At the close of the same year, about the middle of December, some days of severe cold and frost occurred. Upon one occasion, about three o'clock in the afternoon, on a beautiful sunshiny day," he observes, "I saw two boys, each with a piece of ice the size of a coach 
window, and an inch in thickness, which they had taken out of the fields in the neighbourhood. I also observed, on the 24th January of the present year (1816) the surface of the water in the river Mo-yang was frozen, breaking and flying about like glass to the stroke of the oar. The volume of water in this river is equal to that of the Guadalquiver, at the passage of Cordova. It freezes in these parts very often. Snow is not so frequent: this winter we have had none, except on the great and lofty mountains. Yet in a residence of twenty-four years I have twice seen snow on the plains even on the very day of the vernal equinox. Hoar frost frequently occurs between the month of December and April ; and it has happened more than once in my time that the recently planted rice has been destroyed, and this in the month of May, by the severity of the hoar frost." I observe, also, on reference to my orwn official correspondence, that in 1809 the Chinese said that the leaves of the first gathering were injured by the frost and snow which had previously prevailed in the month of April.

It may further be observed that the Dutch embassy under Van Horn* remained from the 10th to the 22d February 1667 at the town of Pu-chinghien, N. L. $28^{\circ} 0^{\prime} 30^{\prime \prime}$ E. long. from Peking $2^{\circ} 9^{\prime} 10^{\prime \prime}$ in this province, in consequence of snow and rain; 
and that after crossing these mountains, when they arrived at Kiu-cheu-fu, in Che-kiang, on the 5th March, they observed that the adjacent hills were all covered with snow.*

A register of the temperature kept at Fogan, N. lat. $27^{\circ} 4^{\prime} 48^{\prime \prime}$ in the eastern part of the province, furnishes a mean temperature so high as $70^{\circ}$. It is remarked, however, that when the thermometer in the open vestibule of the house fell to $37^{\circ}$, it froze in the fields. The following is the mean for each month :-

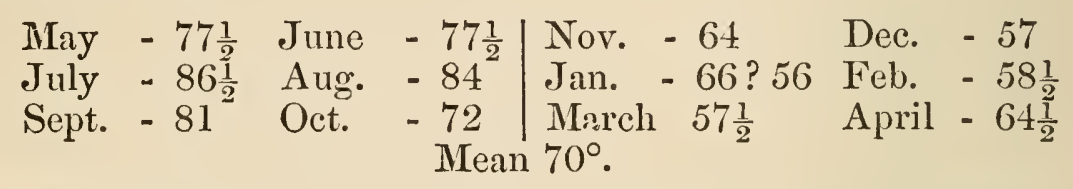

Another, in a part of the province more N.W.:

Jan. - 52 Feb. - 50 Mard -53 April - 54

At Foo cherv-foo, lat. $26^{\circ} z^{\prime}$, the extremes of temperature extracted from Mr. Lay's journal exhibit 96 for the month of August, and 44 for the month of January; thus giving a mean of $70^{\circ} \%$. But during the Rev. George Smith's visit to this port, ice was gathered for a few days. +

At Amoy, lat. $24^{\circ} 27^{\prime} 36^{\prime \prime}$, which is a tea district, producing teas suitable to the foreign markets, and some of very delicate flavour, the temperature seems hardly to vary from that of Canton. From

* Ogilby's China, p. 277.

$\uparrow$ Fortune's Wanderings in China, p. 382.

$\ddagger$ Exploratory Visits in China, p. 328 . 
a very elaborate and apparently carefully kept register on board the Mahamoodie, at Ngo-tsoo, in 1844 , the annual mean temperature was $69 \frac{7}{10}^{\circ}$; the lowest temperature marked being $49^{\circ} 5^{\prime}$, and the highest $90^{\circ}$.

The preceding accounts are sufficient to show, that severe frost and occasional snow prevail in the tea districts; and on some occasions, though rare, so late as the vernal equinox. Yet there is reason to believe, on an average of seasons, that the frost is not very intense, or of long duration. Ice the thickness of an inch does not indicate great severity of cold, or long continuous frost. In these latitudes, from $27^{\circ}$ to $31^{\circ}$, it must be remembered that the sun, as well from its direct influence as from the frequently unclouded state of the atmosphere, has great power in the winter season; so that in the central provinces of the empire there is much reason to believe that the frost, though occasionally intense, is not sufficiently continuous to allow ice of great thickness to form under the influence of so powerful a sun: nor is the monsoon inland and along the coast so steady but that the wind often veers to the south, and brings with it comparatively warm damp weather, and rain.

Nevertheless it is now known that ice-houses of very simple and efficient construction are formed at Chusan and elsewhere. Ice is also collected every year at the city of Nan-king, lat. $32^{\circ} 4^{\prime}$ $30^{\prime \prime}$, in sufficient quantity for the purpose of 
packing fish, which is sent twice a week in the months of April and May to Peking. (Du Halde, translation, vol. i. p. 74.) Again, that in the month of Dec. 1841, snow lay on the ground "knee deep" in the vicinity of Ning Po, N. lat. $29^{\circ} 56^{\prime}$; and that the thermometer ranged so low during the night as from ten to twelve degrees below freezing point. Still this frost only continued a ferv days. (Sir H. Pottinger's despatches, 24th Jan. 1842.)

It further appears that at Shanghai, N. lat. $31^{\circ}$ $24^{\prime}$, long. $121^{\circ} 32^{\prime} \mathrm{E}$, in the winter of $1845-6$ the Woosung river was sufficiently frozen to afford the English an opportunity of indulging in the amusement of skating; but I was informed by Capt. Balfour that there was no foundation for the report that they were enabled to walk from their factories to their ships. Further, in the Rev. George Smith's instructive work on China, the thermometer is there shown to have ranged from $24^{\circ}$ to $100^{\circ}$ of Fahrenheit, and that the mean annual temperature was so low as $61 \frac{1}{2}$ degrees. The temperature of the different seasons extracted from the same work, may be arranged as follows:-

Spring, $57^{\circ}$; Summer, $79^{\circ} 4^{\prime}$; Autumn, $66^{\circ} 4^{\prime}$; Winter, $41^{\circ} 3^{\prime}$. The Mean of the two hottest months, July and August, $83^{\circ} 5^{\prime}$.

Do. do. coldest months, Jan. and Feb. - $40^{\circ} 6^{\prime}$. Mean of year, $62^{\circ}$.

I was also informed by Capt. Balfour, our late consul at Shanghai, that snow will occasionally lie 
on the extensive alluvial plain of that district for ten days together, and more than a foot deep. It rains all the year, as at Canton, but the principal rains set in in April and May.

The difference between the temperature of the harbour of Chusan and that of Shanghai is considerable: but registers kept on board ship seem generaily to exhibit a higher temperature than those kept on shore. Commodore Chad's register kept at that port exhibits the following temperatures.

Spring, $64^{\circ} 2^{\prime}$; Summer, $77^{\circ} 6^{\prime}$; Autumn, $69^{\circ} 5^{\prime}$; Winter, $53^{\circ} 3^{\prime}$. Mean, $66^{\circ} 2^{\prime}$.

The hottest month, viz. August, $81^{\circ} 5^{\prime}$.
The two coldest months, Jan. and Feb. $\left.51^{\circ}.\right\}^{\text {Mean, }} 66^{\circ} 2^{\prime}$.

It may also be seen in the Appendix that a remarkable agreement exists between the temperature of Shanghai and the port of Nangasacki in Japan.

It is correctly stated by Capt. Loch, R.N.*, an intelligent and accurate observer, that every change of wind from the regular monsoon occasions a considerable depression or elevation of temperature; that is, when the wind shifts to opposite points as here alluded to. The great changes of temperature described by Capt. Loch are not experienced in the south during the S.W. monsoon.

If we examine the variation of the highest and

* Campaign in China. 
lowest range of the thermometer as given in the Appendix, we shall be surprised at the little variation which really occurs, at least in the south. The variation of temperature which takes place in the course of a day, and from day to day in England, is frequently greater than that which happens during a whole month at Canton and Macao. The greatest variation occurs during the N.E. monsoon, the monthly mean of which may be stated at $25^{\circ}$, while that of the S.W. monsoon is about one half or $13^{\circ}$. The mean variation of the three coldest months may be stated at $30^{\circ}$, while the three hottest months, June, July, and August, exhibit only $11^{\circ}$. On some occasions at Canton, and apparently throughout the empire, a depression of thirty or more degrees has taken place within twenty-four hours. But these great changes of temperature are rare, and happen only during the N.E. monsoon, when the season of cold and dryness prevails, and vegetation is at rest. Indeed, the few vicissitudes of temperature to which vegetation is exposed during the period of its greatest activity from spring to autumn, when stimulated by the combined action of heat, bright sunshine, and moisture, and the uninterrupted dryness of the atmosphere, with some few exceptions on the seacoast, during the winter season, may account, at least in an eminent degree, for the varied and widely extended distribution and intermixture of inter and extra tropical products over this vast 
empire. And though the climate of China doubtless is a strongly contrasted one, and excessive on a comparison of the heat of summer with the cold of winter, yet there is reason to think that, with the exception of the extreme northern provinces, the rise and fall of temperature is progressive and gradual, and the daily variation remarkably little: it probably seldom exceeds $8^{\circ}$, and on an average is not more than $5^{\circ}$. Thus the climate of the central provinces of the empire cannot be designated otherwise than as a temperate climate. Nor does it appear to me that even the Chinese of Peking need any commiseration; nor in truth does the gifted Humboldt mean under the term excessive, and when he employs* the words of Dante, to include them among the people condemned,

"A sofferir tormenti caldi e geli."

Indeed I am disposed to believe that upon a more intimate acquaintance with the climate of China, it will be found that no portion of the earth's surface of equal magnitude is upon the whole more favoured in point of climate; more congenial to animal and vegetable life, or more salubrious to man.

To vegetation pre-eminently is given a long season of repose during the dormant state of the sap; brought about by a continued state of comparative dryness, low temperature, and occasional

* Cosmos - (Sabine's translation, p. 319.). 
frost, modified in its intensity and duration by position as regarding latitude: while a gradually increasing evolution of heat, accompanied by a humid state of the atmosphere, succeeded by copious rains, attend the renovation of its powers, and the increasing activity of its vital energies.

Thus it appears that, the tea tree is alike exposed to intervals of severe frost, but of short duration, and the intense heat of a vertical sun; that it grows in the neighbourhood of the sea-coast; on islands, as Chusan and Japan; and in the interior and western extremity of the empire, as in Szuchuen, beyond all influence of the sea. If indigenous in all these situations, and under such variety of climate and circumstances, nothing can more strongly prove the hardy nature of the tree (so far at least as its vegetative poivers are concerned, as observed by Mr. M'Cleland); and, if propagated by art and culture, what can more clearly evince its great powers of adaptation to climate, and ease of propagation? It may, indeed, be variously modified with regard to flavour, astringency, and other properties on which excellence of quality depends, but experiment alone can determine that fact. It seems less injured by cold than benefited by heat: that the part of China most congenial to its growth is between $27^{\circ}$ and $33^{\circ}$ of north latitude, where the mean annual temperature may perhaps be considered to range from about $62^{\circ}$ to $68^{\circ}$; where copious rains happen in 
conjunction with a mean temperature, increasing from $64^{\circ}$ to $77^{\circ}$ as the season advances, between the vernal equinox and the summer solstice, or the season of spring, when the vegetation of the shrub is in its greatest state of activity; and where intervals of rain are followed by a succession of bright weather and increasing heat : the one being necessary to the production of a rapid and luxuriant growth of leaves, and the other to fragrance and excellence of quality.*

* The climate found the most suitable at Java for the cultivation of tea, is that of the mountainous regions situated at 3500 to 4000 feet above the sea; where the air is so cool that Fahrenheit's thermometer at sun-rise indicates $58^{\circ}$ in the morning; and $74^{\circ}$ at two o'eloek in the afternoon. On still higher elevations, even 5000 feet and more, the tea will be highly flavoured : but in lower districts the flavour deteriorates in proportion as the situation is low. Both this author and Von Siebold agree that the tea tree requires an atmosphere of much fog and dew, which is generally found in elevated sites. MIr. Jacobson further observes that it requires much freshness, coolness, and exposure to gentle breezes. (Handboek $v$. d. Kultuner en faurikatie von Thee, d. J. J. L. L. Jacobson, d.2. § 15. Batavia, 1843.) 


\section{CHAP. III.}

BLACK TEA-DISTRICTS WHERE THE BEST KINDS ARE FOUND AND CULTIVATED - WHAT SITUATIONS ARE THE MOST FAVOURABLE - Exposure AND NATURE OF THE SOIL - ACCOUNTS GIVEN IN CHINESE WORKS - BY EUROPEAN MISSIONARIES - THE VARIOUS OPINIONS AS TO THE MIOST SUITABLE SOIL EXAMINED - ATTEMPT TO RECONCILE SOME OF THESE DIFFERENCES - SOIL THE MOST SUITALLE - ANALYSIS OF TEA SOILS FROM CHINA AND JAPAN.

THe teas generally known to foreigners may be divided into two classes, the black and the green; and as the manipulation of these differs essentially, it will be advisable to treat of each by itself. The black tea, which forms eight-tenths of the tea imported into England, is grown in the district of Kien-ning-fu, in the province of Fo-kien. The mountains of Vu-ye (or Bohea, as corrupted by Europeans) are situated in a particular division of that district, distant about two leagues from the little town of 'Tsong-gan-hien, lat. $27^{\circ} 47^{\prime} 38^{\prime \prime}$, according to observations made on the spot by the Jesuit missionaries, between the years 1710 and 1718.*

A Chinese manuscript thus describes the teas of this district:_ "Of all the mountains of Fo-kien, 
those of $\mathrm{Vu}-\mathrm{ye}$ are the finest, and its water the best. They are awfully high and rugged, surrounded by water, and seem as if excavated by spirits: nothing more wonderful can be seen. From the dynasty of Csin and Han, down to the present time, a succession of hermits and priests of the sects of Tao-czu and Fo have here risen up like the clouds of the air and the grass of the fields, too numerous to enumerate. Its chief renown, however, is derived from its productions, and of these tea is the most celebrated.

"The town to the north of Csong Ngan is called Sing csun. Here are many houses, as well as markets and fairs, where the merchants or factors (Ke) resort. To the north of Sing.csun is situated the Chung Ling Chy Ky (a range of mountains so denominated), the country the most renowned. It is surrounded by many rocks and mountains, most extraordinary in their form, and irregular in their height, extending for more than $50 \mathrm{ly}$.*

"In the middle of those designated the Vu-ye mountains there is a rivulet which winds about them (called the Kieu Kio Kee, $i$. e. the stream of the nine windings), and divides the range into two districts. Those to the north are called the North Range, and the others to the south the Southern Range. It is here that the priests of the sects of Fo and Tao-czu select the level places upon which

* The ly is about the third part of an English mile. 
they erect their temples and religious houses. Around these they plant the tea shrubs, the leaves of which they gather every year. The north range produces the best."

It is these mountains only which are properly considered the Bohea mountains. It is here that the Ming Yen tea and the finest Souchongs are procured, teas which rarely find their way to Europe, and perhaps never but in very small quantities as presents. This tea is commonly known to Europeans under the denomination of Padre Souchong, from its being cultivated by the bonzes or priests, or Pao-chong tea, from being packed in small paper parcels; and to the Chinese, in addition to these names, by the appellation of Yen or Gam tea, from its growing on the Yen, or ledges and terraces of mountains. Also Nei Shan tea, i. e. inner mountain tea, or inner range tea.

It is here that the imperial enclosures are established for the supply of the court of Peking, and chains are said to be employed for the purpose of collecting the leaves of shrubs growing on the summits and ledges of inaccessible and precipitous rocks. But it may be suspected, without much detraction, that this is one of the many artifices and devices here employed by the priests to increase the interest of their secluded residences, and to attract strangers and devout benefactors to the spot, as well as to enhance the price of their tea. 


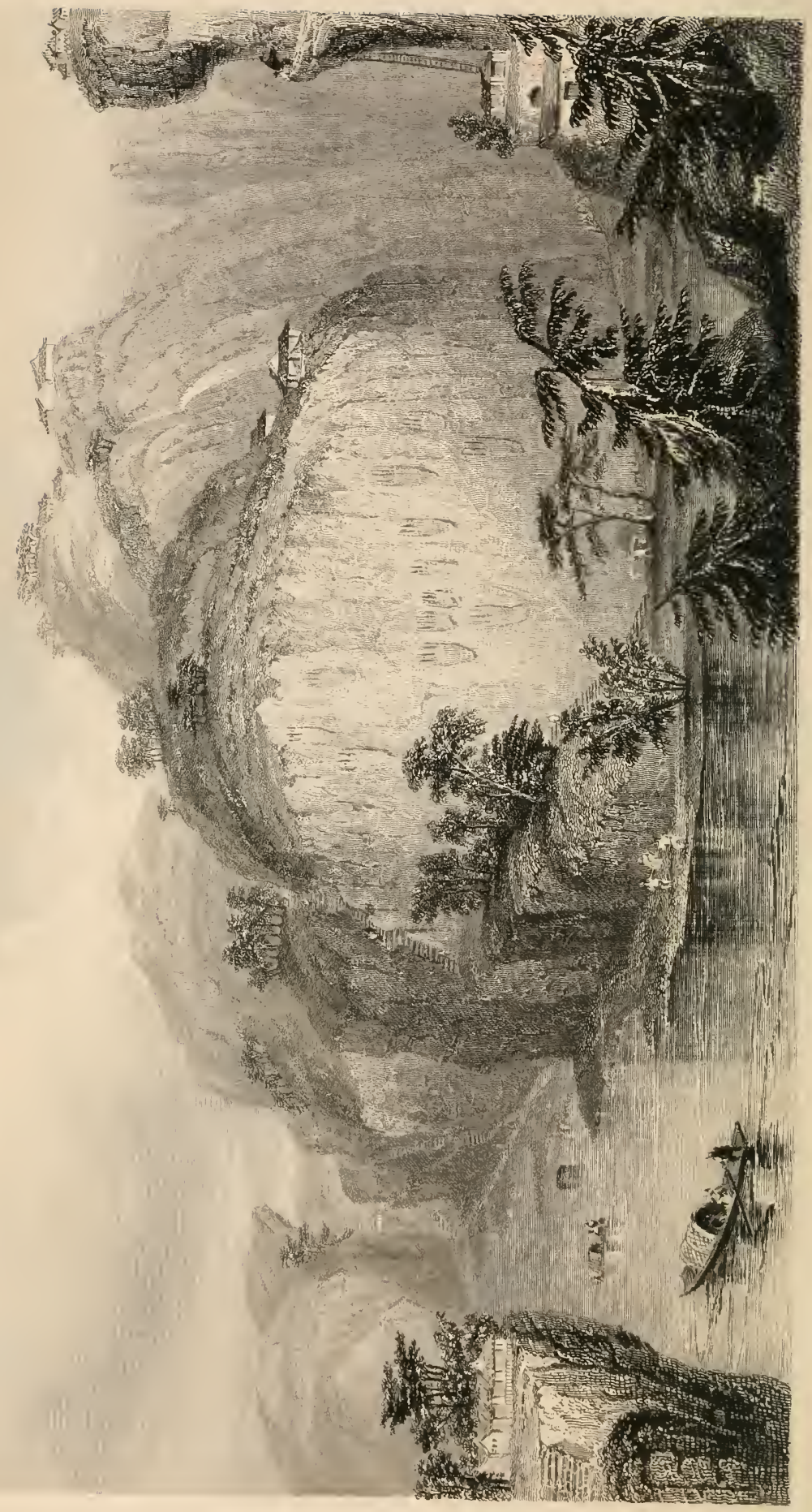


Du Halde* thus speaks of these mountains:"The priests, the better to compass their design of making this mountain pass for the abode of the immortal beings, have conveyed barks, chariots, and other things of the same kind, into the clefts of the steep rocks all along the sides of a rivulet that runs between; insomuch, that these fantastical ornaments are looked upon by the stupid vulgar as a real prodigy, believing it impossible that they could be raised to such inaccessible places, but by a power more than human."

The annexed plate, engraved from a Chinese drawing, portrays some of the geological and picturesque features of these rocks; while the impress of gigantic hands exhibits some of the devices here aliuded to.

The Chinese manuscript continues thus:- "In the surrounding country, extending twenty or thirty ly, there is a range of mountains which encompass and shelter those of $\mathrm{Vu}-\mathrm{ye}$. The names of the places are, Csao Tuon, Hoang Pe, Chy Yang', Kung Kuon, Sin Cheu, Tu Pa, Chy She, \&c. In each of these, tea sheds or roasting houses are erected, and shrubs planted. These mountains are also of the same nature as those of $\mathrm{Vu}$-ye, and the tea is prepared in the best manner. It is fragrant in smell, and sweet in flavour. This tea is called Puon Shan tea, or Mid-hill tea, or 
Mid-range tea, and is gathered to be made into Souchong." Here, I imagine, most of the East India Company's best Souchong teas, as the chop, Lap Sing, \&c., were made. The districts now about to be described are those where the Congou teas are produced. The manuscript proceeds thus: _ "The towns, which extend about $70 \mathrm{ly}$ from Vu-ye Shan are called Py Kung, Tien Czu Ty, Tong Moo Kuon, Nan-Ngan, Chang Ping, Shu-Fang, \&c. The leaves are thin and small, and of no substance; and, whether green* or black, or made with much care, yet have no fragrance. $\dagger$ This tea, however, is that used for Congou in quarter chests, and is called Way Shan tea, i.e. outside-hill tea, or outer-range tea. Tea is also produced as far as Yen Ping, Shau-U, Keu-U, Geu Ning, Kien Yang, Heu Shan, and other places, but is unfit for use." There is reason to believe, however, that the tea from the latter places is constantly mixed with low Congou, and that many of the Congous technically termed faint, whether the leaf be green or black, come from these places, as will be seen by the following account received from another Chinese, where some of the above places are enumerated as producing tea forming a part of the tea imported as Congou.

* By green is meant the green leaves found in black tea, termed by the English dealers yellow leaf.

t Another Chinese observes that "the flavour is bitter, the leaf yellow, and the tea will not keep long." 
"The district of Kien Yang, adjoining Csong Ngan, produces much tea. Some of the leaves are fleshy and large, others thin and small. This is coarse tea. At Geu Ning, adjoining Kien Yang, the leaf is thin and small. This is coarse tea. At Ta Ping Lu, and other adjacent places, the leaf is thin and large, and no labour can make it good. Among the infused leaves very ferw will be found red, and the dried leaves are open, yellow, and dull. But all these teas serve as coarse, or ordinary tea."

The Vu-ye Shan Chy, a statistical account of the black tea districts, enumerates several places in the neighbourhood which produce good tea, but observes that Vu-ye Shan is the best. In this work the qualities of the Vu-ye tea are divided into Yen and Cheu tea. "The rugged sides and terraces of the mountains are called Yen, and the low grounds Cheu. Yen tea is of superior, and Cheu tea of inferior quality. The mountains are divided into the northern and southern range. The tea from the northern division of these mountains is excellent; that from the southern is not so good. The mountains beyond Yen Shan are called Way Shan; and the tea produced there is of indifferent quality. The plantations require sun and wind; yet not too much wind, and if much sun, the tea loses its delicacy of flavour."

Thus the situation the most favourable for tea, agreeably to the foregoing accounts, is on the Yen, or terraces, of rocky hills or mountains; not, how- 
ever, because the soil is stony, but most probably because the alluvial deposit formed during rain enriches the soil of these ledges. The hills whence the greater part of the tea connected with European consumption is procured, agreeably to information received from the tea merchants, are of gentle ascent, and in no way remarkable for their height; neither do they possess the rocky nature or singularity of form of the Bohea Mountains.

I shall now subjoin some extracts from accounts procured by me through the Roman Catholic missionaries resident in the province of Fo-kien in answer to questions proposed to them on the subject of soil, situation, and manipulation of tea.

1. One observes_- "The soil should consist of a vegetable mould, sprinkled with sand, light and loose, and rather moist, exposed to the wind, and fronting the east."

2. Another - "That tea may be planted either in a rich or a poor soil, sandy or garden soil; but that which is moist is the most suitable, and the eastern aspect the best; it need not be exposed to, or sheltered from the wind, neither does it require high hills or level ground; either will do, but garden ground, and the embankments of gardens or fields, are the most favourable."

3. I shall here conclude these extracts with the opinions of the Spanish missionary first allucled to, whose account of the tea plant is so highly valuable. He observes: "In the province of Fo-kien 
there are many plantations, where the care and the method of preparing tea are nearly the same, whilst the tea is very different, whether we consider the leaves, the flavour, or the effects which it produces; consequently the nature of the soil cannot be the same. The Chinese themselves sufficiently prove this, by their frequent declaration that the $\mathrm{Ty} \mathrm{Tu}$, or soil, occasions the principal difference in the quality of tea." *

4. "With regard to the soil which is the most favourable, I shall explain first what I have seen myself, and then what I have heard related of the district of Kien Ning $\mathrm{Fu}$. In the southern part of the province there are many plantations in low situations, some of which are sandy and stony, as may be seen by those which are near rivers; but they are rendered sufficiently moist in consequence of annual inundations. Others are placed in situations a little raised, yet level, like those which are seen at the foot of mountains; the soil of which (as the Chinese express it) is red or pale, rather cold and damp. The other plantations, and these are the most numerous, are situated amidst the declivities of mountains, on sloping ground, many of which are stony and sandy at the surface, but the soil is deep, moist, and, in consequence of the frequent winds, rather cold. Those that are on level

* This observation is confirmed by my own inquiries. Ask a Chinese what causes the difference of quality in tea? and his reply invariably is, the $\mathrm{Ty} \mathrm{Tu}, i . e$. the soil. 
ground, at the foot of mountains, are more bushy, but the quality of the tea is nearly the same.

5. "It therefore follows that the tea shrub delights in very high situations, a compact and rich soil, a temperature cold and humid, and the aspect the most favourable is that which fronts the east."

6. The Chinese speak thus of the soil of the innumerable plantations of Kien Ning Fu:_ "There are some plantations on plains rather low, the soil of which is very compact, a little muddy, black, neither very cold nor very hot, and rather damp. The tea of this place is worth two-thirds more than that of other parts of Fo-kien; but the best of all is procured from plants which are upon high mountains, in steep places, sometimes like precipices; and on this account iron chains are used to ascend them, and to gather the leaves. These are the famous mountains of $\mathrm{Vu}-\mathrm{ye}$, in the district of Kien Ning Fu. It is in situations that front the East that the tea of the first quality is procured. It is there that the Imperial enclosures are found, and the greatest part of that tea commonly called Pekoe. As all the tea which is found upon the neighbouring mountains is of quite a different kind, although the temperature is the same, it necessarily follows that the soil must be different."

The preceding accounts seem to agree, that a compact rich soil is the soil most suitable to the tea plant. Some difference of statement may exist relative to its degree of compactness, and that 
again may depend on situation and circumstances. These statements, however, all agree that the soil should be moist or retentive of moisture, and that an eastern aspect is the best.

Now this conclusion, that a rich compact soil is favourable to the cultivation of tea, appears at variance with the currently received opinions on that subject; for it has generally been believed that tea succeeds best in a stony, gravelly, sandy, or poor soil, where there is little accumulation of vegetable mould. This also was the description of soil which came under the observation of Dr. Abel on his journey from Peking, in company with the British embassy, under Lord Amherst; but he acknowledged that his opportunities of seeing the tea plant were few. Du Halde states that the soil of the Bohea mountains is light, whitish, and sandy. * I once received from that country a fine specimen of the tea plant, the soil of which corresponded very well with the above description, and yielded by simple washing $\frac{64}{100}$ of a light coloured fine sand.

Le Compte states that tea thrives best in a gravelly soil, next in a light sandy soil, and worst in a yellow soil.

The Pen Csao Kiang Moo observes that the best tea grows in a stony soil; the middling in a

* Vol. i. page 11., translation. 
garden and arable soil, and the worst in a yellow soil.*

The opportunities afforded to the two British embassies of seeing the tea plant were too few to aid us in this inquiry. They, moreover, were not fortunate enough even to enter the particular districts connected with home or foreign supply. Lord Amherst's embassy, especially, was remote three degrees of longitude from the black tea country, and that of Lord Macartney more than a degree of latitude. Both routes were north and west of the extensive range of mountains which isolate, as it were, the province of Fokien from the rest of the empire; the transit of which mountains alone occupies a three days' journey by the speediest mode of conveyance, a light bamboo sedan chair. Nor was either embassy within forty miles at least of the nearest point of the green tea country. The specimens they saw were, perhaps, with one exception, such as were cultivated for the domestic use of the farms where they were grown, and probably afforded neither good examples of the plant nor of the soil. It is generally allowed by the Chinese that, with the single exception of the Hyson country, they employ only such ground for the cultivation of the tea plant as is unsuitable to more profitable culture; and this explains why it

* This passage in Du Halde (vol. ii. p. 221. translation) is rendered thus:- "the best grows in rocky places, and the worst in a yellow soil." 
is often found growing on the sides and tops of embankments of cultivated fields; on the declivities of hills, independently of its natural habitat; and such lands as are generally devoted to the growth of timber.

The opinions given by the ancient Jesuits must be deemed authentic, and of high authority. They were men not only distinguished by natural talent and great acquirements, but they were the only Europeans who have had any opportunity of examining the tea plant in those particular sites, where it more especially flourishes, and where it is cultivated for foreign consumption. But whether their information be derived from personal observation, from translations of Chinese works, or from verbal accounts received from the Chinese, does not appear, and this involves a very important distinction.

On the other hand, Dr. Von Siebold* states, that "the soil most congenial to the tea plant at Japan consists of a clayey heavy soil, rich in iron, containing fragments of wacké, basalt, basaltic hornblende, and fossils peculiar to the trap formation. It is somewhat sandy and chalky, and on being washed exhibits very little vegetable mould?" $\uparrow$

A very elaborate analysis has since been made by two able chemists, Dr. Von Essenbech and L. C. Marquart, of a specimen of soil brought home by

* Nippon, part 6. $\uparrow$ Dammerde. 
Dr. Von Siebold. These scientific men describe the soil as a "strong ferruginous clay in which no mixture of sand was perceptible to the naked eye." After analysis they classed it as "an intimate mixture of siliceous earth and clay, with oxyde of iron and manganese." The earth appeared like "atmospherically dissolved slate," and "from its deficiency of carbonic acid, humus, lime, and magnesia, could not be classed as productive ;" and it was their opinion "that it required stronger manure and an addition of alkaline matter. Its water-retaining property was considerable, on account of its great portion of clay, but the soil was deficient in lightness from the absence of coarse sand." *

Several specimens of soil were obtained by me through different channels from the province of Fokien, some from the Bohea district. They were procured by respectable parties; but what dependence can be placed upon them as being true or good specimens I cannot determine. An analysis of these soils, sufficient for agricultural purposes, was obligingly made expressly for me by Mr. Faraday, the result of which is appended to this chapter. It is there stated by that profound chemist that "the general character of these soils seems to be that of a ferruginous clay, but easily crumbling, and falling down in water. None of them contained worn pebbles or worn sand, though some

* See note appended to this chapter. 
included fragmented stones, as decomposing porphyritic rock, granite, and felspar, mica in a finely divided state, small siliceous stones, and one or two specimens of some heavy greenish black particles. The proportion of sand differed very much, and the quantity of oxyde of iron was also remarkable. None gave evidence of containing carbonate of lime, except one, and in that only a single piece was observed, which was probably accidental."

Dr. Guillemin, botanical assistant at the Museum of Natural History at Paris, was charged with a mission to the Brazils with a view to obtain information respecting the culture and preparation of the tea plant, and introduction of that shrub into France. In his report to the minister of agriculture and commerce, made on his return, he states, that "the general character of the cultivated soil at the Brazils is a ferruginous clay, derived from the decomposition of granitic gneiss, and more or less mixed with humus. This soil, which is analogous to the strong earths of the departments of ancient Brittany, is perfectly suitable to tea." $\mathrm{He}$ saw "tea cultivated in different exposures which received the mild winds of these countries, but the sides of the hills with a sunny aspect seemed to suit it best." * Whether this exposure had any influence on the quality of the plant, his inquiries did not enable him to determine. This question,

* La Revue Agricole, Février, 1840, p. 268. 
however, has already been answered in the affirmative. He further adds, that "care is always taken to hoe the ground well, and sometimes it is manured." **

This botanist, however, observes in the course of his report, that he visited the plantations of Major da Luz at Nossa Senhora da Penha, which were exceedingly well kept, and further states that "the ground, which was almost level, had formerly been under water, and had been drained at the expense of much labour by Major da Luz. The soil here," he adds, "is less argillaceous than in other places, and the vast quantity of vegetable detritus which remains in the uncultivated parts, gives it the appearance of a soil richly manured. Besides which the plants here have a vigour of growth I have not observed elsewhere; almost all have attained the height of two or three metres." $\dagger$ But the ordinary height of plants in the settlement generally does not appear by the same author to exceed half that size, or one and a half metres. The plants therefore of Major da Luz mark a great luxuriance of growth, ascribable no doubt to the richness of the soil, and the quantity of decomposed vegetable matter which it contains.

* In his summary or concluding remarks he considers that "an argillaceous ferruginous soil on the slopes of hills is more suitable to the cultivation of tea than light soils and plains."La Rev. Agricole, Févr. 1840, p. 272.

$\dagger$ Ib. Janv. p. 218. 
With this example before us, we must conclude that the author, by his previous observations, means more especially to point out the analogy which exists between the strong soils of the department of ancient Brittany and those of the Brazils, and consequently their suitableness for the cultivation of tea. He leaves the reader to draw his own conclusions respecting the superiority of Major da Luz's plantations, they having less immediate bearing on the object of his inquiry. *

The reader will doubtless recollect, that among: the documents procured from Fokien, a tea is spoken of as being worth two thirds more than that produced in other parts of that province, with the exception of the Yen or Gam tea grown in the inner range of the Bohea mountains. And the plantations here alluded to are described as being " on plains rather low, the soil of which is very compact, a little muddy, black," \&c. (p. 48. §6.)

Thus a considerable discrepancy of opinion seems to prevail regarding the soil the most favourable for the cultivation of the tea plant; but as it has

* With respect to clinate, he considers the cool climate of St. Paul's, and the Serra dos Orgaos as the most favourable. He says, - "the vigour with which the plant grows there is wonderful." Although I found myself at St. Paul's in the middle of summer, I was not incommoded by the heat, and it seemed to me as if I were living in the south of Europe. He ascribes this not so much to the difference of latitude between St. Paul's and Rio de Janeiro, as to the heights of the table land of this province. - (La Rev. Agricole, Févr. 18t0, p. 268.) 
been shown that this shrub possesses great powers of adaptation to climate, so also, as observed by Dr. Wallich, "it may be easily satisfied with respect to soil." *

Kampfer $\uparrow$ states that the tea shrub is planted everywhere at Japan without regard to soil ; and the same may be affirmed of China, when cultivated by the farmer for his own domestic use.

The vine, which seems to partake somewhat of the nature of the tea plant, as regards the extent of its geographical distribution and adaptation to climate, also shows great indifference with respect to soil. De Candolle observes, that "grapes may be produced in almost any soil, provided the Vine be of a nature to suit it. The vineyards of Bourdeaux are planted in a gravelly soil, thence the name of Vin de Grave; those of Burgundy in calcareous clay; Hermitage grows in granite; and Lachryma Christi is raised in the volcanic soil of Mount Vesuvius. The vineyards of Switzerland consist of a stiff compact calcareous earth." +

Mr. M'Cleland also, seeing the various conditions under which the tea plant grows at Assam, concludes that "there is a disposition in the plant to accommodate itself to any soil, as far at least as its vegetative powers are concerned." \$ And he

* Parliamentary Papers, Tea Cultivation, 27th Feb. 1839.

† Japan, Appendix, p. 4.

† Marcet's Vegetable Physiology, p. 406.

$\S$ Transactions of the Agricultural and Horticultural Society of India, vol. iv. p. 28. 
further observes, regarding the soil which came under his inspection, "that the vegetable matter in tea soils acts only as an absorbent of moisture, as appears by the fact, that where the vegetable matter is greatest, alumina, the common absorbent principle of soil, is least*; and the quantity of alumina is also in proportion to the degree of insulation of the soil, in regard to moisture and the greater drainage to which it is exposed;" whence Mr. M'Cleland concludes that "the narrowest inference we can draw from this is, that the same soil would not be suitable to the plant in every situation." $\dagger$

Now there are two circumstances elicited in this inquiry, in which the several statements procured from the missionaries in the province of Fokien agree, and in which the Chinese coincide, viz. that the tea plant delights in moisture, and that an eastern aspect is the best.

Mr. Jacobson of Java states that the tea plant requires a moist soil, but still one where water filters freely.

Mr. Bruce also observes, "that one thing is worthy of notice, that all the Assam tea grows near water, of which it appears to be very fond, for wherever there is a small stream or jheel, tea is sure to be there." $\$$

* Page 33 .

$\dagger$ Page 34 .

$\ddagger$ Handboek v. d. Kult. en Fabrik. v. Thee, § 33 .

$\S$ M. Guillemin states that "the part of the botanic garden at Rio de Janeiro devoted to the cultivation of tea contains only 
Then if this be true, which Mr. Wretgen believes, and in which Lindley* coincides, that it is the temperature and moisture of a soil, much more than its mineralogical quality, which determines its influence upon vegetation, an important fact is here established.

It has been shown, that after a long and uninterrupted period of rest during the winter, copious moisture and rain happen in conjunction with a gradually increasing evolution of heat, at the commencement of spring, when the tea shrub begins to shoot forth its leaves; circumstances which all allow are favourable to the perfection of vegetation and obviously so to the rapid growth of the leaf to its size and succulency.

It is further known by the size and succulency of the Pouchong, Souchong, and Gobee Hyson teas, together with their acknowledged and undoubted superiority, that these conditions can be combined with the highest degree of flavour and quality.

Similar conditions are also necessary to the production of quantity; and quantity is no less important than flavour to insure a lucrative cultivation of tea. Indeed Europeans are unwilling to pay the price which the Chinese obtain in their own country for their high-flavoured teas; nor is the

plants of a miserable appearance, perhaps owing to their situation too near the sea, or from the nature of the soil, for in that part of the garden which is near streams of running water vigorous plants may be observed." - La Revue Agricole, Février, 1840, p. 268.

* Theory of Horticulture, p. 112. 
delicate flavour of the Pouchong tea suited to our mode of using tea, mixing it, as we do, with sugar and milk. We require a strong tea, and strength may depend more on astringency than aroma; and that quality, in all probability, may be less exposed to injury by copious moisture, than the volatile principle on which flavour is very generally supposed to depend.

The soil then should be of a texture to receive and part with water freely. It is on the just balance between these extremes that its suitableness depends; and this again must be regulated by its locality.*

There is a coarse kind of granite everywhere found along the coast of China, which easily breaks down and crumbles by the action of the atmosphere. If the plant be found growing on mountains of this description, in an elevated position, and on a somewhat rapid declivity, in a climate where the rains are copious, and the sun ardent, we shall find the soil broken down, and the alumina washed away,

Mr. Gordon, who seems an acute observer, and whose description of the tea plantations he saw at Amoy is exceedingly valuable, comes to the conclusion that "the tea plant requires absolutely a free soil, not wet and not dry, but of a texture to retain moisture, and the best site is one not so low as that at which water is apt to spring from the sides of the hill, nor so high as to be exposed to the violence of stormy weather. There is no use in attempting to cultivate the plant in an easterly exposure, though it is sufficiently hardy to bear any degree of dry cold." -Journal of the Asiatic Society of Bengal, vol. iv. 
in the form of a finely divided pulverulent clay; the exposed surface will consist of quartz in a finely divided state, felspar, coarse sand and gravel; where indeed there may be little or no accumulation of vegetable mould. But here the plant, stimulated by light and heat, while the roots are deprived of a corresponding supply of moisture, becomes a bushy, stunted, and distorted shrub, with leaves small and thick, like those specimens preserved in the British Museum, erroneously (I believe) marked "Wild Plants."

The same degeneracy of the plant may be observed in an arid soil, even on plains; and similar specimens may be obtained among the Honan plantations at Canton, whence I imagine those in question were procured.

So, on Mr. Gordon's excursion to the Ankoy tea districts, he found some plantations in very sterile ground. "One, in a very bleak situation with nothing but coarse red sand by way of soil, seemed abandoned. In another situation, some of the shrubs scarcely rose to the height of a foot (cubit) above the ground, so bushy, that a hand could not be thrust between the branches, with leaves [only] three quarters of an inch in length. In the same bed, however, there were other plants four feet in height, and about two in diameter, with leaves of from one and a half to two inches in length." *

But this was in the month of November, when

* Journal of the Asiatic Society of Bengal, vol. iv. 
the leaves were principally old leaves, having attained their maturity of size and growth; and yet the largest of these leaves were only about the size of the young and succulent leaves of Pouchong tea, whose leaves of full growth measure five inches.

We therefore here see the degenerating effect of an arid soil. Indeed, Mr. Gordon observes that "the best soil was little more than mere sand."

If we turn to Assam, we there find the effects of the opposite extreme, excess of moisture. There the plant, agreeably to Mr. M'Cleland, "grow's under the shade of dense forests and a gloomy and excessively humid atmosphere, in 'a barren soil, along the verge of rivers, lakes, and marshy lands *," being never wholly inundated, but nearly so.

Thus the plant, "struggling for existencet," being over-excited by excessive absorption of moisture by the roots, while the leaves, deprived of the stimulus of direct solar light and heat, are unable to throw off a proportionate quantity of fluid by perspiration and evaporation, the delicate stem forces its way with difficulty through the dense brushwood, and rises "a tall and slender tree, varying from ten to twenty feet in height, and mostly under an inch in diameter, with its branches high up," and with large

* Transactions of the Agricultural and Horticultural Society of India, vol. iv. p. 35.

† Parliamentary Papers, Tea Cultivation, Feb. 27. 1839, p. 112. 
delicate leaves from four to nine inches long. So that these slender trees, as remarked by Mr. Bruce, when deprived of their support from the surrounding jungle, - which in some instances had been cut down,-seemed scarcely capable of sustaining their own weight.*

We here ses examples of the two extremes of dryness and moisture; but it must be acknowledged, that the plant seems to bear extreme moisture better than excessive dryness; and it has already been remarked that tea is never found growing in arid places.

Pursuing this investigation, and bearing in mind the principle that the tea plant delights in a fertile soil, retentive of moisture, but of easy filtration, we may, perhaps, be enabled to reconcile some of the apparent discrepancies on this subject.

In the first place, "a vegetable mould mixed with sand, light and loose" (p. 46. § 1.), on plains where the drainage is imperfect, or on the gentle slopes and levels of hills, where it is slow, may be a soil of a very suitable character. Independently of the nutritive quality of such a soil, it obviously affords easy filtration, the genial admission of air and heat to the roots, and free evaporation. It will also be seen under the article "Green

* Parliamentary Papers, Tea Cultivation, p. 113. One of the largest trees Mr. Bruce found to be two cubits in circumference, and full forty cubits in height; but he supposed that few attained that size. (Ib. p. 112.) 
Tea," that an immense improvement was effected in that tea by transplanting it from the hills into the plains, and by cultivating it in garden soil, fit for vegetables; moreover, by the use of manure. The black tea, however, is not manured.

Again, in situations "on the banks of rivers, where the ground is level, and subject to inundation," the soil may be "sandy, and stony on the surface" (p.47. §4.), but the subsoil being formed and benefited by filtration from a rich alluvial deposit, the plants are thereby furnished with an inexhaustible source of nourishment; and while the stony and sandy superstratum defends the roots against the scorching heat of the sun, they receive the genial influence of its rays, and are afforded ventilation, evaporation, and filtration.

So on the ledges and terraces of the "inner" range " of the Bohea mountains, a light sandy soil, as described by Du Halde, may be beneficial on these flats. A light soil with a rocky bottom must obviously favour filtration, which these levels or easy slopes, in common with plains, more especially demand; and if in addition to the progressive disintegration which may naturally be supposed to be going on in the rocky substratum by acid excretions from the roots, and from the free action which a light sandy soil affords to moisture and atmospheric influence, these ledges or flats be enriched by alluvial deposits from igneous or primitive rocks, by alumina, and decomposed vegetable fibre from 
the adjacent and overhanging hills; then the elevated situations of these sites, enjoying an open exposure to the morning sun-_-especially useful in dispersing the mists and exhalations which collect in the night in mountainous districts having running streams - seem to combine most of those advantages which the Chinese of this province deem beneficial to the growth and perfection of the tea tree.

It is to be regretted that we have not more authentic and detailed accounts of this soil, or any certain and satisfactory specimens of these rocks to guide us as to its nature. Two or three specimens sent to me with the soils in question, said to be from this particular district, consisted, as has already been observed, of worn pebbles of slate, which were apparently taken out of the bed of a river; and a piece of conglomerate sandstone, or grauwacké, with a Chinese name written upon it, stated to be the name of the tea hill, or rock whence it was taken.

If we may be permitted, in the absence of positive information, to speculate on the nature of these rocks from the views represented by the Chinese in their drawings, or rather maps of this district, the rocks and hills, from their laminated sides in some cases, and their grotesque forms in others, appear to consist of schistose and limestone formation. Those of the more rounded and pointed forms may be sandstone and granite. 
But whatever the peculiarity of the structure of these hills may be-and that they have such the universal testimony of the Chinese will not allow us to doubt_yet it may be fairly surmised that the priests, who have selected this romantic spot as the scene of their seclusion and devotion, have lent a helping hand in rearing up that fame which this particular site has exclusively acquired throughout the empire for the superiority of the flavour and quality of its tea. Careful cultivation through a period of a thousand or twelve hundred years, has doubtless exercised an important influence in modifying the original constituents of this soil, and largely contributed to its improvement, and, perhaps, to that of the plant.

In other situations in this neighbourhood, perhaps in that part which is termed the "middle range," it is said "there are some plantations on plains rather low, the soil of which is very compact, a little muddy, black, and rather damp. The tea of this place is worth two-thirds more than that of other parts of Fokien, with the exception of the "inner range' of the Bohea Mountains." * M. Guillemin notices a similar description of soil at, St. Paul's, which had been recovered from a kind of morass, where the shrubs exhibited great vigour of growth.

These examples afford proof that the tea tree 
flourishes, and arrives at a high degree of excellence in a soil rich in decomposed vegetable matter, and comes in contradiction of the supposition that a poor, sandy, or gravelly soil, with little accumulation of vegetable mould, is alone favourable to the cultivation of the tea plant.*

When cultivated on the embankments of garden grounds or fields of grain, the soil obviously must partake of the nature of those fields, being in some cases a light garden mould, and in others of a more compact and argillaceous character.

The embankments here alluded to are generally about from six to eight feet wide on their summits, and from their inclined position and construction favour filtration. They form sometimes divisions of fields, and sometimes fences, against the encroachments of rivers. They are mostly planted with fruit trees, or other useful plants, as the tea, the mulberry, the orange, and the plantain.

With respect to the outer range of the Bohea

* Mr. Fortune states that the soil of the plantations he saw in Fokien and Chekiang consists of a rich sandy loam. He moreover shows that the tea shrub requires a rich soil. (Wanderings in China, p. 200, 201.) Mr. Jacobson of Java considers that a "temperate" and moderately fertile soil is the best for tea. This may consist of a half or two thirds of a foot of rich decayed regetable matter or humus (which he also terms moer-aarde (peat-earth ?), with a substratum of a compact brown clay earth, which is sometimes termed mountain ground, not rich but by no means poor, and which is of an adhesive character without sticking, when rolled between the forefinger and the thumb. (\$22.) 
Mountains, we have no data to reason upon beyond those specimens of soil already referred to, the character of which is a ferruginous clay mixed with sand. If the "fragmented stones" they contain, together with their ferruginous character, and the quantity of oxyde of iron, be considered as indicative of the rock of which they are formed, it may, perhaps, be allowable to conclude, that the mountains and hills of this particular district consist of granitic, porphyritic, and sandstone formation. These, indeed, with basalt, limestone, and schist constitute the character of the mountains of China, wherever they have come under the observation of Europeans, whether at Canton, along the sea coast, at Amoy, the island of Chusan, or in the interior.*

Thus there seems much analogy between the specimens here alluded to and that brought from Japan by Von Siebold; also in the structure of the rocks and mountains of these two countries, and again between these and the rocks of San Paolo, described by M. Guillemin, so far as their being all of igneous origin.

But though the constituents of any of these rocks be the same, it is well known their com-

* Dr. Abel observes: "Judging from the specimens collected in our route through the province of Kiang Nan, whence the green tea is procured, its rocks consist chiefly of sandstone, schistus, and granite." "The plantations were always at some elevation above the plains on a kind of gravelly soil, formed in some places by disintegrated sandstone, and in others by the débris of primitive rock." (Journey in China, p. 224.) 
ponent parts may differ widely in their relative proportions; and again, as the slope and undulation of hills receive more or less inclination, so may the earth differ in quality and compactness, and thus constitute soils of various degrees of fertility; and hence it may be, that the specimens alluded to vary so much in their proportions of sand. It is obvious that the rich and soluble parts of the soil will be the first precipitated and carried forward to the level parts and plains. In the progress of disintegration the broken and detached masses of rock, deprived of their earthy support, are hurled headlong down the mountain to its base, where they collect in large masses, as may be seen every where along the sea-shore at Macao; while the stones and coarse gravelly parts will be left behind, to wait later effects of disintegration and precipitation by rain, wind, and other atmospheric influences.

Thus it is not surprising, when we are informed of the fact, that the tea tree should be found "to grow with more luxuriance at the base" of granitic hills, and "with more vigour during the heats of summer than on the summits," or that "the soil here should be found more compact and rich."

Mr. Gordon also observes of the Ankoy districts near Amoy, that the plantations he saw were generally at the bottom of hills, where there was a good deal of shelter on two sides, and the slopes comparatively easy. He reckoned the highest 
plantations to be about 700 feet above the plains, [and here, we may add, the plains are nearly level with the sea,] but in those that were less high the shrubs appeared more thriving, probably from having a somewhat better soil.*

Again; if we examine the roots of the tea shrub, we shall find them to consist of innumerable small fibres with fleshy spongioles extending themselves in a circle not far removed from the stem, which indicates that the plant is not one like the vine, which sends forth its roots to a distance in search of food, or that it penetrates deeply into the earth; but that it requires to meet with its aliment within narrow limits, and near the surface of the soil which it inhabits. $\uparrow$

If we further consider the important part which the leaves play in the vegetable economy, that they are in fact the lungs and stomach of the plant, and exercise the important functions of respiration and assimilation; and then reflect on the severe coercion to which it will be seen that the shrub is subjected, during periods of from ten to fifteen consecutive days, of being stripped of its young succulent leaves so soon as they attain their proper size for

* Mr. Fortune states that the plantations he saw in Chekiang; Chusan, and Fokien were situated on the lower sides of the hills, and never on low grounds. (Wanderings in China, p. 201.)

† I am indebted to Mr. Scott, Sir George Staunton's principal gardener, an intelligent and distinguished man in his art, for pointing out this peculiarity to me; and for many other useful and sensible suggestions. 
manipulation, and that this treatment is repeated at certain intervals three times between spring and autumn, we acknowledge it is difficult to comprehend how this shrub can preserve its vigour, without all the aids favourable to vegetation which fertility of soil, heat, and moisture afford.

It is judiciously observed by Mr. Fortune that this frequent "gathering of the leaves is very detrimental to the shrubs, and, in fact, ultimately kills them. Hence a principal object with the grower is to keep his bushes in as robust health as possible, and this cannot be done in a poor soil." *

Moreover; if it be true, as stated by Liebig, that trees, the leaves of which are renewed annually, require for their leaves six to ten times more alkalies than the fir tree or the pine, then the tea tree, by the unnatural treatment it receives as here alluded to, is placed, though an evergreen, in the condition of a deciduous tree. Consequently, it ought to require more alkalies than if left in its natural state, and be less likely to flourish in sandy and calcareous soils upon which the pine thrives. $\uparrow$

Thus there scems little reason to doubt the conclusion drawn by Von Essenbeck after analysis of the Japanese soil, brought home by Von Siebold, that tea soils deficient in lightness require the addition of coarse sand; and failing in nutritive properties, that strong manure and alkaline matter

* Wanderings in China, 201.

+ Agricultural Chemistry, $2 \mathrm{l}$ ed. 132. 
may be employed with advantage *, in which opinion I am disposed to coincide even as regards black tea, though the Chinese universally affirm that manure, is not employed for that tea, and is injurious to its flavour. Further, as has been shown in this investigation, a knowledge of the surface soil only, as in cultivation generally, whether by analysis or otherwise, affords but very inadequate data, unless due attention be also paid to the nature of the substratum rock and subsoil as regarding drainage and nutritive properties.

If by "shelter on two sides" $\uparrow$ be meant open vallies, or hills converging together, with a southern exposure to the sun, we should deem such favourable to the cultivation of tea. But if "shady declivities of hills in moist vallies," + or contracted sheltered vallies, where ventilation is imperfect, and the sun has little influence, be found favourable, which I am disposed to doubt, may it not be because such situations are moist, not because they are shady or sheltered? Whether protection from easterly winds may not be necessary immediately in the neighbourhood of the sea-coast, as at Amoy, I cannot determine; but all inquiry and information on the subject tend to show that, inland, such shelter is unnecessary. The Chinese, however, do say, that an easterly gale is much to be dreaded,

* See note at the end of this chapter, p. 76.

$\dagger$ Journal of the Asiatic Society of Bengal, vol. iv. p. 103.

† Parliamentary Papers, "Tea Cultivation," Feb. 1839. 
but these gales occur but seldom, and only during the great heats of summer, from July to September, when the principal gatherings of the leaves are over.*

Von Siebold (Nippon, part 6.) observes that the Japanese husbandmen consider that hilly sites, elevated from about 700 to 800 feet above the sea, and intersected by brooks and streams, are the most suitable to the cultivation of tea, as in the vicinity of Uresino; and again, in the fertile valley of the River Jodo, in the district of Udsi, where the open flats, not the steep ridges of the hills, are selected for this purpose, and the plantations so arranged as to enjoy the morning sun. $\uparrow$

With respect to an eastern aspect being the best, the Chinese possibly may not mean due cast, but any point between south and east, as southeast. All the Chinese and Japanese accounts agree that a full exposure to the sum is desirable, as other circumstances will prove in the progress of this examination. The morning sun is also supposed to have a beneficial influence on vegetation, while the dew is yet on the leaves, and especially on flower's, as exciting their odorous secretions; and if

* Mild and seasonable rains are desirable, and also gentle breezes; but easterly winds are to be dreaded. If a northerly wind blows in the night, the growth of the leaves is thereby checked; and should an easterly gale prevail, the quantity of leaves will be diminished. (Mr. Reeves' M.S. Papers.)

$\dagger$ the tea tree delights particularly in vallies, or in the declivities of hills, and upon the banks of rivers, where it enjoys a southern exposure to the sun. (LeTtson on the Tea Tree.) 
so, may it not have the same on leaves? At all events it is useful as regarding tea, in dissipating the mists from the atmosphere, as well as the moisture from the leaves, before the gatherers begin to assemble on the hills. It will be seen in the process of manipulation of black tea, that it is desirable to evaporate as much moisture as possible from the leaves before they are roasted.

Thus we come to nearly the same conclusions as the Rev. Father Carpina, that the black tea tree in China delights in hilly sites, though of moderate elevation; yet it is also successfully cultivated in plains, under favourable circumstances, such as along the banks of rivers, in a light stony soil, subject to occasional inundation; in an open exposure to the sun, and the genial winds of a somewhat hot climate, tempered by intervals of rain, and exhalations during the night; an aspect fronting the south-east, or one benefited by the morning sun; a soil rich and somewhat compact, or retentive of moisture, though of easy filtration; sufficiently porous to be permeable to the numerous and delicate fibres of the roots of the plant, as well as atmospheric influences; and sufficiently tenacious to supply a healthy moisture to the plant, without being liable to be dried up and baked during the alternations of sun and rain, which take place at no very remote intervals between the vernal and autumnal equinoxes. 


\section{NO T E S.}

I subjoin a communication on the subjects of the preceding chapter from Professor Faraday:-

Royal Institution, May 11. 1827.

\section{Specimens of Earths from China.}

No. 1. Specimen from the Lapa, a hill near Macao.

No. 2. Specimen from the north-east part of the province of Fokien.

No. 3. Ditto.

No.4. taken out of a pot containing a tea plant from the Bohea country.

No. 5. Bohea country, 1st quality.

No.6. ditto 2d quality.

No.7. ditto 3d quality.

These earths were all of similar ferruginous tints, $i . e$. of light yellow or reddish brown, as the one formerly analysed, except No.2., which was of a grey or brownish grey tint. 'They were all of a clayey adhesive character, but easily crumbling and falling down in water. None of them contained worn pebbles or worn sand, though some included fragmented stones, and all of them sharp sabulous silicious particles. None of them gave evidence of containing carbonate of lime except one, and in that only a single piece of the carbonate was observed, which was probably accidental. Their hygrometric state appeared to be about that of the former sort, viz. 102.

No. 1. contained no stony fragments or pebbles; the aggregated portions were, however, irregular and dissimilar, being of different colours, as if the soil had either been purposely mixed with other soil, or else cultivated and manurcd. It con- 
tained also a few loose fibres. It contained also a trace of sulphate of lime.*

No. 2. contained fragments of apparently a decomposing porphyritic rock; it was in this that the fragment of carbonate of lime occurred. It included also several pieces of charcoal, and a few portions of old decayed regetable fibres.

No. 3. Included some long woody fibres, and a few irregular fragments like those of No. 2.

No.4. contained very few vegetable fibres, some angular fragments of decomposing granite and felspar, and particles of mica diffused through the soil.

No. 5. contained very few fibres; no appearance of pebbles or of mica; but, by washing, a few heary, greenish black mineral particles were found, which had not before occurred.

No.6. A few fibres; no stones; much mica in a finely divided state, but no green particles.

No. 7. A few long, loose, woody fibres; a few small silicious stones; particles of mica, and a recurrence of the same green particles as in No. 5.

The proportions of sand in these soils varied very much, as may be observed in the following table. The clay, \&c. includes not only the argillaceous particles, but destructible matter and water.

\begin{tabular}{|c|c|c|c|c|c|c|c|}
\hline \multirow{4}{*}{$\begin{array}{l}\text { Sand - } \\
\text { Clay, \&c. (ferru } \\
\text { ginous) - } \\
\text { Fragments }\end{array}$} & \multirow{2}{*}{$\begin{array}{l}\text { Lapa. } \\
\text { No. } 1 .\end{array}$} & \multicolumn{2}{|c|}{ N. E. Fokien. } & \multirow{2}{*}{$\frac{\text { Pot. }}{\text { No. } 4 .}$} & \multicolumn{3}{|c|}{ Bohea. } \\
\hline & & No. 2. & No. 3. & & No. 5. & No. 6. & No. 7. \\
\hline & $46 \cdot 1$ & $17 \cdot 70$ & 10 & $51 \cdot 54$ & $\begin{array}{c}\text { 1st qual. } \\
33^{\circ} 08\end{array}$ & $\begin{array}{c}\text { 2d qual. } \\
44 \cdot 61\end{array}$ & $\begin{array}{r}3 \mathrm{~d} \text { qual. } \\
36 \cdot 15\end{array}$ \\
\hline & $\begin{array}{c}53 \cdot 9 \\
-\quad-\end{array}$ & $\begin{array}{l}56 \cdot 53 \\
25 \cdot 77\end{array}$ & 90 & $48 \cdot 46$ & $66 \cdot 92$ & 55.99 & $63 \cdot 85$ \\
\hline & $100 \cdot 0$ & $100 \cdot 00$ & 100 & $100 \cdot 00$ & $100 \cdot 00$ & $100 \cdot 00$ & $100 \cdot 00$ \\
\hline
\end{tabular}

* This soil had been manured with goats' dung, and was taken from the small plantation at the Lapa, described by Dr. Abel. 
Chemical Analysis of the Earth of a Japanese Tea Plantation, by Dr. Th. Fc. L. Nees Von Essenbeck and L. Cl. Marquart.**

The earth given to us to analyse appeared a very uniform fine grained mixture of a yellowish grey colour, having altogether the appearance of a strong ferruginous clay, in which no mixture of sand was perceptible to the naked eye. After the removal of two small stones, one porphyry and the other grauwacke, the weight of the earth amounted to 462 grains. The specific gravity was decided at 2325. 200 grains of airdried earth absorbed 165 grains of water. Of this water, in the first five hours, under a temperature of from $15^{\circ}$ to $18^{\circ}$ Reaumur, 31 grains were lost; after 24 hours, 100 grains; after 48 hours, still 24 grains remained; and not till after 72 hours had all the water disappeared.

Of these 200 grains, the parts soluble in cold water amounted to scarcely one-eighth of a grain, consisting of humus and lime, with traces of muriatic and sulphuric acid, clay and iron.

[Then follows a minute description of the analysis, giving the undermentioned result.]

On placing together the constituent parts of the earth, we find the following results. 100 grains of the earth contain

\begin{tabular}{|c|c|c|c|c|c|c|}
\hline Silicious $\mathrm{e}$ & arth & & & - & - & - 53 grs \\
\hline Oxyde of & iron & - & - & - & - & 9 \\
\hline Clay & - & - & - & - & - & 22 \\
\hline \multicolumn{5}{|c|}{ Oxyde of manganese and magnesia } & - & $0 \frac{1}{2}$ \\
\hline Gypsum & - & - & - & - & - & $0 \frac{1}{2}$ \\
\hline Inumus & - & - & - & & - & 1 \\
\hline \multicolumn{7}{|c|}{ Phosphoric acid, traces of. } \\
\hline
\end{tabular}

[He adds in a note.] On another portion of the earth we succeeded in proving evident traces of kali. It does not appear, lowever, as a fresh soluble combination of salt in the eartl, but is undoubtedly combined with clay and silex.

After we had by these means analysed the carth in its consti-

* See Von Siebold's Nippon, part vi.p. 17. 
tuent parts, it appeared that it should be considered as an intimate mixture of silicious earth and clay, with the oxyde of iron and manganese (eisenhaltiges Aluminiumsilicat). The small portion of magnesia is remarkable, and even this is closely combined in the soil with the silicate mentioned.

Thus the earth appeared like atmospherically dissolved slate. The phosphoric acid is well combined, and arises probably, as well as the gypsum, from the manure in the soil. According to Thaer's classification of soils, this earth belongs to the third class, as a strong sandy clay soil.

The analysed earth is moreover, from its deficiency in carbonic acid, humus, lime, and magnesia, not to be referred to the productive, and assuredly requires stronger manure, and addition of alkaline matter. Its water-retaining property is considerable on account of its great portion of clay, but the soil is deficient in lightness from the absence of coarse sand. 


\section{CHAP. IV.}

CULTURE-ACCOUNTS GITEN IN CHINESE WORKS-DY EUROPEAN MISSIONARIES - PLANTATIONS SEEN BY MIR. GORDON AT AJOY - CULTIVATION OF GREeN TEA DIFFERENT FROII BLACK MIODE PRACTISED IN JAPAN - IN JAVA.

The only mode of propagation of the tea plant mentioned in the Chinese works I have had an opportunity of consulting, is by seed. The Chinese, also, with whom I have conversed on this subject, seem generally to admit that it is the best method, though they affirm that this practice rarely obtains in the Bohea district in the present day. The plantations of Ho Nan, in the vicinity of Canton, to the south, are propagated with seed. The soil consists of coarse red sand and gravel, the situation is low and flat, and the heat of the climate unfavourable. The shrubs are ragged and stunted in their appearance, and the leaves thin and small, producing tea altogether unsuitable for European consumption.

The following instructions for planting are found in the Kiun Fang Pu, under the article "Tea":-

"Seeding. - The seed must be collected in Han Lu (October), dried in the sun, then mixed up with moistened sand, and packed in baskets.

"Planting. - Tea naturally dislikes water [to 
collect about the roots]. It requires a rich soil, shady and sloping ground, to allow the water to drain off. In sowing the seed use paddy husk and parched earth. Put from six to ten seeds into each hole, placing them about an inch below the surface of the ground. When the plants begin to germinate, the weeds ought not to be raked up. If the season be dry, water them with water in which rice has been washed, and manure them often with manure in a liquid state, or with the dung of silkworms. Water lodging about the roots of the plants will inevitably destroy them. After three years the leaves are fit for gathering. The shrubs should be planted in sets, which are separated about two cubits ( 28 inches) from each other."

The above mode of culture appears to correspond more with that of the green than the black tea, for the Chinese generally agree that the latter is not manured. The Hoa King, under the article "Tea," says_ "That tea [black tea] is the most fragrant which is not manured."

Let us now subjoin the accounts received from the missionaries before quoted : - "Put four or" five seeds into one place. When the leaves shoot out, and the plants have grown to the height of a cubit (14 inches), bind them together. Weed them at the four seasons of the year, turn up the ground about the roots, and add new mould. Arrange the binding, and take away the dead shoots. There 
is no occasion to trim or to water them." Another gives the same account of the mode of sowing the seed, but makes no mention of binding the plants. He then proceeds as follows:- "When the aged plants become dry and exhausted, cut them down to the roots, and they will shoot again. The leaves may afterwards be gathered in the second or third year. In planting, it is unnecessary to take slips for that purpose, but simply to cut down the [wild] trees, and transplant the old roots. In the second or third spring the leaves shoot forth in sufficient abundance to admit of their being gathered. The shrubs require neither lopping, watering, nor turning up the ground about the roots. They, however, require weeding; and the old roots must be watered for a few days at the time of transplanting, when they never require it more."

I shall now conclude with the Rev. Vicar-General Carpina's account (the Spanish missionary so frequently alluded to in these pages), which may be considered the mode adopted in the part of the province where he resided, at Fogan, about 240 miles south-east of the Bohea country.

"With respect to the duration of the plants, in places which are suitable to them, and where animals cannot destroy them, they will last fifty years and more. When they are too old, if the soil is rich, they are cut down close to the roots, which is done at the winter solstice, and in the following spring they shoot out vigorously. But 
when the soil is sterile, the old roots are dug up to be planted elsewhere. They easily take root again. It is in this manner that the shrubs are preserved and reproduced, and never by branches that are slipped off. They may also be propagated by seed; but with less success, and much slower. The cultivators of tea take no pains to prevent the growth of the shrubs, for the larger they are the more profitable; but as, in the second or third year after they have been planted or cut down, the leaves are gathered once, and afterwards three times a year, their growth is thereby checked. Yet in plains, and on the mountains where the ground is good, they grow to the height of more than thirteen feet.

"With respect to the culture, it consists in this. Every year in February and August the ground is weeded, raking up even the grass. When the ground is hilly, and appears exhausted and sterile, after having weeded it in February, it is usual to go and dig soil from a neighbouring mountain, and bring it and place it around the roots of the shrubs. If this new soil be previously exposed to the sun, or even burnt, it improves it. No other manure or watering is required, for the plantations are neither so low, nor so flat, but they are casily irrigated. It is on this account that no tea shrubs are found on dry and arid places. We have seen the crops fail more than once, because no rain had fallen between the winter solstice and spring," The writcr here means 
in the eastern part of the province, and near the sea.

It is obvious from the preceding accounts that, under ordinary circumstances, very little attention is paid to the cultivation of tea in the province of Fokien. In fact the original cost paid to the cultivator for Congou or Souchong tea intended for foreign consumption, would not admit of expensive cultivation or costly manipulation. Thus all accounts agree, that the Chinese do not employ any of the ordinary means of selecting and propagating accidental and superior varieties by cuttings, layers, or grafts, though all these methods are understood and practised by them in their garden cultivation. It is not from ignorance, therefore, that none of these methods are adopted. The speediest and most successful practice, agreeably to the Rev. Father Carpina, adopted by the farmers and cultivators in his part of the province, is by cutting down to the roots the wild shrubs growing on the hills and mountains, and transplanting them elsewhere. This doubtless must be a quicker and preferable mode to rearing from seed or any other method where the wild shrubs are sufficiently numerous, and where a quality suitable to general consumption is merely sought. Hence we may conclude that there are many parts of the province of Fokien, where the tea tree has in all ages been found growing spontaneously and abundantly anong the hills, but in situations remote or under 
disadvantageous circumstances; whence they have been transplanted to other soils and sites which experience has shown to be more congenial or more convenient, and which are now in the vicinity of towns and hamlets in part, if not entirely, owing their rise and present support to the cultivation of that shrub.

In districts suitable to its growth it obviously must be the endeavour of every farmer to have his little plantation of tea. Thus Von Siebold informs us, that at Japan the husbandman grows his tea for domestic use in hedges and detached parts of his farm, which are less favourable for tillage. He adds, it is principally from these plantations, which appear to the traveller like scattered hedges and bushes, that tea is rendered available to the lower classes.* The farms which $\mathrm{Mr}$. Fortune saw in Fokien, "were all small, each consisting of from one to four or five acres." $\uparrow$

Mr. Gordon saw at Amoy a little nursery attached to each tea plantation, where plants were "growing to the height of four or five inches, as closely set as they could stand." It may also be remarked, that the Chinese adopt the same practice to bring forward their second crop of rice. Thus, in harvest time, the young seedlings being ready to transplant, reaping, threshing, irrigating, ploughing, and transplanting, may be seen all going on at

* Nippon, part 6.

$\dagger$ Wanderings in China, p. 201. 
the same time, and at no great distance, in the same rice field.

In the "Inner Range" of the Bohea Mountains regular and well kept plantations prevail; also on plains and parts of hills sufficiently level to be formed into beds ; but, for reasons already assigned, the Chinese cannot afford the expense of forming their hills into terraces for this purpose. Mr. Gordon states, that the ground was not terraced at Amoy, but formed into beds which were partly levelled. The plantations were perfectly well dressed as in garden cultivation, and each was surrounded with a low stone fence and a trench.

The cultivation of green tea differs essentially from that of the black, inasmuch as the finest description, denominated Hyson, is cultivated on plains in a fertile soil, and manured. The price paid by foreigners for this quality of tea affords sufficient encouragement to the grower to induce him to appropriate a more fruitful soil to its cultivation. Why the cultivation of Souchong tea is not more extended, I have never been able satisfactorily to understand, except, as stated by the Chinese, that the soil favourable to its growth is confined to a locality of limited extent, whereas Hyson tea may be produced in any quantity. Higher prices have been paid by the East India Company for the finest description of Souchong or Paochong tea, than were ever given for green tea, and every pains taken to encourage its growth. In a free trade these 
high-flavoured teas are not likely to answer to the importer, whose object is necessarily gain. They will probably giradually disappear from the market; but it was a matter of principle with the East India Company to sustain the character and quality of their teas, and to consult the discriminating taste of the rich, as well as to satisfy the demands of the poor, without a strict regard to profit; so that they imported some teas, as they exported woollens and other British products, at a loss. Their aggregate profits enabled them to conduct their trade on generous principles.

The usual mode of culture of the finest description of green tea, known to Europeans by the name of Hyson, originally consisted in taking the shrubs from particular hills favourable to their growth, and transplanting them into fields, gardens, and hedge-rows, a light garden loam being considered the best. Seed is also employed to keep up the plantation, and to renew decayed or exhausted shrubs, when in three years the leaves are fit for use. The shrubs are manured twice a year, in spring and autumn; the ground weeded and turned up about the roots four times a year. In about seven years they are cut down, nearly close to the ground, to produce an exuberance of succulent shoots and leaves; and in about thirty years they become useless, when they are rooted up. 'The inferior Hyson teas, denominated by the Chinese "hill tea," and the common Singlo or Twankay 
shrubs receive no attention beyond that of weeding twice a year, when the grass and weeds thus raked up are placed about the roots where they are left to rot.*

I shall here add a few notes on this subject. It will be seen by Von Siebold's account of the cultivation of tea at Japan, that the mode of culture adopted there accords more with that of green tea in China, than black. Indeed, so far as my information extends, the tea used in Japan, with the exception of the bud of the leaf, is a green tea of the class of 'Twankay. But we shall recur to this subject in treating of the manipulation of tea.

* Tien Hing states that the planters frequently purchase seedlings, which are transplanted and are fit for gathering in two years. The price is 100 cash, or about eight pence for a bundle containing a hundred; half the amount is paid at the time of planting, and the remainder in three months for those that live. He adds they are planted in rows about two cubits (twenty-nine inches) apart, between which they grow vegetables: but this space seems hardly sufficient. The usual space appears to be about four feet. The plants are manured once in the eighth moon (September), a cavity being made about the roots, into which the manure in a liquid state is poured. 


\section{$\mathrm{N} O \mathrm{~T}$ E S.}

TeA is easily obtained from seed, which should be used as soon as ripe, or in a short time after it has been collected; for it soon loses its power of germination. The shrubs produce such an abundance of flowers and seeds, that many of the seeds fall and germinate under the old shrubs, which serve to renew the plantations. Rapport de M. Guillemin, D. M. \&.c. La Revue Agricole. Février, 1840, pp. 268, 269.

Von Siebold states, that the best mode of propagation of the tea plant is by seed, at distances of four feet apart. At Japan the shrubs flower from November to February, and the sowing takes place in the following autumn, when the seed is ripe, and the plants spring up in May or June. After the first year the plants are topped, hoed, and manured. The manure is used both in a liquid and dry state. It consists of a mixture of mustard seed and dried sardels (a kind of herring), oilcakes of the Brassica Orientalis and other coleworts, together with human dung and urine. These manures are found by experience to be suitable to the heavy soils congenial to the tea plant, and to exercise a decided influence on the improvement of the shrub.Nippon, part 6 .

Mr. Jacobson of Java states, that, as a general rule, the cultivation of tea is conducted on the same principle as that of coffee. He justly observes, however, that as leaves are the product of the harvest, and not fruit or flowers, whatever mode of cultivation is suitable to that is the one to be adopted. In plains it must be treated as rice, and irrigated, a greater slope being allowed for drainage; and yet not so much as to wash away the earth and occasion a loss of soil.

The best mode of cultivation at Java, is from seed sown in the ground where the plants are intended to grow, and not from seedlings taken from nurseries; because this latter mode 
causes an unnecessary employment of labour. Seeds sown in their capsules are better than without; but either mode will do. Each bush may produce about 250 capsules, containing on an average 476 seeds; 103 may contain only one seed each; 80 may contain two seeds; 55 may contain three seeds; and 12 4 seeds. Each bush is formed either of 5 seedlings; 10 fresh or dried seeds; or of 8 or 9 capsules containing 14 to 17 seeds.

'The bushes are placed 4 feet square apart, and extend to about 3 feet diameter; so that an opening of only 1 foot remains between each bush in the several rows. The cavities made for the reception of the seedlings are about $1 \frac{1}{2}$ foot in depth, and 1 foot diameter; those for seed are 4 or 5 inches deep. Clay earth taken out of the bed of rivers, put 4 or 5 inches deep and covered one inch with soil, keeps white ants away: in such cases the spaen required will be 7 inches in diameter, and 4 inches deep. Seeds steeped in katjang oil are also a preserva tive against white ants.

In cases where the bushes do not flourish, and where they decay, seed may be sown near the roots of such shrubs; and when the seedlings become productive, the old bushes may be cut down or rooted up altogether.

The bushes should not be allowed to grow higher than 3 feet, for the convenience of gathering the leaves. If higher, men of ordinary stature and boys would not be able to gather them. When the seedlings have attained a foot in height and are strong, they must be stopped, or topped; that is, the crown or head of the young seedling must be nipped off with the thumb-nail. 'This it may be necessary to repeat three or four times during the first year, according to the rapidity of the growth. of the plant. In the first stopping or topping the plant must not be reduced lower than $\frac{3}{4}$ of a foot; in the second, not lower than $1 \frac{1}{2}$ foot; and thus till 3 feet be attained. The term topping. is also applied to the branches as well as the stem. Here the stopping of the lateral shoots should take place on the brown part of the wood, about half an inch or an inch below the green part of the shoot. In this manner the young bushes are made to extend their lateral growth to three feet in diameter, with an exuberance of young delicate leaves. 
In cases where the brown part of the shoot cannot be pinched off, a knife or a pair of scissars may be used.

At Java the seed is sown in the month of November when the ground has become somewhat compact after rain. In plantations where the shrubs are regularly stopped, headed back, and cut round,-in short where the leaves are cultivated to the prejudice of the fruit, - little or no seed is produced. It therefore becomes necessary to set apart a portion of the plantation for this object. In such cases the bushes are placed five or six feet apart and left to their natural growth, and the leaves not gathered. After the third year, the plants should be manured, and the manuring repeated every second year.

Should the bushes thus appropriated to the cultivation of seed exhibit symptoms of exhaustion, which they sometimes do after the third year, then they must be cut down to about a foot and a half from the ground. In about five or six weeks the shrubs shoot out leaves which may be gathered for the harvest. On the other hand, an equal number of bushes cultivated for leaf, must now be left to their natural growth, and the leaves not gathered. In about twelve or fifteen months they will produce seed. In this way the seed garden may be changed when desirable.

Besides the topping or stopping of the young seedlings, the productive bushes require regular pruning. By pruning is here meant cutting and heading back, and freeing the shrubs from dirt, dust and larve of insects, and dead leaves. It is only the work of two minutes for each bush.

The mode of doing it is, by taking as many branches as the left hand can compass, even a hundred, then with the knife to cut upwards, and reduce the bush to the height of the knee, or two feet from the ground. Branches which run along the ground, must be removed; knotty distorted branches growing within the shrubs must be cut out to within one foot from the ground. Lateral branches should be cut within two feet from their point of junction with the parent stem; and all short branches reduced until only one or two eyes or buds be left on each.

After some years the bushes form thick and strong branches low down, and the shrubs consequently decline. In such cases 
the ground must be ploughed up between the bushes, and the prunings buried and used as manure. Should the plant not recover, then an extra pruning must take place, by cutting the bushes down to within a foot and a half of the ground. They will then look like single stems.

In China it is said that by regular yearly cleaning, thinning out, cutting round, and extra pruning, the shrubs may be preserved for sixty years. (Abstracted from the Handboek v. d. Kult. en Fabrik. v. Thee.) 


\section{CHAP. V.}

TIME OF GATHERING - THREE GATHERINGS - DIFEERENCE OF QUALITY OF TIE GATHERINGS - ONLY YOUNG SUCCULENT LEAVES FIT FOR TEA - MODE AT JAVA.

The Pun Csao Kiang Moo states, that for the proper time of gathering flowers, fruits, leaves, and the stalks of plants (for medicinal purposes), this general rule may be observed, that they be gathered in their perfect maturity.

We also say that the best time for gathering simples is when the plant is at its highest state of perfection; and this we deem to be, as a general rule, just at or after its efflorescence.

Now the tea shrub begins to flower in the south generally about October, and seems to continue flowering through the winter, for I have seen some shrubs in flower so late as the beginning of March*; and the first gathering of the leaves for Pekoe tea commences fifteen days after the vernal equinox.

The time of gathering the tea leaves, however,

* Cunningham states that the tea shrubs flower at Chusan from October to January, and that the seed is ripe in September or October. Ting Hing, a respectable green tea factor, states that they flower from September to November; another green tea factor, so late as February. Kœmpfer observes that at Japan the shrubs flower from August until late in the winter. Von Siebold states from November to February. 
seems not to be governed by any rule of this nature. The gathering takes place during the season of spring, when the rains fall copiously, and the shrubs shoot forth their leaves vigorously and abundantly. This period of gathering lasts at intervals of ten or more days, from about fifteen days after the vernal equinox to about the same number of days after the summer solstice. There is also an autumnal gathering; but such teas are weak and not esteemed of good quality. Most of the Chinese accounts agree, that the gathering of the leaves commences with the Pekoe tea, and lasts from the 5th to the 20th April. This tea consists of the convoluted leaf-bud. The first gathering of the expanded leaf commences between the 20th April and the beginning of May; the second, about the 6th June; the third, after the 21st June, or, in other words, in the beginning of May, June, and July respectively; and the autumnal gathering in August and September. The coarse leaves, which form the common Bohea, are collected in September and October.

The Chinese manuscript already quoted states, "In the mild and temperate season of spring the shrubs shoot forth their leaves, when such as are young and delicate must be chosen. Those that are partly unfolded, long like a needle and covered with down, must be gathered to be made into Pekoe.

"A few days after Ko Yu (20th April), the leaves 
become large, and are called the first gathering (Teu Chun). These are thick and substantial, fragrant in smell, and sweet in flavour.

"When the leaves of the first gathering are exhausted, wait till they shoot out anew, about Chung (6th June), when they must be gathered and made. These are called the second gathering ( $U l$ Chun), the flavour of which has no fragrance, and the colour of the leaf is of a lingy black.

"The leaves shoot out again at the summer solstice (Hia Chy): these are called the third gathering (San Chun), and are of a light green colour and coarse in smell."

The Vû Ye Shan Chy* (the statistical work of the black tea country already alluded to) states that

"The first gathering is fragrant in smell and full flavoured.

"The second has no smell and is weak in flavour.

"The third has a little smell, but is also weak in flavour."

A Chinese manuscript gives the following account of the qualities of the different gatherings of the Congou tea which forms the bulk of the black

* This work also observes, that the leaves gathered between 'Tsing Ming and $\mathrm{K}_{0} \mathrm{Yu}$ are called Teu Chun; after Ly Hia, Ul Chun ; and after Hia Chy, San Chun. 'Teu Chun, Ul Chun, and San Chun, signify first, second, and third gatherings. Tsing Ming, Ly Hia, and Hia Chy are periods of the year, viz: the 5 th of April, the 5th of May, and the 21st of June. 
tea imported into England:-_" The first gathering may be divided into superior, middling, and low ; the superior kind resembles the Souchong tea in flavour and colour. The second gathering also produces Pekoe and Souchong; the flavour has a fire smell, and the leaf is coarse and dull. The third gathering also produces Pekoe and Souchong, though not much; neither is it good: the flavour is poor, and the infusion of a light green colour. The autumnal or fourth gathering, Aug. and Sept. (Csieu Loo) - The flavour is poor, and the infusion of a pale yellow colour; the colour of the leaves is also plain and ordinary. In the eighth and ninth moons (Sept. and Oct.), the shrubs are cut, whole branches at a time; the leaves are coarse and stiff, and the flavour exceedingly common and bad." This tea was formerly packed in baskets and sent to Canton to be made into Bohea. It is now packed in the country and sent down in chests.

Thus it appears, that in all the successive gatherings it is the young and succulent leaves only that are chosen. If the leaves be permitted to attain their full growth, they become harsh, fibrous, and brittle, and cannot be made to assume the twisted form in their manipulation, but remain flat, coarse, or open and yellow, and are unfit for tea. The coarseness of the leaves of this description found in tea is chiefly owing to this circumstance. The large succulent leaves of a reddish purple colour are the best. The red or purple colour, however, 
of the manipulated leaves does not arise from their being so in the fresh or natural state, but is occasioned by a particular mode of manipulation previously to roasting.

Now it is obvious, that one great cause of difference in the quality of tea depends upon the time of the year in which the leaves are gathered. Thus the Chinese universally agree that the young luxuriant leaves put forth and gathered in early spring are the best, while the other gatherings deteriorate in quality as they approach the autumn, which are the worst.

In fact, on the return of spring, after a long dry and cold winter, all vegetation acquires a high degree of energy and excitability, which is exhibited in the power of producing a more vigorous foliage than at any subsequent period of the year. The sap is also in a more concentrated or inspissated state from its accumulation during winter, than subsequently, after its first and most vigorous flow in early spring.

Thus it is not surprising that the Chinese should find that the young succulent leaves of spring, which, at this season in particular, have all the important functions to perform which are necessary to the elaboration of flowers fruits and wood, as well as foliage, should furnish the heaviest and the highest-flavoured tea, besides possessing all those qualities on which excellence depends; or that, in subsequent periods, when the sap is in 
a more fluid and diluted state, the tea of this season should be found weak and flavourless, and the prepared leaves, like dead leaves, pale and yellow. Thus we find it stated by Mr. Jacobson of Java, that the leaves of the successive gatherings diminish in quantity and size as well as weight: "that the leaves of the third gathering are less abundant than those of the second; but not in the same degree as those of the second are less than those of the first." *

Again, as the excellence of all vegetable productions is so intimately connected with the state of the weather, it will naturally suggest itself, that the leaves of the tea shrub must also be greatly influenced by it; and consequently we find, that the sun, so essentially requisite to the evolution of the odorous principle of fruits and flowers, is also deemed by the Chinese as indispensably necessary to the production of that fragrance and quality which constitute the excellence of the finest black teas. The Chinese say that the Yen or Padre Souchong tea must be gathered not only in clear and bright weather, but that those teas only are of the first quality which are gathered during a continuation of fine weather, and even after noon, during the greatest heat of the day. On the other hand, a Chinese manuscript states, that "those which are gathered in rainy weather are poor and tasteless,

* IIandboek v. d. Kult. en Fabrits. v. Thee, \$300. 
and unfit for Pao Chong or Padre Souchong; though they will, nevertheless, do for Siao Poey and Ta Poey, or fine Souchong." And it may here be observed, that the Chinese universally agree, that such teas as are made under any unfavourable circumstances of soil, quality of the leaves, or state of the weather, cannot, by any manipulation, be rendered of superior quality. The leaves, therefore, which are gathered in unfavourable weather are made with less care; and such as are gathered after or during much rain undergo some difference in the mode of manipulation.

A further difference is also occasioned by the selection of particular shrubs, and of the best or most succulent leaves at the time of gathering. It is said to be a common practice among those merchants who are in the habit of frequenting the habitations of the Priests or Bonzes, to contract for the produce of certain known shrubs. These are labelled according to their supposed resemblance in flavour to particular flowers *; and at the season of Tsing Ming in the early part of the year, they repair to these plantations, where they prepare the tea

* I was informed by Puankhequa, an intelligent and highly respectable Hong merchant, that sometimes teas are marked scented (hoa-hiang), not because they are really scented, but on account of their supposed resemblance to the odour of certain flowers. It is moreover stated in the Canton Chy (a statistical work on Canton) that some teas resemble the odour of the Yu-lan, Mo-ly, and Chu-lan flowers. Some teas are, however, artificially scented with these flowers, which will be found explained under the article on "Scenting." 
themselves. In these cases each leaf is said to be plucked separately from the shrubs; and the leaves of such shrubs as are known to resemble each other in flavour are mixed together and kept apart throughout the whole manipulation. They are also packed in small paper parcels, each weighing about eight or twelve ounces, sometimes bearing on them, in large flowing Chinese characters, the name of the flower they are supposed to resemble in odour; and sometimes the name of the hill of their growth in small neatly written characters. These symbols can hardly have escaped the observation of the dealer and consumer. This care, however, is only bestowed on the finest description of Paochong tea, which is collected in very small quantities. It is evident, from the quantity of stalks found in even the finest teas which formed a part of the East India Company's Investment, or even in most Paochong teas, that no such mode had been adopted in their gathering. Nor is any particular attention paid to the state of the weather, so far as teas for the European markets are concerned. It is generally admitted by the Chinese that much Congou tea is hastily and rudely gathered, some even by whole branches at a time, in all weathers, and at any time of the day. It is obvious that the Chinese must use their leaves, however unfavourable the state of the weather may be; and thus a further difference of quality is created, dependent on season, as in all other vegetable productions. 


\section{N O T E S.}

Wiтu respect to the mode of gathering the leaves for tea, it is difficult to reconeile all the Chinese say on this subject with what comes under our immediate observation. The finest black teas are said to have their leaves plucked separately; and yet we find, in proportion as the tea is of superior quality, so is it more mixed with tender and delicate stalks. In fact, the luxuriance and delicacy of the shrubs, or the contrary, may be known and distinguished by the quality of the stalks found in the manipulated tea to which they belong. The same may be predicated by the infused leaf. In proportion as the tea is of fine quality, and, consequently, the product of delicate shrubs, the leaves, if masticated between the front teeth, aided by the tongue, will be found soft and pulpy; or harsh and fibrous, if the product be of coarse shrubs. Thus in proportion as the young shoots are tender and delicate, so is the risk increased of tearing away part of the shoot in the act of plucking the leaf. 'This might seem to account for the stalks found in Pachong tea; but the true reason I believe is, that the young tender shoots bearing two or more leaves are nipped off with the forefinger and thumb, as described by Mr. Bruce at Assam, and Mr. Jacobson at Java. This latter gentleman is of opinion that the stalks of black tea should not be plucked off; that they favour the process of withering, and do not impede the rolling, because they are succulent and pliant as the leaves. Mr. Jacobson also states, that the motion of the two hands, for both are employed, is like the oscillation of a pendulum, and that a hundred motions are made in a minute. I have seen the Honan leaves gathered separately; and all the leaves brought to me in the course of experiments, which will hereafter be detailed, were without their stalks.

I believe, however, the mode of gathering the leaves varies according to the suceulency of the shrubs, and the practice of 
different localities. In situations where the shrubs produce long succulent green shoots with many leaves, the leaves are pinched off in pairs with part of the shoot, and classed at the time of gathering; or the whole shoot may be gathered at once, and the leaves plucked off, and classed afterwards by females when received at the roasting sheds. Many Chinese drawings and statements sanction this latter mode. 'The Hyson leaves are said to be so gathered, and the stalks and shoots are separated carefully, because the stalks would injure the tea in the progress of manipulation; but with black teas, the stalks and shoots seem to be separated with less care, because attended with no apparent detriment to quality.

In localities where the shrubs are of less luxuriant growth, and, consequently, produce shorter and less succulent shoots, and fewer leaves, the leaves may be plucked off separately; because it can be done with much less chance of tearing away any part of the shoot, or of injuring the bud left for the formation of new shoots, which will be found at the foot of the leaf-stalk, or petiole. The quantity of rough, ragged stalks, however, sifted from 'Twankay tea, which is a green tea, shows that the leaves of this tea can hardly be gathered separately; and, moreover, from their hard, ligneous character, that the leaves of this tea are the product of inferior shrubs, and that even a knife may partly have been used in the gathering. Indeed, it is said that the leaves of many of these teas are collected whole branches at a time, and that the leaves are rudely stripped off with the hands. The same is also said of some Congou teas. But I am indisposed to give credence to these statements, except in the case of very inferior teas, such as small farmers and peasants use for their own consumption, or sell to other's of the same class, or are used for adulteration. 'The teas which Mr. Fortune saw made in the provinces of Fokien and Chekiang appear to have been so gathered. "They strip the leaves off" rapidly and promiscuously, and throw them into round baskets, \&c." (Wanderings in China, p. 203.)

Mr. Jacobson observes, that when young shoots appear very green and succulent, and deficient in brown wood, the gathering had better be deferred for a few days.

$\$ 290$. When the leaves are fit for gathering, the third and 
fourth leaves, if plucked upwards, will break a little above the leaf-stalk or petiole, consequently, above the bud; thus the leaf-stalk, with its fiagmental leaf, is left to foster the bud, and to act as a conduit of moisture during rain. When the leaves are harsh and fibrous, and, consequently, too old to be gathered, then they generally break in the middle, leaving behind one half of the leaf. 'This is a test that may be relied upon; and the gathering must be regulated accordingly.

$\$ 291$. The planter will soon know by his eye when the time of gathering is arrived : still it is better to observe the above rule. The plant first shoots forth and develops two leaves; it shoots again, and two more unfold; and again in the same manner, till nine or more leaves are produced on one shoot. At this period, the lower part of the shoot becomes brown and woody; later, three or four buds send forth branches on either side, and the whole together assumes a fan-like shape. Before this state of growth arrives, the leaves should be gathered. The plucking of the leaves from the shoots requires a certain skill: yet women and children may do it.

$\S 296$. The gathering is divided into three classes of leaves, and each class is gathered by different men. First, the top-leaf, consisting of the convoluted leaf-bud with its expanding or expanded leaf; then the fine-leaf tea, consisting of the second and third leaves; and, finally, the fourth and fifth leaves, which form the midclle-leaf tea. The coarse-leaf tea is the refuse of these two classes after manipulation. It is the duty, also, of the gatherers of the middle-leaf tea, as they are the last gatherer's, to search for and gather any other delicate leaves which may have been overlooked by the previous gatherers. The mode of gathering is by turning the thumb downwards, and nipping off the young green succulent shoot with the nail and forefinger, first below the top-leaf, with its expanded or expanding leaf. Then below the second and third, and the fourth and fifth leares. If the sixth and seventh leaves are fit for tea, they may be gathered also.

$\S \S 300$. and 301. When the last leares on the shoot are gathered, they must not be nipped off, but plucked upwards, and in such a manner as not to injure the buds; otherwise such shoots or branches would be left without the power of repro. 
duction. It is desirable that two, but not more buds, should be left on each shoot; and the separation should be made about a quarter of an inch from the nearest eye or bud intended to be preserved for the reproduction of young shoots. The stalks of the leaves of black tea must not be detached from the leaves, because, in the process of withering, they improve the flavour of the tea, and do not impede the rolling of the leaves, because they are tender, pliant, and succulent.

$\S 302$. The green tea leaves are gathered without their stalks, because the withering of these leaves would be injurious. The stalks are, consequently, not nipped off, but the leaves plucked upwards.

$\S \S 305 .-308$. The gatherers carry a small basket in front of them, fastened round the body; thus they are enabled to gather the leaves with both hands, and to throw them quickly into the basket. They must not be kept long in the hand, nor in large parcels, lest they should heat and turn sour. Besides the small basket strapped to the body, there are four large baskets each carrying about three pounds of leaves, required for each section of a garden; so that two may remain while two are sent off to the roasting-sheds: one is required for "fine-leaf," and one for " middle-leaf." The Pekoe and Gunpowder leaves are kept in "scoop-baskets," their quantity being small. The baskets containing the leaves of black tea may be left open and exposed to the sun to hasten the withering; but the leaves of green tea must not be exposed to the sun, nor should they be kept long in the garden; nor must the black tea be allowed to wither rapidly, lest they also heat and turn sour.

\$314. After the fourth gathering, the shrubs will once more exhibit an abundant display of foliage; but these leaves must be left to restore the exhausted energy of the plant. (Abstracted from the Handboek v. ג. Kultuur en Fabrikatie van thee d. J. J. L. L. Jacobson. Batavia, 1843.) 


\section{CHAP. VI.}

MANIPULATION PREVIOUSLY TO ROASTING - MODE DESCRIBED BY A CHINESE - EXPOSURE OR NON-EXPOSURE TO SUN EXPEDIENTS ADOPTED IN RAINY WEATHER-DESCRIPTION OF THE SEVERAL PROCESSES - FRAGRANCE, NONE IN FRESH LEAVES - DEVELOPED BY MANIPULATION - PERSONAL OLSERVATION OF THE SEVERAL PROCESSES — REDNESS OF TIIE LEAF.

Loo Lan describes the method of preparing the Yen or Pao Chong tea as follows. This account is principally useful as containing most of the terms of art employed by the Chinese in the manipulation of tea. "After the leaves are gathered spread them upon flat trays, and expose them to the air: this is called Leang Ching. Toss them with both hands, sift them, and carefully examine them with a light to see if they be spotted with red, which is necessary: this is called To Ching. Carefully put them into small bamboo trays, and cover them up quite close with a cloth, until they emit a fragrant smell: this is called Oc Ching. Hand them to a roaster (Chao Ching $\mathrm{Fu}$ ), to roast them in a red hot Kuo (an iron vessel). Throw about five ounces (four tales) of leaves into the Kuo, then with a bamboo brush sweep them out. Let them be well rolled, and afterwards sent to the poey or dryinghouse to be completely dried. This tea is called Souchong and Paochong, and sells at from fifteen to 
thirty shillings the pound (four and eight dollars the catty) in the country where it is made."

Another Chinese, in the manuscript previously quoted, thus describes the process of making the Yen and Puon Shan Souchong: "Spread the leaves about five or six inches thick on bamboo trays (Po $K y$ ) in a proper place for the air to blow on them. Hire a workman, or Ching $\mathrm{Fu}$ (to watch them). Thus the leaves continue from noon until six o'clock, when they begin to give out a fragrant smell. They are then poured into large bamboo trays (Po Lam), in which they are tossed with the hands about three or four hundred times: this is called 'To Ching. It is this operation which gives the red edyes and spots to the leaves.

"They are now carried to the Kuo and roasted; and afterwards poured on flat trays to be rolled.

"The rolling is performed with both hands in a circular direction about three or four hundred times; when the leaves are again carried to the Kuo; and thus roasted and rolled three times. If the rolling be performed by a good workman, the leaves will be close and well twister, if by an inferior one, loose, open, straight, and ill-looking. They are then conveyed to the Poey Long, the fire fierce, and the leaves turned without intermission until they are nearly eight-tentlis dried. Whey are afterwards spread on flat trays to dry until five o'clock, when the old, the yellow leaves, and the stalks are picked out. At eight o'clock they are 
' poeyed' again over a slow fire. At noon they are turned once, and then left in this state to dry until three o'clock, when they are packed in chests. They are now fit for sale."

By the preceding accounts it appears, that no exposure of the leaves to the sun takes place previously to their being roasted. 'This opinion is supported by many authorities, upon the ground that the slightest fermentation would injure them. Mr. Pigou, however, and many Chinese state, that the leaves may be placed in the sun if not too ardent; or, if necessary, that is, if they require it. One person says, "into each tray put five tales of leaves and place them in the sunshine." Another, in speaking of the finest teas, observes, _ "If the leaves require it, they must be placed in the sun to dry. For this purpose they are thinly spread in sieves, and whirled round. If then not sufficiently dry and flaccid, they must be exposed to the sun again." (Chinese Manuscripts.)

The teas which I have seen made, and have made myself after the manner of Souchong, have invariably been exposed to the sun; and some teas are made altogether in the sun, though this is not esteemed a good method.*

* When I say that I have "seen made," I mean simply made to explain the process to me. I wish the reader particularly to understand that I have never seen tea made for sale, or which was fit for sale. The tea districts are distant eight hundred or more miles from Canton. 
It is also certain that the Congou teas are exposed to the sun in the tea country, where large stands are erected in the open air for this purpose. Some are made horizontally, but more frequently obliquely, and usually contain about three rows of trays (Po Ky), each about two and a half feet diameter. Mr. Bruce states that the inclination given to these stands is such as to form an angle of $25^{\circ}$. They are raised two feet from the ground, and incline outwards, towards the sun, as here figured.

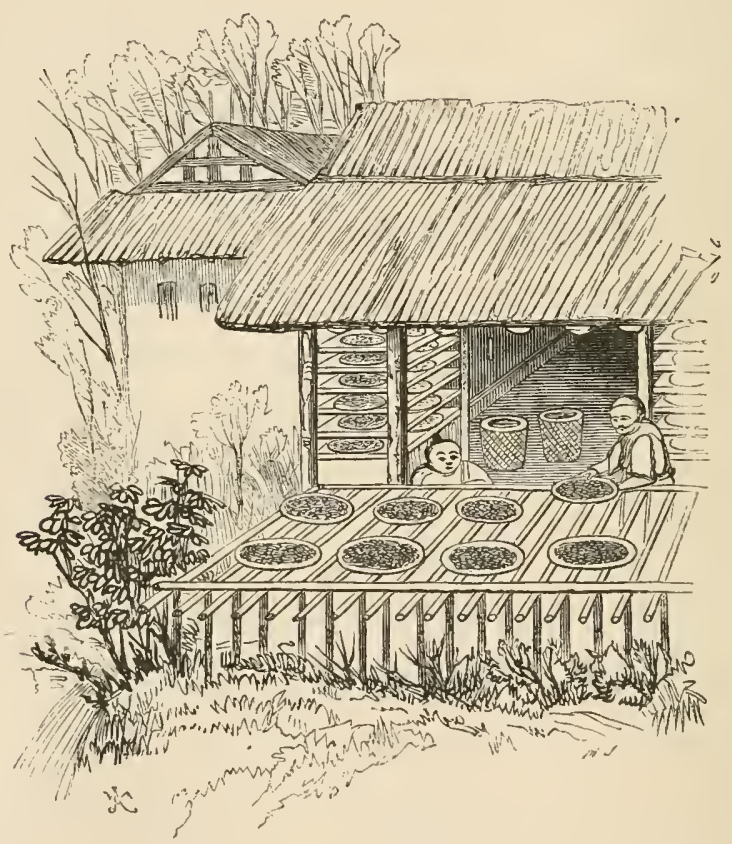

The apparent discrepancy, therefore, in these accounts, like many other contradictions which appear in the different relations concerning tea, will be found to arise in most cases from a difference of manipulation dependent upon the state of 
the leaves, or on the kind or quality of tea required to be made.

The Chinese seem to agree that the finest Souchongs, the Yen or Padre Souchongs, or Paochongs, when made under favourable circumstances, would be injured by any exposure of the leaves to the sun. But it must be remembered that these teas are made from the finest shrubs, the young leaves of which are described as being large, and of great succulency, as well as extreme delicacy. They are also gathered after a succession of bright weather; and the best kinds during the greatest heat of the day. That change, therefore, which is necessary to be produced previously to the process of Leang Ching, by exposing the leaves to the sun, during which they "wither and give*," and become soft and flaccid, may so far take place before and after the gathering as to render a simple exposure to the air sufficient. Indeed this exposure to the shade and air may be necessary to check or prevent fermentation, or some unfavourable change which they might otherwise undergo.

On the other hand, leaves which are gathered from shrubs of inferior delicacy, and are somewhat harsh and fibrous in their texture, may be greatly improved by exposure to the sun, especially if any chemical change be sought. At any rate that state of flaccidity which is desirable must be greatly ac-

* Pigou, Oriental Repertory, vol. ii. p. 288. 
celerated by such means; and whether adopted from motives of utility or economy, it may be sufficient for all purposes of the present inquiry to state the fact, as gathered from the testimony of the Chinese, that the finest teas are not exposed to the sun, but that many souchongs of excellent quality commonly are, and the congous invariably.

Leaves gathered after rains more particularly require exposure to the sun. I have seen the Ho Nan leaves collected under such circumstances so treated, and then kept twenty-four hours in a cool place, and afterwards exposed to the sun again with advantage. Indeed leaves which are gathered during rains, or in cloudy weather after much rain, must be dried before or over a fire previously to their being roasted. "To carry such leaves thus turgid and full of juices to the Kuo," said an excellent workman, "would be boiling them instead of roasting thern."

The houses and stoves erected for this last purpose appear similar to those employed in the process denominated poey, under which article a description of these houses will be found.

The manner of drying the leaves in this process is differently described by different persons ; and I imagine there may be many modes of performing it. Some Chinese say that the stoves are built in the centre, and the leaves placed on stands erected on either side, as for the common Bohea; others, that the stands are placed over the fire, and 
not apart from it, and some that stoves are not used at all, but that the fire is wheeled about under a kind of stand, or framework, fitted to the walls of the building. Perhaps all these methods are used, since this exposure to the fire is simply to produce an evaporation of the exuberant juices acquired during rain; for in proportion as the leaves are full of juices, so is the pain and difficulty, and even expense, of manipulation increased.

The following plate exhibits a room fitted up for this purpose, having a framework to receive the sieves, with earthern chafing dishes or stoves, containing charcoal placed underneath, taken from a Chinese drawing:-

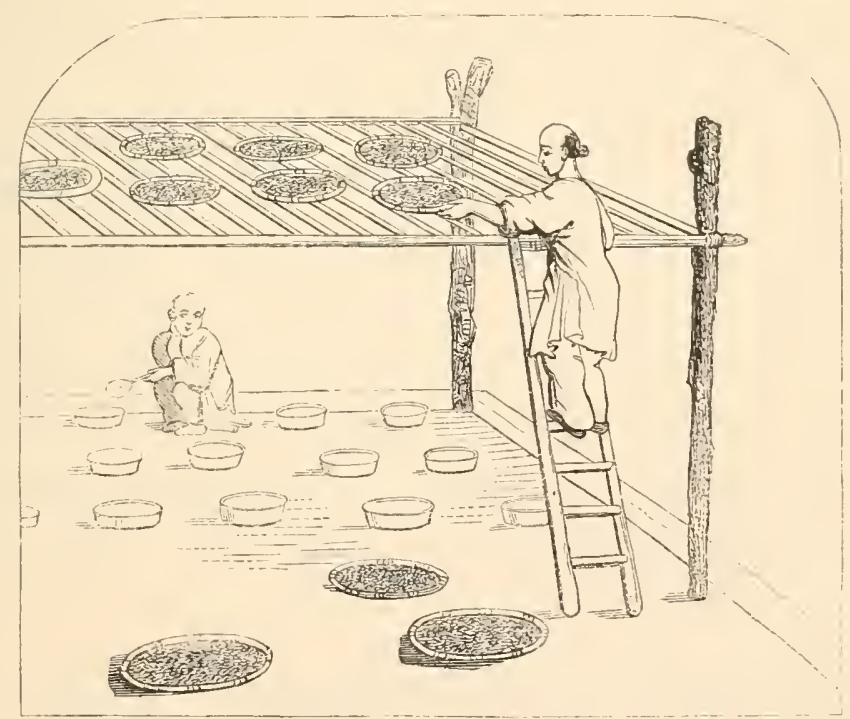

The manipulation now may be divided into1 st, the process previously to roasting; and 2 ndly, the process of roasting. The process previously to 
roasting consists of Leang Ching, To Ching, and Oc Ching.

The process of Leang Ching is literally that of cooling the leaves, or keeping the leaves cool to prevent or check fermentation. For this purpose they are placed either in shady situations in the open air, exposed to the wind, or in open buildings which admit a draft through them. Easterly winds are said to be unfavourable to this process. Tall stands (Kia Czu), about six feet high, consisting of many stages, are employed to receive the different bamboo trays (Po Ky), in which the leaves are placed in quantities agreeably to their qualities, and the care intended to be bestowed on their manipulation. The finest description of Yen or Padre Souchong teas are thinly strewed over the trays; but inferior kinds of Yen and Puon Shan teas are placed five or six inches thick. In this state they are kept, until they begin to emit a slight degree of fragrance, when they are sifted, to rid them of any sand or dirt which may adhere to them, preparatory to the operation of To Ching.

To Ching signifies the tossing about the leaves with the hands.* The manner in which I have

* In composition the Chinese frequently add another word to the word $T o$, which appears to be referable to some modification of this part of the process. Some use 'To Pa, the tossing and patting of the leaves; others To Tuon, the tossing and collecting them into a heap or parcel; others To Nao, the tossing and rubbing them : and again, 'To Lung, which means simply tossing, or 
seen this process performed was thus: a man collected together as many leaves as his hands and arms could compass; these he turned over and over, then raised them a considerable height, and shook them on his hands: he then collected them together again, tossed and turned them as before. In the manuscript already quoted, it is stated that this operation is continued about three or four hundred times; and that it is this part of the process which produces the red edges and spots on the dried leaves.

Another man whom I saw make tea, after having completed the operation of To Ching, pressed the leaves of each parcel together with a slight degree of force into a heap or ball, which seems to agree with what some Chinese call Tuon Ching. In both cases they were kept until they emitted what the workmen deemed the necessary degree of fragrance, when they were roasted. With respect to the quantity tossed at one time, the Chinese differ considerably. Some say that the Siao Poey, Ta Poey, with other Souchong teas, and Congou teas, are made in large quantities. The leaves of six or seven small trays are mixed, they say, together, and placed

literally tossing and tumbling about the leaves. Now the tossing, patting, rubbing, collecting the leaves in a heap and covering them up as in the process of Oc Ching, are doubtless different methods used for the purpose of checking or hastening fermentation, as the leaves may require. The finest descriptions of Yen or Paochong tea are not handled at all, but are simply whirled round in sieves. 
in large trays (Po Lam), and two, three, four, or more men, are employed to toss them. Some say that six or seven pounds (five catties), and others eleven or thirteen pounds (eight or ten catties), are thus formed into one heap even for fine Souchong.

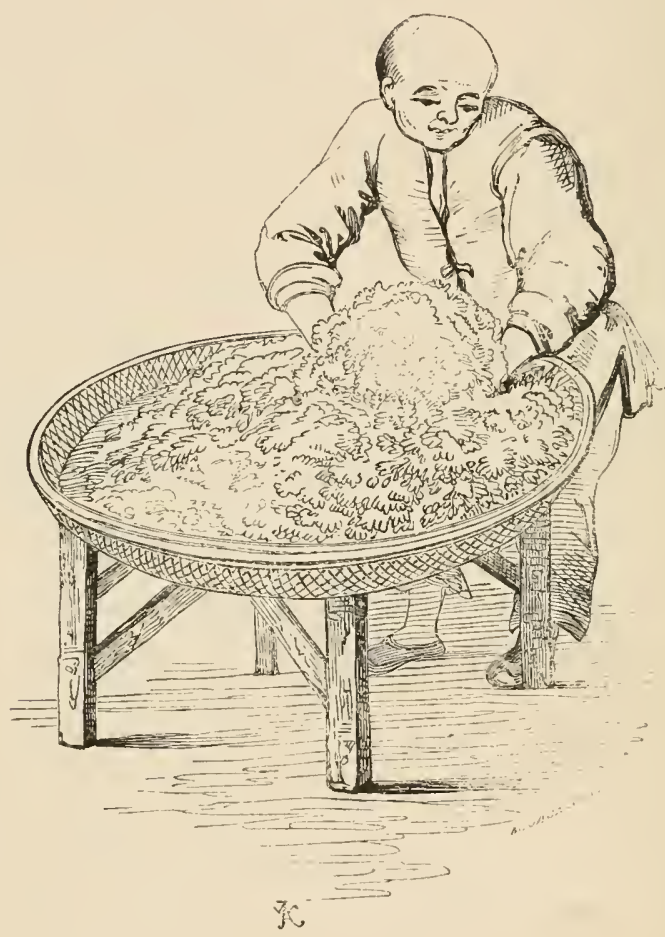

The finest kinds of Yen or Pao Chong teas are said to be placed in sieves in a long narrow close room. Open shelves, made of bamboo, pass along the walls, eighteen or twenty in height, upon which sieves, or small trays, are placed. The leaves of this tea being thinly strewed in the sieves, as already described in the process of Leang Ching, 
require no tossing, but are simply whirled round and shaken to and fro, as in the act of sifting and winnowing, which obviously would produce the same effert. Thus the workman begins at one end of the room, and proceeds in the manner already described, until each sieve has passed through his hands. He then returns to the first sieve, and continues the process until the leaves give out the requisite degree of fragrance.*

These teas, agreeably to the accounts of some Chinese, then undergo another process previously to their being roasted, denominated Oc Ching. This consists in collecting the leaves of each sieve into a heap, and covering them with a cloth. They are then watched with the utmost care, and, as this part of the process is continued during the

* Mr. Jacobson describes this process very accurately. It is employed at Java for all descriptions of black tea, as well as tossing the leaves with the hands. He states, the leaves are strewed about two inches thick on circular trays, measuring about $30 \frac{1}{2}$ inches in diameter. An undulatory motion is given to the tray from right to left, by a slight action of the arms and hands. The leaves thus kept in constant motion, and whirled round, turn as it were on a common axis, and rise in a conelike shape to the height of eight inches, occupying little more than one half of the tray. He also observes, that one man may work eighty trays containing $60 \mathrm{lbs}$. of leaves in this manner in one hour. The leaves are first whirled from thirty to forty times, then tossed from thirty-five to forty times, and so as long as neressary ; but the last motion must be the whirling. They are then covered with a tray, and put aside for about an hour; but this must depend on the state of the leaves. (Handboek v. d. Kultuur en Fabrikatie v.Thee, §333.) 
night, the workmen are described as constantly proceeding round to the different sieves, with a lamp in the hand, gently and carefully lifting up so much of the cloth of each sieve as will permit them to discern whether the leaves have become spotted and tinged with red. So soon as they begin to assume this appearance they also increase in fragrance, and must be instantly roasted or the tea would be injured.*

It may here be observed that the leaves of tea have no kind of fragrance in their unmanipulated state, but have a rank vegetable flavour both in taste and smell. Nor is the fragrance which is evolved previously to roasting in any degree correspondent with that, at least in my opinion, which constitutes the flavour of tea after complete desiccation.

Thus the manipulation previously to roasting

* Lap Sing says, "It is only a common kind of tea that undergoes the process of Oc Ching, and which is consumed principally at Su-chao, in Kiang Nan." It is true, there is a particular kind of common tea called Hong Cha, or Red Tea, which $I$ have seen, and which is said to be made by a longer continuance of the process of Oe Ching, which is the tea he alludes to. But inany Chinese affirm that the Paochong tea is covered with a cloth, as already described, and others with a tray. Nor does Lap Sing's own account differ very materially; for he admits that, after the process of To Ching, the leaves are collected together and suffered to remain in a licap, which he denominates Tuon Ching, during which the leaves become fragrant, and spotted with red. The difference seems only in degree. 
seems to be for the purpose of evaporating as inuch of the fluids as possible without injury to the odorous principle, or aroma; or rather, perhaps, to induce a slight degree of incipient fermentation, or analogous change, which partakes of the saccharine fermentation of hay, during which the requisite degree of fragrance is evolved. But whatever that change may be to which the fragrance of smell, and the red or brown appearance of the leaves, which constitute the peculiarity of black tea, may be due, it is on the management of this change that the quality of the Yen, or Padre Souchong teas, greatly depends. To produce it slowly, to know when to retard it, when to accelerate it, and in what degree, requires some experience; and the Chinese universally consider the management of the leaves of this fine tea previously to roasting, as the most important and difficult part of the whole manipulation.

We also find that the leaves of these teas, which are of great delicacy and succulency, and gathered during a succession of bright weather, are kept in small parcels; and the highest degree of fragrance and incipient chemical change, of which they are susceptible without injury, is induced, besides being exposed to more than ordinary heat in the first process of roasting, denominated Ta Ching ; they consequently receive much care and attention throughout every stage of the manipulation. 
On the other hand, teas which are made from inferior shrubs, whose leaves are of a harsher and more fibrous texture, and, consequently, less disposed to chemical change or to heat, require less care. Thus we find that Congou teas in particular, which form the bulk of those imported into England, are gathered in all weathers, and exposed to the sun or fire, as circumstances permit, to hasten evaporation. They are also kept in large parcels throughout the whole process of manipulation, and less attention is paid to change of colour and fragrance of smell. They nevertheless must undergo the processes of To Ching and Leang Ching, during which they "wither and give," and partially become spotted and tinged with red; for this state of withering is no less necessary to Congou than Souchong tea, and on the skilful management of this process the excellence of quality of all black tea depends.

Having now related what I have been enabled to collect from the Chinese upon the subject of the manipulation of the leaves previously to roasting, it may also be satisfactory to point out what has come under my own personal observation. I shall therefore now describe the mode in which I have seen this part of the process performed, on two occasions, by men from the Bohea and Ankoy countries. The leaves employed for this purpose were collected from Honan, in the southern suburbs of Canton, and Pack Yuen Shan, north of the city. 
Nor did I perceive any material difference in the mode of manipulation as performed by these men.

The newly gathered leaves were first spread about an inch thick on small sieves, and suffered to remain in the sun about twenty minutes. The leaves of each sieve were then taken in succession, and turned and tossed with the hands for a considerable time, as already described in the process of 'To Ching, when they were again spread out and exposed to the sun. When the leaves began to "wither and give," and become soft and flaccid, the leaves of two or three sieves were then mixed together, and the tossing of the leaves and exposure to the sun again repeated until they began to emit a slight degree of fragrance. They were then removed into the shade, formed into still larger parcels, turned and tossed as before, and finally placed on stands in a room exposed to a free current of air, as in the process of Leang Ching. In a short time they gave out what the workmen deemed the requisite degree of fragrance, when each parcel was again tossed in the shade, and roasted in succession.

No attention was paid to any change of colour in the leaves, nor did any appear red or brown previously to roasting, though some ferw had a reddish purple appearance afterwards. The tea, when completely dried, resembled a black leaf Congou; but, while the Honan tea was agreeable, and drew a red infusion, the Pack I'uen Shan tea 
was not drinkable, and the infusion was almost colourless. To what this difference is to be ascribed I am unable to explain, but I am disposed to think it arose from the high temperature employed in roasting the latter tea, it being too great for the then condition of the leaves. Subsequent experiments seem to sanction this opinion.

The reddish-purple appearance of the leaves, however, previously to roasting, is not absolutely necessary to the redness of the leaves afterwards. I once rolled a small parcel of leaves previously to roasting them, in the same manner as it is performed after roasting, and, upon holding them up to the light, many appeared translucent in parts, but not red. When completely roasted, they had a rich reddish-purple appearance, and were more fragrant in smell than other parcels of the same tea roasted in the common manner. Nor did this translucency appear to be occasioned by the leaves having been bruised in the act of rolling, for the same appearance was produced by placing a few leaves under a wine glass exposed to the sun; and, by a still further exposure, the leaves became spotted with red, particularly round the edges.

This experiment gave rise to others, which will more fully develop the cause of the change of colour, and the peculiar effects which accompanied that change. Let it here suffice to say that this state of withering is indispensably necessary to black tea; but whether it be necessary to wait 
till the leaves begin to be spotted with red for black leaf Congous may require further investigation. Mr. Jacobson deems it necessary for all black tea. For Souchong I believe it is; that is, as soon as some few of the leaves begin to show that disposition, it is time to prepare them for roasting. There is an art in the management of this process. 


\section{CHAP. VII.}

ROASTING AND FINAL DRYING OF THE LEAVES - TIVO PROCESSES - RoAsting Vessels and stoves DEscribed - MODE OF ROASTING - MODE OF ROLLING - PROCESS OF TA-CHING FINAL DRYING - STOVES AND INSTRUIIENTS USED - MODE OF DRYING-MARKETS ESTABLISIIED-PACKING OF THE TEA AT THE VILLAGE OH' SING-CSUN - REIIARKS ON THE PROCESSES OF MLANIPULATION - VARIATIONS IN THE MODE OF MANIPULATION - OBSERVATIONS ON THE MODES DESCRIBED BY MR. FORTUNE - SOME TEAS WHOLLY MANIPULATED IN TIIE SUN -EXPERIMENTS ON THIS MODE, AND DEDUCTIONS THEREFROM.

The roasting and drying of the leaves may be divided into the two processes of Chao or Tsao and Poey. The former takes place in a shallow iron vessel called a Kuo; and the latter in sieves over a charcoal fire - a description of which will be found under its proper article. The Kuo is a remarkably thin vessel of cast iron of a circular form, differing in no respect from those used in China for culinary purposes : except that it has no handles.

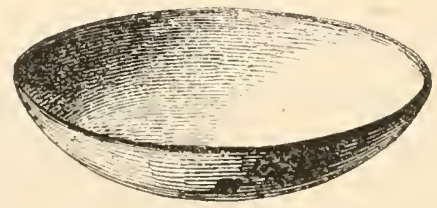

The size most employed is about 2 feet 4 inches in diameter, and $7 \frac{3}{4}$ inches deep; but they vary in size according to the quantity of leaves intended 
to be roasted at one time. The stoves commonly in use are said to consist of oblong pieces of brickwork, resembling the Hyson stoves to be seen in the Hong merchants' roasting houses at Honan, in the district of Canton. The Kuo is fitted in horizontally with its rim even with the upper surface of the stove. The best constructed stoves have a small ledge at the back part, for the purpose of holding a lamp, as the roasting is generally continued until a late hour, and frequently through the night. The fire-places are at the back of the stove: so constructed as to leave an opening underneath for wood or charcoal. As much tea is made by the poor, and small farmers, it occasionally happens that both the stove and the Kuo are identical with those used for culinary purposes; and the vessel, which in the morning is employed to boil rice for their breakfast, is in the evening used to roast tea. Generally, however, separate vessels are used exclusively for tea; for great care must be taken to keep the Kuo clean and free from every thing which might communicate an objectionable flavour. And as a yellowish viscid juice exudes from the tea in the process of roasting and rolling, forming when dry a whitish deposit which adheres to the sides of the Kuo, it becomes necessary during the several stages of the manipulation to wash the vessel and other instruments used, and also the hands. I did not observe any such deposit during the experiments which I witnessed; but I have no 
doubt of its existence when the leaves are thick and succulent.

In the first roasting of all black tea, the fire is prepared with dry wood, and kept exceedingly brisk. The vessel is heated to a high temperature, much above the boiling point; but any heat may suffice which produces the crackling of the leaves described by Kompfer.

I shall now explain the mode in which I have seen the Honan tea leaves roasted after the manner of Solachong and Congou, by men from the Bohea and Ankoy districts, to exemplify this process to me.

The roaster stands on the side of the stove opposite the fireplace, and taking about half a pound of leaves between his hands, he throws them into the Kuo. He then places his hands upon the leaves, and with a slight degree of pressure, draws them from the opposite side of the vessel across the bottom to the side nearest himself. He then turns them over and throws them back again, repeating this action until the leaves are sufficiently roasted.

When the heat becomes excessive, and difficult to bear, the roaster then raises the leaves some height above the Kuo, and shaking them on his hands, he lets them gradually fall, which serves to dissipate the steam, and to cool them. There is one circumstance which it is necessary here to notice, as requiring the attention of the roaster. Care must be taken to observe that none of the 


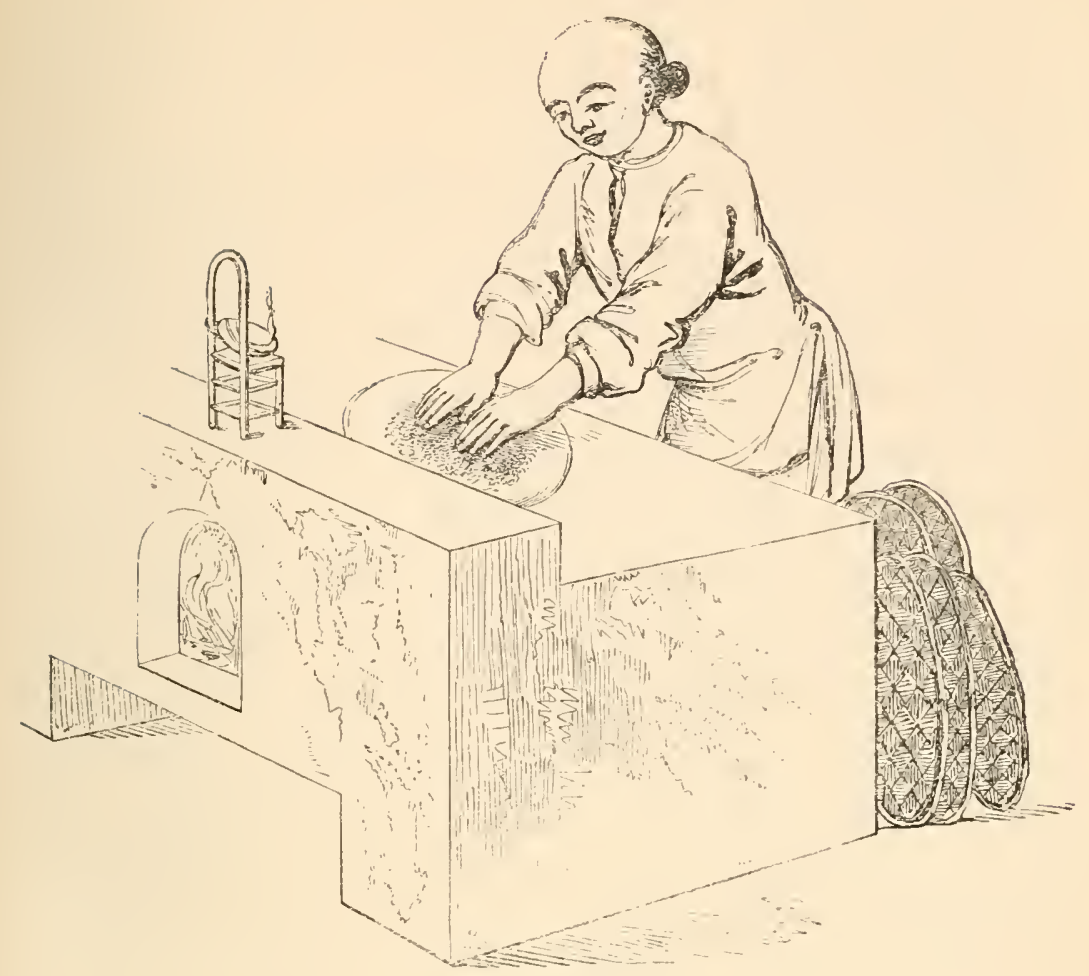

leaves lodge or remain about the middle part of the bottom of the Kuo, for this being the part most heated, they soon begin to burn, and if not attended to, might communicate a smoky or burnt flavour to the tea; though in this early stage of the process there is not much danger of producing that evil. This defect is easily perceived and obviated; for the smoke which arises from the burnt leaves can readily be distinguished from the steam produced by evaporation; then by increasing the pressure of the leaves against the heated part of the vessel as they are drawn across, the roaster is enabled to sweep away or remore such leaves as 
may have lodged in the bottom; and if he quicken the motion at the same time, the smoke and burnt smell will speedily disappear.

With respect to the degree of roasting which is requisite, it may suffice to say, that the roasting must be continued until the leaves give out a fragrant smell, and become quite soft and flaccid, when they are in a fit state to be rolled.

And here it may be important to observe, philosophically as well as practically, that though the leaves are fragrant when brought to the roasting vessel, yet that fragrance is dispersed so soon as the fluids are rapidly set in action, and they again acquire their vegetable smell. The fragrance, however, returns after the loss of a certain amount of moisture; and its return, together with the flaccidity of the leaves, marks, as before observed, the period when the leaves are in a fit state for rolling. The same observation holds during the process of rolling. Here, again, the fluids are discharged, but by pressure, not heat, and the vegetable smell returns. Thus, during the whole process of roasting and rolling, these alterations of smell occur, till the leaves are deprived of all moisture in their final desiccation in the drying tubes, when the fragrance becomes fixed.

In my own experiments, when I found the heat more than I could bear, I removed the leaves from the Kuo, and allowed them to cool a little; as also the Kuo from the fire. This I have repeated two 
or three times during the first process of roasting before the leaves were sufficiently roasted, without any apparent injury to the tea. It is surprising how great a degree of heat the men habitually employed in this occupation can bear; and in my few trials with these people, I always found they could continue the roasting a considerable time after the heat of the steam had obliged me to relinquish it, even with the aid of a pair of thick cotton gloves. After this first roasting (Chao), the leaves are immediately rolled. Each roller is provided with a circular tray of bamboo work, upon which he places as many leaves as the two hands held together in a concave position can cover. They then all fall to work, immediately rolling the leaves round

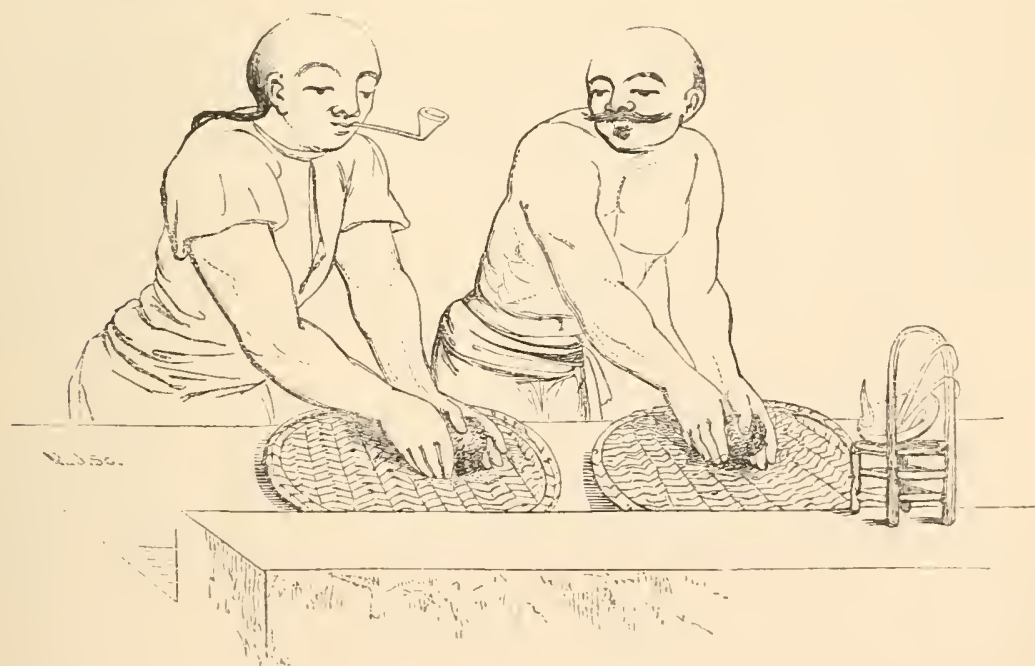

from left to right, using a slight degree of pressure, and attentively keeping them in the form of a ball. Some skill is required to preserve the leaves in this 
form: and it is the test of a good workman to keep the leaves well collected together under the hand, and not allow them to stray and spread themselves

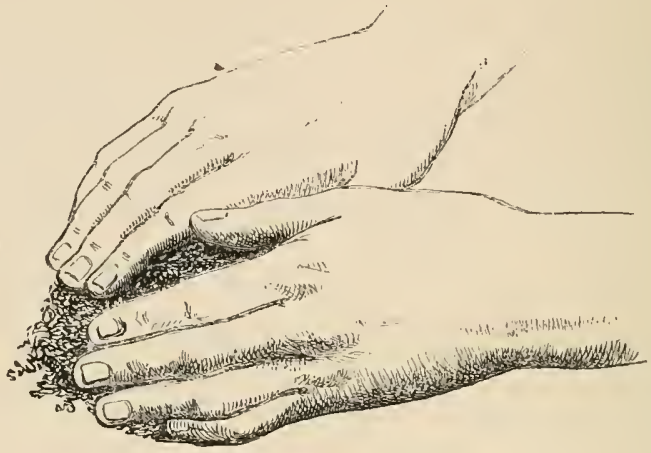

over the tray; for on this depends the leaves being well or ill twisted.* When sufficiently rolled the ball is shaken to pieces. The leaves are then found twisted; and the viscous juices expressed in the process of rolling are sufficient to keep the leaves in the twisted form. They are now spread out on clean trays, and placed on stands several tiers in height, until the whole of the fresh leaves have been roasted, when they again undergo the process

* Mr. Bruce describes the process of rolling very minutely and well. "The art," as he observes, "lies in giving the heap, or ball, a circular motion, permitting it to turn under and in the hand two or three whole revolutions before the arms are extended to their full length, and drawing the leaves quickly back'without leaving a leaf behind. (Parliamentary Papers, Feb. 1839. Tea Cultivation, p. 109.)

Mr. Fortune, also very aptly compares this action to that of a baker kneading his dough. (Wanderings in Clina, $2 \mathrm{~d}$ edit. p. 196.) 
of Chao.* In the second roasting of all tea, the heat of the fire is considerably diminished, and charcoal used instead of wood. The heat of the vessel, however, is considerable, and not supportable to the touch. The fire requires no particular attention. 'The leaves having now been deprived of a considerable quantity of moisture, their bulk is

* It may here be observed that the form of a ball is not a condition to which the Chinese attach any importance ; and that may explain why they frequently make no mention of it. The thing sought by them is the expression of the juices of the leaves to save expense and labour in the process of roasting, the form of a ball is simply an accident, and the twisting of the leaves also ; both arising out of the peculiar mode adopted by the Chinese in the process of rolling the leaves, and which after all may turn out to be not the best method, although a natural one, and such as in a rude state of society is likely to be adopted. But if the mode of expressing the juices is to be by hand, it must be evident that no better mode could be adopted than that of collecting the leares into such a heap or parcel as the hands can cover, pressing, rolling, and keeping them in as compact a form as possible under the hand: the rest follows as a necessary consequence, arising out of the glutinous quality of the leaves, as experiment will show.

These remarks may also serve to prove the fallacy which has so long existed, even to the present day, viz. that each separate leaf undergoes a process of rolling between the fingers and thumb of a female: an operose method which no cheapness of labour, when compared with the known cost of manufacturing tea, would serve to explain.

It must be admitted, however, that the twisted form of the leaf is now considered as a test of quality; for experience has shown, that the closely twisted leaves generally make the best tea. The reason is, that good teas consist of the young leaves; and it is only the young, tender, and succulent leaves that can be made to assume that form. 
consequently much diminished. As much therefore may now be put into the Kuo at one time as was roasted in three or four times during the first roasting. 'The mode of roasting is precisely similar' to the first process, except that the leaves are frequently shaken and strewed round the less heated sides of the vessel to accelerate the evaporation of the steam by the admission of air, and thus to cool them. When sufficiently roasted, they are then rolled as before; and the roasting and rolling repeated a third time; which is applicable to all teas, when the substance and good quality of the leaves admit of it.* No measure of time can be given by which the necessary degree of roasting can be determined. The same may be said regarding the exposure of the leaves to the sun. Both depend, as in every other stage of the preparation, upon the state and quality of the leaves. 'Thus, as we are informed, the Yen teas, whose leaves are large and fleshy, are roasted and rolled three

* Mr. Jacobson states that at Java $1 \frac{1}{2}$ or $2 \mathrm{lb}$. of leaves are roasted at a time, and that this quantity is divided, afterwards, between two men to roll them. He also observes, that after rolling, the leaves are covered with a tray, which encourages their heating, and that this heating improves the colour of the leaf and infusion; besides giving a fuller flavour to the tea. It may here be remarked, that the Chinese differ much as to the quantity roasted at one time. The accounts vary from three or four tales, or ounces, to two, three, or even four pounds, for fine teas. I should deem two pounds a full quantity even for Congou tea. 
or four times; whereas the best Congous are roasted and rolled but twice, and the inferior ones only once; for, say the Chinese, "these leaves being very thin, they would be broken and burnt if roasted more." This simple rule may suffice:When no longer any juices can be freely expressed in the process of rolling, the leaves are then in a fit state to undergo the final desiccation denominated Poey.

Before closing this chapter, it must be observed, that the finest kinds of Yen or Padre Souchong teas are said to undergo in their first roasting a modification of the process of Chao Ching, denominated by the Chinese Ta Ching and Pao Ching, from the particular mode of handling the leaves. In this particular part of the process, the roasting vessel is heated to red heat.

In the operation of $\mathrm{Ta}$ Ching, a man standing on the right of the roaster throws about two ounces of leaves smartly against the Kuo; the roaster then seizes them with his hands, gives them a brisk turn round the Kuo, and sweeps them into a tray, which another man holds in readiness to receive them. In the operation of Pao Ching, the roasting is continued three or four seconds, and about three or four ounces (Tales) of leaves are roasted at one time. In this process, the instant the leaves fall down to the brickwork, the roaster receives them on his hands, and tosses them back against the heated part of the vessel: 
which operation is repeated for a few seconds. They are then collected together, and, having been turned briskly two or three times round the less heated part of the Kuo, they are swept out as before. The leaves are now put aside to cool, and then

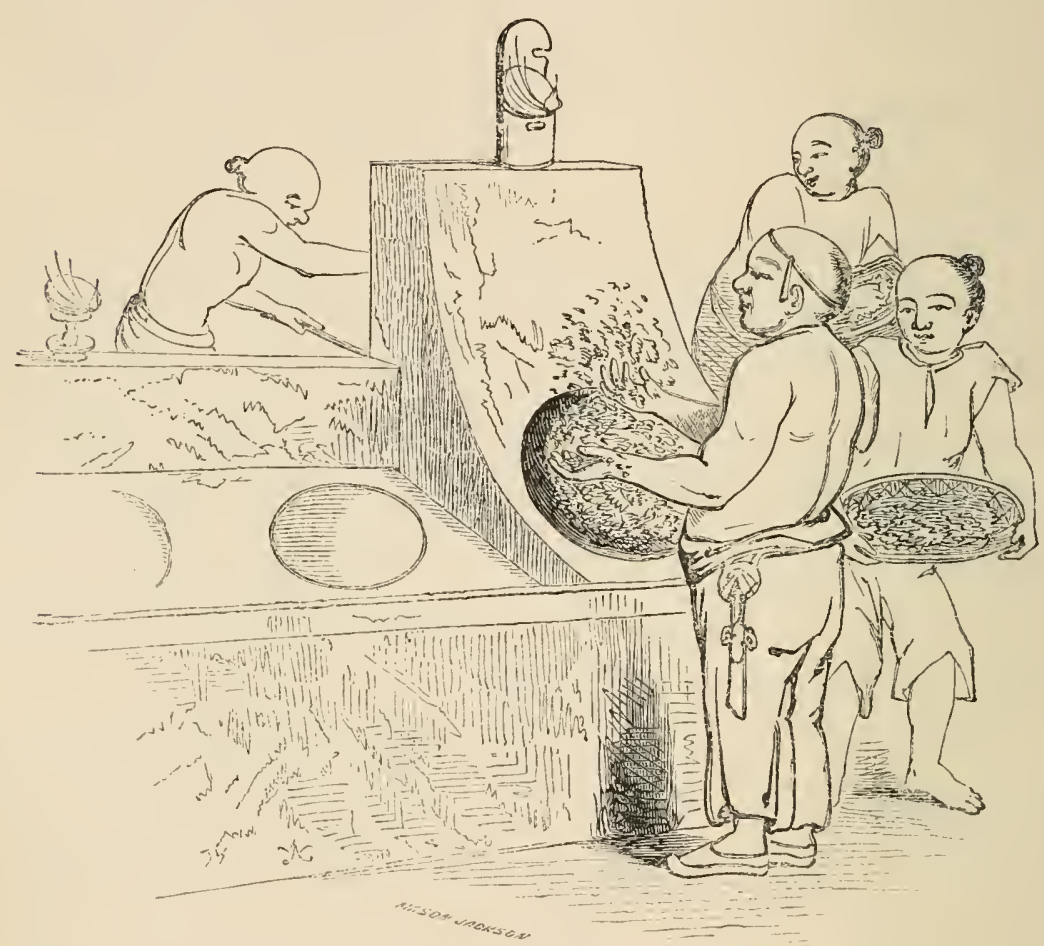

roasted (Chao) and rolled three times, as already described.

Some of the Chinese say that the process of $\mathrm{Ta}$ Ching is not used in the present day; but that Pao Ching is substituted in lieu of it. Others say that these teas first undergo the process of Ta Ching, and then are roasted and rolled three times, after the manner of Pao Ching instead of Chao. These 
modes do not seem to vary essentially from the simple process of Chao, since they depend principally upon the quantity of leaves roasted at one time, and the greater heat of the vessel. It is obvious that the smaller the quantity of leaves used, and the greater the heat employed, the greater must be the risk of burning, which is sufficient to account for the inclination given to the Kuo. It must, however, produce a quicker evaporation of the fluids; and hence, perhaps, it may be inferred here, as in the early parts of the process, that the Chinese deem a quick evaporation of the fluids desirable.

But as this mode requires much care, attention, expertness, and labour, it is not practised, so far as my information extends, except with the finest teas, such as rarely or never form a part of the teas of foreign commerce.

THE FINAL DESICCATION OF BLACK TEA.

(Poey ching or Poey tsing.)

It has already been observed that the process of Poey is considered by the Chinese as a very important part of the manipulation of black tea. This, however, does not arise from any particular nicety of art or difficulty in this process; but simply from this circumstance, that, as the leaves are roasted in open sieves over a bright charcoal fire, a certain degree of watchfulness is requisite, 
to see that none of them accidentally fall through the interstices of the sieves, which would occasion smoke, and thereby injure the tea.

The instrument used for this purpose is a kind of basket, called a Poey Long, about two and a half feet in height, and one and a half in diameter, open at both ends: or rather a tubular piece of basket-work of those dimensions covered with paper, which we may here denominate a "Drying 'Tube," having a slight inclination from the ends to the centre, thus making the centre the smallest circumference. In the inner part, a little above the

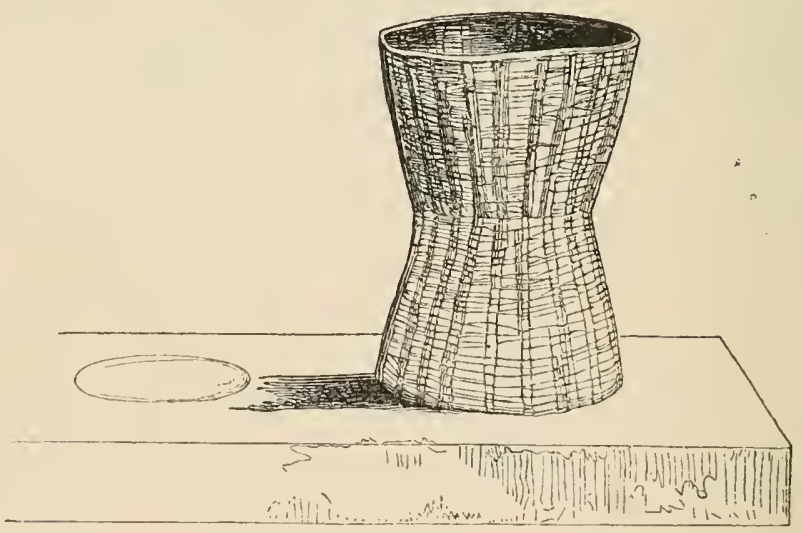

centre, are placed two cross wires for the purpose of receiving the sieve which contains the tea, and which is placed about fourteen inches above the fire. When the tea is sufficiently prepared for this process, the drying-tube is then placed over a low stove built upon the ground to contain a small quantity of charcoal. The stoves, consisting of circular receptacles for charcoal, are constructed 
within a continuous piece of brickwork coated with plaster, extended round three sides of a long narrow room. The brickwork is about $5 \frac{1}{2}$ inches in height and 2 or 3 feet in depth, from the front to the wall. The receptacle for the charcoal must be in proportion to the diameter of the drying-tube. Mr. Jacobson gives the following as the dimensions of the tube used at Java: height $2 \mathrm{ft} .10 \frac{4}{8} \mathrm{in}$; diameter $2 \mathrm{ft.} 4 \frac{7}{8} \mathrm{in}$. ; diameter of centre, $1 \mathrm{ft} .11 \frac{6}{8} \mathrm{in}$.

The process of Poey is used for every denomination of black tea, manufactured with care, whether Paochong, Souchong, Sonchy, Pekoe or Congou. I shall now describe this process as I have seen it performed, and as I have performed it myself.

A bright charcoal fire is prepared in a common Fu-Gong, or chafing-dish, containing about three or four pounds of charcoal: the drying-tube is then placed over the fire, one end resting on the ground. The roaster then takes a quantity of leaves and sifts them, to prevent any dust or small leaves from falling into the fire. When properly sifted, he first spreads them equally in the sieve, and then makes a small aperture in the centre of the heap with the finger, about an inch and a half in diameter, in order to afford a free vent to any smoke which may accidentally be formed. The sieve is then placed in the Poey Long, upon the cross wires before described. A circular flat bamboo tray is placed over its mouth, about one third of which is left open to admit a free evaporation of the steam 
which arises from the leaves, for a considerable degree of moisture still remains, though no more can be expressed by the process of rolling. The leaves also retain their green and vegetable appearance.

The leaves are thus suffered to remain about half an hour, when the drying-tube is removed from the fire, the sieve taken out, and the leaves turned. The turning is performed by the following simple and effectual method. Another sieve of equal size is placed over the one containing the leaves; and both held horizontally between the hands. Then by a sudden turn, the two sieves are reversed, the bottom one being brought to the top in the action of turning. It is then removed, and the leaves are found in the lower sieve completely turned, without being mixed or scarcely deranged. They are then placed over the fire, and suffered to remain as before.*

* Mr. Jacobson ridicules this mode of turning the leaves; to me, however, it seemed a simple and an effectual method. A large quantity being contained in the sieve does not increase the difficulty of turning it. Indeed I thought at the time it appeared a preferable mode to the one very accurately described by him, which I also saw practised by a man from the Ankoy country. But I must defer to his opinion, because he has great practical experience to guide him. 'The method here alluded to is described by Mr. Jacobson $(\$ 400$.) as follows :

When the second roasting is completed the leaves must no longer be spread out, but be pressed closely together into small heaps, a little flattened at the top. In placing them on the drying sieves, each heap is taken up between the hands, and the 
FINAL DESICCATION OF BLACK TEA.

At the expiration of this time, they are again taken out of the drying-tube, and rubbed and

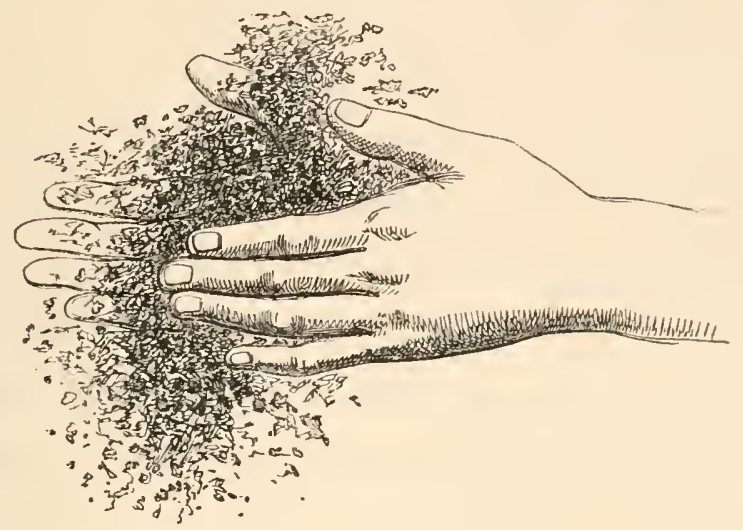

twisted between the hands.* A great change has now taken place in the colour of the leaves. They

leaves are allowed to fall loosely and gently down on the sieve. An aperture of about an inch in diameter is made in the centre of each parcel, and the heaps or half balls are thus placed round the extreme edge of the sieve; about fourteen of such parcels thus occupying that space. Then a second row is placed within, consisting of about ten heaps, which further admits of about four or five more, forming a third circle; and finally, an open space is left in the centre of about four inches in diameter. When the drying-tube is removed from the fire, it must be placed on a tray. In turning the parcels the dryer turns the drying-tube round, bringing each parcel in succession before him, that they may all be turned in due order, but the sieve is not removed from the drying-tube. As the leaves dry, it becomes desirable to mix the leaves of two of the dryingtubes together: this is done by pouring the contents of one drying-tube on to those of another, and not by taking the leaves out with the hand. The charcoal is well covered with ash throughout the entire process of drying.

* The mode of rubbing and twisting the leaves between the hands is rather difficult to explain. About a handful of leaves 
have already begun to assume their black appearance. A considerable quantity of moisture having also been dissipated by this mode of drying, the fire is now covered with the ash of charcoal or burnt paddy husk, which not only serves to moderate its heat, but prevents smoke in the event of any leaves falling accidentally through the sieves.

The leaves are then sifted, and again undergo the process of drying, twisting, and turning, as before; which is repeated once or twice more, until they become quite black, well twisted, and perfectly dry and crisp. As the leaves dry, they obviously must occupy less space in the sieves: the quantity is consequently increased from time to time, in order that each sieve may be full. In this part of the process, as the leaves give out little moisture, the mouth of the drying-tube is nearly closed.

The drying-tube is always removed from the fire, and placed on a tray on the ground, before the sieve is taken out, when the tea requires turn-

should be taken up at one time, and placed between the hands held side-ways, with the thumbs uppermost; the left hand is kept stationary, while the right is brought back, drawing back the leaves at the same time, until the fingers touch the palm of the left hand. It is then advanced, pressing the leaves slightly against the left, until the palm is brought on a line with the fingers of the left hand. The pressure is then relieved, and the leaves brought back as before. This is done with much celerity, and continued until no more leaves remain in the hands, for the leaves are projected forward by this movement. The pressure being all in one direction, the twist of the leaf becomes so likewise. 
ing; and in the act of replacing it over the fire, it is necessary to give it a smart tap on the side, to get rid of any dust or leaf which may be in a situation to fall.

When the leaves appear sufficiently dry, which is ascertained by their crispness, they are then taken from the fire and sifted; and the old, the yellow, and the chaffy leaves are winnowed off by means of a large circular bamboo tray.

The coarse leaves which remain are then, if necessary, picked out by hand, which is seldom, or perhaps never, the case with any black teas forming a part of the foreign investments. They certainly are not hand-picked with the same care as green teas, which is evident from the quantity of stalks they contain, while none are found in either Twankay or Hyson tea. The residue, which is the tea for sale, is again placed over the remaining embers, or over a very slow fire, but in still larger quantities, for about two hours. In some cases they remain throughout the night, the embers being left to die away. In this part of the process the drying-tube is completely closed with the tray.

The tea is then packed in chests or baskets according to its quality, and the practice of the planter or farmer. In this state they are carried to the public markets for sale, and sold from two to one hundred chests at a time, according to the size of the farm or plantation. These markets have 
their regular and appointed times;-as, for example, at Ly Yuen there is a tea market every tenth day during the season; on the $2 \mathrm{~d}, 12 \mathrm{th}$, and $22 \mathrm{~d}$ days of one month, and on the $7 \mathrm{th}, 17 \mathrm{th}$, and $27 \mathrm{th}$ days of the following month; and so on at other places.

As the teas are packed and collected at these country markets, they are sent to the village of Sing-csun. Here the Canton Hong merchants and tea factors have large packing establishments, where the teas are finally packed suitably to the foreign markets. Here, also, the Shan-see merchants or factors procure and pack their teas for the Russian markets. I believe it to be altogether an error to suppose that any other part of China furnishes the Congou and superior teas; or that any other than the Hyson districts of Moo-yuen and Yu-ning supply the Hyson tea, and the districts in the immediate vicinity, the Twankay tea. The rumours recently spread, that some of these teas are now procured, or ever were procured, from other parts of China, I believe to be wholly undeserving of credit. It is not easy in China to obtain accurate information concerning remote districts. Some Congou teas are also packed at the villages where the teas are collected, as at To-pa, and some few other places. These may generally be distinguished by the dark green colour of the chests. The Sing-csun chests are of a lighter colour, and somewhat yellow. The Pekoe 
kind of teas, formerly imported into England as Congou, came from To-pa.

The Congous are packed in parcels, chops or breaks, of about 600 chests, each chest containing about $80 \mathrm{lbs}$. of tea. Each parcel is divided into two packings, consisting generally of 300 chests each, sometimes 500 or 600 chests, according to the size of the packing-house. The teas which are to constitute one uniform quality of 600 or even 1000 chests consist of certain proportions of the three gatherings, collected from the produce of various farms and different localities. These teas having been previously arranged and classed agreeably to quality, and noted in a book, a sufficient quantity to constitute a packing of 300 chests is now started into a heap or pile, and so placed in different layers, that, when raked down with a wooden rake for the purpose of packing, their several and various qualities may all mix and blend together, so as to form one uniform quality suited to a fixed and settled price. The quantity put into each chest is previously weighed, and the packing is performed by men with their bare feet. I do not understand that the black tea is packed hot; or that it is submitted to any further process of heating or drying at the packing houses : it, nevertheless, must be perfectly dry. In the event of damage or injury to the tea, or the teas not having been sufficiently dried, then they doubtless undergo a somewhat similar process of drying in sieves in Poey Longs, 
or on stands in drying-houses, as is practised at Canton, to restore tea which has been slightly damaged on its passage down the country.

Having now explained the manner in which the Paochong, Souchong, and Congou teas are made when manufactured with care, I feel I may have impressed on the mind of the reader an exaggerated sense of the difficulty of manipulating tea for the European markets. Nor do I see how this was to be avoided. It is surely desirable that the superior methods should be known and fully described; and more especially since even the inferior modes are regulated and governed by the same principles; the main difference being the more or less skill and care bestowed on the several stages of the process. It has been my aim so to describe every part of this curious, and to us novel, art, that it may be rendered useful and acceptable to the experimentalist and cultivator, even at the risk of its being tedious to the general reader. But it must be confessed that minuteness of description, and long dwelling on the superior modes of manipulation, may have the effect of discouraging even the experimentalist. This, however, seems to me a difficulty inherent in all minute descriptions of art, even that of making beer or cider. Nothing is more simple than to sketch a general outline of the art of making wine; yet Chaptal devoted no less than ninety octavo pages to the theory of fermentation. Agreeably to this able author, if we seek a wine of high quality 
and of good age, Nature must first be bountiful in her season, and the fermentation so regulated that the saccharine matter and the ferment may be both destroyed, so that no second fermentation shall take place. But here enters the nicety of the art: a certain practical knowledge is required, which though every operator does not possess, and some never, yet is this art neither difficult to acquire, nor are skilful workmen rare or expensive to obtain. The same may be said of the first and highest flavoured teas. But if we simply speak of the art of making wine, in what does it consist ? Press a quantity of grapes in a vat with the feet or otherwise; strain off the juice into a cask ; allow it to ferment, and you have very good Vin de Pays. Thus with tea: place the leaves in a sieve, expose them to the sun and air; toss them and turn them as hay; then place them in the shade till they give out a certain degree of fragrance; then roast them in an iron vessel, roll them with the hands or feet, and finally dry them over a charcoal fire, and you have fair Congou tea. The cost of Congou tea at its place of growth will show, when we come to treat of that part of our subject, that not much skill, labour, or expense are bestowed on its cultivation and manipulation. At the same time it must be obvious, that this art is not to be learned from description: and that our only teachers are the Chinese, such namely as belong to the Bohea and, failing these, the Ankoy districts. Let us beware 
of giving too ready credence to assertions that the art is easily taught. Simple as it may be, like other arts, it requires an apprenticeship.

There are also many inferior methods which are adopted with coarse teas. The best of these is, by continuing the final process of drying in the roasting pan, as in the final drying of green tea, in lieu of the drying-tube employed for black. It is remarkable that all the Chinese factors, whom I have questioned upon this subject, have invariably denied the existence of this method. It nevertheless unquestionably exists; and I shall now describe the manner in which I have seen this process performed by a man from the Bohea country.

The vessel and other circumstances were the same as in the final process of roasting black tea, the heat of the fire being reduced. The leaves were then sprinkled round the sides and less heated parts of the vessel, occasionally collected together, and then stirred about with the hands. This was repeated until the leaves became well twisted, and the colour black; the fire being still further diminished as the leaves dried. They were then winnowed and packed as before. .

Some Congou teas are rolled indifferently with the hands or bare feet after roasting; and are then, it is said, dried in the sun, without any further exposure to the fire. This, however, is only done with the second and third gatherings of inferior shrubs. But some teas are said to be wholly dried in 
the sun : some in a coarse and careless manner, doubtless for the use of the peasantry and others; and some by a laborious and expensive method.

There is also a mode of manipulating black tea in cloths, as described by Mr. Bruce for the manufacture of green tea. But the Chinese all agree that this mode is never adopted except with very coarse and inferior leaves, and for the purpose of fraudulent adulteration of good tea.

It may, perhaps, be expected that I should make a few observations on the modes of manipulating tea, as seen by Mr. Fortune in the provinces of Fokien and Chekiang; and this appears to be a suitable place. It may be succinctly stated, that the difference in the modes of roasting and drying black and green tea arises from the black tea being finally dried in sieves over a charcoal fire, and the green tea in an iron vessel: and this is an essential difference. The modes seen by Mr. Fortune in Chekiang correspond with this rule, with the exception that a flat basket was used in lieu of a sieve, but there, green teas were produced by both methods. Now if we refer to Fokien, where the same modes were employed, we there find that they produced black teas. Thus it would appear a matter of indifference which of the two methods be adopted, which seems to me to strike the mind at once as a fallacy. It is partly true with respect to black tea, but wholly false as regarding green; and indeed that the results should be so different 
where the means employed are the same, presents a discrepancy which we find it embarrassing to reconcile. The only mode of doing this, is, by supposing that some of the teas so manipulated were not truly what we understand by black and green tea, but were peculiarities, such as Lin-czu-sin or others, made exclusively for Chinese consumption. Indeed, Mr. Fortune speaks only of one tea in each province, which seemed to correspond with the teas of European consumption. It is true that black tea may be produced in an iron pan, as we have already seen; but the Chinese all agree that this is an inferior method, of which the tea-men from the Bohea district deny the usage. It therefore seems probable, that Mr. Fortune was misinformed, when he was told that this was the mode employed for the manufacture of "our common black teas *," if by that term be meant the black teas commonly in use. It has been shown that the mode adopted in the Bohea district for the final drying of black tea is in sieves over a charcoal fire.

And with respect to green tea, it would be impossible to produce the peculiar and characteristic colour of green tea, by any process of drying the leaves in a sieve or basket. When Mr. Fortune states, that the green teas which he saw manufactured in Chekiang were not the painted bloom-like teas seen in our shops, which he so justly ridicules, the

* Wanderings in China, p. 210. 
reader must nevertheless not imagine that there is no natural foundation for this colour. 'I'he expression of Mr. Fortune is "the leaf has little or none of what we call "the beautiful bloom ' upon it;" * but then it has some, and be it ever so little, it is naturally produced in the course of manufacture, as I shall show under the article green tea. It is evident that Europeans could never have suggested to the Chinese to dye their teas blue, if there had not been some foundation for it in the natural process of manipulation.

I believe also that Mr. Fortune was misinformed, when he was told that the districts in which he was, formerly furnished a portion of the tea intended for foreign consumption. But it is no disparagement to Mr. Fortune even if he was misinformed. He states what he saw and collected. In a paper on the expediency of opening a second port in China, printed in 1816 and públished in 1840, I computed that the black tea districts were about 240 miles from the city of Foo-chew-foo, and about 270 from the sea. $\uparrow \mathrm{Mr}$. Fortune states that he penetrated into the interior about thirty or forty miles north of that city; consequently he must have been at least 150 or 200 miles from the district which supplies the foreign markets with black tea.

With respect to the exposure of the leaves for

* Wanderings in China, 2 d edit. p. 200.

$\dagger$ Journal of the Royal Asiatic Society, May, 1840, p. 38. 
"two or three days on screens after they have been roasted and rolled," and "while yet moist," * this assuredly is a mode not to be imitated. It has been shown that in the Bohea district, so important is it considered to complete the roasting and drying of the leaves on the day they are gathered, that the work is often continued to a late hour, and sometimes through the night. Under the long exposure to air as seen by Mr. Fortune, there must be a danger of the leaves turning sour; but at all events red, as the name of the tea "hongcha" (red tea) indicates, a species often made, as already stated, for the Su-chao market.

I think the account already given of the manipulation of black tea in the Bohea country, must be sufficient to prove, that the dark colour of the leaf and infusion of black tea, does not necessarily depend on a long exposure of the leaves to the air, while yet "in a soft and moist state," after they have been roasted and rolled; though I have little doubt an increased redness of the leaf and infusion may be produced, under proper management, by such means, and may be employed for some teas. Nor does it depend, as I think I shall be enabled to prove, "on the leaves being subjected to a greater degree of fire heat." $\dagger$

I have seen a sample of black tea, and another of green tea, which Mr. Fortune very handsomely

* Journal of the Royal Asiatic Society, May, 1840, p. 212.

$\uparrow$ Wanderings in China, $2 d$ edit. p. 213. 
showed to me. Unhappily they were not marked with the name of the province whence they were procured; but on comparison with the preceding accounts, I should imagine that the green tea was brought from the province of Chekiang and the black from Fokien. The green tea had been much injured by damp, and was somewhat mouldy; but the bluish or greyish colour of the leaf was sufficiently indicated to prove the class to which the tea belonged. It was a coarsely made tea, not very suitable to our market. The black tea, however, seemed a sufficiently well made tea. Thus there is every reason to believe that Mrr. Fortune saw black and green tea made from the same species or variety, that variety being the Thea viridis, as stated by him.

But the fact of black and green tea being made from the same leaves is not a novel discovery. Mr. Bruce states, in his report on the cultivation of tea at Assam *, "I am now plucking leaves for both black and green tea from the same tract and from the same plants; the difference lies in the manufacture and nothing else." There are still more early authorities on the same point, and so far back as Dr. Abel's journey in China, 1818.

In conclusion I may say, that the tubs containing charcoal used in the final drying of black tea or green tea, and the shifting of the iron pan and

* Asiatic Journal, January, 1840, p. 26. 
employing the stove for the same purpose, though in principle the same as the mode adopted in the black tea district for drying black tea, yet obviously indicate the employment of make-shifts, and rough methods, fit only for peasants and small plantations. It will also be seen, when we come to examine into the mode of manipulating green tea, that the forms of the stoves and vessels, used in the Hyson district, differ essentially from those seen by Mr. Fortune in the parts of China which he visited.

I shall now explain the manner in which I have seen black tea manipulated in the sun by a man from the village of Puck-Uen-Hiang, in the district of Sy-Chu-Shan, about a day's journey from Canton.

1. I first made him divide the leaves into three parcels, with a view of trying some experiments. The leaves of the first parcel were then placed in sieves in the sun for three quarters of an hour. They were afterwards rolled in the manner already described under the article on "Rolling;" and upon the ball being shaken to pieces, the leaves were equally well twisted as if they had been previously roasted. In the district where the man resided a square stone channelled in a regular manner is used for this purpose. The one I saw was a piece of granite measuring eighteen inches by fourteen, and two inches thick. 'The surface was channelled and made rough. It was hollowed out on two sides to afford a place for the hands to lift it. 


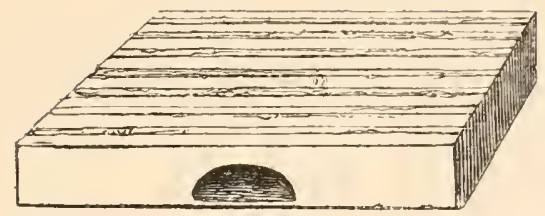

The leaves were then placed in the sun again, and thus rolled and exposed to the sun twice. The leaves were afterwards divided into smaller parcels in each sieve, and rolled up into small balls about the size of a duck's egg, considerable pressure being used for that purpose. They were then placed in the sun again, and turned once during the exposure. The balls were now partly broken to pieces with the hands, spread out, and placed in the sun again. During this process the leaves gradually became black. They were then removed from the sun, and rolled into balls the size of an orange, and exposed to the sun again for a quarter of an hour. The balls were then shaken to pieces, the leaves spread out loosely in the sieves, and thus left to dry. When completely and properly dried, they were exposed to the air to cool, when they were packed. This tea was fragrant in smell, and had a rich reddish appearance, resembling in colour the Hong-Moey pekoe: the infusion was a deepish red; and the flavour fragrant, but somewhat sweet, as if mixed with sugar; nor did I think that tea so made would keep. I have seen samples of tea, which this man affirmed were made precisely in the manner here described, which would have sold at the East India Company's sales at 3s. 10d. the 
pound. 'This want of success in my presence he ascribed to the unfitness of the Honan leaves for the preparation of tea.

2. The leaves of the second parcel, after exposure to sun, were roasted once in the usual manner, at my suggestion, and the process completed as above described by rolling and exposure to the sun. This tea was less mixed with red leaves, and better suited to the taste of Europeans; and I thought more likely to keep than the former parcel.

3. The leaves of the third parcel having been exposed to the sun were by my desire, roasted twice, and the desiccation completed by the process of poey. But these leaves were of a paler colour; much mixed with green and yellow leaves, and wholly without fragrance. The infusion also was as light as green tea, and almost tasteless. This inferiority of quality the workman ascribed to the leaves having undergone the process of chao twice instead of once.

4. On a subsequent occasion, I saw the same man, after having placed the leaves in the sun for half an hour, roll and sun-dry them twice as already described, forming them into a ball, \&c. When completely dried in the sun, a kuo was slightly heated, more to warm than to roast the tea. It must here be remembered that the leaves were deprived of much of their moisture, and consequently the roasting now corresponded with the final process of drying in the drying-tube, when a very moderate 
temperature is employed. The leaves were put into the kuo, and kept constantly stirred, until the vessel became too hot, though of a very moderate temperature. It was then taken off the fire; but the leaves were gently stirred about until sufficiently dry.

These leaves previously to roasting had a vegetable smell, as if not sufficiently dried; which, however, the roasting entirely dissipated, and made fragrant like tea. They were then packed warm; and a piece of charcoal wrapped up in paper was placed in the canister, to absorb any remaining moisture in the leaves, or any humidity which might penetrate.

This tea, like the first parcel, resembled a "Hong Moey" pekoe, and was agreeable in flavour. The manipulator informed me that he could afford to sell tea of this description, though of superior quality, for about 18 tales the pecul, which at $6 s$. $8 d$. the tale. or $5 s .6 d$. the ounce of silver, would cost $10 \frac{1}{2} d$. the pound.

5. Now these experiments, though they do not afford examples of the best mode of manipulating tea, seem nevertheless to me not devoid of interest, nor without their utility. In fact I am disposed to think, that they point to the true direction, in which we must seek to discover the real cause of the distinctive character and quality of black tea.

6 . The first experiment shows, that, by exposure to sun and the rolling or kneading of the 
leaves, a sweet principle was either elaborated or preserved; and that the reddish-purple appearance of the leaves, and the red infusion co-exist with and may depend on this principle. And this experiment serves to strengthen the opinion already expressed, that the manipulation previously to roasting may be to produce some slight chemical change analogous to hay when stacked, or to the germination of barley in the process of malting, on which the sweetness and delicacy of flavour, the red infusion, and the rich reddish-purple colour of the leaves may depend. It also proves that the colouring matter of black tea in leaf and infusion is not necessarily due to the agency of heat; and still less to high temperature.

7. The second experiment shows that by the application of heat the saccharine matter was diminished, and the leaves became less red; but the tea was improved thereby, and more likely to keep; thus indicating that a completely sun-drying process is an inferior method; also that the excellence of black tea depends on the combined and skilful management of the leaves previously to, and during the process of roasting. Whereas green tea will be found to depend solely on a peculiar management of the leaves during the final process of drying.

8. The third experiment shows that by an application of heat too great for the then condition of the leaves, though at a moderate temperature, the 
saccharine matter was altogether destroyed, and with it those elements on which excellence of quality depends. The dried leaves also became pallid and yellow, the infusion as light-coloured as green tea, and almost flavourless. This experiment further proves, what has already been explained, that no measure of time or degree of heat can be given for the roasting and drying of tea: they both depend on the state of the leaves, as regarding their succulency and aqueous condition, the mode of manipulation, and the kind of tea required to be made.

9. This example, moreover, shows that what was here effected by excess of temperature, as connected with the state of humidity of the leaves, though at a low degree of heat, was not very dis. similar to that which takes place in nature under the ordinary conditions of decay. Thus in autumn the leaves of deciduous trees having performed the several functions for which they were destined in the production of flowers, fruit, and wood, are no longer required : assimilation is impeded, they begin to absorb oxygen from the air, decay and dryness follow, the leaves change colour and fall, and nothing remains but red, or brown, or yellow cellular tissue, and woody fibre. We will here leave these experiments for the present, though we shall have occasion to recur to them, when we come to treat specifically of the degree of heat employed in the manipulation of tea, and of its chemical constituents after desiccation. 


\section{CHAP. VIII.}

MANIPULATION OF PEKOE, CAPER, NAO-CSEE, AND LONG-CSIN TEAS - THE SCENTING OF TEA - BOHEA TEA- ORIGINALLY BROUGHT FROM THE TEA COUNTRY UNAANIPULATED ATTEMPTS TO PROCURE IT MANIPULATED - SIZE OF CHESTS FOUND TOO LARGE FOR INLAND CARRIAGE - BROUGHT BY SEA - ALSO LARGE QUANTITIES OF CONGOU - JEALOUSY OF CHINESE GOVERNIENT AT THIS INNOVATION-IMPERIAL EDICT PROHIBITNG THE SHIPIENT BY SEA FROM THE PORT OF FOO-CHEW-FOO - IMPORTANCE OF THIS PORT - DOUBTS REGARDING THE PORT EXAMINED AND ANSWERED - MODE OF ROASTING AND DRYING BOHEA TEA AT CANTON-BRICKTEA - ITS FORM AND MANIPULATION - ITS EXTENSIVE USE IN MONGOLIA - DESCRIPTION OF A FÊTE AT OURGA - CARAVANS OF THIS TEA FREQUENTLY FALLEN IN WITH BY TRAVELLERS - EMPloyed AS A CiRCUlating MEDiUM - AS MONEY AT HORSE RACES, FEATS OF STRENGTH, AND ARCHERY - ESTABLISHMENTS OF TEA HOUSES ACROSS THE DESERT OF GOBI FREQUENT - EXTENSIVE USE IN TIBET-MODE OF PREPARATION FOR USE THROUGHOUT' CENTRAL ASIA - MIXED WITH BUTTER AND FLOUR, AND CHURNED - CAPT. TURNER'S OPINION OF IT - MR. MANNING'S OPINION - TEAPOTS EMPLOYED HIGHLY ORNAMENTED - TEA OF BISAHAR.

The Pekoe tea consists of the unexpanded terminal leaf-bud, in which state the convoluted part is covered with a white hair or down, whence its name, Pe-hao (white hair), Pac-ho, or Pekoe, as corrupted by us, is derived. The white hairy appearance of the leaves found in this tea is termed flower by the dealers in England; which term, as 
well as that of Fleur de Thé, appears to have originated in a supposition, that these white downy leaves were the blossom of the tea. The Fleur de Thé, so much esteemed on the Continent, and particularly in Russia, for its exquisite odour, is no other than fine Pekoe tea. The tea blossom has little fragrance at any time, and still less when preserved in a dried state; it is, therefore, quite incapable of diffusing that delightful and powerful scent ascribed to the Fleur de Thé. It is true, however, that the blossom of tea has a slight fragrance, and is occasionally used by the Chinese in their tea. Two or three of these dried flowers are put into a cup of tea, not on account of their fragrance, but for their ornamental appearance, which is certainly elegant, when seen in their expanded state floating on the surface of the pure and bright infusion of tea, as used by the Chinese, who do not cloud and adulterate it with any admixture of sugar and milk.

The manipulation of this tea is thus described by an old and respectable Chinese tea factor:"After the leaves are gathered, they are spread out on flat bamboo trays in the air to evaporate the watery juices, which is termed Leang Ching; they are then roasted (chao) once over a slow fire, spread out again in trays to cool, and are afterwards dried in a poey long. They require no rolling."

The usual mode of rolling is certainly not em- 
ployed in the manipulation of Pekoe tea; it would obviously injure the hair or down of the leaves. If of superior quality, it evidently can require none, for the bud is already more compact in its natural state than any process of art can make it. Yet, as I have seen tea made after the manner of Pekoe, a slight, but very slight degree of rolling or pressure took place during the process of chao, whilst the leaves were yet in the roasting vessel; and I imagine this mode may prevail with such Pekoes as have little flower, and where the bud is partly expanded. It has already been explained, that the process of rolling is simply to express the juices from the leaves; the twist of the leaf is a mere accident. This tea requires little roasting, and a very moderate fire. Its principal drying takes place in the poey long. It may have been remarked in England, as in China, that Pekoe teas, and especially such as have much flower, have sometimes a musty smell and flavour, which I imagine arises from the juices not having been sufficiently evaporated in the process of roasting, little or no pressure being used.

The gathering of this tea properly takes place between the 5th and 20th of April (from Tsing Ming to $\mathrm{Ko} \mathrm{Yu}$ ); though it is obvious that it may be gathered at any time when the leaf is found in the state of bud. Most Chinese say that the newly gathered leaves are first placed in the sun, and afterwards in the air to cool. The Hong Moey 
Pekoe, much of which is made for the Russian market, is gathered rather later, and consists of a more expanded leaf. The peculiar red appearance of this tea is produced by a lengthened process of the operation of To-ching, that is, by tossing the leaves on trays, or by whirling them round in a sieve, and by covering them up with another tray, to promote the withering. Eck Hing, the teamerchant who introduced the Pekoe-kio teas, informed me that the Hong Moey teas were partly dried in the sun after the first roasting (chao). I am disposed to think that the peculiar flavour of this tea, its redness of leaf and infusion, may be derived from some such cause. A lengthened process of To-ching, the leaves being collected in a heap and covered with a tray, both before and after each roasting, together with a slow process of drying in the drying tubes, would produce the effect here sought. Mr. Jacobson states that Pekoe tea requires much exposure to the sun previously to roasting; it should also be placed in close rooms, and not exposed to the air, but kept warm; because it is advisable to hasten and promote the withering of the leaves.

SONCHY, OR CAPER TEA.

Each leaf of the superior kind of Sonchy is said to be plucked separately from the shrubs; being nipped off by women, leaving no part of the stalk. The 
apex of the leaf is also said to be pinched off afterwards ; so that only the largest of the young succulent leaves are fit for this tea. The preparation of the leaves previously to roasting is similar to that of the Souchong tea. They undergo the process of Leang Ching. If the leaves are full of juices they are not roasted until the second day, and are exposed to the sun, if necessary. Teas gathered during rain are considered unfit for Sonchy. They are roasted and rolled three times in the usual manner.

The difference in the manipulation of this tea takes place in the process of poey. I shall therefore now explain the manner in which I have seen the process performed. After the first drying in the poey long, which is understood to include the turning and drying the leaves on both sides, the roller divided the quantity dried into two parcels: each parcel was then formed into a ball, which the roller pressed and squeezed with all his strength between his hands. The leaves were afterwards separated and spread out again in the sieves, and dried as before. In this manner they were dried and rolled eight times. The leaves, however, were not so long exposed to the fire during the several dryings as is usual with other teas, for this reason: the juices which now remain being of a viscous nature assist in the adhesion of the leaves to each other, which in this tea is desirable; since the ultimate object is to form them into lumps. As the 
leaves dried, this mode of rolling them into a ball seemed also to increase their tenacity, so that after two or three of the last rollings, when it was necessary to separate the leaves preparatory to the farther roastings, the balls broke into large lumps, which were again broken down and shaken into still smaller pieces. Such of these lumps as were yet too large and unsightly, were then pressed and rolled between the finger and thumb, into the small round pieces of which this tea principally consists; and which, from some fanciful resemblance to the caper, is supposed to derive its English name of Caper tea. The rolling being thus completed, the leaves were again roasted, turned once, and then left to dry in the usual mode. The caper tea, however, made in this manner is an expensive tea, delightful in quality, but which rarely finds its way to Europe.

'The whole of the Caper or Sonchy teas, formerly imported into England either by the E. I. Company or the officers of the Company's ships, were the produce of the Ankoy country. The best kinds of these teas were all scented more or less with the Chu-lan flower (Chloranthus inconspicuus); but the majority were made in a very coarse manner, purposely burnt to supply the deficiency of flavour, and consisted mainly of the leaves of the third and fourth gatherings. During the process of rolling, as above 'described, the leaves of some of these teas are said to be dried in the sun, and not by means of 
the poey long. It is further said, that when the leaves are old and coarse a little liquid starch made of rice is used to make them adhere together. For the manner of scenting these teas, see the article on "Scenting."

\section{THE LONG-TUON AND NAO-CSEE TEAS.}

The Long-tuon tea sometimes called Long-yen, is a tea made into small balls about the size of a nutmeg. It is made somewhat in the above manner, and also that which is formed into little bundles like fagots (Nao-csee). After the last process of chao, the leaves are rolled between the fingers and thumb into the size required for the ball, and the ball is screwed up in a piece of paper. The leaves of the fagot tea are stretched out and tied at the two ends into a bundle. In this state both teas are placed in the poey long to dry, care being taken to turn them occasionally, and to remove the paper from the balls when the leaves are sufficiently dry to admit of it.

\section{LONG-CSIN 'TEA.}

This is a description of tea to which we must devote a few words. It is a green tea, and consists of the bud of the leaf like Pckoe tea. It is made in Kiangnan and Chekiang, and is occasionally used by the high officer's of the government on visits of ceremony. It was sometimes 
sent as presents to the E. I. Company's agents in China, packed in small canisters containing about a pound or half a pound of tea, with the name of the tea engraved on the canister. Mr. Abel met with this tea on his journey from Peking; and describes it as being a tea of considerable strength. It is not esteemed by Europeans. This tea is prepared agreeably to the ancient mode of steaming the leares, and afterwards drying them in an iron pan. Ton Siebold gires a sufficiently accurate account as to the mode in which this tea is prepared at Japan; and which corresponds, with some slight difference, to the mode said to be employed by the Chinese. This author has fallen into an error, howerer, in supposing that to this mode of steaming the leares the peculiarity of green tea may be due; and that black tea is manipulated by what he terms the "dry method." The practice of steaming the leaves must be considered as altogether peculiar; and is little employed either in China or Japan. It accords more with the early art of making tea, than the usual mode in practice at the present day. More nearly approximating to the two modes of manufacturing black and green tea are those which he describes as the two dry methods. In one case the entire desiccation takes place in an iron ressel; in the other, the desiccation first takes place in an iron ressel, and finally in a kind of drying chest fitted up with square divisions or drawers haring paper bottoms placed over a charcoal fire. The 
mode as described by Kœmpfer may be considered the one most in use, which corresponds with the mode of manufacturing Twankay tea in China.

THE SCENTING OF TEA.

The Chinese seem universally to agree, in ancient as in modern times, that no factitious scent can be given to tea which at all equals its natural fragrance; in short, they say, that "only common tea requires scenting." 'Those persons who have had the opportunity of drinking some of the finest kinds of Souchong tea, will perhaps agree with the Chinese in this opinion. There are, however, many scented teas, which, so far from being inferior, are even costly, and much esteemed both in China and in Europe. Of these the Chu Lan, or Cowslip Hyson, may be considered the best. I shall therefore now explain the manner in which I have seen this process performed; which, indeed, does not differ greatly from that in practice 900 years ago, as described in the Keun-fang-pu, a Chinese herbal. The flowers may be gathered at any time of the day, but those are considered the best and most fragrant which are gathered while the dew is yet on the leaves.

The tea about to be scented inust be taken hot from the last roasting, which inmediately precedes the packing, and poured into a Hyson chest, so as to form a layer of two inches in height from the 
bottom. A handful or more of the fresh flowers, already separated from the stalks, is then strewed over the tea. In this manner the tea and flowers are placed in layers until the chest is quite full. The mouth of the canister is then closed; and the tea thus remains twenty-four hours. The proper proportion is three catties of flowers to one hundred catties of tea. The next day the chest is emptied, when the tea and flowers are mixed together. They then undergo the process of Poey, about three catties being put into one sieve. The Poey Long is completely closed, and the tea and flowers are thus roasted about from one to two hours, or rather until the flowers become crisp. The flowers are then sifted out, and the tea packed. If the tea requires any further scenting, fresh flowers must be used, and the process repeated as before. The method of Poey is the same as that used for the black tea, only that the bottom of the sieve is covered with thin paper. The tea thus prepared is then mixed with other tea in the proportion of one part of scented tea to trenty of plain. The whole is then slightly heated in a Kuo (Chao), and, when packed, constitutes the description of tea denominated in England Corslip Hyson. Tea may be scented at any time with this kind of tea, but it must be previously heated or roasted about two hours.

The mode of scenting black tea differs from that of green : and, so far as I understand, there are two 
or three methods of performing this process. The Sonchy or Caper teas, the Tet Siong, and other teas of the cowslip flavour, are also scented with the Chu Lan flower (Chloranthus inconspicuus).

After gathering, the flowers are separated from the stalks as before, when some people dry them in the sun; but the best mode is to dry them in a Poey Long over a slow fire, taking care not to change the yellow colour of the petals. When dried, they are put aside to cool, and are afterwards reduced to a powder. If this powder, the scent of which is very powerful, be sprinkled over the leaves previously to the last or two last roastings and rollings in the process of Poey, the tea will be highly scented: but this is an expensive mode on account of the additional quantity of flowers required, and therefore is seldom practised. The usual mode is by sprinkling a small quantity of this powder over the tea during the last process of Poey, which takes place previously to packing. A small white powder, frequently found in black teas of the caper flavour, cannot have escaped the observation of the tea-dealers in England: this powder is that of the Chu Lan flower, whose colour has been changed to white in the process of Poey.

There is another scented tea, of excellent flavour, which is made in small quantities, and occasionally sent to foreigners as presents. This is a Souchong tea, scented with the flower of the Pac Sheem (Gardenia florida). 
There are two other scented teas, also of fine flavour: both Souchong teas, the one scented with the Quy-fa or Kuey-hoa (Olea fragrans); and the other with the Moo-Ly-Hoa (Jasininum Sambac). Some people say that these three last teas are mixed with the flowers, as the Hyson tea is mixed with the Chu Lan, and are scented in the same manner. But others say that two sieves are placed in the Poey Long, the lower one containing the flowers, and the upper one the tea. The latter is the mode in which the Pac Sheem tea, to which I have previously alluded, is scented. These are all the flowers with which I am acquainted, which are employed to scent tea; but in the Keun Fang $\mathrm{Pu}$ and Quang Tong Chy (or Canton Geographical History) many others are enumerated as eligible for that purpose. These works also observe that flowers so used should be full blown.

\section{BOIJEA TEA.}

In the early part of the eighteenth century, the word Bohea was applied in general society to all black tea in contradistinction to Singlo or green tea; as may be seen by our poets and dramatists of that age.

With merchants and dealers it has long since been considered to mean the coarsest description of tea imported into Europe. To the Chinese it was known by the name of Ta Cha (large leaf tea), 
because it consisted of the old full-grown leaves which remained on the shrubs after the regular tea harvest had been gathered. It was formerly brought from the Bohea country in baskets, in an unmanipulated state, to be roasted and packed at Canton. On its arrival, some had a heated sour smell; some a musty, and others a saponaceous smell: so that all this tea had, I imagine, undergone a partial, if not complete, fermentation. Nevertheless it entirely lost this objectionable character in the subsequent process of roasting, though it still remained of very inferior quality.

Some years since a great improvement was effected in the quality of this tea, as well as in all the arrangements connected with it. An attempt was made to discontinue the drying and packing at Canton; and to obtain it packed, and of suitable quality, direct from the tea country. Instead of the bulky chests containing $300 \mathrm{lbs}$. of tea, a size which long custom had sanctioned without much reflection or consideration, others were now constructed of dimensions more convenient, both for stowage on board ship, and for transport down the country.

Mr. Elphinstone (to whom I am happy in having an opportunity of alluding), then the president of the Select Committee for the management of the British affairs in China, a man of enlarged views, of great firmness of character combined with a most conciliating disposition and mild deportment, and who was well known for his strenuous and success- 
ful resistance to the vexatious exactions and obnoxious and embarrassing policy of the officers of the Canton government, has the merit of having introduced this great improvement into the conduct of this part of the tea trade: to which I here advert, because it led to consequences and benefits at that time little contemplated or understood; viz. the discovery of the port of Foo-chew-foo, the nearest port to the black tea districts, and the most eligible for the shipment of the black teas.

The first experiment, so far as my memory serves, was tried in season 1811 or 1812 ; but the large chests, though greatly reduced in size, were still found too cumbersome and inconvenient on account of frequent transhipment by water, and portage across the mountains, during the inland transport of this tea to Canton. It happened, however, that the coast at this period was no longer infested with pirates, so that in subsequent years it was found practicable to bring this improved description of Bohea to Canton by sea. It was designated "upcountry Bohea," and was collected and made in the neighbourhood of Fong Lock, north of Kien-ningfoo. In three or four days it was transported down the River Min direct from the Bohea district to the city of Foo-chew-foo, the capital of the province. Hence it was transhipped on Junks, carrying from three to five thousand chests; and in about thirteen days it arrived at Canton.

The usual route, through the province of Kiang- 
sy, is a tedious and expensive journey of about 800 iniles, occupying about forty days or two months.

The great saving of time and expense thus effected by the conveyance of the Bohea tea by so novel a route, immediately attracted the attention of the Tea Men; and during the four following years a vast quantity of Congou tea was brought to Canton by the same channel.

The jealousy of the Canton Government, however, was soon excited by the Hong merchants; and finally, in consequence of gross misrepresentations transmitted to the Court of Peking, an Imperial Edict was obtained, prohibiting the transit of tea by sea to parts of the empire south of the port of Foo-chew-foo. But for this interference, little doubt can be entertained that the whole or the greater part of the black teas would shortly have been brought to Canton by sea. And were this edict rescinded, or no longer in force, there seems little reason to doubt that the black teas would again find their way to Canton by this route, as formerly; and thus afford a practical illustration of the capabilities of the internal navigation, the practicability of the port, and the apparently exaggerated and ungrounded reports and apprehensions with which the Europeans resident at Canton are at present assailed.

But in the present temper of the Imperial Government, any rescinding of the edict may be hopeless, though it may be prudent to keep the removal of 
this restriction constantly in view. There is in the minds of the Chinese an apprehension of evil from the opening of this port; and though neither the Imperial nor the local Government might be disposed to commit themselves by interposing any direct impediments in the way of the trade, yet they show no anxiety to favour its extension at this port.

The edict alluded to, when first issued, prohibited the shipment of all tea from this port. 'The merchants engaged in the northern trade petitioned against this prohibition, and obtained an exemption : but the restriction remained in force against the shipment of teas to the southward. The grounds also on which the law was framed are offensive to Europeans; and, since the motives for its continuance no longer prevail, in consequence of the extension of our commercial privileges, no favourable opportunity should be lost sight of to procure the repeal of this edict.

It appears, by a statement transmitted to the Court of Peking by the Viceroy of the province of Quong Tong, that the quantity of tea thus brought by sea amounted in the year 1813 to $1,019,720 \mathrm{lbs}$. English; and that in the year 1816 it had progressively increased to $8,965,200$ lbs. : thus exhibiting an increase of nearly nine-fold in three years. In the report here alluded to, the Viceroy proceeded to state that_-." If the transit of tea coastways be permitted, there will be no security that traitorous 
natives may not combine with crafty foreigners, and form an emporium for tea upon some island; and having succeeded in so doing, the proud foreigners, getting their tea with such facility, may become indifferent, and no longer respect or seek the favour of China." *

About this period Puankhequa, who had been the principal Hong merchant for many years, but had obtained permission from the Imperial Government to retire from business, was now recalled, and to his interference, I am disposed to think, may be ascribed the impediments now thrown in the way of this mode of transit. This wealthy merchant was an able man, and possessed many excellent qualities. In his habits he was social and kind, and in his control of foreigners not ungenerous: but he was vain, and fond of power, and of keeping foreigners under restraint. This wily politician soon saw that if the teas were brought by sea from Foo-chew-foo, Europeans could not fail to be struck with the absurdity of a voyage so unnecessary and disadvantageous, and would become the more impatient under the restrictive and vexatious policy to which they had so long submitted; but under which, as they advanced in a knowledge of the language, which had recently been cultivated with much assiduity and success, they were daily becoming more impatient. He therefore determined 
to nip their hopes in the bud. His mode of accomplishing this object was, I believe, by bribing the Custom-house officers at Sheu-chew-fu to report to the Provincial Governments of Quong Tong and Kiang Sy, that a considerable defalcation had taken place in the transit duties in consequence of the novel mode of transit of teas by sea. Nor were the officers of the Canton Government less alive to the threatened reduction of their emoluments, in the event of the removal of the trade to a northern port. The late negotiations also have proved how reluctantly the Imperial Government consented to the opening of the Port of Foo-chewfoo: not, however, from any anticipated loss that might accrue to the Imperial or Provincial Treasury on account of a defalcation of the duties, for these are small, and altogether insignificant; the whole amount of transit duty through the provinces of Kiang Sy and Quong. Tong not exceeding 2 mace 4 candereens the pecul, or half a farthing on the pound avoirdupois; but on a well-grounded apprehension that the opening of this port, and this port alone, might accomplish what all the other ports may fail to effect, viz. the removal of the greater part of the black tea trade from the port of Canton: thus occasioning the serious inconvenience of throwing a number of men and boats out of employ in the provinces through which the teas had been so long conveyed; besides a depreciation of property, and other disadvantages not easy to enume- 
rate. In short, it cannot be doubted that the readiness with which all other demands were granted, and the resistance offered to the opening of this port, mark its importance in the estimation of the Imperial Government, as threatening the removal of the black tea trade from the port of Canton. And too much praise cannot be bestowed on Sir Hemry Pottinger for his great sagacity in at once duly appreciating the importance of this port, and for his firmness in risking a renewal of hostilities to secure so great a privilege. It is to be hoped that advantages thus obtained by arms, may not be cast to the winds and rendered nugatory, through the supineness and want of enterprise on the part of the British merchants established at Canton.

It must be acknowledged, however, that the navigation of the river Min, both above and below bridge, does appear to present certain difficulties; and the port, especially, is not so accessible as that of Amoy or Shanghai : but let these disadvantages be examined dispassionately, and with a disposition to counteract them, and we shall then find, perhaps, that many ungrounded fears may vanish before a strict and fair investigation, and that such as are real, and remain, may be surmounted by the ordinary means and expedients which navigators are compelled to adopt at even the most favoured ports of the world.

But in this examination it must be borne in 
mind that this port has never been recommended or selected as one favourable for the diffusion of our manufactures over the empire (Shanghai is the natural port for our imports into China), but simply as the best port for the shipment of our black teas; in consequence of the great expense of transporting so bulky an article across the mountainous ranges which isolate, as it were, the province from the rest of the empire.

First, with respect to the river Min abore the bridge of Foo-chew-foo, Ogilby observes, that, "from the town of Pu-ching-hien to Kiu-keu, the river falls with great force of water through valies, rocks, and cliffs; but from thence glides on but slowly. In three days they go from the above town to Foo-chew-foo with the stream, whereas they are fifteen days towing up against it." **

Kiu-keu I understand to be on the Pu-chinghien branch of the river, before its junction with the other branch at Kien-ning-fu: consequently these difficulties, if so considered, are not connected with the transport of the teas from the Bohea country to Foo-chew-foo.

The Fokien merchants say that in spring, the currents then being rapid, in four days the teas are transported down to Foo-chew-foo, but that in autumn it requires eight.

The Dutch embassy under Van Hoorn, in $1647 \uparrow$, 
which passed up this river in the month of February on their way to Peking, were (exclusive of stoppages in certain towns) about seventeen days on their passage from Foo-chew-foo to $\mathrm{Pu}$-ching-hien, and seven days on their return in the month of September and November. They met with rocks and falls, and one boat was wrecked.

Here, then, we see nothing but a laborious current to stem, and a descent requiring care and a certain amount of skill. There may also be falls and rapids, over which pilotage may be necessary, dangers to which the teas are already exposed in passing the She-pa-tan, or eighteen cataracts, in the province of Kiang-sy, where pilots are hired, and where the principal part of the damage takes place on their transit to Canton. But whatever these dangers may be, Mr. Alcock observes, "they are made light of by the best informed. The loss of a boat is of rare occurrence, and generally attributed to carelessness, or the untrustworthy state of the boat." * Moreover, the tea-men are ready to conclude bargains in tea, taking all risk and cost of transport on themselves, and to deliver them at fixed prices at any part of the river where it may best suit a ship of burden to lie for her cargo (page 10.); and this at a rate much less than the same can be purchased at Canton (page S. ib.).

* Parliamentary papers on the returns of the China trade, January, 1847, p. 8. 
But the surest test in all matters of risk and danger, whether by sea or land, is the rate of insurance, or the cost of transport. This is an unfailing measure of danger and difficulty, which mercantile men will be unwilling to discredit.

With respect to the cost of transport of the teas from the Bohea country to Foo-chew.-foo it is stated by $\mathrm{Mr}$. Alcock to be about 9 mace the pecul, a charge by no means exorbitant; and only one fourth of the simple expense of carriage to Canton, viz. 36 mace. But I have reason to think, on very good authority, that this charge does not amount to more than 4 mace 3 candareens the pecul*; while the cost of carriage simply across the mountains which separate the Bohea country from the other provinces amounts to no less than 12 mace 5 candareens. Nor can the teas (as already shown) be moved out of this province without incurring an expense of carriage of five times the amount necessary for shipping them from the port of Foo-chew-foo. If these calculations, coming from different sources, and at remote periods of time, be correct, how utterly insignificant must the amount of danger be in the navigation of the river Min, which entails so small an amount of comparative cost. But, even admitting these drawbacks to be greater than they appear to be,

* R. Asiatic Society's Journal, Miny, 1840, p. 36. A paper of mine, whence much of the matter that follows is taken. 
still, supposing the trade once to be set in action and progressing; they are not likely to present serious and permanent obstacles to a people who have carried the great wall of China over mountains and through vallies for a distance of a thousand miles; who have constructed that great work, the grand canal, extending in an irregular line for five hundred miles, with its spacious quays and locks of solid granite and marble; who have turned the course of a rapid river* ; directing, by a happy conception of genius, one stream to flow to the north, and the other to the south; who have cut capacious passes over lofty mountains, as the Ta-moey-lingt, in Kiang-sy, and the pass of Pu-ching-hien $\ddagger$, in Fokien, and other passes of the empire, solely for the purpose of increasing the facilities of communication and transport of goods.

Nor is it easy to find any part of the habitable globe where the mountain streams and rivers have been turned, by art and enterprise, to an equally beneficial account for the economic purposes of irrigation and navigation; and still less where a complete water-communication, perfectly uninterrupted and unimpeded by mountains and land journeys, has been secured by a favourable confi-

* The River Luen, at the summit level of the Grand Canal. See Staunton's Embassy to China, vol. ii. p. 387.

$\dagger$ Ibid. p. 507.

† Du Halde’s China, vol. i. p. 87., translation. 
guration of the country, improved by art, skill, and intelligence, to seven-tenths of a population reckoned at the lowest estimate to amount to $200,000,000$ of souls. Nor shall we readily find elsewhere boats of such various forms and con. structions, some built with lofty and well-decked prows to pass falls and rapids; others long, low, and narrow, for speed; others broad and high, for cargo; and others for comfort and the convenience of travelling, as well as some gaily ornamented, for pleasure and amusement.

Again, if we test the navigable condition of the river Min by the population on its banks, we find the city of Foo-chew-foo rated at 500,000 souls. The Rev. G. Smith is disposed to estimate it even as high as 600,000 , a population the two thirds of that of Paris, nearly double that of Vienna, and nearly equal to that of Naples. The population of Kienning-fu was estimated by a census taken in 1790 to contain 250,000 persons - a population superior to Manchester, and nearly equal to Liverpool. The population of Yen-ping-foo, the key of the province, must also be considerable, and likewise the towns of Kien-Yang-foo, Pu-ching-hien, and others; so that the population on the banks of the Min alone may not be overstated at one and a half million of souls. But if we turn to the map of the province in Du Halde, or, still better, to Martini's Geography of China, we shall perceive that the Min and its tributaries cover two thirds of the province; 
and if we reckon the whole population at $8,000,000$, agreeably to the Père Allerstain*, in lieu of $15,000,000$, as given by the highest modern authorities, still even this estimate, low as it may be, would furnish to the Min and its tributaries a population of $5,500,000$. And can a free and easy communication with a population of this magnitude be a matter of indifference, as affecting our imports into China? Or, is it probable that a commercial population, of double the amount of that of the second commercial city of Great Britain, could have risen up in the principal city of the province, without possessing, like Liverpool, all the attributes which an extended commerce demands?

Du Halde informs us, that no less than 10,000 porters are regularly employed at the town of $\mathrm{Pu}$ ching-hien, in the transport of goods across the mountainous range which separates Fokien from Chekiang, which is the direct route from Foo-chewfoo to Hang-chew-foo and the grand canal. This mountain pass extends for thirty leagues, and is furnished with towns full of inns for lodging travellers. $f$ Thus it is obvious, from the number of towns, inns, and porters employed, that this route must be a much-frequented one, and that considerable traffic consequently exists on the river Min, to and from the province of Chekiang.

The trade of Foo-chew-foo is also considerable.

* Mémoires des Chinois, tom. vi. p. 275.

$\uparrow$ Du IIalde's China, vol. i. p. 87., translation. 
It is stated in the parliamentary papers on the returns of the China trade, printed January, 1847, that the actual quantity of imports in 1678 junks, is valued at $3,177,145$ dollars; exports in 1281 junks, at $11,654,653$ dollars. The quantity of tea recorded to be shipped from this port is so insignificant, that I cannot but suspect that some concealment has been practised by the Chinese with regard to the quantity shipped to the northern ports. It seems inexplicable that the northern merchants should petition against a prohibition in which they had no interest. Thus by whatever test we examine the practicability of the navigation of this river, whether by the quantity of tea brought down to be shipped to Canton from the year 1813 to 1816 ; the rate of charge for boat hire; the amount of population on its banks; or the annount of the existing trade of the port, and traffic on the river; they all furnish evidence of great internal activity and prosperity, an actual state of trade of considerable magnitude, and the elements of great future increase;-deficient in one point only, the energy and enterprise of British merchants to develop it.

Let it also be remembered that Canton owes her prosperity mainly to the foreign trade. It is neither the place of consumption of our imports into China, nor the seat of growth of any of our exports from it; but in whatever degree onr trade has nursed and reared up new domestic industry at Canton, the habits, taste, and disposition of the people, being in 
these respects everywhere the same, similar effects would be produced at any port to which our trade may be extended.

Moreover, if we are to look to an extension of the cultivation of tea, as a mode of payment for imports, and as the principal means by which an extension of our imports into China may be rendered profitable, where can we hope to accomplish this end with the same promise of success, as in the vicinity of the districts where it may be said, without any exaggeration, that nearly the whole of our black teas are manufactured, and whence, by a circuitous, tedious, and expensive route, they are at present procured? The whole line of the river Min and its tributaries, with their mountainous aspects, and their vallies, with running streams, may afford suitable and untried sites for the cultivation of tea; and here, in fact, the tree may be seen growing wild among its native hills. There is much reason also to think, that superior modes of manipulation prevail in the Bohea districts, which must be adopted in other provinces before the teas of such provinces can be rendered available to the European.

With respect to the navigation up the river Min below bridge, and the approach from sea, Mr. Alcock observes _ "I must believe from all the information to which I have had access, that the entrance to the river, and its navigation to Pagoda Island, to an experienced pilot offers no insurmountable 
difficulty; no danger which is not equalled by physical peculiarities of many flourishing ports in different parts of the world.

"The bad approach and troublesome navigation are, doubtless, disadvantages; which, together with the long prevalence of the north-east monsoon, and the want of a good harbour off the mouth in the south-west, are unquestionably grave and serious drawbacks, but no more." (Parliamentary Papers on the Returns of the China Trade, January, 1847, p. 10.)

But I learn from Capt. Collinson, R.N., who was employed in making extensive surveys along the east coast of China, that by fixing a "basket" on some rocks visible, at low water, and by erecting a small pagoda on one which is never covered (privileges secured by treaty), ships may sail into this port in a gale of wind without a pilot; and that by advancing up the river at a suitable time of the tide, the navigation as high as Pagoda Island, which is within ten miles of the city, is a less intricate and less difficult navigation than either the Thames or the Mersey. There are eddies and currents in this river, but they offer no impediment or difficulty at a proper time of the tide.

It was long since suggested, however, that the islands at the mouth of the river, and especially one now known by the name of Wo-ga, would afford all the requisites for a port of trade. Here is an ample supply of water, and the anchorage is as safe 
and good as in any part of the river; the distance is about the same as from Canton to the second bar. Were it deemed advisable to establish the trade at this point, it would not be difficult to induce the tea-men to deliver their teas at this port: the construction of a suitable form of boat would offer no more impediment here, than it did at Canton; the chop-boat, as it is called, was constructed, and is exclusively used, for the foreign trade. In the event of any future collision with the Chinese, it might be a matter for grave consideration, whether this island might not be rendered an important commercial settlement in our hands.

Although far from meaning to advocate monopoly in any form, yet justice compels me to say, that had the privilege of trading to Foo-chew-foo been obtained during the existence of the East India Company's charter, from the unity of action and energy which a corporate body possesses over individual traders pursuing their separate interests, the greater part of the black teas would have been shipped from this port in less than four years. The usual contracts would have been made with the tea-men at Canton, and the usual monies advanced; but with this simple difference in the engagement, to deliver their teas at Foo-chew-foo instead of bringing them to Canton. And can it be doubted that these people would gladly have hailed a change which ceased to inflict on them the penalty of a tedious and harassing journey, as well as a long and painful separation from their homes and families? 
"But time alone can show," as observed by Mr. Alcock, "how far the advantages of this port are of a nature to excite the British mercantile community to divert their capital from Canton, and employ the same amount of energy and intelligence at Foo-chew-foo; for on this, after all, must depend the prospects of this port, as a mart for tea and British produce." (Parliamentary Papers on the Returns of the China Trade, January, 1847, p. 10.)

Venice preserved much of her commerce with India for nearly half a century after the discovery of the passage by the Cape of Good Hope. 'Thus the apparent predilection still subsisting for Canton, and the mistrust now operating against the port of Foo-chew-foo, may furnish history with another example, that _ "When any branch of commerce has got into a certain channel, although it may be neither the most proper, nor the most commodious one, it requires time and considerable efforts to give it a different direction."

To return to our subject after a long digression, though, I trust, not an unimportant or irrelevant one : - the prohibition of the transport of tea by sea rendered other arrangements necessary regarding the Bohea. The large chests, even though reduced in size and weight, were found too bulky and heavy for inland conveyance. Finally, after a few more experiments, it was found expedient to adopt the form of the ordinary Congou chest. Consequently a strong chest of this description was constructed, 
bearing a roughly printed chop-mark or inscription, in unusually large and conspicuous Chinese charac. ters to distinguish these teas from the regular Congou teas. Thus the large chests intended for the floor. ing of the ships were again obliged to be prepared and packed at Canton. But the packing was now performed at the risk of the Hong merchant; and the price settled on examination of a sample of packed, instead of unpacked tea, as in all other cases.

The leaves of this tea, whether collected in the Bohea or Wo Ping districts, all consist, as before observed, of the old and coarse leaves left on the shrubs after the gathering of the usual harvest. Suey Lan states, that these leaves are plucked in July and August, but not bought before September or October. They are gathered by bending down the branches of the shrubs, stripping them in the rudest manner, by passing the hand along the branch, as described by Mr. Fortume, and sometimes with a bamboo knife held between the forefinger and the thumb.

They are then exposed to the sun, or air, a short time, when they are packed in baskets.

In the Bohea country, it is the practice of the merchant to send the tea, which he has contracted for, or purchased in the rough state, to his own packing houses, where it is roasted two days in roasting houses constructed for that purpose. In the Wo Ping country, it is packed sometimes in 
baskets, but generally in tubs, and sent to Canton, where it undergoes a similar process of roasting. When brought in tubs it is sifted, assorted, and started into a pile, from which it is loosely repacked into bamboo "barrel-shaped baskets" slightly put together, and of somewhat open work, for the better admission and circulation of heated air; but the inside is well lined with soft paper to prevent loss of tea.

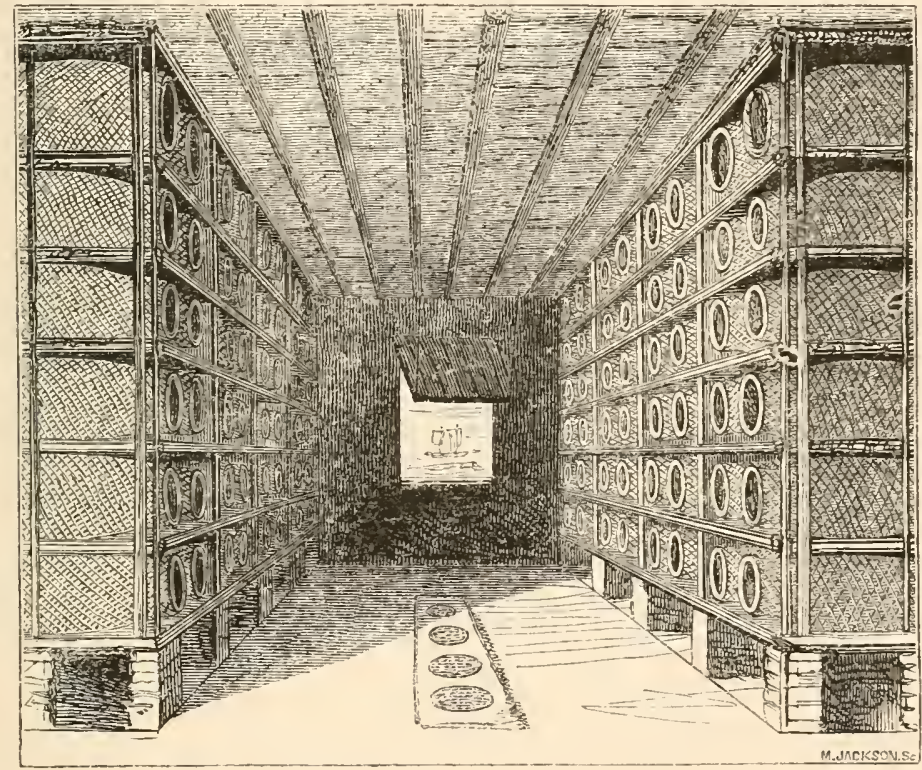

The houses constructed at Canton for this purpose consist of brick buildings divided into as many chambers as may be required, all on the ground floor. Each chamber has a door in front with a small opening at the bottom, to which is fitted a slide which opens and shuts at pleasure. This small aperture is for the purpose of admitting a 
long rake, with which the charcoal when in a perfect state of ignition is stirred and spread out. At the end of each chamber, opposite the folding doors, is a square opening or window which closes with a shutter, opening outwards, so that a thorough draught may be produced as required, to ignite the charcoal or to cool the tea when sufficiently roasted. For this latter purpose the doors are also opened to produce a draught through the building. On the ground, or tiled floor, a channel is constructed, or a receptacle built up about sixteen inches in width, extending nearly the whole length of each chamber. Into this receptacle or open stove, the charcoal is placed in heaps at convenient distances till properly ignited, when it is raked and spread out. An open frame-work rudely constructed of small spars, and divided into six tiers, or heights, receives the baskets, and thus occupies either side of each chamber, the charcoal being placed in the centre between the two frames. These frames are raised on square pillars of brick-work about two feet in height, and at such intervals as may be necessary to support the superincumbent weight. The baskets are placed on the stands in single rows on their sides, having their mouths torvards the fire. The mouth of each basket is closed with a thin sheet of lead, mostly a piece of an old tea canister, in order to protect the tea from the extreme heat of the fire. The backs of the baskets are some inches distant from the wall, so that a free circulation of heat may 
be kept up throughout the stands and around every part of the baskets. Each tier contains 20 baskets, or 120 on either side of the chamber. The usual quantity roasted at one time in the several chambers is sufficient to pack 400 large chests of Bohea, each weighing 132 catties; thus making the total quantity in all the chambers 528 peculs, or 70,400 lbs. of tea.

Goqua, a Hong merchant, informed me that each of his chambers contained 300 baskets of fifty catties each; and that the roasting was continued three days, the charcoal being renewed every six hours, at the rate of two and a-half peculs each time, or ten peculs the night and day; thus making the consumption of charcoal 30 peculs to 150 peculs of tea, or as 1 to 5 . A pecul is $133 \frac{1}{3} \mathrm{lbs}$.

The following are the dimensions of three sets of chambers belonging to Conseequa, Chunqua, and Goqua.

\begin{tabular}{lcccc} 
& \multicolumn{2}{c}{ Conseequa. } & Chunqua. & Goqua. \\
& Cubits. & Feet. & Fect. & Feet. \\
Depth & $28 \cdot 5$ & 34.9 & 32.5 & $41 \cdot 5$ \\
Breadth & $9 \cdot 5$ & $11 \cdot 7$ & 11 & $14 \cdot 7$ \\
Height & 10 & $12 \cdot 2$ & $11 \cdot 8$ & $15 \cdot 2$
\end{tabular}

The window in Chunqua's roasting houses was $2 \cdot 6 \mathrm{ft}$. by $1 \cdot 10 \mathrm{ft}$. wide. Agreeably to Conseequa's statement, his chambers would only roast 240 baskets each, or 140 peculs of tea ; thus making the contents of each basket $58 \frac{1}{3}$ instead of 50 , as stated by Goqua. 
The tea thus roasted is then mixed with a superior kind of Wo Ping tea roasted in the Wo Ping * country, and brought down in tubs by water carriage; together with old and low Congou, and sometimes with low green tea. This mixture is regulated according to the quality required. The proportions being determined, the tea is then thrown into a heap or pile as already described, so as to form a mixture of one uniform quality.

Each Hong merchant has a place fitted up in one of his warehouses for this purpose. The floor is boarded and a little raised above the general level of the floor or ground of the warehouse. This compartment is fitted in front with sliding pannels for the purpose of retaining the tea, which are removed by degrees as the tea is diminished in bulk in the course of packing. Its dimensions are about fifty feet long, twelve broad, and eight high. The tea is weighed in baskets as filled from the heap, to secure a uniform weight in the packing; and each large or whole chest, as it is termed, contains on an average about one hundred and seventy-two pounds.

\section{BRICK OR TILE TEA.}

The name of this tea is obviously derived from its form, and might be supposed to furnish a clue

* N. Lat. $24^{\circ} 30^{\prime}$, Long. $1^{\circ} 35^{\prime}$ west of Peking. 
to its bulk. It, nevertheless, varies much in form as well as in weight. Pallas, Mooreroft, and a Chinese with whom I was acquainted, who was afterwards unfortunately banished for some years to Ili, furnish an average length of 16 inches, breadth $5 \frac{1}{2}$, depth $1 \frac{1}{2}$, and of weight $7 \frac{1}{2}$ lbs. avoirdupois. But Dr. Falconer met with tablets of this tea in cubes of nine inches.

Again, these tablets not only differ in size but in appearance. Some seem composed of leaves as if wetted, and in that state forcibly compressed *; others of leaves which have been rolled like tea; and some of leaves as if macerated in water and reduced nearly to a state of pulp, or pulverised while dry and then wetted. The angular form, shape, and solidity of these tablets, clearly demonstrate, that a mould and considerable pressure are employed in their formation. Their cohesion is supposed to be derived from a process of steeping the leares in the serum of the blood of animals, agreeably to some; or from their being sprinkled with a solution of rice, according to others. Both these expedients may be employed, when the leares are found deficient in viscidity, from age or other defects. I have no information on which I can rely concerning the manipulation of this tea; but I feel confident that when the leaves are young or in a suitable state of maturity, as regarding growth,

* MLoreroft's Travels, vol. i. pp. $350,351$. 
the viscid juices which they naturally contain would be found sufficient to preserve them in any form impressed on them. Indeed, one of the inconveniences experienced in the manipulation of tea, is the necessity of constant attention lest the leaves agglutinate and form into lumps or masses. On a small scale, as in Caper, Long-tuon, and Gunpowder teas, we have known examples of this power of natural cohesion; and in fact the same may be remarked of all tea, as the twist and curl of the leaf is fixed and rendered permanent by the gluten contained in it, aided by heat, and the processes of manipulation.

But when we consider that this tea is for the most part of very inferior quality, as I know from personal examination, and may be classed with our common Bohea,_-consequently fabricated of leaves deficient in natural gluten, - it is quite possible that both the above expedients may be resorted to in order to retain the leaves in a mass. Thus, the use or otherwise of a gelatinous fluid may depend entirely upon the quality of the tea.

Regarding the districts where this tea is produced, all my inquiries induce the belief, that the bulk is the produce of the province of Szu-chuen, one of the border provinces adjoining Tibet. It is there packed in bales or parcels, secured with a kind of basket-work of grass: and in the country known by the name of Sifan (Moorcroft says Lassa) it is further packed in raw skins of the Yak, the hair 
inwards, and the joints neatly secured by a sewing of thongs.* The finer descriptions of brick tea sent into Mongolia are packed in boxes and canisters like other tea; and probably come from other parts of China.

At Ili, the principal place of banishment of the Chinese, situated on the extreme western frontier of Mongolia, the brick tea is known by the name of Hu Cha: and, thus, my informant imagined it came from Hu Quong, the adjoining province to Szuchuen.

Pallas gives us a translation of an inscription in the Mongolian language, which he found printed on the coarse yellow paper envelope of some brick tea; which, so far as can be judged from the orthography given, indicates that the tea which this paper enveloped was made in the province of Kiang Nan.

I was informed by the Chinese that a superior kind of brick tea is made in the Bohea or Black Tea country. I have received specimens of this tea, which were brought down from this district expressly for me. One exhibited the complete twist and curl of the leaf, but forcibly compressed into oblong masses; the other bore no trace or form of the leaf. Examples of these two conditions of leaf maybe seen in a specimen of $\mathrm{Po} \mathrm{Ul}$ tea, a medicinal tea, and of brick tea in the Museum of the Royal

* Moorcroft's Travels, vol. i. p. 350. 
Asiatic Society. The two specimens first alluded to were of different qualities; the first superior to many Congous imported into England, and was employed by me for domestic use, so long as it lasted; the other was of inferior quality. This indicates, as has already been surmised, that form may have little to do with quality; moreover, that the coinpressed form of the brick tea may be adopted in many cases with advantage. Again, it is possible that the tea here alluded to was of the same description as that spoken of by Moorcroft as of superior quality, and as coming from Yarkand to Bokhara; which tea was packed in chests, not in skins.

It may now be observed that the brick tea is extensively used throughout every part of Central Asia, from the Gulph of Corea and the great wall of China on the east, to the Caspian Sea on the west; and from the Altai chain in the north, to the Himalaya mountains on the south. It is also largely used in Siberia, and somewhat in the Caucasus; in short, wherever the Calmuc and Mongolian races have extended themselves. "The Calmucs," says Bergam, "are great consumers of this tea." And it is truly observed by the Edinburgh reviewer that, "like Boniface's ale, it is meat and drink to them. It is mixed with milk, salt, and butter, so that it forms a more substantial diet than the fragrant fluid which smokes on our tables. This preparation requires time and care, and the 
'tea-cook' is an important domestic in the train of every substantial Calmuc." *

Thus this tea may be seen traversing Central Asia in all directions. Mr. Manning, the only English traveller who ever penetrated to Lassa, the court of the Grand Lama of Tibet, fell in with several caravans of oxen laden with this tea. Again, Moorcroft, during his stay at Ladakh, speaks of a caravan of traders which arrived there from Lassa with many yaks laden with brick tea; also another caravan from Yarkand, of twenty-five horses with shawl-wool, felt, tea, and silks.

Timkowksi on his journey with the Russian embassy to Peking in 1828 also fell in frequently with caravans of this tea; and this road, though not the post-road, according to this traveller, was nevertheless much frequented by merchants and travellers.

"On approaching Ourga they met with a splendid troop of persons, consisting of a dzassak accompanied by his mother, his wife, and young brother, his sister, and a numerous suite, all mounted on fine horses, and armed with bows and arrows. The women in particular were remarkable for their rosy countenances, and the richness of theil dresses. Their robes were of beantiful blue satin, their caps of sable, their silken zones interwoven with silver, and adorned with large cornelians,

* Edinburgh Review, Aug. 1817, p. 306 . 
with which even their saddles were decorated. The fair Amazons," adds Timkowski, "approached us without timidity, and condescended to honour us with their notice." *

During the sojourn of the embassy at Ourga, on one of their cxcursions they met with a party of Bucharians with 140 camels, on their way from Ourga to Ouliassoutai with brick tea. (Vol. i. p. 121.) On others, a caravan with 200 carts; and again, belonging to another, he saw 400 oxen grazing in the steppes. These latter were merchants, natives of Shansy, carrying fine tea for the Russian market. The coarse kinds he states to be carried during the winter [?] on camels. And as they drew near to Peking, all the way from Sue-hoafoo, distant about 340 ly, they constantly met with caravans of camels laden with brick tea.

Timkowski describes a fête which took place on the banks of the Orchon near Ourga in the year 1729, which description I here cite, because it is not only interesting in itself, but as exhibiting how much this brick tea enters into the economy of Mongolian and Tibetan life. In fact from its universal use, it is sometimes employed as a circulating medium, or currency. The occasion here alluded to happened during the celebration of the manifestation [of the Deity in the person] of a new Koutouktou or Grand Lama. After receiving

* Embassy to Peking, vol. i. p. 75. 
the presents which were offered to him, the Koutouktou gave his benediction to the emperor by laying both hands on the head of the amban (a Chinese officer). He then gave his blessing to the Lamas and the people.* The Chinese merchants who were present at Ourga made an offering of 350 pieces of satin and 400 chests of brick tea. $\uparrow$

Wrestling, archery, and horse-racing followed. The race-course was 18 versts in length (about 12 miles); 1110 horses ran at once. On another occa. sion 1627 horses, of six years old, ran 16 versts: and on a third, 985 of 4 years old, ran 12 versts. On all these occasions 100 horses were selected as victors.

At the expiration of two days, when the games were concluded (July 8.) all the Mongols returned to Ourga. A richly decorated tent was erected, into which the Koutouktou was conducted. Seve. ral idols were carried before him, and incense was burnt in silver censors. When he had entered the tent and mounted the throne, all the nobles took the places assigned to them. Brick tea in silver cups was brought in, and presented to the Koutouktou and his sister. The former, after having tasted it, returned it, and gave orders to pour a part of it into each tea-pot. As soon as this was done, a cup of this tea was presented, first to the Koubilgon and the Dalama, and then to all the

* Embassy to Peking, vol. i. p. 100.

$\dagger$ †b. p. 101. 
persons of distinction. As for those who had no cups, some of the tea was poured into their hands. Prizes were then distributed. The first wrestler received for his reward a fowling piece, a cuirass, 15 oxen and cows, 15 horses, 100 sheep, a camel, 1000 bricks of tea, some pieces of satin, and several fox and otter skins. The others received presents proportional to their strength and agility. A similar feast is celebrated every year by the Mongols, who assemble near one of the obas of their horde.*

The road to Ili, the place of banishment for Chinese criminals, is through Hami. Within the Great Wall, or China Proper, the road is divided off into stages of $100 \mathrm{ly}$; but without the Great Wall, and especially in crossing the sandy and flinty desert of Gobi, the stages are irregular, extending to distances of 120 and $140 \mathrm{ly}$, in consequence of the scarcity of water. Small inns are established at intermediate stations, wherever water can be procured on the spot, or from a distance of a few leagues, and tea may be obtained at any hour of the night; for during the summer the Chinese, in consequence of the scorching heat of this desert, travel by night, and rest during the day. $\dagger$

In Tibet, Moorcroft informs us, that all classes of Tibetans eat three meals a day: the first consists of tea; the second of tea, or of meal porridge,

* Embassy to Peking, vol. i. pp. 101. to 105.

$\dagger$ Portuguese MS. in my possession. 
if tea cannot be afforded; the third of meat, rice, vegetables, and bread, by the upper; and soup, porridge, and bread, by the lower classes. At breakfast each person drinks about five or ten cups of tea, each cup containing about one third of a pint; and when the last is half finished, he mixes with the remainder as much barley-meal as makes a paste with it, which he eats.* At the mid-day meal, those who can afford tea take it again, with the wheaten cakes, accompanied with a paste of wheat flour, butter, and sugar, served hot. The poorer people, instead of tea, boil two parts of barley flower with one of water, or meat broth, seasoned with salt, until it becomes of the thickness of porridge. The evening meal of the upper classes is formed of some preparation of the flesh of sheep, goats, or yaks, and eaten with rice, vegetables, and wheaten cakes, leavened or unleavened. The poorer classes eat at night the same barley porridge as at noon; or a soup made of fresh vegetables, if procurable, or of dried turnips, radishes, and cabbage, boiled with salt and pepper, in water, along with pieces of stiff dough and wheaten flour. The use of tea has been common amongst the wealthy Tibetans for some centuries, but it has been uni-

* The reason of this is, that "a rich fatty scum floats upon the surface, which is too precious to be lost. It is blown aside in drinking to be mixed with malt-meal, and well kneaded with the fingers by way of conclusion to the feast." ('TunNer's Embassy to the Teshoo Lama, p. 176.) 
versal only within the last sixty years. It has extended itself within the same period to Bokhara and Kashmir. In a simple state of infusion, its use is becoming general in the Punjab and Kabul.* Moreover, Capt. Mignon, in his journey through Persia, the Caucasian Alps, and Georgia, states that the use of tea as a beverage is becoming very general throughout the northern parts of Persia, although it bears a high price. He met with it at Tebriz, and it is much used at Aserbijoum. Burns says, the love of the Bokharians for tea is, he believes, without parallel, for they drink it at all times and places, and in a half a dozen ways - with and without sugar, with and without milk, with grease, with salt, \&c. $\dagger$

For a breakfast of ten persons in Tibet, this, says Moorcroft, would be the preparation: about, an ounce of brick tea, and a like quantity of soda, are boiled in a quart of water for an hour, or until the leaves of the tea are sufficiently steeped. It is then strained, and mixed with ten quarts of boiling water, in which an ounce and a half of fossil salt has been previously dissolved. The whole is then put into a narrow cylindrical churn, along with the butter, and well stirred with a churning stick, till it becomes a smooth, oily, and brown liquid of the colour and consistence of chocolate, in which

* Moorcroft's Travels in the Himalayan Mountains, vol. i. pp. $328-331$.

+ Travels into Bokhara, vol. i. p. 277. 
form it is transferred to a tea-pot for immediate use.*

It will be observed that the mixture here described contains no flour; and Moorcroft decidedly says that the Tibetans do not use milk. The Mongols, however, do; and one may imagine a mixture of milk instead of water with which to dilute the strong decoction of tea would be an improvement, where the refreshment sought is not a beverage, but a broth or meal. This, however, may depend on taste, and other circumstances, as in the use of chocolate, \&c.

Mr. Manning described to me the mode of preparing tea in Tibet, as follows:-A small quantity of flour is put into an iron vessel over a slow fire, and slightly parched; to which is added a small portion of butter. These two ingredients are then stirred and formed into a paste; to which is added at intervals a portion of the strong decoction of tea, the whole being constantly stirred and well mixed, and blended together. It is then diluted with milk or water, and churned as already described. I also understood that it is poured from one vessel into another backwards and forwards several times. It obviously thus forms not merely a refreshing beverage, but a somewhat nutritious meal.

When Mr. Turner, on his visit to the Teshoo

* Moorcroft's 'Travels in the Himalayan Mountains, vol.i. p. 329 . 
Lama, first met with this tea in Tibet, disappointed at receiving a greasy broth in lieu of the fragrant infusion he had been accustomed to drink under that name, he turned from it with disgust; but I must quote this elegant author's own remarks on this subject :

"Presently a servant came, bearing a large teapot of white metal, embossed, and highly ornamented with some other metal, of a yellow colour. He approached the Raja, and then giving a circular turn to the tea-pot, so as to agitate and mix its contents, he poured a quantity into the palm of his hand, which he had contracted to form as deep a concave as possible, and hastily sipped it up. To account for a custom which has so little either of grace or delicacy, in its observance, however recommended by extensive fashion, we are obliged to have recourse to the suspicions suggested in remoter times, by the frequent and treacherous use of poison. Hence originated a caution, in which the national character of this people readily disposed them to acquiesce; and the same jealousy and distrust which gave birth to its adoption has contributed inviolably to preserve it to the present day; so that however humble or exalted the rank of the person who introduces to his guests the refreshment of tea, the cup-bearer, which is an office of the first credit, never presumes to offer it without previously drinking some of the liquor that he brings. 
"The Raja held out upon the points of the fingers of his right hand a shallow lacquered cup of small circumference, which was filled with tea. Three cups had been sent, and were set down before us; the Raja directed his servant to fill them also: still holding the eup in his right hand, he repeated, in a low and hollow tone of voice, a long invocation; and afterwards dipping the point of his finger three times into the cup, he threw as many drops upon the floor, by way of oblation, and then began to sip his tea. 'Taking this as a signal, we followed the example, and partook of the dishes of parched rice that were served up with it. We found this liquor extremely unlike what we had been used to drink under the same name; it was a compound of water, flour, butter, salt, and Bohea tea, with some other astringent ingredients, all boiled, beat up, and intimately blended together. I confess the mixture was by no means to my taste, and we had hitherto shunned, as much as possible, these unpalatable libations, yet we now deemed it necessary to submit to some constraint; and having at last with a tolerable grace swallowed the tea, we yet found ourselves very deficient in the conclusion of the ceremony. The Raja, with surprising dexterity, turned the cup as he held it fast betwixt his fingers, and in an instant passed his tongue over every part of it: so that it was sufficiently cleansed to be wrapped in a piece of scarlet silk, which bore evident marks of having 
been not very recently devoted to this service. The officers who had entered with us were not permitted to partake of this repast; and, but for the honour of it, we would willingly have declined so flattering a distinction." *

In another part this author states - "Our Tibetan friends gave a preference to the buttered tea, but we chose an infusion of rice, and drank deeply from a cauldron of it, around which we sat, upon the sod. Our grooms and other humble attendants imitated the example, forming different groups, in whish their cups and pipes very cheerfully circulated." $\uparrow$

It so happened, however, that this dire aversion to buttered tea was soon converted into an opposite feeling; and, finally, Capt. Turner acknowledged in these words - "That habit had not only rendered this composition agreeable to our tastes, but experience most fully proved that warm liquids, at all times, contribute to alleviate the sensation of fatigue. I was never more disposed to praise the comfortable practice of the country, having constantly observed that the first object of attention with every man at the end of a long journey is to procure himself a dish of hot tea." +

It may here be remarked that Mr. Turner's disgust, no doubt, arose simply from a feeling of disappointment or incompatibility often experienced

* 'Turner's Embassy to the Teshoo Lama, p. 69.

† Ib. p. 180.

$\ddagger$ Ib. p. 195. 
at one thing, though good in itself, being presented, when another is desired or expected. A cup of chocolate might have produced a similar effect; and this shows the errors to which travellers may be exposed by trusting too much to first impressions.

It is curious, also, to perceive that when Capt. Turner afterwards discovered that buttered tea was no such despicable thing on coming to a halt after a long and fatiguing journey, still he seemed to cling to his original prejudice; and instead of ascribing the alleviation from fatigue which he experienced in the use of tea to some inherent active principle in the leaf, he was disposed to attribute its virtues solely to hot water.

Mr. Manning found this mixture so agreeable to his taste, that he frequently indulged in its use for breakfast on his return to England; and but for the trouble of preparing it, this mode of using tea might be found to furnish a refreshing, acceptable, and economical meal to the labouring classes of this country. To the Hindoo it would be a very God-send, when we consider the spare and little-varied diet on which superstition has hitherto doomed that race to live.

The tea-pots used by the richer classes of society are made of silver, or silvered copper or brass, ornamented with flowers and foliage, and grotesque figures of leopards, crocodiles, dragons, or heads of elephants and the like, in embossed or filigree 
work. The poorer people use plain brass or tinned copper tea-pots. Each man carries his own cup about his person either of China porcelain, or, which is more common, made of the knot of the horse-chestnut, edged or lined with silver, or plain. About 5000 of these, in the rough, are annually exported from Bisahar to Gardokh, and sold at the rate of six for a rupee; they are finished and ornamented in China.*

Moorcroft speaks of a discovery of much interest made in the course of his inquiries into the tea trade of Ladakh. It appeared that a considerable importation of a vegetable product used as tea, took place from the British dependency of Bisahar. There were two kinds, green and black. The black tea, however, he was informed by two intelligent natives of that province, was the product of a deciduous tree, and, consequently, could not be the true tea-tree. The green tea was the product of an evergreen; but as it seldom exceeded the height of four and a half feet, I should doubt it being the tea-tree. It must always be borne in mind that a height of from three to five feet is the cultivated and stunted height of the tea-tree, and not the natural height of its free and unrestrained growth.

That the tea-plant, says Moorcroft, grows more extensively through the hill tracts than has hitherto been imagined, is probable, from various circum-

* Moorcroft's Travels in the Himalayan Mountains, vol. i. p. 329 . 
stances; and it is said that the Chinese troops returning from Nepaul were observed to gather the leaves of some shrub near Zigachi, which they used as tea, disposing of their own country tea in exchange for tobacco. These statements were communicated to the Bengal government in 1821 . However this may be, the subject is of national interest, and well entitled to the fullest investigation.*

* Moorcroft, vol. i. p. 351. 


\section{CHAP. IX.}

GREEN TEA - THE HYSON SHRUB IS THE SINGLO SHRUB IMPROVED BY CULTIVATION - GATHERING AND MANIPULATION - ROASTING VESSELS DESCRIBED - MODE OF MANIPULATION OF HYSON TEA-COLOUR NOT FACTITIOUS-MANIPULATION CONTINUED - ASSORTMENT OF LEAVES INTO GUNPOWDER, HYSON, HYSON SKIN, AND YOUNG HYSON, BY SIFTING AND WINNOWING - TWANKAY TEA - MODE OF MANIPULATION DESCRIBED BY A CHINESE - FACTITIOUS COLOURING OF GREEN TEA - EXPERHIENTS TO DETERMINE ON WHAT THE PECULIAR COLOUR OF GREEN TEA DEPENDS. - FACTITIOUS COLOURING OF GREEN TEA, CONTINUED - MR. WARINGTON'S EXAMINATION OF THIS SUBJECT - EXPERIMENTS WITH STEAM - OBSERVATIONS ON THE USE OF MACHINERY AS ABRIDGEMENTS OF LABOUR.

The green tea connected with the foreign markets is grown in the southern part of the province of Kiang Nan, in the district of Whey-chew-fu. The Hyson tea is chiefly, if not entirely, brought from the country in the immediate neighbourhood of the two towns of Hieu Ning and Moo Yuen*; the former situated in lat. $29^{\circ} 56^{\prime}$, long. $118^{\circ} 15^{\prime}$; and the latter in lat. $29^{\circ} 12^{\prime}$, long. $118^{\circ}$ E. A coarse kind of Singlo is also brought from the Hien, or town of Tay Ping, situated in lat. $30^{\circ} 15^{\prime}$,

* In Du Halde see Yew-ning and Yu-ywen. 
which is said to be the utmost northern limit whence the tea sold to foreigners is procured.

The green tea known to foreigners may be classed under two kinds, Hyson and Singlo; all other kinds are made from these shrubs, and there is much reason to think that even the Hyson is merely the Singlo shrub improved by soil and cultivation.

It is universally admitted by the Chinese that the term Hyson arose out of an accidental circumstance connected with their intercourse with foreigners, which shall be hereafter explained. It is also generally admitted by the Chinese that the Singlo tea grows in every part of Kiang Nan; but some people assert that the tea produced on the hills in the immediate neighbourhood of the two towns of Hieu Ning and Moo Yuen differs from the Singlo tea; though this cannot be said to apply to all tea grown in this neighbourhood, for the Singlo hill or mountain, where, agreeably to Chinese authors, the green tea was first discovered, and whence it derived its name, is seated in one of these districts, Hieu Ning.* It seems, however,

* Hieu-ning or Yew-ning. Du Halde places the Singlo mountain in lat. $29^{\circ} 58^{\prime}$ - also the city of Whey-chew-fu, which seems like an error. It is said by the tea-men to be in the neighbourhood of Yew-ning, which is a few miles south of Whey-chew-fu. Du Halde describes it as being "neither high nor of great extent, but covered over with the tea shrubs, which are cultivated on its sides, in the same manner as at the foot of the neighbouring mountains." 
that in very early times a new mode of culture sprang up in the neighbourhood of these towns. The wild shrubs were taken from the hills or mountains, and planted in the plains, and round the borders or embankments of fields, and manured; so that this improved mode of cultivation pro. duced a great and favourable change in the shrub. Hence arose a distinction between that grown on the hills, which is called hill tea (Shan Cha), and that grown on the plains, called garden tea (Yuen Cha); so that the ancient term Singlo seems, in these districts, so far to have given place to the more recent classification into hill and garden tea, that some of the Chinese of the present day are unwilling to admit that these teas were originally the same.

As the fact of their identity, therefore, cannot be established on the universal testimony of the tea factors, I shall simply state what I have collected upon this subject.

In the first place, Du Halde observes that "there are only two kinds of tea, the Singlo, which takes its name from a mountain in Kiang Nan, and the black tea, produced in the mountains of $\mathrm{Vu} \mathrm{Ye}$, in Fokien."

In the Chinese statistical works of the districts of Hieu Ning and Moo Yuen, the Hyson districts of the present day, all that is said under the article Tea is as follows :- 
"There is plenty of common tea; that which is called Singlo tea is of excellent quality, and therefore requires a suitable soil, much labour, and is not easy to make."*

"The hill or mountain where tea is produced is called Singlo mountain. A Bonze of the sect of Fo taught a Kiang Nan man, named Ko Ty, the art of making tea; and thus it was called Singlo tea. The tea got speedily into great repute, so that the Bonze became rich, and abandoned the profession of priest. The man is gone, and only the name remains. Ye men of learning, and travellers who seek Singlo tea, may now search in vain; that which is sold in the markets is a mere counterfeit." $\dagger$

Thus it appears that the Singlo tea, in addition to its being the only tea named, was obviously esteemed by these writers, and considered the best description of tea produced in the Hyson districts in their days. For it would have been a strange omission in persons professing to make statistical reports of a country, and especially one of so small an extent, had they neglected to speak of a tea which differed essentially from Singlo tea, and more especially if it were superior to it.

In the Hoa King, a kind of herbal, published

* Moo Yuen Hien Chy, published in the Dynasty of Sung, A. D. $960-1278$.

$\dagger$ Hieu Ning Hien Chy, published 32d year of Cang Hee, A.D. 1693. 
A.D. 1688 , containing an account of a considerable number of plants and flowers, under the article "Tea" it is said, "The teas produced in Kiang Nan are Sung lo (Singlo), Fu Long, Tien Chy, Yang Sien, \&c. The colour is of a bluish green, and very fragrant in flavour. It is said that if Singlo tea be dried with the Chu Lan flower it will improve its flavour. However, it cannot be said that this flavour is so good as its natural one."

Here again we find the Singlo tea ranking first among the teas produced in Kiang Nan, and it is remarkable that the custom of scenting the green tea with the Chu Lan flower obtains only with the Hyson tea in the present day. This circumstance, therefore, together with the excellence of its flavour, described as being very fragrant, and not to be improved by any factitious means, when combined with the previous observations on the same subject, seems to indicate a care in the cultivation and manipulation of this tea, which bears a greater relation to Hyson tea than any kind of Singlo or Twankay tea known as such in the present day. Thus, as far as this question can be decided from the works of the Chinese, it appears that the best tea grown in the province of Kiang Nan was originally considered Singlo tea, deriving its name from a hill or mountain so called in the district of Hieu Ning, one of the Hyson districts of the present day.

I shall now add the statement of one of the 
oldest men in the trade, Cow Mow, upon this subject, whose age, known respectability of character, and long intercourse with the East India Company, must ever give weight to the opinions of that honest merchant. The document states that "Tea has been known from time immemorial. There is a mountain called Singlo mountain. Tea was originally produced here, so that the tea planted in other places was called Singlo tea, also hill tea. That which is called Yuen or garden tea is the Singlo tea planted in gardens. This custom prevailed so far back as the dynasty of Sung (9601278). Hyson tea was formerly called garden tea, and was first cultivated in the towns of Hieu Ning and Moo Yuen. In the reign of Cang Hee (1661-1722) a man used for his Chao Pay (firm or sign) the two characters Hee Chun, or Hyson. Shortly after all garden tea was called Hee Chun, or Hyson."

Tien Hing, another highly respectable merchant, states: "The green tea grown in the towns of Moo Yuen, and Hieu Ning differs in its cultivation from that of other places. This tea is divided into two kinds, the hill tea and the garden tea. The leaf of the hill tea is of a yellow colour, small and thin, and vapid in flavour, and makes middling and common Hyson. The garden tea is grown in vegetable gardens, and also on the borders and embankments of fields. The ground must be manured with the Tong Ping, and manure from 
tanks constructed for that purpose. The leaf then becomes thick, flat, and large, and the colour green. The infusion is also clear and fragrant in smell and flavour. The infused leaves are green, and greatly superior to the hill tea. The garden tea was first brought down to Canton in the present dynasty to be sent to foreign places. The quantity then gradually augmented until every village began to plant it [that is, from the hills] and to manure the ground. The leaves then became of a light green colour, thick and shining, and pleasant in smell; and the infusion sweet and fragrant in flavour." Tien Hing also agrees as to the origin of the term Hyson, and says the person's name was Lee, but the name of his firm was Hee Chun. In fact no difference of opinion exists among the Chinese on this subject, which they say "took place when the trade was carried on at Ning Po."* "Perceiving," they add, "that Europeans inquired eagerly after" a tea that bore the 'Chop Mark,' or characters of a man's Chop or Firm, called Hee Chun, which was garden tea, this induced the merchants generally to adopt that term for that description of tea, as well as to extend the improved mode of cultivation." 'l'o my mind these observations show conclusively, that the Hyson shrub is no other than the

* This must have occurred prior to 1756 , for no ship has traded to Ning-po since that period (Horsburg, page 272.) : and this agrees witl Cow Mow's statement, that this custom first arose in the reign of Cang Hee or between 1661-1722. 
Singlo improved by cultivation: but leaving this question, we will now proceed to treat of the manipulation of green tea.

There are only two gatherings of the leaves of green tea : the first begins between the 20th of April and the 5th of May (Ko Yu and Ly Hia), and lasts for about ten or fifteen days : and the second at the summer solstice. The green tea factors universally agree that the sooner the leaves of green tea are roasted after gathering the better; and that all exposure to the air is unnecessary, and to the sun, injurious." But as all the leaves cannot be roasted at the same moment, means are necessarily resorted to in order to prevent their heating or turning yellow. They are therefore thinly strewed on tiled floors, or placed in flat bamboo trays on stands in shady places exposed to the air, or on the low walls which are commonly seen about Chinese houses and gardens: which process, as the reader will recollect, corresponds with that of Leang Ching, already described under that article. A man or woman occasionally passes round to examine the leaves; and if those at the bottom show the least disposition to heat or ferment and turn yellow, they are then turned, otherwise they are allowed to remain undisturbed.

* Tien IIing observes, if the roasting be deferred till the following day, or if the leaves be exposed to the sun, the veins become red and the flavour is injured. (MS.) 
It must be understood that the different parts of the manipulation of tea, the roasting, rolling, sifting, \&c., are all carried on at the same moment, so that a multitude of hands are employed.

Thus, while some women are employed in preparing the leaves for the process of Leang Ching, others are engaged in picking off any remaining stalks which may be left on them. They are then sifted to rid them of dust and dirt, after which they are in a fit state to be roasted. The Chinese say that the roasting requires a man who understands his business, as the quality of the tea depends much upon this process.

The Hyson Kuo is a thin vessel of cast iron, but differing in form from that used in the manipulation of black tea; being considerably deeper, with sides partly perpendicular, as may be seen in the following plate: besides being fitted low down in the stove.

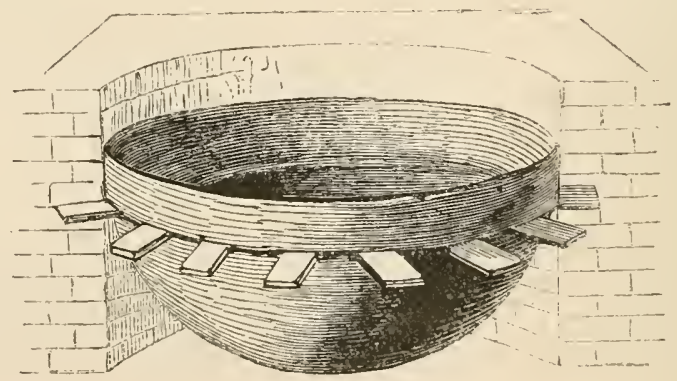

The arms are flat pieces of iron, projecting from the sides of the vessel, by which it is fitted into a stove of brickwork. 'The surface of the 
stove is horizontal, and the mouth of the Kuo is placed above five inches below the surface. The depth of the Kuo is about ten inches, thus forming a depth of fifteen inches from the surface of the stove. The diameter is about sixteen inches. The inside of the Kuo is said to be quite bright from constant friction.

The Twankay Kuo is the same as that used for black tea: but is placed obliquely in an angle of about sixteen degrees, the surface of the stoves being built with that inclination. The Kuo is placed about nine inches below the surface, the depth of the Kuo being about eight inches, and the diameter twenty-four inches. *

I shall now describe the mode in which I have scen the roasting of the honan leaves performed, after the manner of Hyson tea, by men from the green tea districts. The reader will here remember that the same description of leaves were employed in the manipulation of black tea; and indeed the honan leaves are never otherwise employed by the Chinese.

The fire was prepared with dry wood, and kept so very brisk that the flames rose above the surface of the stove. The bottom of the Kuo soon became red hot, and the heat intolerable. This excessive heat, however, was not approved by the conductor of the process. It must therefore be considered as

* See plates in Appendix. 
an example where the roaster wished to display his skill, rather than as one to be imitated. The steam also arising from the leaves was so considerable that I could scarcely bear my hand over it for an instant. This great accumulation of heat and steam, more than in the manipulation of black tea, is solely to

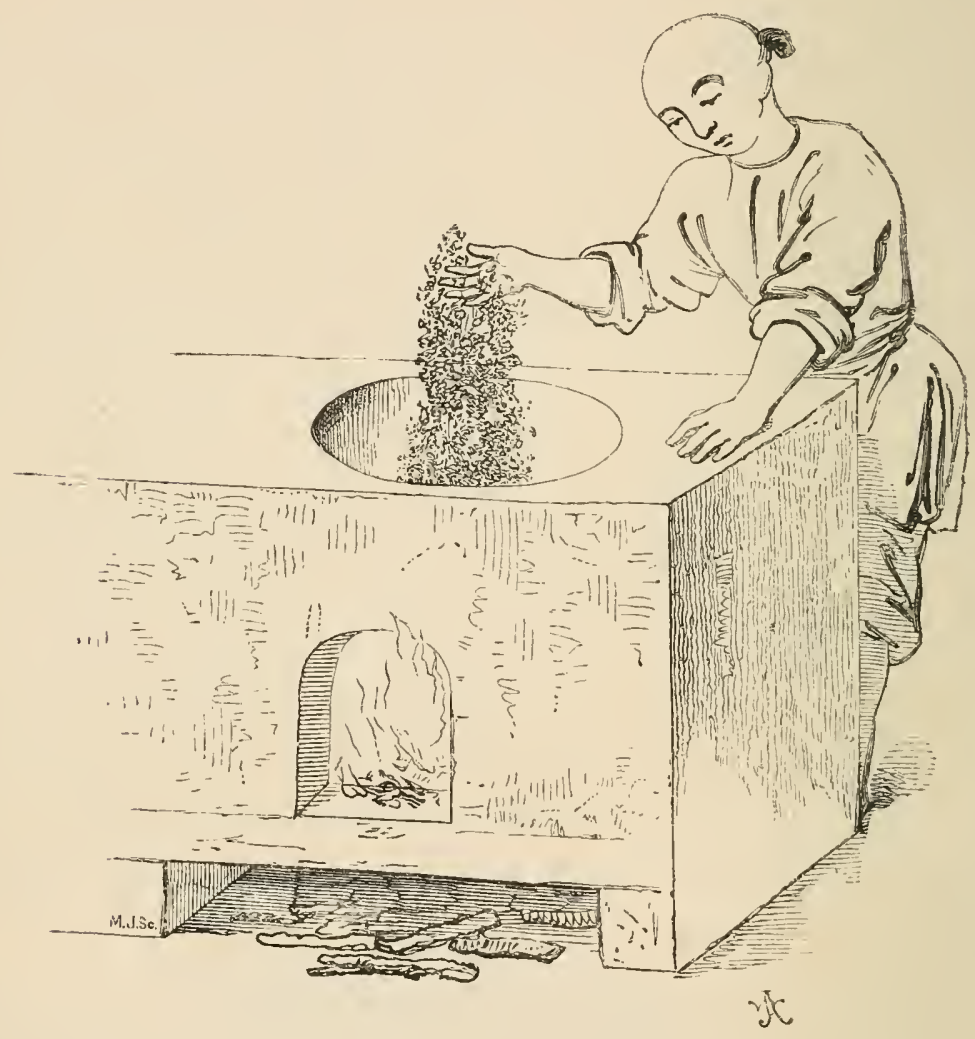

be ascribed to the greater depth of the Kuo from the surface of the stove, thereby confining the steam, and preventing that rapid dispersion of the fluids which takes place in a vessel of flatter construction.

About half a pound of leaves were put into the Kuo at one time, when they produced the crackling 
noise described by Kompfer; and were quickly stirred about, first with one hand, and then with the other; the roaster being frequently obliged to change the hand on account of the excessive heat. For the same reason, almost at the end of every turn, he raised the leaves about six inches above the surface of the stove, shaking them on the palm of the hand to separate them, and to disperse the steam. This process was continued until the heat appeared to be more than the roaster could bear. He then gave them two or three brisk turns round the Kuo, when suddenly collecting them together in a heap, he passed them to another man who stood in readiness with a basket to receive them. The few leaves which remained were speedily swept out with a damp cloth, kept in readiness upon the top of the stove for that purpose.

The process of rolling is much the same as that employed in the rolling of black tea, the leaves taking the form of a ball. After the ball was shaken to pieces, these people twisted the leaves again between the palms of the hands, the right hand passing over the palm of the left, using a slight degree of pressure, as the hand was advanced from the body, and easing it again as it returned, as described under the article Poey (p. 135.); so that the leaves might be twisted regularly, and in the same direction. They were then spread out in sieves, and placed on stands in a cool room.

The sooner the leaves are roasted again after 
rolling the better; but if the roaster have not finished roasting all the fresh leaves, care must be taken to turn those which have undergone the first process of roasting, as the leaves which are at the bottom of the sieves or trays are apt to spoil and turn yellow.

Previously to the leaves being carried a second time to the Kuo, the fire was considerably diminished; and charcoal used instead of wood. The Kuo, however, was still preserved hot enough not to be endurable by the touch for more than perhaps a second. Throughout the whole of this second roasting, great attention was paid to the fire in

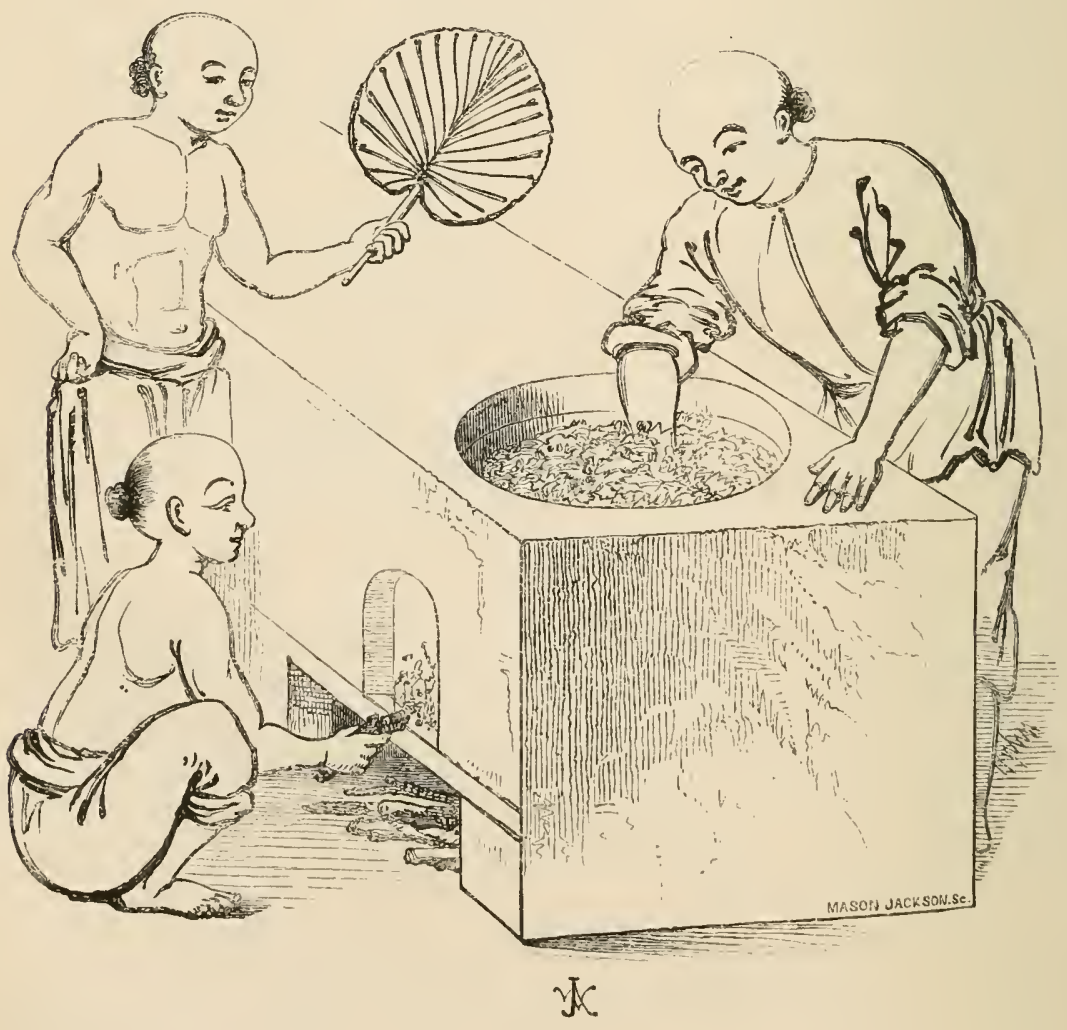


order to preserve an equal degree of heat, a man almost constantly attending it, sometimes increasing and sometimes diminishing the fuel, agreeably to the directions of the roaster. The leaves were also constantly fanned by a boy who stood near.*

In this second roasting, the roaster began by slightly pressing the leaves with the palms of both hands against the bottom of the Kuo; then drawing them towards himself to the top of the stove, he shook them on his hands to cool, and to separate them. As the steam diminished, he pressed the leaves against the opposite sides of the vessel, and drew them round until the hands met, when he raised them, and twisted them, as before described, between the hands. When the leaves have lost so much of their aqueous and viscous qualities as to produce no sensible steam, they no longer retain any disposition to adhere together; but, on the contrary, having acquired a twisted form in the process of rolling, the simple action of the fire naturally disposes them to separate, twist, and curl of themselves. The operation, therefore, of twisting the leaves with the hands, now becomes of minor importance, and consequently the roaster here twisted them but once to every four or five times that he stirred them about in the Kuo. At length

* A Chinese manuscript observes, "In the second roasting the fire must be moderate, and the roasting not hurried. The fanning to hasten the cooling of the leaves also requires constant attention." 
he discontinued altogether this action of twisting the leaves; and the remaining part of the process in this as in the other consecutive roastings was confined to the simple action of stirring them about. This was performed by slightly pressing the leaves against the sides of the vessel, and slowly passing them round, sometimes from right to left with one hand, and sometimes from left to right with the other, turning them over the hand and arm at the end of each revolution. This operation was continued until the leaves became tolerably dry. When taken from the Kuo, they appeared of a dark olive colour, almost black. After being sifted they were placed on stands as before, until the whole of the leaves had undergone the second roasting: when they were roasted a third time.

In the third roasting, which in fact is the final drying, the heat of the fire was again diminished, and reduced to that degree which the hand can bear for some seconds without much inconvenience. The quantity put into the Kuo was greatly increased, and the time of roasting regulated by means of the instrument denominated a Che Hiang. The fanning and the mode of roasting were the same as in the final part of the second roasting. It was now curious to observe the change of colour which gradually took place in the leaves; for it was in this roasting that they began to assume that bluish tint, resembling the bloom on fruit, which distinguishes this tea, and renders its appearance so agrecable. 
Thus it is obvious that the peculiar colour of green tea does not properly arise from the admixture of colouring matter with the leaves, but naturally out of the process of manipulation. Indeed, if we reflect a little, it must be evident, as before observed, that it was quite impossible that Europeans could suggest to the Chinese to colour their teas blue. There must have been some foundation for this practice originating with the Chinese themselves. As a close twist and curl of the leaf is one test of superior quality, so also is brightness of colour. The factitious colouring; then, of green teas has originated with the Chinese to give a spurious superiority to inferior teas: and it must be acknowledged that foreigners have been too easily duped by these deceptions. It would be wiser to appreciate strength and flavour more, and colour less. It has been shown that the Hoa-king, a Chinese herbal published in 1688, speaks of Singlo tea being of a bluish green colour. Again, Mr. Jacobson *, in describing the change of colour which takes place during the process of roasting, states:- "Now the colour becomes greener and brighter; but, properly speaking, the infused leaf only is green, the dry leaf is bluish. As the drying progresses, the leaves assume a light blue tinge, resembling the bloom of grapes." But we shall furnish proof of this fact a little later. The factors say that the true colour is not thrown

* Handboek, \$ 456 . 
out until about a month after the tea has been roasted. No rest can be afforded the workmen until this colour is produced; for not until then are the leaves properly dried. The three roastings occupied about ten hours, and the original quantity of leaves, $33 \mathrm{lbs}$. ( 25 catties), required the constant labour of one roaster.**

In this state, the tea is usually packed in chests in the tea country, and called Mao Cha, from its being unsorted. The Ching Cha is the Hyson tea, after the IIyson skin, young Hyson, and gunpowder have been separated from it. Both kinds are sold in the tea country, though it is commonly sold by the farmers and peasantry in its gross or unsorted state of Mao Cha; and from the samples

* In the tea country, it appears that the Mao-cha or unpicked tea undergoes but two roastings instead of three. Nor are any more necessary, if care be taken to moderate the fire as the leaves dry. 'This slow process of drying at a low temperature seems essentially requisite to the production of the delieate bluish colour of the leaves, significantly termed bloom by the dealer's in England. The fanning also accelerates the formation of the colour, as well as the drying process, by a quick evaporation of the fluids. I found by experiment that the colour could be produced without it, but less expeditiously. I also found that the taking the leaves off the fire, just as the colour was about to form, and suffering them to cool a little, had a tendency to produce the same effect, when the roasting was again resumed; but the use of the fan was preferable. Kompfer observes, that the Japanese fan the leaves for the purpose of cooling them, and of fixing the curls; but describes this process as taking place during the rolling (Japan, Appendix, p. 11.) I am disposed to think that Kompfer may have failed in his usual accuracy on this point; and that the famning took place during the roasting, or at any rate in both instances. 
of this tea which I have seen at Canton, I imagine that many Hysons are sold to foreigners in this state without any further sifting or separation.

"In about a fortnight," Tien Hing observes, "every farm has completed its harvest, and sends its tea to market; at the same time the numerous factors attend the different villages to make their purchases. There are all the various kinds of tea sold, the Mao Cha, the Ching Cha, the picked, the unpicked, the garden, and the hill tea; and the different kinds of Singlo tea; so that it requires a complete acquaintance with the leaf and colour to be enabled to make a judicious selection. When the factors have concluded their purchases they carry their tea home, where it is sifted, winnowed, and assorted into different kinds suited to the foreign markets.

"The large closely twisted leaves, of nearly equal size and brightness of colour, form the Hyson tea.

"The large, open, or coarsely twisted leaves, and also the large, round, knobby leaves, of nearly equal colour, form the superior Hyson skin teas; and the thin twisted leaves of good colour, with the yellow and broken leaves, the middling kinds.

"The small, round, closely curled leaves, which are bright in colour, form the round gunpowder; and the still smaller and more closely curled leaves, the Che Ma, the hemp-seed, or small imperial gunporvder. 
"The broken leaves, which are very thin and small, and of a wiry nature, form the U Chien, or young Hyson.* The fine dust, and part of a kind of chaffy dust, is sold in the tea country; also at King-te-ching + , the celebrated town for the manufacture of porcelain, and other places. The remainder of the dust is mixed with common Hyson skin."

I shall now describe the manner in which I have seen this process performed with the honan leaves; the roasting of which has already been described. The leaves were first sifted in a fine sieve, and passed a kind of dust, similar to that which is described as being partly sold in the tea country, and partly mixed with Hyson skin.

The returns of the first sieve were again sifted through a second and coarser sieve, and passed the young Hyson, which was tossed or winnowed on a large circular bamboo tray, and threw off a flat chaffy leaf, which was also disposed of by mixing with Hyson skin. It was then roasted about fortyfive minutes (one che hiang), the heat of the Kuo being the same as in the last roasting, when it was winnowed as before, and fanned off more of

* Mr. Reeves justly observes, "the difference between the gunpowder and the young hyson will be this: when fairly made the young leaf which takes the long twist will form the young hyson; and that which takes the round twist will form the gunpowder." (Parliamentary Papers, 1813. Evidence on East India Company's Charter.)

$\dagger$ Lat. $29^{\circ} 15^{\prime}$ N., long. $47^{\prime}$ E. of Peking. 


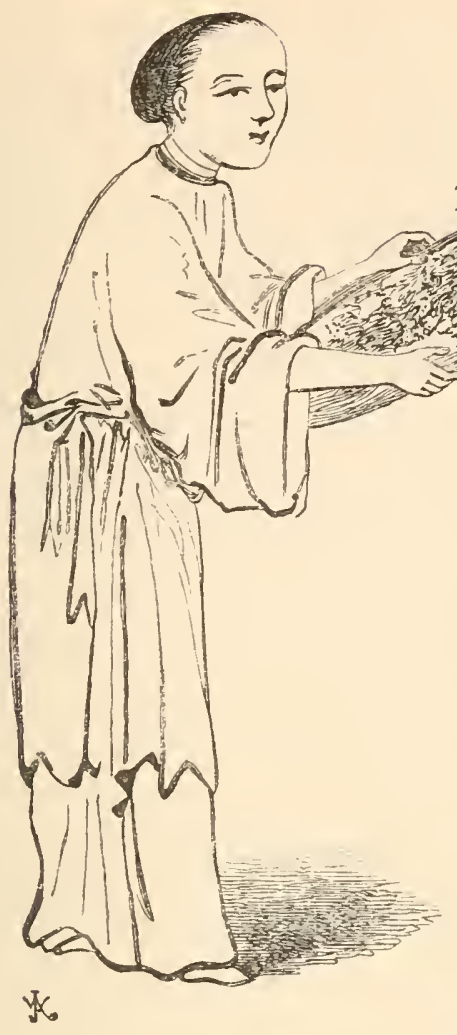

that quality called Hyson skin. It was then packed, and formed what in the tea country would have corresponded with the best kind of young Hyson. The skin fanned off in this

last process was of a superior kind to the former, the leaf being better twisted. The flat and coarse leaves were therefore picked out by hand, and the residue formed an inferior kind of young Hyson.

During the above process of sifting and roasting the young Hyson, other men were employed in winnowing the remaining leaves to separate the skin from the Hyson. It is here necessary to observe that only the light, flat, chaffy leaves are fanned off in this process, so that the round knobby leaves, the yellow twisted leaves, and the coarse leaves, still remain mixed with the Hyson. The whole of the remaining leaves were therefore all 
poured upon a table, and four persons were employed in picking out, leaf by leaf, the remaining Hyson skin leaves. This operation is in the tea country performed by women; and it is, most probably, from a drawing of this nature, which generally accompanies the descriptive drawings of the manipulation of tea, that the error has arisen, that each separate leaf has passed through the hands of a female, by whom it was twisted and curled. The leaves, thus separated, were mixed with chaffy leaves, and roasted forty-five minutes. The dust was then sifted, and the tea packed, forming what might be termed fine Hyson skin.

The remaining leaves, consisting of the even, the well twisted, and bright leaves, formed the Hyson tea, which was roasted one hour and a half, then sifted, and afterwards packed. This tea, supposing the leaves to have been gathered from shrubs equally good with those of the tea country, would have been equal in quality to the chop Cow Mow, and teas of that class, for which the East India Company usually paid 44 tales the pecul, or $2 s$. $3 d$. the $1 b$.

The finest Hysons, such as the chops or breaks, Tien-Hing, and Lum-Hing, or teas for which the East India Company paid 64 tales the pecul, or $3 s$. $2 d$. the $1 \mathrm{~b}$., undergo a still further selection, until all the open and pale leaves are picked out, in the same manner as the skin is separated from the Hyson; so that the "superior Hysons" require much labour and attention, and are expensive to 
make. It obviously follows, also, that no tea of this description can be brought to market, without increasing, at the same time, the middling and common Hysons, so that if an extensive sale did not exist for middling teas, none of the superior kinds could be made; for it is difficult to conceive of any price which foreigners would be willing to pay, which would afford an adequate compensation for the labour of making the fine teas only. Indeed, if any reliance can be placed on the reports of the Hyson merchants, the Hyson tea grown in garden soil is much affected by the fluctuations of the foreign markets; so that the shrubs are rooted up and planted again just as the demand increases or diminishes, which may have some foundation, in truth, when it is considered that these teas are principally made for foreign consumption; and that these shrubs occupy a rich and fertile soil, easily convertible to other purposes, and too valuable to be permitted to remain idle.

The tea in question yielded very few knobby skin leaves, and nothing that could properly be termed gunpowder. There were a few round leaves, closely rolled up and knitted together, resembling that tea, but so small and flat as to be useless. This inferiority was ascribed, as in the leaves made into black tea, to the general smallness and want of substance of the Honan leaves. It must also be observed, that the colour was greatly inferior in brightness to the tea usually imported 
into England. In fact, it had somewhat the ap. pearance of being artificially coloured, or, what is technically termed, glazed. It, nevertheless, produced none that could with propriety be termed yellow leaves.

Having now deseribed what I have seen myself, I shall proceed to relate what I understand to be the practice adopted in the Hyson districts for the separation and classification of the different kinds of Hyson tea. I have twice seen a chest of Mao Cha sifted at Canton, but I found it difficult to note down the process, on account of the confusion which was created by all the different parts being carried on at the same time, and from the number of hands employed. Eight or nine persons were all at work at the same time; some sifting, some roasting the leaves, others fanning off the skin with a tray, some winnowing with a machine, and others picking out the skin leaves; and, though I stopped the men occasionally, and took samples through every stage of the process, as well as noted down every particular at the time, yet I will not be answerable that no mistake was made. The accounts, as they were taken, will be found in the Appendix. In this examination I was aided by my friend and colleague, Mr. John Reeves, whose statement I have adopted as being more minute, and, I believe, more accurate than my own. My present observations will, therefore, be the result of general inquiry, and what I have been enabled to collect at 
different times, as well as what I witnessed on the occasions here alluded to.

The factors say, that when they have concluded their purchases, and brought home their Mao Cha, they roast it three che hiang (two and a half hours), and then pack it in canisters. In the course of a month it is sifted. 'The number of sieves used are four ; the three first retain the Hyson, and the fourth the young Hyson; the round gunpowder is picked out from the third sieve; and the che-ma (hemp seed), or imperial gunpowder, is winnowed from the fourth by means of a machine. Though it is usual to speak of four sieves, yet the number used must evidently depend upon the size and quality of the leaves, as in all other parts of the process. I understand that seven sieves are commonly used in the Hyson districts; five and six I have seen used myself: and the reader will remember that the Honan leaves, from the thinness and poorness of the leaf, required only two. Nor must the writer's words be taken literally; for all that the Chinese mean by four sieves being used is, that the tea is first divided by means of four sieves into five principal divisions; and not that only four sieves are used. The order, too, in which the sieves are used, differs from that about to be described; the coarsest sieves being used first in the Hyson country, agreeably to the foregoing account, whilst the finest were employed at Canton to exhibit this process to me. 
The first and finest sieve sifts the Mao Cha, and passes young Hyson, Che Ma (hemp seed) or smallest gunpowder and dust, which we will call No. 1.

The second sieve sifts the returns of the first sieve, and passes the small leaves of the Hyson tea, and the large round gunpowder, No. 2 . The third sieve sifts the returns of the second sieve, and passes the middling sized leaves of the Hyson, No. 3.

The fourth sieve sifts the returns of the third sieve, and passes large Hyson leaves, No. 4 ; and returns still larger leaves, No. 5 .

No. 5. The largest Hyson leaves are then roasted until the requisite excellence of colour is produced, two or three catties (from three to four pounds) being put into the Kuo at one time, the heat of the Kuo being about $90^{\circ}$ of Fahrenheit. They are then winnowed, whilst hot, with large circular bamboo trays, when a chaffy kind of skin, or large dust (No. 6.), is fanned off. The leaves are then strewed upon a table, when the large open leaves, and large knobby leaves, are picked out by hand, and form the finest description of Hyson skin.* The remaining leaves are Hyson.

No. 4. The large Hyson leaves are next roasted, the fire being somewhat diminished: they are then winnowed, when the same kind of dust is fanned

* Pretty good bloom, brightish Hyson kind mixed, knobby leaf. 
off as before, which we will also call No. 6. The tea is then hand-picked, and yields knobby and other fine skin leaves*, the residue being Hyson. $\dagger$

No. 3. The middle-sized Hyson leaves are now roasted, the heat of the fire being again diminished, and the tea not roasted quite so long. They are then winnowed, when a middling quality of skin is fanned off $\ddagger$, leaving the Hyson as before.

No. 2. The smallest Hyson leaves are then roasted and winnowed, when a small, thin, twisted skin leaf is fanned off.§ The residue is hand-picked, to select the round gunpowder leaves; and the leaves that remain are Hyson.

No. 1. The young Hyson and small gunpowder leaves are now winnowed by means of a machine called a Fong Kuey, which is the same used to separate the chaff from wheat, both in China and in England. It is a well known fact that we are indebted to the Chinese for this machine; it is said to have been first introduced into Belgium, and thence into England. leaf.

* Middling to good middling, bloom brightish, mixed knobby

$\dagger$ Middling bloom, brightish twisted leaf.

$\ddagger$ But middling to middling bloom, small twisted wiry leaf.

$\S$ In the process of winnowing Nos. $4 . \& 5$., besides the chaffy dust that is fanned off, there is a light wiry kind of skin, or dust, which is projected towards the extremity of the winnowing tray. This is skimmed off by hand, and mixed with the chaffy dust, and sold in the tea country, though sometimes mixed with Hyson skin. 
Those used for tea, some people say, have three side mouths, besides the large one in front. The heaviest leaves fall through the side mouth nearest the fan, and so in succession, according to their gravity; the chaff and dust being projected from the mouth in front. The mouth of the hopper is regulated in an ingenious manner by a lateral piece of wood, the handle of which rests on a longitudinal slide, which widens and closes the mouth at pleasure. As this machine has great power, the handle of the fan is turned very slowly.

The first process is to separate the young Hyson from the small skin and dust with which the tea is mixed. For this purpose, the mouth of the hopper is nearly closed, and the tea thus winnowed four or five times. In the first winnowing, the tea which falls through the second mouth is a chaffy dust mixed with fine dust; and nothing but fine dust through the front one. In the other winnowings, the tea which falls from the second mouth is now mixed with a heavier skin, and that projected from the front mouth mixed with chaffy dust. After winnowing, the young Hyson is sifted again through the same sieve as before, and a large twisted leaf mixed with skin is skimmed off the top; the residue forming the young Hyson. The mouth of the hopper is now widened, and the young Hyson slowly winnowed again; when the che-ma, or small imperial gunpowder, falls through the first mouth, and the young IIyson through the second. During 
the roastings of the Hyson tea, which take place at this period of the siftings and classification, great attention is paid to the colour; and, though the roastings are regulated by the measure of time designated a che hiang (the one I tried burnt forty-five minutes), yet that instrument is used more as a guide than a rule; for, as the time of roasting draws to a close, each parcel is frequently compared with a sample kept for that purpose, and the roasting increased or diminished as the colour approximates to that of the sample. The superior Hysons (as Tien-Hing and Lum-Hing) are afterwards picked from the third and fourth sieves. It is hardly necessary to observe that the more the teas are roasted the closer becomes the curl.

The teas being now assimilated in colour and leaf and properly assorted, are arranged according to their classes of Hyson, Hyson skin, young Hyson and gunpowder; and these classes again arranged and mixed agreeably to their qualities, which are noted down previously to packing the tea in canisters.

In about the sixth or seventh moon (July or August), the tea harvest being concluded, the qualities of the aggregated purchases are further arranged, and the teas of suitable and nearly equal qualities are started into a heap or pile in sufficient quantities to form a chop or parcel of one uniform quality, which in Iysons is about one 
hundred or more chests. The quantity packed in each chest is previously weighed, that the weight may be uniform. The green tea is not trodden down with the feet, but is packed by simply striking or shaking the chest against the ground. The Hyson tea is said to be roasted three or four che hiang previously to packing, and the young Hyson ten. The tea is packed hot. The gunpowder and Hyson skins are said not to be roasted previously to packing; but that, of course, must depend upon circumstances, whether they require it or not.

In this manner are the Hyson teas made, whether the produce of the hills or the plains, as also the Singlo Hysons and "Superior Twankay." The latter have frequently a glazed appearance, as also the Singlo gunpowders, which I imagine may formerly have arisen more from the quality of the leaf, than from any factitious means employed to produce the colour. Still, in some cases a small quantity of colouring matter may have been used. It has also been shown that the tea made from the Honan leaves had a glazed appearance. It nevertheless is true, that when the leaf is deficient in the requisite colour the Chinese do not hesitate to employ colouring matter to improve it. Those Hysons which have a Singlo or Twankay flavour are more or less mixed with Twankay teas, the greater part of the Hyson skins, particularly those which are yellow in leaf, are wholly of that descrip- 
tion. The yellow leaf in Hyson partly arises from the age of the leaf, and partly from such leaves being of the second gathering; but principally from some circumstance connected with soil.*

\section{SINGLO OR TIVANKAY TEA.}

The Singlo or Twankay tea is grown in the districts of Hoang Shan, Tuon Ky (Twankay), Thie Ping, and Ning Kuo, in the province of Kiang Nan; the manipulation of which does not differ essentially from that of Hyson tea, but is performed with less care. And as I have already given a circumstantial account of the mode of preparing that tea, the following translation of a document procured from a respectable tea merchant or

* Some of the Chinese say, that good Singlo tea cannot be distinguished from Hyson; and some of the dealers in England have thought some chops of "superior 'Twankay" to approximate to Hyson, as may be seen by their characters, viz., "pretty good Twankay, brightish curled leaf, Hyson kind of leaf and flavour."

The chop, Lum-Hing, frequently the finest chop of Hyson of the season, had occasionally a tendency to Twankay flavour, which most probably arose from some peculiarity of soil, which improved cultivation could not subdue. I was informed that this tea grew in the Twankay district. Since the tea plant is propagated by seed, or by transplanting the wild shrub in favourable soils, it is highly probably that the young plants may long retain their original flavour, though under improved cultivation, and in some cases never entirely lose it. 
factor, Tien Hing, will suffice to describe the mode of making the Twankay tea.

He observes - "The Singlo tea is grown in all parts of Kiang Nan, but Hoang Shan, and Tuon Ky produce the best. The leaves begin to bud every year in about the 5th of April (Tsing Ming), and are gathered about the 20th of April (Ko Yu). It is gathered by whole branches at a time, and the leaves and stalks are afterwards stripped off rudely with the hands. It is then roasted in a Kuo, and rolled indifferently with the hands or feet.* It is gathered and roasted every day, and sold as soon as made. The factors who purchase it, carry it home, and roast it again two or three hours, when it is sifted (to take away the dust) and packed in canisters. Some of the factors use charcoal, others wood; and there are some petty dealers, who do not roast it immediately, but pile it up in their houses and afterwards roast and pack it. $\dagger$ It is sifted through four or five sieves.

* I have seen tea rolled with the feet with almost the same dexterity as with the hands, always kecping the leaves well collected together in the form of a ball. The use of the feet, however, is only employed as a relief to the hands and arms when tired; and I believe principally practised with inferior teas.

$\dagger$ That is, they do not roast and pack it in canisters as it is purchased of the farmer, but keep their daily purchases in their houses until they have a sufficient quantity to make a parcel of 500 clrests, when they roast, sift, and pack it at once for the Canton market; which is a careless and a bad mode. 


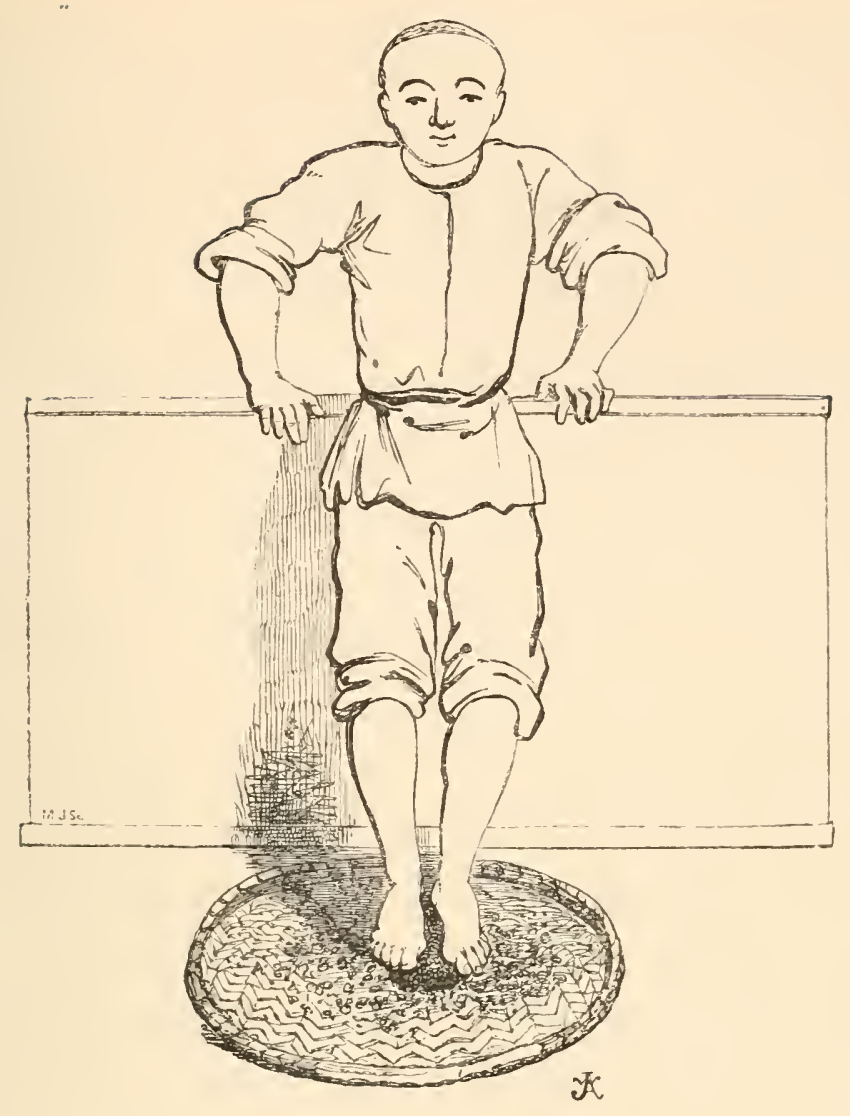

While the sticks and stalks are being picked out by hand from the first sieve*, the tea of the second

* Here, the order of the sieves is again reversed, the coarse sieves being the first used. I shall here describe the manner in which I saw a chest of Twankay sifted at Canton.

The leaves were first sifted through a fine sieve, which passed the young hyson leaves and dust, No. 1.

The returns of the first sieve were sifted through a coarser sieve, and passed Twankay small leaves, No. 2.

The third sieve sifted the returns of the second sieve, and passed Twankay, No. 3.; and returned the large leaves of the Twankay, No. 4. 
and third sieves is roasted. The fire must be brisk, and the change of colour carefully watched. The stalks (remaining) on the leaves must be plucked off by hand. The fourth and fifth siftings are also roasted over a strong fire. They are then taken from the Kuo and tossed or winnowed. Women are now employed to pick them clean. Each parcel is then carried to the Kuo, and roasted four or five che hiang. The colours are then assorted, and the tea packed in canisters. The colour of the leaves is now of a bluish tinge, and the tea pleasant in smell and flavour.

"In the seventh or eighth moon (August and September) each parcel is compared together, when such as correspond in quality and colour are formed into one pile*, roasted three che hiang, the dust sifted, and the tea packed [hot] in chests for Canton. The leaves of the second gatherings have no juices,

No. 2. was roasted and winnowed on bamboo trays, and threw off a chaffy skin and dust, which is sold in the tea country.

No. 3. was treated in the same manner.

Nos. 2. and 3. were then hand-picked, from which were taken a vast quantity of sticks and stalks, many an inch long, and of a hard and ligneous character.

No. 4. was roasted longer than the other parcels of leaves, and the heat of the fire increased. It was then hand-picked to take away the large skin leaves, which were mixed with Hyson skin.

* The usual quantity packed at one time is about 300 chests, and two of these packings constitute a chop or break. Some chops consist of 1000 chests, each chest weighing about $80 \mathrm{lb}$. 
are light, thin, and of no substance; the infusion weak and tasteless; the colour red; and the infused leaves black. If very common and old, colouring matter is then used; and the tea is kept in the ****. $\dagger$ The factitious colour is produced by a mixture of Ma Ky Hoey $\ddagger$, Tien Hoa (Indigo), and She Kao powder (calcined foliated gypsum). The smallest quantity put into the Kuo at one time is one or two tea-spoonfuls; and the largest three or four. The colour then changes to a light blue.§ The fire must be made of charcoal, and much attention paid to the roasting. Now, if the chests be not in readiness, it is to be feared the tea may be mixed with false leaves, the smell thereby injured, and the tea rendered unhealthy. But I must refer you to abler men than myself for

$\dagger$ Here follows some obscure expression which has an allusion to the mode practised by petty dealers mentioned before.

$\ddagger$ I am ignorant of the botanical name of this plant.

$\S$ The mode in which I have seen Twankay teas coloured is as follows:- The gypsum was the foliated kind, calcined, and reduced to a powder. It was then mixed in equal parts with Chinese Indigo, also reduced to a powder. A common saltspoonful is enough to colour four lbs. (three catties) of tea. The colouring matter may be added at any time after the teas are completely roasted and made. It is usually added in the last process of roasting, whilst the tea is hot: but if the tea be cold, it must then be roasted a few minutes till quite hot, when the colouring matter is sprinkled over the leaves. The tea is then briskly worked round the Kuo with the hand, and the change of colour attentively watched, for the colour will be injured if the tea be roasted too long. 
instruction on that point. I have no information on such practices."

It may here be observed, that most other merchants or factors agree with the foregoing account of the Twankay teas; and particularly as to the circumstance of their being partly glazed or coloured by factitious means; and, also, that some chops are mixed with leaves which are not tea leaves. Others say, that some leaves are simply dried in the sun. A factor furnished me with the following account of the mixture of his tea, which was generally classed in the first class of contract teas purchased by the East India Company :-

Two parts of the first gathering of common Twankay shrubs from Tuon Ky, Hoang Shan, and other places.

Two parts of the second gathering, ditto.

Three parts of leaves produced at Thie Ping, which is an unfavourable district, and where teas are always glazed, and some dried in the sun.

The chop Hong Sing (a well known and much esteemed chop) was frequently what in my time was considered very much glazed; but which in the present day would be called unglazed. Thus, the Twankays imported into England consist of a mixture of leaves of inferior shrubs gathered in a careless manner, some by whole branches at a time; are indifferently rolled with the hands or feet; some merely dried in the sun; and all mixed more or less with tea coloured by factitious means.

It may now be remarked, that it was long an 
established opinion in Europe that green tea derived its grey or bluish appearance from being dried on copper. The preceding accounts demonstrate that such an opinion is altogether unfounded. The same colour can be produced by drying the leaves in a copper vessel, as I have proved by experiment; but the tea thus dried appeared to me to partake of the flavour of the vessel; and consequently a vessel which produces a flavour so objectionable is not likely to be employed. Nor does this peculiarity of colour arise from any metallic influence of the vessel in which the leaves are roasted, for I found by experiment, that the same bloom-like colour could be produced in an earthen vessel.

The reader will now remember, - and I wish to draw his attention particularly to this fact, - that one of the inferior methods of completing the final desiccation of black tea was by means of the iron vessel denominated a Kuo, in lieu of the poey long or drying-tube commonly used: which inferior method does not seem essentially different from the mode now described of making green tea. In order therefore to discover to what so great a difference of colour, produced by means almost similar, was due, I went through the following experiments.

1. I put a small parcel of Honan leaves into a common culinary kuo, and after having roasted and rolled them twice, I divided them into two parcels. I then completed the roasting of one parcel with as fierce a fire as I could bear, keeping 
the leaves in constant motion in the kuo: and of the second with a moderate or slow fire in the same manner ; and in both cases green tea was produced; but the colour produced by the slow fire was preferable.

2. After the second roasting and rolling of another parcel of leaves, I divided the kuo into two equal parts by means of a thin partition of wood fixed in the centre; and then placed an equal quantity of leaves on either side of the wood. The one I kept in constant motion, the other in as quiescent a state as possible, consistently with the leaves not burning, as in the inferior method already described of drying black tea. The leaves kept in constant motion dried rapidly, and soon assumed the colour and appearance of green tea. The other parcel required a much longer drying; and when completed assumed the colour of black tea.

Thus the difference of colour in black and green teas does not appear to be derived from any management of heat, but from manipulation; the heat being the same in both cases. I therefore conclude that the colour of black teas, when roasted in the manner herein described, arises from the quiescent state of the leaves during the final desiccation; and that of the green from incessant motion - the formel producing a slow, and the latter a quick evaporation of the elastic fluids. The fanning of the green tea seems also employed 
for the same purpose; and it obviously may be surmised, that the freer admission of light and air may work very considerable chemical effects, altogether sufficient to account for the different results in these two processes.

So far as the characteristic colour of green tea is concerned, the mode of producing it has here been explained and established. If factitious means are now generally or almost universally adopted to imitate or to increase the effect of the natural colour, it may be considered as a great and novel abuse, and ought to be discouraged by brokers and dealers. It is injurious to flavour. Whether the Chinese do employ colouring natter or not for the teas they use themselves, there can be no doubt that the bulk of the Hyson teas of the present day, and, indeed, all descriptions of green tea, are now glazed to a degree that would have insured their rejection by the agents of the East India Company during the existence of their charter. Mr. Warington, chemical operator of Apothecaries' Hall, published an interesting paper in the "Memoirs of the Chemical Society" read February 1844, proving by chemical examination and analysis the fact, that the Chinese green teas are artificially coloured with ferrocyanide of iron or prussian blue, and sulphate of lime or gypsum - the greater part with the two combined, some few with sulphate of lime only, and some with a yellow or orange-coloured vegetable sub- 
stance, but none with indigo as represented by the green-tea merchants.

On what the colour of black tea more particularly depends, when manipulated with care, I shall attempt in a subsequent chapter to explain.

I next tried some experiments to ascertain how far the agency of steam might be rendered subservient to the inanipulation of tea: but having no other instruments at hand, than the rude vessels already described, I had no means of confining the steam, except with cloths, and thus endeavouring to raise the heat above the boiling point. For the first part of the process, the heat of boiling water so employed was not sufficient to produce the crackling of the leaves described by Kœmpfer : nor a sufficiently quick evaporation of the fluids, so that it required considerable force to express the remaining juices before the leaves could be perfectly rolled. For the final drying of green tea, it seemed to answer, and might perhaps be used with advantage. It is necessary, however, to lower the heat of the water as the leaves dry, for I found by this experiment that the heat produced by boiling water was too great for the final desiccation of green tea.

With respect to machinery, it is obvious that sifting machines, in lieu of sieves worked by hand, might be employed with advantage in separating the different kinds of leaves of green tea, in addition to the winnowing machine already used for the purpose of separating the young Hyson and 
imperial Gunpowder. Other simple contrivances might be invented. Mr. Jacobson of Java has invented an instrument, a kind of cylinder, for the purpose of turning and tossing the leaves (Toching) especially after rainy weather, previously to roasting. * He has also intimated his intention of inventing an instrument to perform the whirling motion which takes place in the sieves analogous to the tossing and tumbling the leaves with the hands. Novel modes of producing and regulating the heat, and even of drying the leaves, may be devised; but it is important first to learn, and render familiar, the Chinese methods, before any experiments are tried which are likely to affect the quality of the tea.

* See plate in the Appendix. 


\section{CHAP. X.}

HEAT EMIPLOYED IN THE MANIPULATION OF TEA IN CHINA AT JAVA - ABSORPTION OF HEAT BY THE LEAVES LIMITED BY EVAPORATION - PROVED BY EXPERIMENT - CAUSE OF LEAYES NOT BURNING - AMOUNT OF HEAT REGULATED ACCORDING TO THE SUCCULENCY OF THE LEAVES - HEAT EMPLOYED AT JAVA TOO LOW FOR GREEN TEA-DIFFICULTY IN DETERMINING THE REQUISITE AMOUNT OF HEAT — TEMPERATURE RECOMMENDED - USED AT JAVA - MODE OF MEASURING IT LIABLE TO ERROR.

Having now described the mode in which the black and green teas are prepared for general consumption, it may be advisable here to make a few observations on the ordinary temperature employed by the Chinese in the manipulation of tea, as well as on the heat employed at Java.

For the first part of the process of manipulation by the application of heat, and so long as any juices can be expressed in the act of roasting, I have usually employed the word "Roasting," and for the remaining and final desiccation I have used the term "Drying." In this sense we will henceforth more precisely employ these terms.

Now in the first part of the process of roasting the finest Souchong tea, denominated Paochong, we have seen, that the Chinese do not hesitate to employ so high a temperature as the red heat of 
iron; and in order that this may not seem, or be mistaken for, exaggeration or error, it may be advisable now to state, that the knowledge of this fact is derived from too many independent sources of information to leave any room for doubt.

Mr. Bruce at Assam states*, that the Chinese there affirm, that a red heat is employed in China for, the manufacture of Paochong tea. Mr. Reeves possesses Chinese papers corroborative of this fact. I also have several Chinese documents (See chap. vi. p. 103.) procured from different persons, all conclusive on the same point, besides having been on two occasions an eye-witness of the red heat having been so used by different men, both from the green and black tea districts. It is necessary, however, to advert to the form of the vessel in which tea is roasted. It is not flat but concave; and it must be borne in mind, that it is only the extreme point or pole of this concavity, which is somewhat flattened, that is even permitted to attain that high temperature. This heat is also a dull red heat, though visible by daylight, and not extending more than six or eight inches in circumference from the central point of the pan or vessel. Further, the vessel is fitted into the stove in a slanting position, having an angle of about fortyfive degrees. Thus the leaves which are simply dashed and tossed against the heated part of the

* Journal of the Asiatic Society of Bengal, vol. viii. p. 504 . 
iron vessel in the process of Ta-ching, fall down immediately to its extreme edge and the sides of the brick work, which of course are less heated. Positive contact, therefore, as in some analogous cases, may not take place, or be only momentary. It is observed by Brande, that " if a little water be carefully dropped into a platinum crucible, heated nearly to redness, the water lies quietly upon the metal, so long as it is prevented coming into perfect contact with it by the interposed layer of steam; but as soon as the crucible cools down so as to admit the water to touch it, it instantly boils off." * In this example we seem to have strong evidence of the nonconducting power of steam; but as here the almost quiescent state of the water is a necessary condition to the success of the experiment, whereas the tea leaves are kept in constant motion, it may be, that the true cause of their not burning is due to a rapid conduction of heat, which takes place through every particle and pore of the leaf, by the sudden and copious generation of steam which is thus called into action; as in a well known and familiar experiment, heat by rapid conduction may be transmitted innoxiously through a sheet of paper, whereas if slowly conducted the paper ignites.

But whether one or both of these causes may operate, or to whatever cause the effect may be

* Manual of Chemistry, p. 158. 
ascribed, it is obviously due to a copious and rapid evolution of steam that the leaves do not burn. Still after much thought and inquiry, I am disposed to believe, that the red heat is never intended to be used for the green tea, nor even for the black, which forms any part of European consumption. Yet in the rude manner in which the Chinese regulate the heat, especially in the first process of roasting, when dry wood is used instead of charcoal, it may occasionally happen, as in the instances which I saw, that the roasting vessel may attain a very high temperature, if not red heat. Mr. Jacobson of Java states, that the "Kwalie" or roasting vessel becomes red hot in a quarter of an hour, and cools as rapidly. In fact, from the excessive thinness of the vessel, "not exceeding a line in thickness in the thickest part,"* and the means employed to heat it, there is a real difficulty in maintaining any fixed or equable degree of heat. It necessarily must be, from the means employed, a varying quantity having a considerable range. In fact, it is in the dexterous management of the leaves under these varying conditions of temperature that the skill of the roaster is displayed. A difference of twenty or thirty or even fifty degrees of heat is, I believe, of little importance during any part of the process of roasting. With respect to the amount of heat

* Handboek v. de Kult. en Fabrik. v. Thee. § 374. 
required, some vague and general idea may pe given, but nothing fixed or positive. There must be no lack of heat, that is the main point; the management of it must be left to the skill and judgment of the roaster. If excessive, he can compensate for this excess by increased action, or other expedients within his reach; but if deficient, his power is paralysed and his skill lost. Science may suggest much in reference to the maintenance of a fixed and equable temperature, with easy modes of raising or lowering it at pleasure, but the control of it may ever remain dependent on the skill of the operator, unless indeed new methods be discovered, which is by no means improbable. There are many experiments which in due season may be tried in the manufacture of tea, by which similar results may be obtained by less elaborate means; but the time is not yet arrived. Let it be the object of every cultivator and experimentalist to well introduce and disseminate the Chinese methods before any such experiments be made. These remarks, however, do not apply to simple abridgements of labour by mechanical means.

On the other hand, Mr. Jacobson states that at Java all tea is roasted at a temperature below the boiling point (ib. $\$ 379$. ), and it must be acknowledged that teas of good quality are now made at Java. Still I am disposed to think that the heat employed there is of too low a temperature, or that some error may exist in that intelligent author's 
mode of estimating the temperature. In China, judging from what has come under my own observation as now described, and from certain experiments which I have recently made in this country with other leaves, I feel little hesitation in affirming: that, with the exception of Pekoe tea, a temperature of from 300 to 400 degrees of Fahrenheit is used in the first roasting of all tea of good quality whether green or black. In fact, one may be almost justified in concluding that the Chinese consider no temperature too high in this stage of the process, so long as they can manage the leaves and keep them free from burning.

Thus finding it difficult to reconcile the high temperature employed by the Chinese in this art with the power of manipulation, since the men's hands were neither burnt with heat nor scalded with steam, but seeing at the same time the rapid and copious evolution of vapour which arose from the leaves, I was induced to suspect, that they could not attain a degree of heat approaching the boiling point. It is familiarly known that steam given out under the ordinary pressure of the atmosphere cannot acquire a higher temperature. I therefore tried the following experiments, which were made with as much care as an unpractised hand could perform them.

The occasion was one of those before alluded to, when I saw black tea roasted by a man from Fokien. The vessel was heated to a high temperature, but not 
to red heat. The thermometer used was one of Fahrenheit, graduated only to the boiling point; I could not obtain one graduated higher, or one the bulb of which could be laid bare. On approaching the bulb of the thermometer carefully, and placing it against the inner part of the iron vessel, but remote from the centre or part most heated, the mercury rose instantaneously to the utmost range, so that I was obliged immediately to withdraw it. This example may be sufficient to mark the high temperature to which the vessel was raised. After the first roasting I placed as quickly as possible the thermometer in the parcel of leaves about to be rolled, and slightly pressed them against the bulb. The mercury rose only to 138 degrees. I repeated the experiment with another parcel of leaves in the same manner, and the temperature indicated was $136^{\circ}$. After the second roasting of the same leaves the thermometer rose only to $132^{\circ}$. This lower temperature, however, I consider as accidental; some allowance must of course be made for loss of heat in carrying the leaves from the roasting vessel. Still on a recent occasion, I roasted some hawthorn leaves at a temperature of $270^{\circ}$, and another thermometer was kept above the boiling point in readiness for use. At an agreed signal I raised the leaves from the vessel, and an assistant immediately thrust the heated thermometer into the leaves, which I gently pressed against the bare bulb. The thermometer 
fell rapidly to $170^{\circ}$, and continued to fall slowly. Thus taking the mean of the extremes of the cold and het thermometers $138^{\circ}$ and $170^{\circ}$ equal to $154^{\circ}$, the temperature thus given very little exceeds the point at which steam is said to scald. Hence it seems to me conclusive that, agreeably to the mode of manipulation practised by the Chinese, a very high temperature may be used without incurring the risk of raising the heat of the leaves to any degree approaching the boiling point; and, consequently, agreeably to the commonly received opinions of scientific and practical men (as a general rule), without injury to the aroma. Indeed it may be doubted whether there be any connexion between the heat employed and the amount received by the leaves; that is, whether the leaves have the power to receive above a certain amount of heat, so long as copious evaporation be maintained. Analogy seems to favour this doubt. Fluids in undergoing the change from a liquid to a gaseous state send or carry off all superabundant heat, and thus is kept down the temperature of the body from which they emanate. Thus the temperature of the body and blood cannot be raised much above $98^{\circ}$ or $100^{\circ}$, so long as copious perspiration be maintained; nor can water be raised beyond $212^{\circ}$ under the ordinary pressure of the atmosphere-or ether above $98^{\circ} \dagger$, and so

\footnotetext{
* Brande's Manual of Chemistry, p. 1337.

† Ib. p. 1278.
} 
on. So tea and other leaves, according to their succulency and viscous qualities, may have their determinate amounts of heat, so long as copious evaporation continues; and this, in the case of tea leaves, seems to be between $150^{\circ}$ and $170^{\circ}$ Fahrenheit at this particular stage of the process.

Thus the rapid evolution of steam and the copious moisture with which the leaves are covered and surrounded, must be considered as the cause of their not burning. The dexterity of the workman, doubtless, has much to do in preventing this evil. The mode of manipulation, as already described, the constant stirring about the leaves in the vessel; the new surface, which is ever presented to the heated part of it; the raising them in the air, shaking them on the hand, and scattering them loosely in the fall, are all expedients of the roaster to dissipate the steam, to spare his hands, and to keep down the temperature.

Upon trying a similar experiment in the drying tube, or poey long, used in the process of drying black tea, I found that when one thermometer, placed in the sieve immediately over the fire, marked $250^{\circ}$ of heat, the leaves, suddenly raised in the same manner as just described, indicated, with a cold thermometer, a temperature of $179^{\circ}$; thus showing, as might be expected, that as the leaves part with their moisture, their capacity for heat increases; and all agree that it is in the process of drying, when a comparatively low temperature is 
employed, and not in the roasting, that tea more frequently acquires a burnt smell and flavour.

Thus I am disposed to think that the main object which the Chinese have in view in the use of a high temperature is, first, to drive off the elastic fluids as rapidly as possible, as every part of the process indicates. The act of rolling is simply with a view of hastening the drying by expressing the juices; and, secondly, that the temperature of the steam, and, moreover, that of the leaves themselves, may not attain a degree of heat which would render the manipulation unmanageable. Experience has taught them that a high temperature favours this object, and may be employed beneficially, and without injury to the aroma. Perhaps the best test for the temperature required, at least the lowest temperature suitable, is that degree of heat which bursts freely, quickly, and abundantly, the parenchyma of the leaf; and which bursting of the leaf is the cause of the crackling noise decribed by Kœmpfer. This rule is also in accordance with an observation already made, that no fixed measure of heat can be given; the amount required depends on the succulency and aqueous condition of the leaves.

If Pao chong tea is exposed to a higher temperature than any other tea, it is because the leaves are of more luxuriant growth and greater succulency, and also because a supposed chemical change has been induced, and is going on in these delicate 
leaves with activity, but which it becomes necessary suddenly and quickly to check, by the application of intense heat; as the germination of barley is arrested by a moderate and gradually increasing heat in the process of malting, or the saccharine fermentation in the process of bread-making; and if Pekoe tea is roasted and dried at a lower temperature than any other tea, whether green or black, it is because this tea is made from the convoluted leaves of the unexpanded terminal bud of the leaf or twig, and has little moisture to part with. Thus, as before explained, young succulent leaves require a high temperature, and dry, old, coriaceous leaves, a low temperature; so, again, spring leaves more than autumnal. The yellowish green leaves found in fine black tea are doubtless due to similar causes.

All leaves cannot be gathered of the same age, or under equally favourable circumstances and condition. Thus the yellow or light green leaves found in black tea of fine quality are doubtless due to a higher temperature having been used than was suitable to the condition of those particular leaves, though favourable to the general mass. Sometimes, however, it arises even in spring leaves from too advanced a stage of maturity, their virtues being partly lost. Spring leaves especially, and the young leaves generally of black tea, at all seasons of the year, from the course of manipulation which they undergo previously to roasting, 
are disposed to turn black, which is exemplified in the Pekoe kinds of tea ; but the autumnal and old leaves, green, brown, or yellow. The difference in these effects must be ascribed to natural causes, such as the different state of their constituent properties at these two periods of the year. Perhaps spring leaves may be considered to bear the same relation to autumnal, that young leaves do to old. Young leaves, says Liebig, contain more alkalis than old ones; and old leaves lose their astringency. Again, Péligot states that Pekoe and Gunpowder tea contain a larger proportion of azote than any other tea." In fact so long as the leaves are engaged in the extension of their own growth, they contain a larger amount, than at any subsequent period, of organizable matter, as starch, sugar, gum, and acids for the formation of their own cellular tissue and woody fibre; but when they have attained their full maturity, the superabundant quantity of this nutriment, above what was necessary for their own formation, is sent off as fast as assimilated for the production of cellular tissue, wood, and new organs in other parts of the tree. The sap is also in a more inspissated state, as has already been observed, in the spring season, than at any subsequent period. Similar effects are also produced by different soils. Some soils will not produce the finest quality of tea. And it is

* Monographie du Thé, par J. G. Houssaye, p. 101. 
observed by Mulder, that in analysis the Chinese tea could not be distinguished from the Java tea except by the ashes, and perhaps by the gum, and that soil has much to do with this.

If the succulency of the leaves be unduly increased, as by rains, such a condition on the application of no more than the ordinary degree of heat would operate like a diminution of temperature. Evaporation would go on slowly, and after the usual time of roasting, the leaves would be found too full of juices to be fit for rolling. It would be necessary in fact to squeeze out the juices with the hand, as practised at Java and at Rio de Janeiro, and which also occurred to myself, when too low a temperature was employed, in an experiment with steam, already detailed. No such practice obtains in the tea districts with which I am acquainted, nor can I consider it a good method. It obviously implies a deficiency of heat. On the other hand, if the heat be raised to meet this turgid state of the leaves, the temperature of the steam and heat of the leaves might reach a point more than the hands could bear. Indeed notwithstanding the low temperature employed at Java in roasting tea, $\mathrm{Mr}$. Jacobson states that the green tea leaves become "nearly as hot as boiling water"," that is, they nearly scald.

Accordingly we find that in black tea, in which it is here supposed that a certain amount of spon-

* Handbock, § 444. 
taneous heating may be beneficial to the leaves, evaporation is hastened by exposure to the sun, and after excessive rains to the action of fire, in cach case for the purpose of effecting that state of dryness or relative moisture in the leaves which is favourable to the elaboration of a saccharine principle, which is here surmised to be necessary to black tea previously to roasting. But with green teas any lengthened exposure to sun or air, or spontaneous heating of the leaves, would be injurious. Thus we find it to be the practice of the Chinese to keep such leaves as cool as possible. If the leaves of these teas are overcharged with aqueous fluid, evaporation is hastened, not by sunshine or artificial heat as in black tea, but by spreading the leaves loosely on tiled floors, or on sieves, or stands, in cool places exposed to a current of air ; and this when necessary even through the night, as the Chinese say, without injury. At Java it is stated, however, that the leaves there cannot be so exposed without detriment. This may be due to the greater heat of the climate, and even in China it is not desirable and cannot be done without risk. In ordinary cases the green teas are roasted as soon as gathered, even with the dew on the leaves. It is therefore evident, from the difference of treatment which these two classes of tea receive previously to roasting, that the green tea leaves are brought to the roasting vessel more exuberant in juices than the leaves of black tea. Consequently they ought to re- 
quire, and are, I believe, submitted to a higher temperature. At Java this is stated most unequivocally to be the fact. Still, notwithstanding the higher temperature there employed, the green tea leaves are found so full of juices after roasting, that it becornes necessary to press out these juices with the hands on sieves over a pail before they can be rolled. So that we seem justified in supposing that the heat employed there, especially for green tea, is of too low a temperature.

If we examine the construction of the two vessels employed in roasting these two classes of tea, wo shall find that the one used for black tea is shallow and somewhat flat; thus favouring a rapid dispersion of the fluids as well as heat; but the one used for Hyson tea seems not known at Java nor at Japan, nor does it appear that Mr. Fortune met with it in the districts he visited in China. This vessel is three times the depth of the other, besides having perpendicular sides. It is also fitted low down in the brick work, five inches below the surface of the stove. Thus both the form and fitting of the Hyson tea vessel are favourable to a concentration of heat; and it has already been remarked, that in the example which I witnessed of the roasting of green tea, the heat of the steam which issued from the leaves was so great, that I could not bear my hand exposed to it an instant. It must be acknowledged, however, that the temperature employed upon that occasion was much too high. The flatter form of the black tea vessel demonstrates that a crm- 
centration of heat is less important. It is singular that Kompfer, so accurate in his description of the manipulation of green tea at Japan, mistook the Twankay roasting vessel used there for a flat iron pan. The fact is, that when the vessel is fitted into the stove in a slanting position, as it is used for the manipulation of Twankay tea, it certainly resembles and might easily be mistaken for, a flat piece of iron turned up at the end. This is Kœmpfer's description of the vessel which he saw used at Japan. It may be seen, however, by the drawing given by Von Siebold in his account of Japan, that the vessel and inclination of the stove correspond with those adopted for Twankay tea in the green tea districts in China.

With respect to handling leaves exposed to so high a temperature, it may be observed, that the leaves do not attain a higher temperature than the hands of workmen accustomed to this occupation can bear; and the quantity put into the vessel at one time is sufficient, under due management, to prevent any contact between the heated vessel and the hands, though the intense heat which from habit these men can endure is certainly surprising.

In the second and third processes of roasting, charcoal is used instead of wood; and the heat is lowered as the leaves part with their moisture, but a high temperature is still maintained so long as any juices can be expressed in the act of rolling, say from 220 to 250 degrees. Thus far the means and temperature used are essentially the same for 
both classes of tea, black and green, although the green tea leaves require generally a somewhat higher temperature, in consequence of their greater humidity or aqueous condition, and because they are roasted as soon as gathered, without any previous evaporation of the fluids.

In the subsequent and final stages of the manipulation, or the process of drying, an essential difference arises in the mode of manipulation, as well as in the application of heat. On this depends, as already demonstrated, the distinctive colour of green tea more than on any management of the heat, or any difference of temperature. The black is dried in sieves through the interposition of one of the slowest conducting powers of heat, - air; and the green tea by contact with heated iron, one of the quickest conducting powers. Moreover, the leaves of the black tea are kept in a quiescent state, receiving the full impression, though slowly, of the heat thus transmitted; while those of the green tea are kept in constant motion, besides being fanned; so that this latter tea is exposed during the process of manipulation to the alternate impressions of heat and cold in rapid succession, by the free admission of air to every part of the leaves. Thus a rapid evaporation of the fluids is produced, and consequently rapid desiccation. But how this effect, or the amount of heat thus impressed on the leaves in these alternations of a heating and cooling process is to be measured, seems to me a matter of no small difficulty. All 
my attempts to appreciate this effect have proved most unsatisfactory in their results. I mean the results have differed, though the means employed were apparently the same. Then again all endeavours to institute a comparison between the heat employed in these two methods will be met by similar difficulties. Without entering upon the many failures which I have experienced in such attempts, the general reader will sufficiently comprehend by the following experiments the difficulty with which this subject is invested.

With four pounds of good strong charcoal, I raised a drying-tube (Poey long) used for drying black tea, to $220^{\circ}$ Fahr.; the thermometer being placed on the sieve, which was elevated 18 inches above and immediately over the fire. At this temperature I could bear my hand to rest on the sieve without inconvenience, though water boils at $212^{\circ}$. Indeed I have borne my hand in the same position when the heat has been raised to $300^{\circ}$ without feeling any sensation of pain. But the iron roasting vessel heated to $180^{\circ}$ I could hardly bear to touch. Hence it follows that the iron vessel heated to $180^{\circ}$ transmits heat to the leaves, in immediate contact with it, more rapidly, and produces a much greater impression on them, than when placed in the drying-tube, though the heat may be raised to $220^{\circ}$ by the conduction of air. So much does the transmission of heat depend on the conducting media. Indeed it is stated by 
Brande* that iron heated to $120^{\circ}$ is painful to the touch, but that air may be heated to 250 and $300^{\circ}$ without being painful to our organs. He moreover states that Sir F. Chantrey had a room for drying his models for casts heated to $300^{\circ}$ Fahr., which the workmen were accustomed to enter in the ordinary course of business. Thus if we take the difference of temperature given by the thermometer as indicative of the amount of heat impressed on the leaves in these two methods, it is obvious we shall be led to form very fallacious conclusions.

Moreover, in these experiments much depends on the strength of the charcoal, the state of the atmosphere, force of wind, and other conditions, as such experiments can only be conducted with convenience in open sheds, where there is a free current of air. Much also depends, I believe, on the size, form, depth and thickness of the roasting vessel as affecting its radiating powers and focus of heat, not to speak of the many sources of error to which all such experiments are exposed.

If any satisfactory comparisons can be instituted on this subject, they are only to be obtained by the joint efforts of a good practical chemist, and a skilful manipulator, with an abundance of leaves at their disposal, and with all the necessary implements at hand.

* Manual of Chemistry, p. 159. 
It is now to Java and to India that our attention must be directed in order to procure accurate information on these points. It is there that experiments may successfully be tried, where Chinese acquainted with the art, though not perhaps with the best methods, may be called to aid these researches. Neither at one settlement nor the other, nor at Rio de Janeiro, have the best methods of preparing the green teas yet been introduced. It has been already stated that the roasting vessel used for Hyson tea seems unknown at Java.

If I may be allowed to offer a conjecture (for it is nothing better), in the absence of more perfect information, regarding the heat desirable to employ in the process of drying black and green tea, I should suggest the under-mentioned temperatures to be tried.

For the drying of black tea in the drying tube (Poey long). 1st. drying

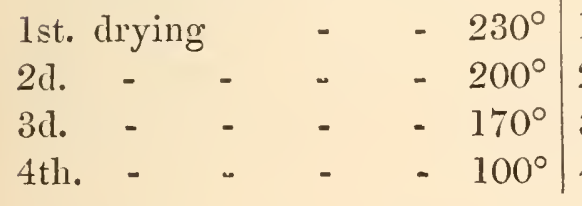

For drying green tea in the iron ressel.

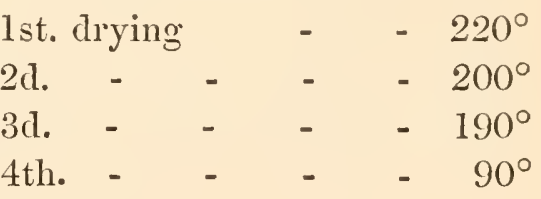

Mr. Jacobson gives the following temperatures as those used at Java:

For drying black tea in drying-tube.

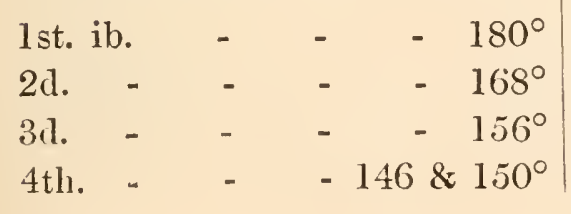

For the final drying of green tea in iron vessel.

1st. ib. - - - $196^{\circ}$ $2 d$.

3d. - - - - $176^{\circ}$

4th. - - - $\quad-162^{\circ}$ 
It has before been mentioned, that all tea at Java is roasted and dried at a temperature below the boiling point.

$202^{\circ}$ is given by Mr. Jacobson for the first roasting of black tea, and

$197^{\circ}$ for the second roasting.
For the first roasting of green, $206^{\circ}$; and it is observed that, during the roasting the leaves nearly attain the heat of boiling water.

The second roasting of green tea is stated at $190^{\circ}$.

For Pekoe tea, which undergoes only one roasting, the temperature of $196^{\circ} *$ is given by him, and it is stated that even at that temperature the leaves crackle when they are first put into the vessel. The heat employed in the drying-tube is $142^{\circ}$. About three quarters of a pound of leaves are used at one time.

Supposing the above statement to be correct, then, so far as the thermometer indicates, the question whether black tea is roasted and dried at a higher temperature than green, is here decided and proved not to be the fact at Java. Further, I have

* I cannot but express my surprise, that the crackling of the leaves should have been obtained at a temperature of $196^{\circ}$. It has already been seen that this effect was not produced when the heating medium was steam generated by rapidly boiling water. It is possible, however, that after a certain amount of heat had been absorbed, the radiation from the vessel was greater than the absorption, so that the vessel did not attain a temperature equal to boiling water. I acknowledge it was a great omission not to have determined this by experiment. 
already observed that the heat employed there for green tea seems to me of too low a temperature.

Before closing these remarks on the heat employed at Java, it is necessary to observe that in repeating the experiment by which Mr. Jacobson determines the heat required, his results and mine do not coincide.

It is first remarked by him, that the thermometer must not be used to determine the amount of heat. The roaster should from habit be able to determine that, by holding his hand one inch above the vessel while he can count twenty. Now I heated a roasting vessel to $350^{\circ}$ of Fahrenheit, determined by placing the bare bulb of a thermometer in contact with the iron, and in the centre of the pan, or the part most heated. Another thermometer, also with the bulb exposed, was held even with the edge of the pan also over the centre, and it marked only $180^{\circ}$ of heat. With my hand held in this positicn so long as I could bear it I deliberately counted thirty. At $315^{\circ}$, the upper thermometer marked $150^{\circ}$ : at $300^{\circ}$ the upper thermometer marked $145^{\circ}$ : and in order to guard against all suspicion of error, I placed a piece of wood across and resting on the edges of the pan. Then with my hand held first above, and then below the wood, I counted one hundred, and felt no inconvenience.

Now I do not mean here to impugn in any degree the accuracy of Mr. Jacobson's experiment. 
On the contrary, I have great pleasure in bearing testimony to the general exactness of his descriptions and great minuteness of detail, as well as to the philanthropic and benign spirit which pervades his work-it is refreshing to hear the Planter in a remote colony advocating the cause of the Peasant, and upholding the Christian principle that "the labourer is worthy of his hire." In short his work on the cultivation and manipulation of tea at Java is well worthy of a literal translation into our own language, and would form a useful manual in the hands of all persons engaged in the cultivation of tea. The difference between this author's results and mine, I ascribe to the difference of size, thickness, and depth of the vessel used; and partly also to his mode of holding the thermometer, which indicates that it was one, the bulb of which could not be laid bare. I have already observed that I am disposed to believe that the temperature employed at Java, especially for green tea, is too low ; or that there may be some error in the mode of computing it. But we will here assume it to be correct; and as I have already admitted that some Java teas, black and green, are equal to the average quality of Chinese tea, then it may be asked-If teas of equal quality can be produced at temperatures so different, in what consists the advantage of the Chinese methods over those of Java? 'They appear to be these-economy of time, labour and fuel; and consequently of expense. Moreover, the 
leaves of green tea remain so full of juices after the first roasting, in consequence of the low temperature employed, that it becomes necessary to squeeze them between the hands to express their juices before they are found in a fit state for rolling. Thus they agglutinate into a solid mass, which it is necessary to separate and pull to pieces. Still many adhere together, so that more "lumpy and knobby" leaves than usual are thus formed; that is, more hyson-skin, and less hyson, or more inferior and less superior tea.

With respect to black tea, the low temperature used at Java may be in consequence of more of the aqueous fluids having been evaporated in the process previously to roasting, than takes place in China. 'The redness of the leaf is carried to excess. There are no teas (at least I have seen none) which correspond with what is understood by black-leafcongou. It may be also that the leaves are smaller and less succulent than the Chinese: especially as it is stated that they give out little or no juice in the act of rolling. In short the first samples of these teas which found their way to England exhibited a complete failure. They resembled what the Chinese term hong cha, i. e. red tea : a tea little used. It has already been explained that the redness of the leaf previously to roasting is not necessary to the redness after: also, that the more the aqueous juices are evaporated previously to roasting the less heat is required in that process. 


\section{CHAP. XI.}

REVIET OF P. MULDER'S ANALYSIS OF TEA. - COLOUR OF BLACK TEA NOT DUE TO HIGH TEMPERATURE.- BLACK TEA NOT DRIED AT A HIGHER TEMPERATURE THAN GREEN.-GUNPOWDER TEA DRIED AT THE HIGHEST POINT OF THE SCALE OF TEMPERATURE, AND PEKOE TEA AT THE LOWEST. - THE RED OR BROWN COLOURLNG MATTER OF BLACK TEA NOT DUE TO HIGH DRYING.-THE TERM BLACK A MISNOMER.-ANALXSIS OF TEA.- ODOROUS PRINCIPLE DERIVED FROII A VOLATILE OIL. - DEVELOPED IN COFFEE BY HIGH TEMPERATURE. - THE RED OR BROWN COLOURING MATTER OF BLACK TEA IN LEAF AND INFUSION TRACED TO CHEMICAL CAUSES.OTHER PARTS OF THE ANALYSIS RECONCILED WITH THE PRECEDING THEORY. - FLAVOUR DEPENDENT MAINLY ON MANIPULATION.- RECAPITULATION OF THE MIODES OF MANUFACTURING BLACK AND GREEN TEA.-DIFFERENCE OF QUALITY OF TEA TRACED TO VARIOUS CAUSES.

LET us now proceed to examine a very elaborate analysis of tea made by an eminent chemist, $P$. Mulder*, so far as that analysis is connected with the belief that black tea is roasted and dried at a higher temperature than green tea; that being the cause of its darkness and redness of colour in leaf and infusion.

It is stated by Mons. Péligot, Professor of Chemistry at the "Conservatoire des Arts et Métiers" at Paris, that with the exception of some errors,

* Annalen der Physick und Chemie von J. C. Poggendorff. Leipzig, 1838, B. 43. S 161-180. und 632-651. 
this analysis of tea is the best that has yet been made. And I believe the same degree of merit is awarded to it in this country. There are, however, errors resulting from information derived from questionable and imperfect sources, for which this able chemist can hardly be deemed responsible.

It shall be my endeavour then to reconcile the facts of the analysis with the account here given of the manufacture of tea in China, and to show that though the explanations and deductions therein laid down are erroneous, because grounded on false assumptions; yet that these erroneous deductions in no way detract from the merits and accuracy of the analysis itself: nor do the results of this analysis tend to contradict any of the facts and principles developed in the course of this inquiry.

First, it is treated as a fact well established, though Mulder * gives no authority for this belief, that black tea is roasted and dried at a higher temperature than green; and that this is the cause of its blackness of colour.

But it has been shown that the difference of colour of black and green tea does not depend on any due management of the heat, but on manipulation; since both teas have been made from leaves out of the same parcel, simultaneously in the same vessel and at the same temperature, 
(chap. 9. p. 242. 2 ). It may, however, be said that the black tea leaves took a longer time to dry; and therefore received a greater amount of heat, which is equal to higher temperature. But if the capacity of the leaves for heat is dependent on their aqueous condition, then the use of a high or low temperature causes no other effect than to produce, as in water, a quick or slow conversion of the fluids into a gaseous state: no more heat is received by the leaves in either case. The one is a rapid process of drying by quick evaporation; the other a slow one by slow evaporation. It is a question of time, not of heat. It is true that slow evaporation causes a greater expenditure of heat and fuel, but that is due to loss of heat, in consequence of slow absorption.

Again, if equal states of dryness in tea require equal amounts of heat, as some scientific and practical men seem to believe, then there are no solid grounds for supposing that green tea is less perfectly dried than black. Indeed I have always inclined to the opinion that the contrary is the fact. As, howerer, Mulder considers black tea more friable than green tea, and ascribes the quality to high drying and high temperature, I was induced to request the favour of $\mathrm{Mr}_{\mathrm{r}}$. Warington, the chemical operator at Apothecaries' Hall, to put this question to the test of experiment. After experiment, it was his belief, though contrary to his previous opinion, that both teas, black and 
green, could be reduced to an equally fine powder. He also observed very little difference between them while working them under the hand. But, as he justly remarked, the same degree of dryness may be obtained by opposite methods, that is, by a higher temperature employed for a short time, or a low temperature continued for a long time. It was his opinion that both teas were reduced to an equal state of dryness.

The hygrometric state of tea can afford no solution to this question; because, should any water remain in the leaves after the usual processes of desiccation, it could not be distinguished from water afterwards absorbed from the atmosphere. It is well known that tea readily imbibes moisture, even when packed in chests containing leaden canisters well soldered down. Tea kept through the summer at Canton termed "-winter-tea" increases in weight; and as it is dried at a high temperature, the whole of the water driven off in analysis is most probably water of absorption. However, so far as this test is concerned, the loss of water in green tea is less than in black. Agreeably to Péligot, green tea loses only eight per cent of water by desiccation, whereas black tea loses ten per cent. Gumpowder he states at six, and Souchong at 11.7 per cent.* Mulder makes the loss of water and essential oil very trifling, and nearly equal; viz. Hyson 4.44,

* Monographie du Thé, par J. G. Houssaye, p. 90. 
and Congou 4*48. But if Hyson and Gunpowder tea in analysis lose less water by desiccation than black tea, this may arise as much from the leaves of these teas being less absorbent of moisture in consequence of their greater hardness and compactness of form, as from high drying.

Still if we examine the close compact globular form of Gunpowder tea, and bear in mind its consequent superior gravity and ease of gravitation among leaves kept in constant motion, the inference seems to be, that this form, though first accidental, must finally be derived from a greater impression of heat. Moreover, if after breathing on these leaves we examine their yellow discoloured speckled appearance, which arises from burning, we shall be the more confirmed in that opinion. In fine, there can be no doubt that these leaves by reason of their superior weight and roundness of form, are constantly sifting through the other leaves, and making their way to the sides and bottom of the vessel in which they are dried; and thus coming in frequent contact with the most heated parts of a vessel of high thermal conducting power, it necessarily follows, that they must be more highly dried than the other leaves with which they are mixed, and even occasionally become scorched and burnt. It is familarly known to dealers that Gunpowder tea frequently possesses an agreeable burnt flavour, highly appreciated, and which enhances its value. Yet the Hyson leaves with 
which it has been mixed throughout the whole process of manipulation, and of which it has formed a part, may have no such flavour. Thus I am disposed to think that on a more exact investigation of this subject, Gunpowder tea may be found to have received a greater impression of heat, and to be more highly dried than any other tea, black or green.

Then with regard to black tea, the Chinese, and all who are conversant with the subject agree, that Pekoe tea is roasted and dried at a lower temperature than any other tea. Indeed it occasionally happens, that newly manufactured Pekoe tea, even in China, has a musty smell, alike indicative of readiness to absorb moisture, as of insufficient desiccation.

Here, then, we have Gunpowder and Pekoe tea, the one a green and the other a black tea, at the extreme points of the scale of temperature employed in the manipulation of tea. No fairer comparison, not even between Congou and Twankay, can be made. These are teas as nearly resembling each other in circumstances as possible. At Java they are frequently identical in all other respects; from the same shrubs, of the same age, from the same parcel of leaves, and in all other circumstances the same. Yet we find there, as in China, Gunpowder tea representing the highest point of the scale of temperature, and Pekoe the lowest. Thus, so far as the teas of commerce are concerned, there can 
be no doubt that green tea is manufactured at a higher temperature than black. But in China Paochong tea, which is a black tea, is submitted for a few seconds to the red-heat of iron. Thus it is obvious that the difference and apparent blackness of colour of black tea must depend on other causes than high or low temperature, or any management of heat.

This able chemist proceeds to state, that a substance which he describes and terms "Apothem" is obtained from "Extractive." It is found in black tea, but not in green; and it is this product which gives the colouring matter, and red or brown infusion to black tea. He further adds, that it is not the product of analysis, but is due to manipulation and high temperature: also that the properties of the extractive of black and green teas are different. (Ib. p. 639.)

But the red or brown colouring matter of black tea, and the red infusion, have been shown to arise from a particular treatment of the leaves by exposure to sun and air, like hay (To Ching), previously to roasting; and that corresponding results have been produced by exposure to sun, without the action of fire. (P. 148. $\S \S 1$ \& 6.)

Again, so far from the black, brown and red appearance of the dried leaves being the effect of high temperature, even a moderate degree of heat, if more than the aqueous condition of the leaves can bear, has the effect of turning them pallid and 
yellow, and making the infusion as light as green tea. (P. 150. \$3.) The yellow speckled leaf of Twankay tea affords another example of the effect of excess of temperature turning the burnt parts not black, but yellow.

Mulder further states, that frequent effusions and evaporations of the infused leaves of green tea, by a continued application of heat at a low temperature, was found to darken their colour to that of black tea; and that "extractive" thus procured yielded "apothem," which experiment Mulder considered sufficient proof that black and green tea could be made from the same parcel of leaves by use of a high or low temperature. (Ib. p. 639.)

That black and green tea can be made from the same parcel of leaves, no longer admits of doubt. Moreover, it is clear, that the difference of colour does not arise from difference of temperature. These facts have been sufficiently established in the course of this examination. They also receive confirmation from Mr. Jacobson at Java: this author distinctly states, that black and green teas are made in the same plantation, from shrubs propagated from the same seed, and occasionally, as in Pekoe and Gunpowder, from the same parcel of leaves: also, that the colour of black tea is due to manipulation previously to roasting.

That the leaves of green tea darken in colour after infusion if re-dried, is also true; for if after 
infusion, or even before infusion, the bright bloom colour of the leaves be injured by moisture, or even by strongly breathing on them, it can never again be restored. This is one of the occasions when the Chinese have recourse to factitious means in order to reproduce the colour. So if the infused leaves of green tea be exposed to the air, and, still more, if exposed to the action of heat, they darken in colour in drying, even so as partially to resemble black tea : but if infused again, they will not be found, like black tea leaves, spotted and tinged with red or brown colour, which is more especially the characteristic feature and colour peculiar to the infused leaves of black tea. Indeed the term black is a misnomer altogether; the leares are in no degree black, as is readily proved by examination of the infused leaves: they are not charred, as some persons seem to imagine; their colour is of a dark green partly tinged with red or brown. It is a curious fact, also, that the Germans as frequently employ the term brown for this description of tea as that of black.

The Analysis proceeds to state, that the principal constituents of tea consist of volatile oil, tannin, gum, and extractive matter, all which properties are found to exist in a larger amount in green tea than in black. Hence this author infers that the original properties of green tea are more intimately preserved than those of black tea; and 
that the loss in the latter is due to high temperature.*

With respect to the essential oil of tea, it may be desirable here to repeat, that the fresh unmanipulated tea leaf has no fragrance; but has a raw vegetable astringent and acrid flavour, which is nauseous and disgusting: nor does the odour emitted cluring the process of manipulation at all correspond, at least in my opinion, with that which constitutes the agreeable odour of tea after com-

* Péligot justly observes, that tea, practically considered, contains two parts essentially distinct; that which is soluble in boiling water, and that which is not. The first contains the essential oil, tannin, gum, thein, the extractive matter, and the greater part of the salts. The other contains the Chlorophyll, wax, resin, albumen, fibre, and cinder. (Monographie du Thé, par J. G. Houssaye, p. 89.)

Mulder's comparative analysis of Chinese and Java teas is as follows: - (Poggendorf p. 169.)

\begin{tabular}{|c|c|c|c|c|c|c|c|}
\hline \multirow{2}{*}{. } & & & & \multicolumn{2}{|c|}{ Chinese. } & \multicolumn{2}{|c|}{ Java. } \\
\hline & \multicolumn{2}{|l|}{$=$} & & Hyson. & Congou. & Hyson. & Congou. \\
\hline Ethereal oil & - & - & - & 0.79 & $8 \cdot 60$ & $0 \cdot 99$ & $0 \cdot 65$ \\
\hline Chlorophyll & - & - & - & $2 \cdot 22$ & $1 \cdot 84$ & $3 \cdot 24$ & $1 \cdot 28$ \\
\hline Wax - & - & - & - & 0.28 & 0.00 & $0 \cdot 32$ & 0.00 \\
\hline Resin & - & - & - & $2 \cdot 22$ & $3 \cdot 64$ & $1 \cdot 64$ & $2 \cdot 44$ \\
\hline Gum & - & - & - & $8 \cdot 56$ & $7 \cdot 28$ & $12 \cdot 20$ & $11 \cdot 08$ \\
\hline Tannin - & $=$ & - & - & $17 \cdot 80$ & $12 \cdot 88$ & $17 \cdot 56$ & $14 \cdot 80$ \\
\hline Thein - & - & - & - & $0 \cdot 43$ & 046 & 0.60 & 0.65 \\
\hline Extractive & - & - & - & $22 \cdot 80$ & $19 \cdot 88$ & $21 \cdot 68$ & $18 \cdot 64$ \\
\hline Apothem & - & - & - & traces & $1 \cdot 48$ & trace & $1 \cdot 64$ \\
\hline Muriatic Acid & Extract & - & - & $23 \cdot 60$ & $19 \cdot 12$ & $20 \cdot 36$ & $18 \cdot 24$ \\
\hline Albumen & - $\quad-$ & - & - & $3 \cdot 00$ & $2 \cdot 80$ & $3 \cdot 64$ & $1 \cdot 28$ \\
\hline Fibrin - & $-\quad-$ & $-\quad-$ & - & $17 \cdot 08$ & $28 \cdot 32$ & $18 \cdot 20$ & $27^{\circ}$ \\
\hline $\begin{array}{l}\text { Salts contained } \\
\text { mentioned cou }\end{array}$ & d in the & above- & \} & $5 \cdot 56$ & $5 \cdot 24$ & $4 \cdot 76$ & $5 \cdot 36$ \\
\hline
\end{tabular}


plete desiccation. Thus, whether the essential oil of tea be a product of manipulation; or whether it be one of the natural constituents of the plant, analysis has not yet determined. Naes von Essenbach, from an experiment which he tried by roasting some newly gathered leaves taken from the botanic garden at Bonn, doubts whether the fresh unroasted tea leaves contain a volatile oil; and considers the aroma of tea analogous to that of coffee, requiring a high temperature to develop it. He considers it, moreover, the effect of a peculiar decomposition analogous to fermentation.*

There is no doubt that, in either case, whether generated or inherent in the plant, the aroma of green tea is developed entirely by artificial heat: but it becomes a subject worthy of investigation to determine whether the odour of black tea be not generated or developed, or at all events modified, first, by the action of sun and air, and finally by artificial heat. There is no doubt that the newly gathered tea leaves have a strong tendency to heat and ferment. It is obvious also by the fragrance emitted during the process of manipulation of black tea previously to roasting, that the odorous principle is set in action by that process; and consequently, artificial heat does not appear to be necessary to the elaboration of this principle; however requisite it may be to its perfection, its excellence and its fixity.

* Von Siebold, Nippon t. $6 . \S 8$. 
Liebig is of opinion that the peculiar "odorous principle of many vegetable substances is newly formed during fermentation of the saccharine juices of the plant. At all events," he observes, "it is a fact that very small quantities of the blossoms of the violet, elder, linden, or cowslip, added to a fermenting liquid, are sufficient to communicate a strong taste and smell, which the addition of the water distilled from a quantity a hundred times greater would not effect. The oil of the berries of the elder-tree, many kinds of oil of turpentine, and oil of lemons, possess a smell only during their oxidation or decay." *

"The leaves of the tobacco plant present the same phenomena: when fresh they possess little or no smell; but when the same plant, after being dried, is moistened with water, tied together in small bundles, and placed in heaps, a peculiar process of decomposition takes place. Fermentation commences, and is accompanied by an absorption of oxygen; the leaves become warm, and emit the characteristic smell of prepared tobacco and snufi. When the fermentation is carefully promoted, and too high a heat avoided, this smell increases, and becomes more delicate; and after fermentation is completed, an oily azotised volatile matter, called nicotine, is found in the leaves. This substance, nicotine, which possesses all the properties of a

* Liebig's Chemistry of Agriculture, translation, $2 \mathrm{~d}$ edit. p. 320. 
base, was not present before the fermentation. The different kinds of tobacco are distinguishable from one another, like wines, by having very different odoriferous substances, which are generated along with the nicotine." *

As connected with this subject, though dependent on other causes, it may here be observed that it is remarkable with what ease tea gives out its own odour, and imbibes that of other substances by contact or proximity, especially in a humid state of atmosphere. Even a compound flavour is sometimes formed, which neither resembles its own nor the one it imbibes. It is well known that turmeric, and some other drugs, deprive tea of its agreeable odour, and change it into one resembling that of herbs. This flavour may often have been detected in tea during domestic use. This objectionable smell and flavour is perfectly well known to dealers, as well as its cause.

As, however, much stress is laid on aroma as depending on a volatile oil, which, is known in some cases, and is very generally supposed in others, to be readily driven off by high temperature, I was induced to try, through the assistance of a friend, this experiment on coffee.

We pounded a few unroasted coffee berries in a mortar, till they were reduced to a fine powder. 'This was put into a glass tube, and both the tube

* Liebig's Chemistry of Agriculture, translation, 2 d edit. p. 319 . 
and the thermometer were placed in quicksilver, heated by an Argand lamp.

It required a heat of between $450^{\circ}$ to $470^{\circ}$ of Fahrenheit to produce any aroma, when the odour increased rapidly. At about $370^{\circ}$ the coffee had not changed colour; at $450^{\circ}$ the aroma began to form, and at $470^{\circ}$ the coffee charred. It is familiarly known that as coffee browns, and gives out its odour, a fatty substance is formed.

This experiment also shows that the art of roasting coffee is a delicate art; a difference of about $20^{\circ}$ leaves it either raw and tasteless, or destroys the aroma altogether. This may be one reason why in England we so rarely meet with good coffee; whereas on the Continent the art of roasting and making coffee is known to every common lackey: still it must be remembered that coffee is the beverage of those countries; and it is only fair to the English to say, that on the Continent it is as difficult to get boiling water for tea as it is to procure good coffee in England.

With respect to the principle on which the odour of coffee depends, we find in Brande's Chemistry that "Schrader endeavoured to ascertain the particular principle to which the flavour and aroma of roasted coffee are due, by exposing each of the proximate principles of unroasted coffee separately to heat; but he found that no one of them yielded any peculiar flavour; and that the ligneous residue when roasted acquired as much of the characteristic 
flavour as when the other principles were retained; so that the flavour of roasted coffee must be ascribed to the joint effect upon all the constituents."

In fact Mulder, though he considers the odorous principle of tea dependent on a volatile oil, nevertheless states, that the properties of tea are best ascertained from the four principal constituents already named.

The volatile oil of tea Mulder considers of a highly poisonous character, and difficult to obtain : it possesses the flavour of tea in a high degree, and in contact with the tongue causes a strong taste of tea in the mouth, without astringency.*

To the astringent principle, however, he attaches even more importance than to the essential oil. He describes it as refreshing in the mouth, and states that analysis and price both show that teas are of superior or inferior quality in proportion to the quantity of tannin they contain.

Gum, agreeably to this Author, also plays a very

* Mr. Jacobson. states, that a single drop of the juice expressed from the fresh leaves of inferior shrubs growing in low clay grounds 2000 feet above the sea produces nausea; but that obtained from leaves of finer quality grown 4000 feet above the sea in rich, brown, and particularly black ground (consisting of decayed vegetable matter), may also be termed nauseous, though in fact it is only harsh, and astringent in the throat, and at length becomes sweet. (Handboek $v$. $d$. Kultuur en Fabrikatie v. Thee, § 463.) 
important part in softening and cloaking this principle; so that the better sorts of tea are indebted to gum for their agreeable flavour; without which they would be no better than a decoction of oak bark. Those teas have the best flavour, which have a tolerably large quantity of tannin, with enough of gum to moderate the astringency on the tongue. Culture, he states, has much to do with this.

The analysis shows that green tea is more astringent than black; and that this principle is also less covered or concealed; for though the actual quantity of gum is greater in green tea than in black, yet the proportion of gum to tannin is less. In fine, the Author concludes, that it is from a happy combination of its four principal constituents that an agreeable tea infusion is obtained. To which he adds that cream and sugar contribute to mellow the astringency.

'The difference in the quantity of tannin contained in black and green tea is remarkable; viz. Congou 12.88, and Hyson 17.80.* Mulder considers that part is converted into "apothem," a change which likewise takes place in extractive; and hence black tea is less astringent than green. But this hardly seems to account satisfactorily for the great deficiency of tamnin in black tea. The whole

* The comparison ought to be made between Congou and Twankay; between Souchong and Hyson; and between Gunpowder and Pekoe; these being teas whose conditions and circumstances relatively approximate most nearly to each other. 
quantity of apothem is only $1 \cdot 48$, whereas the loss of tannin is about 30 per cent. of the whole quantity.

To whatever cause this loss of tannin in black tea may be due, in that will be found, I am disposed to think, the true solution of the difference between black and green tea. That this loss does not depend on difference of temperature, or different amounts of heat, has been abundantly proved. It is then in that process which the black tea leaves undergo previous to roasting, during which they are treated as hay, that the true cause must be sought.

This process (To Ching) has been aptly termed "withering." It is in fact incipient change, fermentation, or eremacausis. In a state of decay all organic substances absorb oxygen from the atmosphere, which, acting on the azotised elements contained in these bodies, sets in motion a new arrangement of their constituent parts; absorbing oxygen and evolving carbonic acid. There are certain groups of vegetable substances also, whose constituents are the same, varying only in their quantity of the elements of water. These are held together by very feeble affinities; so that certain transformations from one to the other easily take place. Starch, Cane sugar, Gum, Sugar of milk, and Grape sugar constitute one of these groups. The ease with which starch is converted into sugar is seen in the process of germination in the malting 
of barley; in the ripening of certain pulpy fruits; and by the action of acids.

Now there is no one substance so universally diffused throughout the vegetable economy as starch. It seems the very pabulum of vegetable life. It is found in roots, bulbs, seeds, stalks, twigs, leaves, and fruit; and even in solid wood. It is abundant in all the green parts of plants, especially leaves and fruit, so long as the functions of these organs are required. Thus in Hay it is found in the largest quantity just at the period. when the seed is perfected, which is the season for cutting. In unripe fruits it is found so long as the green growth continues; but not a trace when ripe. It is transformed into sugar; and the sweetness of the fruit when ripe will always be in exact proportion to the quantity of starch which it contains unripe. Ripeness, however, chemically considered, may be termed decay. When the seed is capable of reproducing the species, the fleshy covering in which it has been perfected begins from that moment to decay; and man avails himself of this condition of decay to use the fruit in the most palatable state. This change is effected by the absorption of oxygen from the air, which converts the starch into sugar. *

* The observations in this paragraph are principally taken from the Maidstone Gazette, of December 1845, and January 1846 ; but from what authorities extracted I know not. 
Liebig states that, though this change takes place in nature during the vital action of plants, it is nevertheless a purely chemical process. It occurs equally in the dead as in the living plant: in the dark as on exposure to solar light.* "The green resinous principle of the leaf," says this able chemist, "diminishes in quantity while oxygen is absorbed, when fruits are ripened in the dark: red yellow colouring matters are formed; tartaric, citric, and tannic acids disappear, and are replaced by sugar, amylin or starch, or gum." $\dagger$ Again "When the leaves of the poplar, the beech, the oak, or the holly, are dried under the air-pump, with exclusion of light, then moistened with water, and placed under a glass globe filled with oxygen, they are found to absorb that gas in proportion as they change colour. The chemical nature of this process is thus established. The oxygen unites with the substances already in the state of oxides, or to the oxidation of the hydrogen in those vegetable compounds which contain it in excess. The fallen brown or yellow leaves of the oak contain no longer tannin, and those of the poplar no balsamic constituents." +

Here, then, it appears to me, that the true

* Liebig's Chemistry of Agriculture, translation, 2d edit. pp. 30,31 .

$\dagger$ Ib. p. 67. 
solution of the distinctive character and qualities of black tea may be found. I employ the phraseology of Liebig that the coincidence may appear the more striking; and also that the opinion now given may derive countenance from his authority. Newly gathered leaves exposed to sun and air soon begin to suffer change; and all organic substances during this state of change absorb oxygen from the atmosphere. "The green resinous principle of the leaf disappears," and in leaves containing tannin, as tea leaves, "red or brown colouring matters are formed; the tannic acid disappears, and is replaced by sugar." Thus is the loss of tannin in black tea accounted for ; and the red colouring matter of the leaf, as well as the red infusion, explained.*

* It is satisfactory to state, that the presence of sugar in the teas of commerce was proved by analysis, obligingly undertaken by Mr. Warington at my request, in the early part of the year 1846. It was found both in black and green tea in large quan • tities, but not a trace of starch in either. My expectation was, that the tannic acid might be found converted into starch in green tea, and into sugar in black. In this expectation I was disappointed; and now I must leave all further research in the hands of the chemist. Could the quantity of sugar be accurately measured, it might lead to further and more certain results; but it appears that the power of accurately measuring minute quantities of saccharine matter in vegetable substances is still a desideratum in chemistry. It may be surmised, however, that a larger quantity is elaborated in black tea than in green; and that the excess is carried off by fermentation of the saccharine juices, during the manipulation of the leaves previously to roasting; and in some cases, as in the Hong Moey teas, also during the manipulation after roasting and rolling while 
Then, if the difference of black tea should be found to be due to the elaboration and fermentation of a saccharine principle, the reason becomes obvious, why leaves gathered during bright weather, and even in mid-day, should be more suitable for this purpose than when collected during cloudy or rainy weather. Liebig states, that during the absence of solar light and heat, whether by night or day, the leaves form acids, which during bright sunshine and heat are converted into starch, gum, and sugar. Thus in southern climes grapes contain more saccharine matter, and those of northern ones more acids.

Tea leaves gathered after heavy and long continuous rains, being exuberant in aqueous juices, are not in a state to favour the elaboration of this principle; as we know by fruits, which under similar circumstances do not ripen. The juices of the leaves being too watery, they readily run into the putrefactive fermentation. Thus it is obvious why it may be beneficial under circumstances of exuberant moisture to expose the leaves of black tea to fire, as practised in China, to hasten evaporation, in order to bring them quickly into that state of relative moisture which favours the elaboration

the leaves are yet moist, if found necessary. But it has been shown, that not only the saccharine principle, but also the red colouring matter of the leaf and infusion may be diminished and even altogether destroyed, by a small excess of heat in the process of roasting and drying. In such cases, the leaves turn yellow, and the infusion is as light as green tea. 
of the saccharine principle, which the Chinese unconsciously seek, though they are perfectly aware that a heating or fermentation is necessary. It moreover explains why the black teas are not roasted as soon as gathered, like green tea. It is a well established fact also, that black tea may be preserved without injury to flavour a longer time than green tea. May not this quality be due to the same cause, the effect of fermentation of the saccharine juices of the leaves, as in hay, tobacco, \&c. ?

In the Hong Moey Pekoes it is apparent that the process of withering borders on excess. This is indicated by the greater redness of the leaf and infusion; and also by a compound flavour, which partakes of a flavour between that of Pekoe and Souchong. Occasionally these teas have been significantly termed malty by the brokers. Many Ankoy teas and some of Java participate in the Hong Moey flavour. Thus the quality of this tea may depend much on the management of this process. If pushed to excess the leaves become red, and the flavour sweet and vapid. Further, the experiments already alluded to, made by manipulating leaves altogether in the sun without the application of fire, show how the kneading and working the leaves in the sun produced the redness of leaf and infusion as well as an excess of sweetness in the tea.

If we compare the black-leaf flowery Pekoe with 
the Hong Moey Pekoe, we readily perceive that the characteristic appearance of the Pekoe is marked by the blackness of the leaf, and that peculiar smell and flavour, which is familiarly known to belong to that description of tea. On the other hand, the Hong Moey Pekoe is distinguished by the redness of its leaf, and its compound flavour: if tasted against Pekoe tea, it is found to have little or no flavour of Pekoe, but approximates more to the flavour of Souchong. If tasted against Souchong, however, the Pekoe flavour may then be traced. Now this peculiarity in this tea cannot be ascribed to the more expanded growth of the leaf; because the Pekoe-kio consists of leaves perfectly developed in form though of young growth; yet it does not possess the Hong Moey flavour. The word kio means foot: the literal meaning, therefore, of Pekoe-kio is, tea made of the expanded leaf found at the foot of the Pekoe leaf or convoluted leafbud. Moreover, as this difference may be produced from the same parcel of leaves, it obviously can only arise from a lengthened process of withering in the case of the Hong Moey teas.

Now if we class all black teas under these two denominations, conspicuous for the difference of colour in the leaf, they would range in the following order:- 
Black-lerif teas.

Pekoe, with its different degrees of flower.

Congou Pekoe-kio.

blackish leaf Pekoe kind.

blackish leaf, strong. blackish leaf.

Assam tea.

The above are more conspicuous for their strength than delicacy of flavour: and with the exception of the Assam tea, partake more or less of the Pekoe flavour.
Red-leaf teas.

Houg Moey Pekoe.

Pao Chong.

Souchong.

Sonchy (Bohea and Ankoy).

Some Campoi teas.

Congou or but mid. tea, Sou-

chong flavour.

Many Ankoy teas: as -

Ning Yong.

Orange Pekoe.

Shang Heong.

Java tea.

Kamaon tea in India.

The above are distinguished for their delicacy of flavour ; but are deficient in strength, and are all more or less of Souchong flavour.

Thus it can hardly be doubted that the manipulation of the leaves previously to roasting, or the process of "withering" (To Ching), exercises a very important influence on the quality and flavour of black tea. Nor does there appear any reason to doubt the testimony of the Chinese, that the management of the leaves of black tea previously to roasting is the most difficult part of the whole manipulation. And this leads me to suggest, whether the Java teas (at least the first importations) may not have been withered too much, and the Assam too little. A vast improvement has 
recently taken place in the quality of all the teas now received from both these colonies.*

It further appears from the above classification that the recl-leaf kinds are the product of superior shrubs in the Bohea districts; though the Ankoy teas ranging with them are weak and peculiar in flavour, and less esteemed. Soil unquestionably has much to do with this. Thus we see how some districts may be suitable for the production of Souchong, and others for Congou; just as the banks of the Garonne are more favourable for wines of delicacy and aroma, and the banks of the Douro for those of strength and astringency.

Mulder attaches very little importance to what he designates the "ines" of some chemists. The quantity of thein he found in Chinese tea was small, viz. 0.43 in Hyson, and 0.46 in Congou. But Péligot ascribes to this principle most of the virtues, medical, and perhaps even nutritive, of this leaf. He found in 100 parts of Hyson 2.79 of thein,

* It cannot be doubted that able Chinese manipulators are there employed; yet there is reason to think that these men are from the Ankoy districts at Amoy, or from the province of Kiang-sy; and not from the Bohea districts. With respect to green tea, it is certain they are unacquainted with the best modes of preparing that tea. Still they are quite competent to the manipulation of black tea.

I have lately seen two samples of tea, one black and the other green, made at Kamaon, in the Upper Provinees of India. They were both deficient in strength and flavour, but still excellent teas. The Hyson tea especially would find a good and l'eady sale in India and England. 
and in Gunpowder tea 3.00, and believed that even this quantity was deficient.

This chemist moreover considers it of importance to determine the quantity of nitrogenised matter contained in tea. He found in 100 parts dried at a temperature of $110^{\circ}$, that Pekoe contained 6.58 , and Gunpowder 6.62 of nitrogen; which is a larger anount than has been found in any vegetable which has beenen examined up to this day. He also found in the exhausted leaves a substance which appeared to have some relation to caseum. From all which circumstances he inferred that tea was a nutrient, as well as a stimulant.*

The green colouring matter of leaves, Mulder states, depends on a green cerin. The cause of the loss of this green colouring matter of black tea has now been explained; and the wax after decomposition may be driven off by heat in the process of roasting. The loss of volatile oil is doubtless due to the same cause. The odour emitted during the process of manipulation, previously to roasting, indicates that this principle is set in action: and as all volatile oils absorb oxygen with avidity on exposure to air, while they deposit a resin, the loss of volatile oil and increase of resin in black tea may be thus accounted for.

And may not an action of a similar kind account for the black and coal-like appearance found in

* Monographie du Thé, par J. G. Houssaye, pp. 100-108. 
black tea, and not in green, which Mulder terms Apothem? It would be desirable to know what this product is.

The greater amount of extractive, and less amount of lignin, contained in Hyson tea,- may be traced to other than chemical causes. It may depend on cultivation, or soil, or both. The com. parison is made between Hyson and Congou: the one a highly cultivated plant; the other a comparatively neglected shrub, which receives no attention beyond that of weeding. The leaf of the one is soft, flaccid, and pulpy; the other harsh, stiff, coriaceous, fibrous, or even ligneous. Again: the Hyson is a carefully selected tea; all the old coarse and badly curled leaves being separated from it after skilful manipulation. The Congou tea is a comparatively coarse cheap tea, in which all the leaves remain mixed together. It also contains many stalks, in common with all black tea; which are carefully sifted and separated from all green tea. 'Thus it is clear how more extractive may be obtained from Hyson tea, and more lignin from Congou.

Again : the greater amount of soluble matter in boiling water found in Hyson tea is doubtless due to the greater delicacy of the leaf. Agreeably to Péligot, Gunpowder tea contains 51.9 per cent. of soluble matter, Hyson $47 \cdot 7$, and Twankay $42 \cdot 2$ : thus affording also a test of quality. The quantity of soluble matter found in black tea does not afford 
an equally satisfactory result. This may arise from many causes, and partly from black teas being more mixed with teas of different growths. The result, however, is altogether unsatisfactory. Some of the Pekoes contain less than the common Bohea, which is improbable. Orange Pekoe is given at $48 \cdot 7$, while other Pekoes are marked at $34 \cdot 6$ and $38 \cdot 1$, Congou at 45 , and best Bohea $44 \cdot 4 . *$

The reason why fewer perfect leaves are found in black tea than in green, though this assertion does not accord with my own experience, but the contrary, can hardly be ascribed to the greater friability of black tea, in consequence of high drying, as Mulder conceives. It is true that black tea is more frangible than green, but not more friable, as has been proved. It is more easily broken down with the hand, as every dealer knows; but this arises from the longer twist of the black tea leaf. It is also more crushed in the act of packing; but still this would be insufficient to explain why so few perfect leaves are found in green tea. The true reason is, that they are broken and torn asunder in the act of rolling, while yet humid; and not from the action of heat. The difference of form between black and green tea arises from a different treatment of the leaves during the process of drying. The black teas are placed in sieves and allowed to remain quiescent; thus they

* Monographie du Thé, par J. G. Houssaye, p. 91. 
twist longitudinally, and preserve somewhat the original length and form of the leaf. But green tea leaves, from an uninterrupted rotatory motion which they receive in the act of manipulation in the iron vessel in which they are dried, are constantly exposed to friction against the heated sides and bottom of the vessel, and against each other ; thus they contract and curl. Some even double their ends inwards, others form into knots at one end, and others agglutinate and become round and knobby, and form "Hyson-skin." The small young leaves and the broken pieces of delicate ones adhere together in the same manner as the Hyson-skin, and assume a compact, hard, and altogether globular form, constituting "Gunpowder" tea. Thus the leaves of green tea are more compact and hard, as well as shorter than black tea, and, measure for measure or bulk for bulk, are heavicr. Thus we sce why the comparatively long thin form of the black tea leaf should render it more frangible than the contracted compact form of the green tea leaf.

It must also have been very commonly remarked that green tea on infusion gives out its strength and flavour more slowly than black. It takes a longer time for the leaves to unfold, in consequence of their compactness and hardness. It cannot have escaped observation that when black and green teas are mixed prior to infusion, the flavour of green tea predominates in proportion to the length of time the tea is allowed to draw. If poured off 
DIFFERENCE BETWEEN BLACK AND GREEN TEAS. 299

soon after infusion, the flavour of the green tea is hardly perceptible.

Thus it does not appear, either from analysis or otherwise, that there are any sufficient grounds for believing that black tea is roasted and dried at a higher temperature than green; or that the characteristic peculiarities of black tea are due to any condition or management of heat. They obviously arise from no such cause : no more than the conver'sion of barley into malt depends on high or low drying. Without previous germination there could be no malt. So black tea is here supposed to undergo, previously to roasting, a change analogous to what takes place in hay, during which a loss of tannin occurs, and a saccharine principle is set in action. On this change, its darker colour and mixture of red and brown leaves, its redness of infusion, and mildness of flavour, seem to depend ; independently of the temperature employed, or any management of heat. The manipulation of the leaves previously to roasting, as already described, is indispensably necessary to constitute black tea of good quality. Analogous effects may be produced by other means, but they must be considered as inferior methods.

But green tea seems to derive the better preservation of its natural colour and peculiar flavour from what approaches nearer to simple desiccation. Whatever decomposition here takes place, it must be sought for exclusively in the processes of roasting and drying. The light bluish colour of the dried 
leaves, resembling the bloom on some fruits, is due to a rapid process of drying, in consequence of a free admission of light and air to every part of the leaves while yet moist, and exposed to the action of a moderate temperature.

If the aroma of tea be not inherent in the plant, but generated during the process of manipulation, then that change which is effected in black tea by spontaneous heating, as in hay or tobacco, may in green tea, like the aroma of coffee, be elaborated by artificial heat by a process analogous to fermentation, as surmised by Von Essenbeck.

Hitherto, in tracing the causes of difference between black and green tea, I have endeavoured to direct my investigations mainly to colour. Flavour obviously depends on those general laws which govern the odorous principle of all vegetable productions. Some are the product of the plant itself; others are generated by various processes of manipulation. Thus, on what rests the characteristic difference of flavour between black and green tea, with all the modifications and varieties peculiar to each class, we may not, in our present state of information, be able satisfactorily to explain. Nor can anything short of a local examination of the tree in the several districts wherein it is grown, together with a chemical analysis of the leaf, in its fresh as well as its manipulated state, be deemed sufficient to satisfy any scientific rescarch on that subject. It has been demonstrated, however, that 
an essential difference exists in the manipulation of these teas sufficient to account mainly, if not entirely, for their characteristic difference of flavour and quality as classes.

It has, moreover, been stated that the fresh unmanipulated leaves have no kind of fragrance in their natural state: and in this particular resemble each other, before and after manipulation, no more than the smell of grass resembles the odour of hay; the odour of tobacco before, that after fermentation; the flavour of barley, beer ; the juice of the grape, the characteristic flavour of wine; or the aroma of coffee before, that after roasting.

In black tea, we find a mild, bland, fragrant, and agreeably astringent flavour, with a slight degree of sweetness, and both leaf and infusion of a reddish colour, apparently indicative of chemical change in its original constituents: which change has now been traced to a peculiar manipulation of the leaves previously to roasting.

But if we attentively observe the flavour of Hyson tea, however agreeable it may be when blended with rich cream and highly refined sugar, it undeniably possesses a raw astringent quality, and (if I may be allowed the expression without exciting alarm) even a poisonous flavour, which reminds one of the flavour of bitter almonds, of peach kernels, and laurel leaves. The manipulated leaf also retains much of its original colour, and the infusion is pale and yellow. Thus, both leaf 
and infusion seem to indicate little change in the constituents of this tea, and the process it undergoes seems more immediately connected with simple desiccation.

Thus it appears probable, as well from analysis as from manipulation, from examination of the infused leaves, the infusion itself, and the flavour, that green tea retains more of its original vegetable properties and character unaltered than black tea. Hence if there be anything narcotic or deleterious in the plant, as is generally surmised, these conditions may serve to explain why green tea acts more powerfully and detrimentally on some nervous and irritable constitutions than black tea. It must also be remembered that green tea contains a larger quantity of the essential oil than black tea, which Mulder considers of a highly poisonous character : it also contains more tannin; and green tea is used somewhat stronger in infusion than black tea, the quantity employed being regulated by measure, not weight.

Analysis shows that the characteristic flarour or aroma of tea is due to an essential oil; which in black tea is here supposed to be modified by fermentation, or some analogous decomposition of a saccharine principle, with which it unites; but in green tea the volatile oil and saccharine principle both remain intact. We further perceive how flavour may be variously modified by the fermentation of a saccharine principle in conjunction with 
a volatile oil: and, as in tobacco and wine, the odoriferous principle of tea may be susceptible of much variety by the management of this fermentation. It is, moreover, a fact, that black tea furnishes a greater variety of flavours than green tea. Strength or body seems to depend on the amount and quality of the astringent principle, or tannin.*

Now the difference of black and green tea, as classes, having been traced to difference of manipulation, it may be desirable here, in conclusion, to recapitulate concisely the different processes to which these teas are submitted.

The leaves of black tea are exposed to the sun and air on circular trays, and treated as hay, during which an incipient saccharine fermentation is supposed to take place in conjunction with a volatile oil. Various modifications of flavour are thus produced by the management of this fermentation; a loss of tannin takes place by the conversion of a part of the tannic acid into sugar.

* In conclusion it may be asked :-

1. If the distinctive character of black tea be the result of fermentation, may not some new principle be found in the leaf, analogous to nicotina in tobacco, which was not present previously to fermentation?

2. Whether the same or any other analogous principle be found in green tea after desiccation, which was not previously present?

3. What is the nature of the grey or blue colouring matter of green tea resembling the bloom on some fruits, when produced naturally in the regular course of manipulation?

4. Does liay contain any product not found in grass? 
During this change the leaves become flaccid, and slightly tinged or spotted with red or brown colouring matter; and give out a peculiar odour, approximating to, or, as some think, identical with, the odour of tea. A certain change in this odour is carefully watched by the workmen, this being an indication that the roasting must not be delayed. It is not necessary to wait till the leaves become spotted with red. They are then roasted in an iron vessel, and afterwards rolled with the hands, to express their juices. The roasting and rolling are repeated so long as any juices can be expressed from the leaves in the act of rolling. Finally, they are dried in sieves placed over a charcoal fire in drying-tubes, during which the leaves are occasionally taken from the fire, and turned until completely dried. It is in this last stage of the process that the leaves turn black, though this change of colour is mainly due to the process of manipulation previously to roasting, and not to the action of heat.

The leaves of the green teas are roasted, also, in an iron vessel, but as soon as gathered, without any previous manipulation, all heating or fermentation of the leaves being studiously avoided: they are then rolled as black tea, and finally dried in the same vessel in which they have been roasted, by constantly stirring and moving them about. They are also fanned to hasten evaporation, and the drying and formation of the peculiar charac- 
QUALITY DEPENDENT ON VARIOUS CAUSES. 305

teristic colour of this tea, which it gradually acquires in this process, and which resembles the bloom on some fruits. This peculiar colour is the result of a quick evaporation of the fluids, and the admission of light and air to every part of the leaves; and which, it is surmised, may work certain chemical effects altogether sufficient to account for the different results in this process. The essential oil of green tea, on which its aroma depends, appears to be developed, as in coffee, solely by artificial heat.

Thus the various known differences in tea may now be classed in the following order: -1 . Differences arising from natural causes, - as the age of the leaf; for instance, the unexpanded convoluted bud of the leaf, as in Pekoe tea and Longcsin tea, the one a black and the other a green tea; - the fully expanded, though young leaf, in all other teas; - the young and succulent leaves being only fit for tea:- and, the season of gathering, the spring leaves being the best, and the autumnal the worst.

2. Differences occasioned by atmospheric influences, as the state of the weather or season; the presence or absence of sun, rain, \&c., in common with all other vegetable productions.

3. Differences caused by various modes of manipulation, as the treatment of the leaves of black tea as hay previously to roasting;-- a difference in the processes of roasting and drying certain black teas, 
as Paochong, Sonchy, Pekoe, Souchong, and Congou; -a difference in the process of drying black and green teas; - a difference arising out of the assortment and separation of the leaves of green tea, by sifting and winnowing, into the classes of Gunpowder, Hyson, Young Hyson, and Hyson Skin; the same for Singlo and Twankay, when classed in the same manner, into Hyson, \&c. :- and, finally, that difference in all teas, black and green, which is occasioned by assortment and mixture of qualities to suit particular standard qualities and prices.

But due allowance being made for all these differences, though the mode of manipulation, care, skill, and all other circumstances be the same, yet, in common with all other vegetable productions, there remains a difference of quality which can only be ascribed to situation, soil, and cultivation, or some natural or accidental difference in the plant. Let us now proceed to examine this subject. 


\section{CHAP. XII.}

OBSERVATIONS ON THE BOTANICAL AND SPECIFIC DIFFERENCE OF TEA.-OPINION OF THE CHINESE, SOIL TIE ONLY CAUSE OF DIFFERENCE. - ANALOGOUS CASES IN OTHER VEGETABLE PRODUCTIONS. - NO DIFFERENCE AT JAVA.- NO CERTAINTY THAT WE POSSESS TRUE SPECLMENS OF THE BLACK AND GREEN TEA SHRUB OF COMMERCE. - THE THEA BOHEA A CANTON PLANT. - THE ASSAM PLANT DOUBTFUL AS TO SPECIES.EXAIINATION OF THE GROUNDS ON WHICH BOTANISTS HAVE ESTABLISHED A SPECIFIC DIFFERENCE. - OPPOSED TO ACTUAL OBSERVATION AT JAPAN, JAVA, AND THE BRAZILS. - PROBABLY ONLY ONE SPECIES BUT SEVERAL VARIETIES. - ALL BOTANICAL DIFFERENCE DESTROYED IN THE COURSE OF PACKING PROBABILITY THAT SUPERIOR SHRUBS DO EXIST IN TIE BOHEA AND HYSON DISTRICTS, THE EFFECT OF LONG AND CAREFUL CULTIVATION.

IT has already been observed, that the Chinese universally agree, from remote antiquity to the present day, that only the Bohea mountains produce the highest flavoured black tea. They noreover affirm that it is only in the central division of these mountains, which are known to the Chinese by the appellation of Nuy Shan (inner mountains), where the highest flavoured teas are produced; and that the teas deteriorate in quality as the plantations diverge from that particular locality; till in some of the most remote districts, "the leaves are thin and poor, have no fragrance or 
swectness in infusion; and that no labour can make them good." (pp. 44, 45.) The Ankoy teas growing in the vicinity of Amoy in the same province, are for the most part inferior; and the Honan and Wo-ping teas, both the growths of the province of Quong Tong (or Canton), may be given as examples of still greater inferiority.

Further, the Chinese profess to distinguish, even in their manipulated state, the teas of certain districts and situations, both in the black tea country and in the green. It has also been shown, that particular shrubs in the most favoured districts of the Bohea country are said, in some few cases, to be labelled, and designated after certain flowers, which they are supposed to resemble in flavour; and that good judges of tea recognise the hill or site of the growth of these and other teas, by their flavour in infusion.

There can be no doubt that the Wo-ping and Ankoy teas have their characteristic flavours; and that the latter teas especially, are distinguishable by the general appearance and odour of the leaf, as well as flavour in infusion. It is also remarkable that this peculiarity in the character of the leaf, and flavour in infusion, seems at present to be retained at the plantations of Kamaon in India; which (as we learn from Dr. Falconer, who reared up these plantations) were formed, as it is supposed, from the seed of Ankoy plants brought by Mr. Gordon from Amoy. 
Now it has been shown, that all these differences of flavour and quality, the Chinese most unequivocally ascribe exclusively to soil. In the black tea districts of the province of Fokien, they positively affirm, that there is no difference in the plant. Similar opinions almost universally obtain in the green tea districts, nor do I see any reason to discredit this belief on the part of the Chinese, since they are perfectly conversant with the art and necessity of propagating certain varieties of plants by grafts and such like expedients.

Nor does this testimony of the Chinese differ essentially from the commonly received opinions entertained by scientific and practical men, regarding the effect of soil and atmospheric influence on vegetable economy, and known facts of other plants, such as wheat, barley, rice, cotton, the vine, coffee, the orange, the citron, \&c.

It has been shown, that a vast improvement was effected in green tea, by bringing the plants from the hills into the plains, and by cultivation and manure. This practice has existed for at least six hundred years. It is, therefore, easy to conceive that the cultivated plant, thus renewed, and propagated for centuries from the seed of improved plants under altered circumstances of site, atmosphere, soil, and cultivation, may so far have estranged itself from its original parent stock that, even in the green tea districts, these two plants. 
may have assumed, externally, all the distinctive characters of two species.

Thus, botanists ignorant of the causes of this difference, and left with no other means of judging than the external characters of the plants, might, having such specimens before them, very probably, and very justly, class them as two species.

The vast inferiority of the flavour of Twankay tea, the product of the green tea plant growing on the hills, with little or no attention paid to its culture, to that of the Hyson tea, the product of the highly cultivated plant on the plains, would be apparent and interesting to any one disposed to try the experiment, by purchasing these two teas in any well known and respectable grocer's shop; viz. common Twankay and fine Hyson at fair average prices.

If, then, so great a change is effected in the plant by soil and cultivation, and the opposite colours and flavours which exist between black and green teas are exclusively due to manipulation, as has now been proved, not only by myself but in Java, may not soil and cultivation be sufficient to account for the difference, if any there be, between the Congou and Twankay shrubs, - the two teas, black and green, whose circumstances of situation and cultivation approximate nearest to each other? So far as Java is concerned this question no longer admits of doubt. It has been satisfactorily proved that all the distinctive characters of black and 
green tea are now produced there from the same shrubs and the same leaves. Mr. Jacobson assures us, that black and green teas are reared in Java from the same seed; and that all difference in tea is due to soil and manipulation.* In a botanical sense there is no difference of species. One part of a plantation may produce highly flavoured teas; other parts only common tea. Both may be of the nature of Souchong tea, or both of that of Congou; or one Souchong and another Congou. As regards green tea, one may be of the nature of Twankay; and the other of Hyson. $\dagger$ Nor can any thing be predicated of these plants, as being more suitable to the manipulation of either of these two classes of tea. Experiment, by the ordinary course of manipulation, can alone determine what part of a plantation is more suitable to black tea, and what to green. $\ddagger$

But if this be true regarding Java, it affords a strong presumption that it may be equally true with respect to China.

It may, moreover, be observed, that the Chinese universally agree, that the consumption of green tea in China is of very limited extent. The green tea merchants and factors affirm, that it is hardly used out of the province where it is grown. A little "superior Twankay" is sent to the Court of

* Handboek v. d. Kult. en Fabrik. v. Thee. $\$ 6$.

$\dagger$ Ib. $\S 197$.

$\pm \mathrm{Ib} . \S 34$. 
Peking and into Tartary; but the bulk of the green tea made with care in the district of Wheychew-fu is intended for foreign consumption. So if any particular species or variety found there be necessary or advantageous for the manufacture of green tea, it must then be conceded that this species differs from all others in China; or, that in other parts of the Empire it is made into black tea, or, indifferently, into black and green.* But who can affirm whether all the different kindsspecies, or varieties - here alluded to, may not be common both to the black and green tea countries; and to the several districts in each, or even on each farm; and that all these differences are for

* The Lo-gan tea, which is extensively used in the vicinity of Macao in the province of Quong Tong, is a black tea grown in that part of the province of Kiang Nan now called Ngan Goey. It is packed and sold in small baskets containing about $1_{3}^{1} 1 \mathrm{~b}$. of tea. The Jesuit missionaries say, that they compared this shrub with the tea grown in the district of Whey-chew-fu, and did not find that it differed from that plant. I think it proper to draw the reader's attention to this observation, though I do not attach much importance to it myself, because, to determine whether there be any botanical difference between these two shrubs, the one employed in the manipulation of black tea and the other of green, they must be examined by a botanist. To those who were acquainted with the little plantation reared by me on the Lapa, but now I understand altogether neglected, it may be useful to remark that the shrubs grown on the little raised embankment on the left hand side of the plantation, were said to be Lo-gan plants. They were remarkable for their upright stems and large and coarse leaves. It has before been remarked that these shrubs were manured, to which their luxuriance of growth appeared to be mainly due. 
the most part disregarded by the Chinese, and all mixed together in each country and on each farm, in the course of manipulation and packing, like many varieties of the apple in most cider orchards in the making of cider ; or like different varieties of the grape in making the vin de pays. I am much disposed to believe that this may be found to be the fact.

But we have no authentic information on this subject; no botanist has ever been able to penetrate into those particular districts, where the tea shrub is cultivated for foreign consumption.

So far as my information extends, there is not even any certainty that specimens of the plant from the black and green tea districts have been examined and described by any botanist. It is an undeniable fact that no reliance can be placed on the genuineness of the numerous specimens sent to Europe. The plants generally furnished and sold by the Chinese as such, are mostly Canton plants; the Thea Bohea, or Stricta, being the Honan plant, and the Viridis or laxa, consisting of plants procured from Sy-chin shan, Pe.yuenhiang, and other villages in the province of Quong Tong; the fresh leaves of which are of a light green colour, though they are commonly employed to make black tea for Chinese consumption.

That true specimens have been procured at different periods from the tea districts cannot be doubted, but the instances have been rare; and 
no certain record has been kept, or at least published, of which I am aware after diligent inquiry, of the locality of any such plants. It is obvious from the remote distance of the tea provinces situated 800 or 1000 miles from Canton (the only port till lately accessible to Europeans), and the jealousy and suspicion of the Chinese, in common with all artisans and manufacturers on subjects of craft, that specimens must be difficult to procure; and, even when obtained, a doubt must always remain as to their being genuine or not.

- Thus, so far as Chinese testimony, and facts collected from the Chinese are concerned, there seems no reason for supposing that a natural difference exists in the plants in China, which furnish the teas of commerce, any more than at Japan, Java, or Rio de Janeiro.

To the general reader it may be advisable to observe, that there are two points involved in this investigation of a botanical difference of the tea plant. 1. Whether there is a specific difference between the plants called the Thea Bohea, and Thea Viridis. 2. Whether there be a specific difference between the plants from which the black and green teas are made.

If some botanists deem the difierence between the Thea Bohea and the Thea Viridis, as seen in our gardens, to be a specific difference, that is a matter of fact which admits of no argument according to their views and definitions of species. But 
other botanists, having the same specimens before them, dissent from that opinion, so that this point must remain an open question among botanists.

With respect to the Thea Bohea of our gardens, Mr. Reeves and myself have always been of opinion that this plant is identical with the Honan plant. It may now be considered that Mr. Fortune has fully established the fact of the identity of character of these two plants; but whether this plant represents the plants exclusively cultivated throughout the province of Canton, and that the teas manufactured in that province are therefore the product of the Thea Bohea, as Mr. Fortune appears to consider*, seems to me to require much more examination. It does not appear that Mr. Fortune was enabled to penetrate into any parts of that province not accessible to others, or that he visited any other plantations than those of Honan.

Certainly the Thea Viridis is just as common in the nursery gardens of Canton as the Thea Bohea. It was a common practice among the captains and officers of the E. I. Company's ships to make purchases of both these varieties; which the Chinese ordinarily procure from the neighbouring districts, and from which there is little reason to doubt, that our public and private gardens have been mostly stocked. It is true that a very ordinary kind of green tea is made in this province, and which is

* Wanderings in China, 2d edition, pp. 189. 213. 219. 
coloured at Canton for the American markets; and also different kinds of black teas for Chinese consumption, but from what shrubs or in what localities is not precisely known. The places indicated by the Chinese are, for the most part, remote from the city, such as Tien-pack, Sam-ta-chok, Wo-ping, \&c. But this green tea never formed any part, at least of late years, of the E. I. Company's investments; nor did the black, which was Wo-ping tea, except as a mixture with common Congou to pack as common Bohea, the lowest quality of tea imported into England. What is said of the manufacture of black and green tea at Canton, and also of the conversion of black into green, and green into black, and the use of colouring matter for such purposes, must not be confounded with the regular mode of manipulating tea in the tea provinces. All such transactions, however extensive, can only be viewed as frauds practised on Europeans.

The total quantity of the teas manufactured in the Canton province for the supply of foreigners must be altogether insignificant. They are invariably of the lowest description, and, properly considered, do not constitute any of the teas of foreign commerce.

Nor can it be admitted as prored, as Mr. Fortune would seem to think, "that the black and green teas of the northern districts of China, (those districts in which the greater part of the teas for the foreign markets are made,) are both pro- 
duced from the same variety, that variety being the Thea Viridis."*

What Mr. Fortune has proved is, that the plants he saw in the province of Fokien, on some farms about from thirty to forty miles north of the city of Foo-chew-foo, corresponded with plants seen in the province of Che Kiang. They were all alike, of the species Thea Viridis, - on comparison "no difference was to be observed." $\dagger$ It is hardly necessary again to point out to the reader that the hills and plantations here alluded to were at least 150 miles from these Bohea districts, where the black teas for foreig consumption are almost exclusively made. The Chinese say that none of this tea is produced south of Kien-yang-fu : however, I believe some inferior kinds are procured from localities not far north of Kien-ning-fu, but none south of that city.

Still less can we accept the conclusion, that the teas of the Ankoy district are the product of the Thea Viridis. For it does not appear that this district, which really does produce some of the teas of commerce, or any other tea plantations in the vicinity of Amoy, were visited by Mr. Fortune.

Thus, the question whether there be a specific difference or not between the black and green tea, connected with foreign consumption, seems to me still to remain an open question.
* Wanderings in China, 2d edition, p. 189.
† Ibid. p. 260.
$\ddagger$ Ilid. p. 220. 
The preceding remarks are not intended as any disparagement of Mr. Fortune's work, which conveys in a lively and pleasant manner much interesting information respecting the coast of China and the districts in its vicinity, but introduced merely to prevent erroneous conclusions being drawn from the unavoidably partial and imperfect intelligence he was enabled to pick up in the course of his tour, on a subject of much real intricacy and difficulty.

With respect to the Assam plant some botanists and practical gardeners find it difficult to believe, and with much show of reason, that a tree of from thirty to forty feet in height, and eight inches in diameter*, can be of the same species as the diminutive tea plant of China and Japan. Yet it is affirmed to be identical by competent botanists, and otherwise scientific men, sent expressly to determine that doubt.

But whether the Assam tea tree be a distinct species or not, it is evident that the form, height, and circumstances under which it was found, are those of a forced and unnatural growth. "When the surrounding jungle was cut down," says Mr. Bruce, "the long slender stems of the tea tree seemed hardly capable of supporting their own weight."

It is said on good authority $\uparrow$ that the Chinese

* Journal of the Botanical and Horticultural Society of India, p. 30 .

$\dagger$ Private correspondence with Father Carpina. 
tree attains a height of from 12 to 15 feet, in places where it is undisturbed by cattle. The Pen-csao-kiang-moo states, "from 20 to 30 feet (literally many tens of feet); and some are so large that two men cannot clasp them, but then they are cut down as useless." These last, however, cannot be deemed tea, and the authority of the compiler is weakened by this classification.

It remains to be considered, whether the Assam tea tree is a greater deviation from the ordinary growth of the wild tree in China, than the wild tree from the stunted cultivated shrub. Are we not too much in the habit of considering the cultivated form as the natural one? And is not the tea tree presented to our minds, as resembling more a gooseberry or currant bush, than a tree whose natural growth is from twelve to fifteen feet in height? Further, it may be questioned whether this deviation in height and form is greater than may be found in other trees, - such as the olive, the apple, the pear, oak, \&c. Liebig says we know nothing of the size which trees are enabled to attain; and it must be acknowledged that our acquaintance with the habits of the tea tree is very limited.

If it be questioned whether a plant, indigenous to a climate subject to severe frosts in the winter season, can possibly be identical in species with one growing luxuriantly under a tropical sun, it is perhaps some answer, that the tea tree is known to 
be cultivated in Tonquin and Cochin China; and was, so far as regards its vegetative powers, successfully propagated at Penang at low altitudes, but its cultivation there was finally abandoned on account of a total deficiency of flavour.

However, whether the Assam tree be a distinct species or otherwise, it is certain that teas of useful quality are now made at Assam. By cutting down the stems of the old trees to encourage the growth of young shoots, by exposure to direct solar light and heat and free ventilation, and by cultivation from seed, the character of the Assam tree has been much improved, and now approximates more to the flavour and quality of Chinese tea. It is diminished, however, in strength, and is still very deficient in flavour.

Let us now examine on what ground the specific difference of black and green tea was originally received and now stands.

The first classification of the tea plant of any authority was by Linnæus, in his Species Plantarum of 1753. He first classed it as one species (Thea Sinensis), but in the second Edition, 1762, he was induced, by reasons which do not appear, to alter his specific arrangement to the Thea Bohea and Thea Viridis. Up to that time he had seen no living plant, but in October, 1763, he obtained living specimens through C. G. Ekeberg, a captain of a trading vessel, which were the first brought to 
Europe, and were planted in the Botanic Garden at Upsal. These, it appears from the edition of the Systema Vegetabilium, 1774, were of the Thea Bohea, and the learned naturalist seems always to have had a difficulty in discriminating his two species. In the Amœnitates Academicx, Vol. vii. 239. t. 4. (1765), it is said that the two species are so alike, that they might be considered to be varieties only; and he there states that in the specific difference founded on the number of petals, he had been guided by the authority of Hill, and not by his own experience. In an interleaved copy of the Species Plantarum which may be seen at the Linnæan Society's House, he has made frequent alterations in his specific character's, and there is much reason to think he never satisfied himself in this respect.

Loureiro, who saw the tea tree both in Cochin China and at Canton, adopted the classification of Linnæus, making the specific difference to depend upon the number of petals. He judiciously named these plants after the places where he saw them Cochin Chinensis and Cantoniensis. But according to the petalous classification, the Cantoniensis, as it consists of seven, eight, and nine petals, ought, agreeably to the Linnæan arrangement, to be the green tea plant; and probably was so considered by Loureiro, as it has since been by many, if not most botanists. (See Encyclopédie Mléthodique.)

But if it were from the Honan plantations that 
Loureiro framed his description, (and it was not possible he could have seen any other,) every one conversant with the subject knows, that the leaves of the Honan plant are exclusively made into black tea. Further, it is believed by Mr. Reeves and myself, that the Thea Bohea of our gardens, and the Stricta of Aiton, are identical with the Honan plant; and I believe it may be asserted without much fear of contradiction that both these are again identical with the Cantoniensis of Loureiro. It seems to me important that botanists should fully comprehend the fact, that the Cantoniensis of Loureiro, the Stricta of Aiton, and the Thea Bohea of our gardens, are all identical with the Honan plant. They are all descriptions of the same plant, taken from the same plantations. Aiton does not give the Stricta and Laxa as new varieties, but as new terms, in lieu of those of Bohea and Viridis; in the same manner as Stricta and Diffusa are employed by Von Siebold. Indeed it must be acknowledged that the terms Bohea and Viridis may have been adopted too hastily.

No doubt much confusion has been introduced into the botanical classification of the tea plant, in consequence of the imperfect sources of information, from which botanists could alone draw their conclusions.

Thus in the Encyclopædie Methodique and other works, we find the Cantoniensis' (Lour.) regarded as a variety of the Viridis (Linn.), and by De Candolle 
as the Bohea (Linn.). Again, De Candolle, though he regards the Cantoniensis as the Thea Bohea, yet considers the Stricta of Aiton (which we have here supposed to be identical) to be the Viridis. In these respects De Candolle adopted the views of Sims.

Moreover, botanists now agree that no specific difference can be established on the number of petals of polyandrous plants, in consequence of the disposition of the stamens to transform into petals. Then, if the corolla be rejected as a sign of species when its character is not sufficiently permanent, can it be said that the other character's of Loureiro prove any thing more than that the Cochin Chinese plant is one of luxuriant growth, and the Canton a stunted distorted shrub? "Arbor octo pedes alta; ramis diffusis," the one; and "Arbuscula quatuor pedalis, ramosissima, tortuosa," the other.

Again, if we examine the shape, size, and form of the serratures and colour of the leaf, we shall find them, as it appears to me, from their inconstancy, equally unsatisfactory signs of species with the corolla. Lettsom describes the leaf of the Viridis as "latitudine triplo longioribus," and Sims the Bohea, "latitudine duplo longioribus;" which descriptions agree sufficiently well with that of Linnæus, "Bohea ovalia, Viridis autem oblongiora habet folia." But I have impressions of some infused leaves of a fine Paochong tea in daily use in the year 1823, taken accidentally and without any definite object, which correspond not with the 
description of black tea as given above, but with that of the green tea. Other examples of leaves, however, as in Congou tea, do accord better with the descriptions of botanists; but this only shows again, that the form and size of the leaf are inconstant.

Kœmpfer, who saw the tea tree at Japan, simply describes it ; thus considering it of one species.

Thunberg also saw it at Japan, and he classed it as one species, but two varieties, making the difference to depend on the form and colour of the leaf.

A very recent traveller Japan, Dr. Von Siebold, makes no less than four varieties dependent also on the form of the leaf, but only one species. *

M. Guillemin also states in a letter addressed to a friend of mine, in answer to some questions put at my instance, that only one species is cultivated at the Brazils, which is the Thea Viridis. The other species, the Thea Bohea, he consider's as a mere curiosity. "On ne cultive au Brazil qu'une seule espèce de Thé ; mais cette espèce offre un grand nombre de variétés quant a la forme des feuilles. Cette espèce est le Thea Viridis L. L'autre espèce botanique (Thea Bohea L.) est maintenant cultivée en Europe. Cette plante est de pure curiosité. Je ne sache pas qu'elle soit cultivée pour la pré- 
paration de ses feuilles; du moins je ne l'ai pas vuc dans la culture Brasilienne."

Thus all botanists who have seen the tea plant under extensive cultivation out of China agree, (and Loureiro had no such opportunity in China) that there is no specific difference in the tea plants which came under their observation. And even Loureiro states, that all the differences of the Chinese Thea may be derived from a single botanical species, consequent upon diversity of soil and culture. Von Siebold, moreover, observes that, in a plant which has been cultivated for so many centuries, and in such different climates, the number of petals, the growth of the shrubs, and the shape and largeness of the leaves, are not sufficiently permanent characters to constitute signs of species.

It must, however, be acknowledged, in conclusion, that botanists generally agree that there are two distinct characters of the tea plant, whether specifically different or not, having for types the Thea Bohea and Thea Viridis. So far also as experience of these plants in our gardens is concerned, they differ in habits, as well as in appearance. The Bohea is a more tender plant than the Viridis. The latter, under certain management, bears our climate in the open air in winter; the former not.

But whether the differences found in these plants justify a classification into separate species, must depend upon the views and opinions of botanists as to what constitutes, or what conventionally, 
for accuracy of language and nomenclature, it may be deemed convenient to make a specific difference.

I shall now describe what has come under my own observation.

A curious and beautiful specimen of the tea plant was brought to me from the Bohea country. The leaves were large, broad, and luxuriant, and their colour of a dark green. I was surprised to find the leaf wrinkled (bullate); a character which I had until that time, in common with others, considered peculiar to the green tea, but which I have since had reason to think is not confined to that species or variety. 'This plant was afterwards placed in a good garden soil in an elevated situation at Macao, with a northern exposure. In the course of a few months it changed colour, and the leaves became of a bright green, and the plant resembled those specimens I had seen in gardens at Macao, which were considered green tea plants. This plant was afterwards placed in a small plantation on the Lapa, an island forming one side of the harbour of Macao. It was here placed near an excellent specimen of the green tea plant, brought to me by a green tea merchant, Tien Hing, in whom I had great confidence. These with many other plants were seen by a skilful botanist and scientific man, Dr. Abel, who accompanied Lord Amherst on his embassy to Peking. His attention was particularly directed to the two plants in 
question, concealing nothing from him as to their origin; but he saw nothing in the leaf or general character of the plants on which he could establish a specific difference. He nevertheless, on his return to England, inclined to the opinion from impressions received on his journey from Peking, and from information obtained at Canton, that a difference of species might be established.

It must be remembered, however, that this scientific and well informed author suffered a severe fit of illness during his journey down the country, and finally, the loss of many of his papers and collections in the wreck of the Alceste. But if these specimens were really what they were represented to be, I do not know that a more satisfactory test has ever been afforded of the specific identity of the plants yielding the teas of commerce-so far as that can be established on the comparison of only two plants. For if we doubt the specimens procured by respectable parties, each from his own country, how can this question ever be settled except by a competent examination on the spot in the particular districts where these teas are grown?

Mr. Reeves, whose contributions and labours as a botanist and naturalist, while in China, are well known and highly appreciated, is of opinion that there are two strongly marked rarieties, if not two species, constituting the difference between black and green tea. No one can doubt the respect due 
to the authority of this gentleman on such a point. But it may be here observed, that Mr. Reeves speaks doubtingly as regards species, and evidently contends simply that manipulation would not be sufficient to account for the dissimilar flavours found in these teas, black and green, without some marked and essential difference between the two plants. But Mr. Reeves is willing to admit, as every other botanist must be, that variety is sufficient to produce all the difference here required. There is a diversity of flavour and quality found in the golden pippin, the nonpareil, and the codling, and in the common crab and the cultivated apple; yet botanically they are all of the same species; and, again, in different wines made from different varieties of the grape.

All, therefore, that Mr. Reeves means to observe is, that there must be a strongly marked difference between plants yielding flavours so distinct as those of black and green tea, whether there be a specific distinction or not.

It was the opinion of Kerr the botanist, a highly respectable and meritorious man, who was sent to Canton by Sir Joseph Banks, and who resided there several years under the protection of the British Establishment, that there was only one species, but many varieties, and this opinion was formed on examination of plants seen at Canton.

Not having made botany a study, my opinion of course is deserving of less weight, but having paid 
some attention to the botanical question as concerning the two species of the tea plant, and having had the opportunity of seeing many different plants, as well as hearing the opinions of men qualified to judge, I may, perhaps, be excused for offering that opinion here.

I incline, then, to the belief of Kerr that there is only one species in China; by which I mean, that there is no natural difference in the plant. Whether any varieties have become permanent in the soils where they grow, that is, capable of propagation by seed, as appear's to be the fact with the Honan plant at Canton, and apparently with the Ankoy plant near Amoy; or whether the plants, found in the black and green tea districts, vary from each other, and are more suitable to the modes of manipulation adopted in each, is a question which can only be satisfactorily determined by examination and experiment on the spot.

Enough, however, has been said to prove that the modification of colour and for'm of the black and green teas in their manipulated state, arises from a different process of manipulation, independently of any variety of the plant, or any quality of the soil. And of flavour it may be said, that, all other circumstances being the same, the difference also arises mainly from manipulation, though partly, perhaps, from some accidental change produced in the plant by atmospheric influence, soil, and cultivation.

But whatever diversity of flavour may be due to 
difference in the plants themselves, or however much certain qualities may be confined to particular localities, both in the black and green tea countries, yet it is very doubtful how far such peculiarities affect the teas of commerce, except so far as mixture is concerned in forming a particular quality suited to a fixed price.

The Congou tea, which constitutes the bulk of the tea imported into England, is formed into parcels, each sufficient to pack 600 chests, together weighing 52,000 lbs. of tea, all of one uniform quality, and purchased at the same price. Some of these parcels are sufficient to pack 1000 chests. Thus all difference of gathering, age of leaf, and district, all individuality, botanical distinction, and difference of quality must be lost in this mixture. The same may be said of the Twankay teas in the green tea country.

Still it is highly probable that a superior kind of tree does exist in the central division of the Bohea mountains, the product of long and careful cultivation carried on under favourable circumstances through a period of at least one thousand years: and the same in the green tea districts of Wheychew-fu. In these two districts, also, more skilful as well as more careful modes of manipulation prevail; and to these circumstances, more than to any natural difference in the plant, may be ascribed the high estimation in which these teas, and especially those of the Bohea district, are held through- 
out every part of the Chinese Empire, as well as to the preference given them by Europeans.

It is probable therefore that, like the Chinese, we may still be indebted to these districts for superior teas, however successfully the shrub may be cultivated in other parts of the world.

At the same time it is impossible to foresee what improvements may be made in the plant, by the novel modes of cultivation which science has - introduced into Europe. It has already been observed, more than once, that a vast improvement was effected by the Chinese in the Singlo tea by an improved mode of cultivation, by which its value was enhanced in some cases nearly threefold. And though the Chinese cultivators of black tea may not have received sufficient encouragement to attempt any great amelioration of the shrub by improved methods of cultivation on an extensive scale (the great profit on black tea having always been engrossed and monopolised by the Hong merchants at Canton), yet it by no means follows, when the superior activity, enterprise, skill, intelligence, and capital of Europeans shall be brought to bear on these points in our own colonies, that such efforts may not be rewarded with eminent success.

It is encouraging, then, to reflect, that a field so vast, with so goodly promise, is now opening to the exercise of ingenuity, skill, and commercial advantage of those enterprising individuals, and those en- 
lightened governments whose thoughts are now turned to this subject.

I shall now make a few observations on the probable success which may attend the cultivation of the tea tree in our colonies. 


\section{CHAP. XIII.}

INTRODUCTION OF THE CULTIVATION AND MANIPULATION OF TEA INTO INDIA. - SUPPOSED LOW RATE OF WAGES IN CIINA, AND GREAT COST OF PRODUCTION EXAMINED. - MODE OF LIVING OF THE HINDOO CUITIVATOR - OF THE CHINESE CULTIVATOR, - COMPARATIVE IRATE OF WAGES IN THE TWO COUNTRIES. - SKETCII OF THE TRADE UNDER THE EAST INDIA COMPANY. - EFFECTS ON PIICE SINCE THE ABOLITION OF TIIE CHARTER. - GREAT PROFITS OF THE HONG MIEICHANT. - EXPENSE OF TRANSPORT OF TEA FROM THE TEA COUNTRY TO CANTON AND FOO-CHEW-FOO COMPARED. - COST OF TEA AT ITS SEAT OF GROWTH. - COST TO THE EUROPEAN AT CANTON - AT FOO-CHEW-FOO. - PRICE WITH WHICH THE CULTIVATOR WILI, HAVE TO COMPETE. - COST OF PRODUCTION AT ASSAU - KAIAON - JAVA AND TIIE BRAZILS.

The discovery of the tea tree in Assam, and the recent successful cultivation of the Chinese plant at Kamaon, in the upper provinces of India, encourage a well-grounded hope, that this valuable tree may soon be enumerated among the useful products of our extensive Eastern possessions, and thus conduce to the comfort of the native inhabitants, as well as to the internal prosperity and commercial relations of the country.

It is generally admitted that the natives of India have a decided predilection for tea; and could this article be afforded at a sufficiently low price, little doubt is entertained that its consumption would 
rapidly spread over that immense peninsula; and when we consider the abstinence from animal food, which is imposed on the Hindoo by his religion, we cannot but think that the introduction and adoption of the Mongolian method of using tea in its broth-like form, mixed with butter and meal, would furnish not only a refreshing, but a somewhat substantial adjunct to his meagre dietary; while the leaf used as an infusion, -

That cheer, but not inebriate,"

"the cups

would administer greatly to his comfort, health, and sobriety.

The population of British India and its dependencies is computed at 114,430,000. Supposing these to become, like the Chinese, all consumers of tea, the impulse which this novel demand for labour would give to a country mainly dependent on its agricultural resources; the new, unprofitable and otherwise unoccupied mountain lands which would thereby be brought under cultivation; the industrial activity its manipulation and preparation would call forth; as well as the new and indirect demands on industry it would develop; and lastly, though least to be considered, but nevertheless of high importance, the new sources of revenue it would open to the government - are all considerations of such vast interest, that it ought not to be a matter of surprise, that the encouragement of the cultivation of tea on an extensive scale, is daily 
becoming more and more a subject of anxious solicitude on the part of the India Government.

Great as these immediate advantages may be to India, as administering to the comfort and happiness of its native population, yet its remote benefits are not less pleasing and important to contemplate.

If tea can be produced in India at no greater cost than in China, can it be doubted, that an extensive cultivation of it must be greatly instrumental in promoting, and even forcing, an opening to commercial intercourse with the whole extent of Central Asia, and which may not be so readily effected by other means?

It would be easy to exchange our tea, woollens, and perhaps felt and calicoes, for shawl-wool, horses, metals, and other articles, as well as for rhubarb and musk, which are already procured from Tibet by way of Canton.

In a previous chapter, I have dwelt at some length on the extensive use of tea in Mongolia and Tibet, in order to show how much that particular form of tea denominated "Brick-tea" has become not only a necessary of life, but an article of daily, and, even, of frequent use during the day, among these people.

Indeed, this brick-tea may be seen traversing all Central Asia in every direction from the Gulf of Corea to the Caspian Sea. So far back as about 1818 or 1820 , that learned and accomplished tra- 
veller, Mr. Manning, who penetrated to Lassa, suggested to the directors of the East India Company that we might supply Tibet from Canton by way of Calcutta and Bootan, at a lower rate than the Chinese furnish it by the tedious and expensive route at present pursued over-land, and which I believe to be true. Still more advantageously, then, could it be supplied as a product of India.

Nor does there appear much reason to doubt, that we may even compete with China in the British, European, and American markets, in the supply of teas suited to general consumption, if not in the highest flavoured teas.

We will now proceed to examine this latter subject in its different bearings.

The prominent argument put forth against a successful cultivation of the tea tree in our colonies, has chiefly been the great cheapness of labour in China; its dearness in our colonies, and an erroneous supposition that the process of manipulation was a laborious and expensive art. It is unnecessary here to enter into a detailed examination of these supposed impediments, but it may be remarked in passing, that the successful competition of any agricultural or manufacturing product does not depend entirely or even mainly upon the difference of price of labour in the two countries making the exchange. The relative value of the commodities in the two markets between which the exchange is made is a surer test, for example, 
the relative prices of woollens, or cotton yarn, and tea in China, and their prices in England. Nor is this a certain test, even if true in theory ; because a number of disturbing causes affect and perplex the calculation, such as monopolies, protective and differential duties, bounties, and imposts generally.

Thus the higher price of labour alone in Europe would not be an infallible test against the power of successfully competing with China in the cultivation of tea, as I shall, by-and-by, incidentally show. A far safer comparison for our purpose seems to me to be the cost at its seat of growth, and the price at its place of consumption.

The comparison, however, with which we have to deal at present, is not between its cost of manipulation in China and our colonies in general, but between that country and India.

The climate of China, as already shown, is a climate of extremes; that is, the cold of winter and heat of summer are both excessive. Thus, while the inhabitants of Calcutta are experiencing comparatively warm weather in the winter season, the Chinese of Canton, in about the same latitude, are clothed in their fur garments, woollen and quilted cottons.

Again, if we examine into the domestic comforts and habits of these two people, we find the Hindoo satisfied with a small mud hut or shed, which he hardly inhabits by day, preferring the shade of a palm or other tree. An unformed piece 
of calico thrown about his half uncovered person serves him for a garment, while a thin waxed calico cap or small turban protects his head. Frequently a small piece of cotton cloth, rolled and fastened about the waist, is his only covering in the hot season. In the cold season a coarse piece of woollen cloth, as it comes from the loom, and of the manufacture of the country, serves to protect him from the inclemency of the weather by day; and spread on the bare earth, or on a rough framework raised a foot or more from the ground, is made to supply the place of a bed and blanket at night. Seated on the ground he requires no other instrument than his fingers with which to eat his food. This consists of rice savoured with a little clarified butter, a few condiments, and some vegetables, no animal food - no flesh. Furniture he has none, and his household utensils consist of a brass or iron vessel in which he boils his rice, and an earthen platter to eat from. To these may be added a brass or earthen vessel to contain the impure water he is occasionally doomed to drink. 'The dried leaf of a palm serves him for a fan to cool himself with, and to beat off the musquitoes: but a somewhat elaborate and luxurious instrument containing tobacco administers to the comfort and indulgence of smoking.*

* Minutes of Evidence on the Renewal of the East India Company's Charter, 1813 ; see Mrajor General Kyd, Sir Thomas Munro. Thomas Graham, Esq. and others. 
The Chinese, on the contrary, has a good substantial mud or brick house, generally thatcher, but not unfrequently tiled. Within are seen chairs, stools, and tables, a moveable bedstead formed of planking and bamboo, besides bedding. His shelves are well stored with cups, sancers, tea-pots, jugs, basins and jars; and his culinary vessels consist of iron and earthen pots, pans, and kettles. Nor are his shelves altogether devoid of books. At his meals he is seated in his chair or on a bench at table, and uses two neatly turned little sticks of lacquered-ware or bone, which he places between his fingers, and uses with the same dexterity and efficiency as the European his fork or spoon. He has his little spoon, also, but made generally of glazed earthenware, for soup or soy. And his frugal repast, though it consists mainly, like that of the Hindoo, of rice in the south, or some form of wheat in the northern provinces, yet two or three little dishes, neatly served and agreeably cooked, consisting of fresh or dried fish, dried water-fowl or other dried meats, a little fat pork, and some vegetables, complete the bill of fare. And, like a highly polished people, to whom the Chinese have been compared by very experienced judges, he closes each meal, of which there are three in the course of the day, not very dissimilar, with his petit verre, or small cup of samshew or spirit, but taken before his tea instead of after coffee. In this manner live the boatmen, the coolies or porters, the packers of 
tea, and the few agriculturists who have come under my observation at Canton and Macao. His dress consists of various cotton garments, light for summer and quilted for winter; and he wears on his head a strong and well-made bamboo or straw hat, broad enough to protect him both from sun and rain. Nor is he without his great coat, which, though not made of costly materials, being of flags, is nevertheless very effective in protecting him from rain.

It must by no means, however, be inferred, that the condition of the Hindoo is one of privation; on the contrary, slender as are his means, they are adequate to his wants: nor ought he to be disadvantageously contrasted with the labourer of China as regards the ease and comforts of life. It is evident that the wants of the two people are necessarily and widely different; that the climate of China calls for more warmth, a greater variety of clothing, and more animal food. These greater requirements of the Chinese labourer have stimulated his industry; and being favoured by the institutions of his country, he has been enabled to secure to himself a greater amount of the comforts and conveniences of life than the Hindoo, if not more than some Europeans. He is raised in the scale of humanity; he feels his independence; he must be proportionately remunerated; and he is too active in mind and body to sink into indolence or apathy; preferring, as a last resource, expatriation to abject poverty. 
The following statement, may suffice to furnish some general idea of the comparative value of labour in India and China.

Sir Thomas Munro states the wages of an agricultural labourer at Madras to be from $4 s$. to $6 s$. the month; that the expense of a single individual among the class of cultivators and manufacturers does not exceed 27.s. the year; and among the lower classes 18s. including food, clothing, furniture, and every thing else. Mr. Cockburn states this expense at 32s. Lord Teignmouth also states, that at Bengal 3s. a month is adequate for the support of a single person.* Dr. Falconer informed me, that the pay of an agricultural labourer at Kamoon is $8 s$. the month; and $8 s$. will dress him from head to foot.

In the south of China it is very much the practice to feed agricultural servants and workmen. A labourer who can plough is a yearly servant; he has his dinner found him, but his other meals he takes with his family; and receives about 10s. the month. The packers of Bohea are allowed three meals a day, and five pence wages. The Hong merchants' coolies or porters are supplied. with three meals a day, their lodging, and $15 \mathrm{~s}$. the month. 'The East India Company's coolies were lodged but not fed, and received 20s. the month. A common carpenter or bricklayer re-

* Minutes of Evidence on the Renewal of the East India Company's Charter in 1813. 
ceives his food and about seven pence the day. These calculations are framed after the accustomed mode of calculating the dollar at $5 s$.

Thus, it appears, that so far as the wants of the two people, and wages of labour are concerned, India possesses no small advantage over China for the successful cultivation of tea.

Before entering on the subject of the cost of tea to the European in China, it may be desiralale, to make a rapid sketch of the comparative state of the trade during the existence of the East India Company's Charter, and the non-restrictive system now established in China.

It is familiarly known that the trade of China was long conducted at the port of Canton by twelve or fourteen Chinese merchants enjoying the exclusive privilege of trade with foreigners. This monopoly, however, does not appear to have formed any part of a general system of trade among the Chinese, as may sometimes have been imagined, but was purely accidental, and arose mainly out of our ignorance of the language. Mr. Pigou distinctly states that in early times there was no association of merchants at Canton*; and that Europeans were at liberty to pay their own duties and to deal openly with any merchants on the spot. These facts are also confirmed by the East India Company's records, to which I have recently been 
permitted to have access. * By association, Mr. Pigou means no association of merchants with exclusive privileges in connection with the European trade - such as the Hong merchants were ultimately enabled to establish by means of their Kong-soo.

The term Kong-soo signifies an association, company, or brotherhood. Every trade may be said to have its Kong-soo, - the Hong merchants among the rest; which associations are not very dissimilar to our ancient guilds. They have their public halls, to which sometimes, as in England, a garden for recreation or ornament is attached. Here the standard weights and measures belonging to the particular department of trade are deposited, and kept for comparison and reference. It rarely happens, too, that goods are bought or sold without such reference being made. Thus the Kiong-soo weights belonging to the foreign Hong merchants may be seen daily passing through the streets of Canton to their warehouses, in order to test the Hong merchants' weights, for the satisfaction of the tea merchant before his teas are weighed. At the Kong-soo house or hall, the rules and regulations of the association are kept, as well as all public documents connected with the trade. Here meetings are also held, with their own body, to discuss and frame new laws; and with others, to settle disputes and make arrangements of trade.

* See Ship's Diaries, 1703. 
They also meet to resist exaction or oppression on the part of the officers of Government. In fine, it is an association for the preservation and promotion of the interests of the trade, and no more. Price is not interfered with, and each individual maintains a perfect independence in all his dealings. Further, it appears to me, that the character and privileges of the Hong merchant have in recent times been greatly misunderstood. The terin Hong merchant is more especially applied to the particular class of merchants connected with the maritime trade. Properly considered, they are bonded warehouse keepers, and not merchants. Occasionally they act in both capacities. Nor is the term simply confined to merchants trading or dealing with foreigners. Each maritime province, I was informed, has its regularly appointed and licensed Hongs throughout the empire, through which all goods landed or shipped must pass by a proper document or clearance from the Custom House. Thus the particular set of merchants who were appointed at Canton to be the sureties for the payment of duties on goods connected with foreign vessels were termed foreign Hong merchants, in contradistinction to those from Fokien or Tien-sing, who were designated Fokien or Tien-sing Hong merchants. Now, the Chinese importer has complete control over his own goods, sells and buys in the open market, and pays his own duties. The office and privilege of the Hong merchant is to 
guarantee to the Government the proper payment of the duties before the goods are delivered, and no other.

So far as the sanction of law and custom prevailed, the European enjoyed all privileges in common with the native trader. Nevertheless, it does appear, that even in our earliest intercourse with the Chinese, the right of free trade was imperfectly and with difficulty maintained. Various and untiring were the efforts of the Chinese to establish some form of monopoly. On some occasions it appeared in the person of a privileged individual engrossing the whole trade, or granting licences to others, in his capacity of imperial merchant; on others, in the form of an association of the tea-men, the dealers from remote provinces, the shopkeepers of Canton, and the Hong merchants collectively; and, lastly, by the Hong merchants exclusively. The former attempts failed; but the Hong merchants ultimately succeeded in obtaining the privilege of exclusive trade; which association was maintained, under forms more or less stringent, for more than a century. Consequently the non-restrictive policy now obtained by the treaty of Nanking is no more than a return to the original privilege of free trade, which we might have enjoyed had our industry prompted us to master the language. But Europeans, ignorant of the language, and ignorant of the customs and regulations of the empire, too readily suffered their transactions with 
the government and the country dealer to be conducted by linguists and Hong merchants ; first, as agents for the payment of their duties to the government; and again, as interpreters and brokers for the sale and purchase of the commodities they exchanged. Thus they became exposed to gross frauds and much calumny in all their relations with the government and the people, and speedily fell completely into the power of these agents. Mr. Pigou speaks with much naïveté on this subject. He observes,_ _ The English trading directly with the merchant who brought his goods to Canton, the agency of the Hong merchant was required, because the country merchant clid not speak English!"

Canton, also, being the capital of the province and the residence of a viceroy, possessed an immense advantage over the other ports of trade, as Amoy, Ning-po, and Chusan, in all that regards influence at the court of Peking. The government officers of these latter ports were altogether of a very low grade.

Europeans also, finding that they were much exposed to insult, vexation, and extortion from the low and corrupt officers who presided over the northern ports, often adopted the expedient of anchoring their ships outside the port of Canton on their way northward, in order first to try what terins or arrangements they could effect with the merchants and custom-house officers of that port; and, as it obviously was the interest of all parties 
to effect an accommodation, it is not surprising that satisfactory arrangements were speedily concluded; and thus much of the trade was gradually attracted to the port of Canton.

Finally, many of the Fokien merchants, an active and enterprising class of Chinese, seeing that the trade was gradually leaving Amoy, began to withdraw themselves with their families from that port, and to domicile at Canton. Here, also, they became Hong merchants; and at length, receiving the countenance and aid of the superior local officers of the province, they ultimately succeeded in procuring an Imperial edict, interdicting the trade at all other ports; and securing to themselves the right of exclusive trade with Europeans in the capacity of a Joint Stock Company or "Co-hong," by which latter term this association is known to Europeans.

This association, however, did not trade openly as a body, but as individuals. The prices were fixed and regulated at the commencement of each season, and the profits divided among the several members of the company, agreeably to a scale previously agreed upon. Thus, though the trade bore a semblance to the European, of being for the sole benefit of the individual Hong merchant dealt with, the transactions, in fact, were with a company who possessed all the advantages of the closest and most objectionable form of monopoly. The records of the East India Company, up to a ver'y recent 
period, afford ample proof of the struggles of their agents in China to prevent the re-establishment of this close monopoly or "Co-hong," and of the Chinese Hong merchants to perpetuate it.

At length, at the period here alluded to, the Europeans, by strong remonstrances and representations to the viceroy of the province, succeeded in obtaining the suppression of this monopoly, at least in its most objectionable form, that of a Joint Stock Company. Its abolition appears to have occurred, by the East India Company's records, in February 1771; but at a sacrifice on the part of the Company of the almost incredible sum of 100,000 tales or 30,000l. Still the Hong merchants possessed sufficient influence with the government officers, to secure the retention of their exclusive privileges, though each merchant henceforth traded on his own individual account.

This important and beneficial change having been effected in the conduct of the trade, sufficient competition and rivalry were now created among the Hong merchants to secure to the foreigner something like fair dealing. The exclusive privileges seemed altogether stripped of their odium. Indeed this form of monopoly has had its advocates even in the present day; because, in return for the exclusive privileges, the Hong merchants were inade by the government responsible for each other's debts. Still, in the opinion of others, in which I concur, this responsibility was objectionable. It 
encouraged the foreigner to deal with embarrassed and bankrupt merchants, and to obtain from them higher prices than the market commanded. 'This associated form also enabled the Imperial grovernment to levy contributions on these merchants as a body, which were followed by additional charges on the trade. Again, it enabled the local officers to fix undue responsibility on them, so that they finally became, not only sureties for the duties, but responsible for all infringements of the law by foreigners, and also for their general good conduct.

Thus an easy mode of exaction was afforded the local officers; and out of this form of association arose frequent stoppages of trade, detention of ships at great cost, and most of the disabilities, discomforts, and vexations to which all classes of foreigners were subject. But if the Imperial government found in the monopoly granted to the Hong merchants a convenient mode of taxation; and the local officers a ready means of exaction; it may easily be surmised, that the Hong merchant did not fail to seek compensation and to avail himself of all the advantages of his exclusive privileges. Thus the wealth of the judicious and able members of this community was enormous, and altogether without parallel except among the merchant princes of the middle ages, or the millionaires of our own days. Thus one considerable item which entered into the cost of tea to the foreigner, was the Hong merchant's profit; which 
amounted to no less than 25 or 30 per cent. on the cost of tea after payment of all duties and charges of shipment.

These large profits on tea of course enabled the Hong merchants to pay liberal prices on all imports where tea was received in exchange; and the East India Company's agents did not fail to employ their knowledge of the acquisition of these large profits, as an argument to induce the Hong iner. chant to participate in some degree in the heavy loss annually sustained by the East India Company, in their efforts to promote and extend the demand for British manufactures.

Still it does not appear, agreeably to the opinions of the best informed on the subject, notwithstanding the assertions and belief of the contrary, that, prior to the treaty of Nanking, any reduction of price had been effected in tea since the abolition of the East India Company's Charter; but, on the contrary, that prices had advanced.

It must be borne in mind, however, that the consumption of tea in England has been increased fully one half since the period here alluded to, in consequence of the reduced price at which it has been afforded to the consumer. Nor has any great, at least proportionate, reduction of price taken place at Canton since the abrogation of the privileges of the Hong merchants, and the abolition of all monopoly. Still the introduction of free trade, as now established on the solid basis of payment of 
duties through the Consuls, together with the power of warehousing goods in our own warehouses, and the privilege of trading to four new ports in the empire, must ultimately have the effect of reducing the price of tea obtained by the native grower and factor to a fair mercantile remuneration. What that price may be, or whether any reduction may take place under the circumstances of an increasing demand for tea at the different ports of trade, in consequence of a forced introduction of our imports into China, it is impossible to conjecture; but as a large annual balance of trade has to be paid to India, there is reason to think that the shipment of tea to England will afford for years to come little more than a bare remittance.

Another considerable item which enters into all calculations concerning the cost of tea to foreigners at Canton, is the great cost of transit from the tea provinces. The province of Fokien, especially, is encompassed by lofty mountains on every side towards the main, which seem to isolate it, as it were, from the rest of the Empire: and perhaps the difficulties of communication by land, added to the natural sterility of the soil and mountainous aspect of the country, may have tended in some degree to create that superior hardihood and adventurous spirit which the people of this province are said to possess over the other inhabitants of the coast, and which render them the great carriers by sea of the produce of the neighbouring provinces, as well as 
the principal traders to Japan, Formosa, Manilla, and the Eastern isles.

The expense of transit across these mountains amounts to no less than 1 tale, 2 mace, 5 candareens the pecul; which is more than one third of the whole expense of carriage, though the pass is not one seventh of the whole distance, nor the time occupied one fifth of the whole time necessary for the transit of tea to Canton. Nor can the teas be moved out of this province without incurring an expense of five times the amount necessary for shipping them from the port of Foo-chew-foo. Such is the importance of this port: and whatever contingent advantages may render other ports desirable, still these advantages can never lessen the importance of the port of Foo-chew-foo. The saving which may be effected in boat-hire alone has been shown to amount to $300,000 l$. per annum.

The usual route by which the black teas are sent to Canton, is through the province of Kiang-sy. They are first transported down the river Min in Fokien to the small town of Tsong-gan-hien, whence they are carried, by porters, an eight days' journey, over mountain passes to Ho-keu, and the rivers of Kiang-sy, which conduct to Nan-chang-foo and Kan-chew.foo ; and then, suffering many transshipments on their way, to the pass of Ta-moey-ling, in that part of the same chain of mountains which divides Kiang-sy from Quon-tong. At this pass the teas are again carried by porters - the journey 
occupies one day -. when they are re-shipped in large vessels which convey them to Canton. The time occupied in the entire transport from the Bohea country to Canton is about six weeks or two months; and the whole expense is 3 tales, 9 mace, 2 candareens the pecul, or $2 d$. the $1 \mathrm{~b}$ : which amounts to no less than about one-third of the cost of Congou tea at its seat of growth.*

Regarding the cost of tea at its seat of growth it will be unnecessary to embarrass the reader with complicated details on this subject. The several items are given in the Appendix. Let it suffice here to state, that the cost of growth and manipulation of Congou tea, of good or average quality, may be estimated at 12 tales the pecul, or $7 d$. the pound avoirdupois, reckoning the tale at $6 s .8 d$., or $5 s .6 d$. the ounce of silver. $\mathrm{Mr}$. Pigou about fifty years ago estimated the cost of the same description of tea at 11 tales. The expressions used by Mr. Pigou cast somewhat of a doubt as to the precise amount of cost, but the explanations given in the Appendix seem to justify the conclusion I have adopted.

Thus the cost of tea to the Hong merchants at Canton during the period of the East India Company's charter may be thus stated:-

* The foregoing remarks on the cost of transit are taken almost literally, from a paper of mine in the Royal Asiatic Society's Journal for May 1840, entitled: "Observations on the Expediency of Opening a Second Port in China," originally printed at Macao, in 1816. 
Cost of growth and manipulation

Tales. m. c. c.

Cost of chests, canisters, and packing

$\begin{array}{llll}-12 & 0 & 0 & 0\end{array}$

Expense of transport from the black tea districts to Canton -

Charges at Canton on account of government duties, Hong merchants' expenses, and boat hire to the ships

\begin{tabular}{rrrr}
3 & 0 & 0 & 0 \\
\hline 20 & 2 & 3 & 6 \\
\hline
\end{tabular}

The cost of this description of tea to the East India Company was about 27 tales the pecul; thus leaving the Hong merchant 6 tales, 8 mace, the pecul; or, as previously stated, about 30 per cent. profit. This tea usually sold at the Company's sales in England at three shillings the pound or sixty tales the pecul; thus yielding a large surplus to the East India Company. But, it must be remembered, that at this period the Company's ships were expensively fitted, and manned in a very efficient manner for defence as well as trade; and that every department of their establishment connected with China was maintained on a munificent scale, though the charge did not exceed 2 per cent. on the trade. Further, that all above 10 per cent. dividend paid to the proprietors on their capital stock was returned to the country, - in the support of the Government of India; on extensive surveys both by sea and land; in the encouragement given to British manufactures at a great loss; and in an unbounded and liberal 
support to every branch of art and science connected with their Eastern possessions.

Thus the total cost of tea at its seat of growth amounted to no more than twelve tales the pecul; yet it sold for no less than sixty tales the pecul at the East India Company's sales; or about 500 per cent. on its cost. Thus, though labour might have been five times dearer in England than in China, yet, if difference in the price of labour had been the only obstacle, it might have offered no impediment to the successful cultivation of the tree in England, at the period here alluded to. Still less would there have been any obstacle to the successful cultivation of it in India.

We have now, however, to examine the question of the cultivation of tea in India under a new and less flattering aspect. The abolition of the monopoly of the Hong merchants in China, the introduction of free trade, and the privilege of trading to no less that five ports of the Empire, now place the question of the cultivation of tea in our colonies upon a new footing, and render its success of more doubtful issue.

The privilege of trading to two ports in the province of Fokien, has brought us into close contact with the black tea districts. The port of Amoy is in the immediate vicinity of the Ankoy district; and the port of Foo-chew-foo possesses the great advantage of a direct and uninterrupted water communication with the Bohea country at a 
distance of about 270 miles. The transit of the teas occupies about four or five days; and the expense of conveyance does not exceed 4 mace, 3 candareens the pecul; whereas, by the usual route through the province of Kiangsy, it costs no less than 3 tales, 9 mace, 2 candareens, as already shown.

The difference of cost of Congou tea at Canton and at Foo-chew-foo, may be thus stated:

Canton. Foo-chew-foo. Tales. m. c. Tales. m. c.

$\begin{array}{lllllll}\text { Cost of cultivation and manipulation } & -12 & 0 & 0 & 12 & 0 & 0\end{array}$ Cost of chests, canisters, and packing $\quad \begin{array}{lllllll}1 & 3 & 1 & & 1 & 3 & 1\end{array}$ Expense of transit $\quad-\quad \begin{array}{llllllllll} & - & - & 3 & 9 & 2 & 0 & 4 & 3\end{array}$

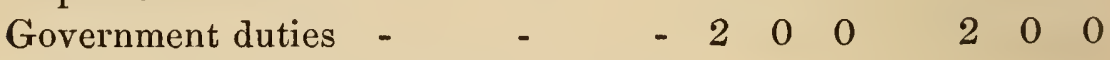
Profit to factors or merchants, charges

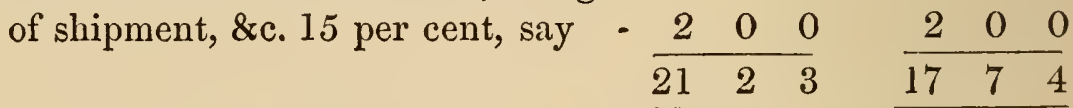

Thus teas ought to be bought from 15 to 17 per cent. cheaper at Foo-chew-foo than at Canton.

But there are savings on other items connected with the transit of the teas to Canton, and those considerable, the precise amount of which cannot be estimated: such as the personal expenses of the tea men; those of their clerks and others attending the boats ; loss of time, and loss of comfort in being separated so far and so long from their homes and families; the expense of transport of silver from Canton to the amount of 3,000,000 dollars annually; interest of money at a high rate, and damage of goods. All these expenses fall, either directly or indirectly, on the price of tea, and obviously must 
be greatly diminished by our trade being conducted at the port nearest the spot where the black teas, the principal article of export, are grown and manufactured.

It further appears, that good Congou tea, such as used formerly to cost 27 tales the pecul at Canton, ought now to be purchased at the port of Foochew-foo at from 17 to 18 tales the pecul, or about $10 d$. to $10 \frac{3}{4} d$. the $1 b$. This, then, should be the price which the foreign merchants ought to pay at this port: and this may be the probable price with which the cultivator of tea in other parts of the world may ultimately have to contend.

But should no more reduction take place in the price of tea at Canton than has hitherto been experienced, in consequence of the great competition which prevails among the purchasers of tea, then the same description of tea, bought at 27 tales the pecul, would cost no less than $16 d$. at Canton; or $14 d$. the pound, when purchased at the most favourable port of the empire. It must be borne in mind that these calculations are framed after the usual mode of considering the value of the tale to be $6 s .8 d$., or $5 s .6 d$. the ounce of silver.

Thus, it appears, that, under the most favorable circumstances, the Chinese are not able to furnish good teas, suitable to general consumption, at a less cost than from $10 d$. to $11 d$. the pound; and, from the present state of our commercial relations with China, it seems probable that the 
cost may continue so high as from 1 s. $2 d$. to $1 s .4 d$. the pound.

The experiments on the cultivation of tea in India have not yet furnished any results regarding the actual cost of tea after manipulation, on an extensive scale, upon which we can satisfactorily rely. The plantations of Kamaon in the north west districts of the Himalayan Mountains, however promising they may be, are yet in their infancy: and those in Assam have been conducted expensively, and, to all appearance, injudiciously.

The actual quantity of tea manipulated at Assam in the year 1846 amounted to 170,000 lbs., which cost in India, all charges included, 7,600l.; thus furnishing a cost price of about $10 \frac{1}{2} d$. the pound, while it sold at an average price of $2 s$. the pound in England. But there are certain charges not included in this account: and the large expense in Assam is said to be attributable to a fixed establishment of superintendence and management sufficient for a cultivation of four times its present extent. The wages paid to the manipulators of tea are 5 rupees, to their assistant coolies 3 rupees, and, to the labourers, from 3 to 4 rupees the month; and the chests cost only 1 rupee each.

With so low a rate of wages can there be any doubt that, under a suitable and inexpensive system of management, Assam ought to be able to compete with China in the cultivation of tea; provided the plant be found to possess all the essential pro- 
perties of the Chinese plant? It is not for me to point out modes of cultivation or suitable sites, but it naturally suggests itself, that, agreeably to the Chinese practice, the cutting down to the roots the wild trees growing in inconvenient localities, and transplanting the stools in the vacant spaces of plantations already appropriated to cultivation, as well as with seed, might be found advantageous. I think also that the plantations should be as rapidly renewed from seed as circumstances will allow; and if tried in more healthy localities in the northern plains of India, along the banks of rivers, the plant might be found to yield all those properties which are more essentially important to the manufacture of brick tea, and its mode of use. Strength and astringency are more important qualities in that tea than flavour; and the Assam tea tree seems to possess both these in an eminent degree. Moreover, it may be found a useful substitute to the native population in sites and localities less favourable to the cultivation of the Chinese plant.

With respect to the Kamaon tea, I must refer the reader to the observations of Dr. Royle on that subject. This intelligent and scientific author recommended, so far back as the year 1827, the introduction of the tea plant into the north western districts of the Himalaya range.* Dr. Falconer,

* Royle's Illustrations of the Botany of the Himalayan Mountains. Also, Essay on the Productive Resources of India. 
now the superintendent of the botanic garden at Calcutta, who reared up the plantations at Kamaon, also wrote an excellent paper on the same subject.* I learn from him that tea may be produced there at sixpence the pound, and that the expense of transit to Calcutta would amount to about three farthings the pound more. Dr. Jameson, now in charge of these plantations, has recently confirmed that statement in an estimate appended as a note to this chapter.

The quantity of tea manufactured at Java from 1839 to 1844 , exhibits an annual average of $218,000 \mathrm{lbs}$., so far as the contents of each package can be established. $\dagger$ And Mr. Jacobson, the superintendent of the plantation, shows, by calculations grounded on the actual cost of cultivation and manipulation, the fact that tea may be shipped from that island at eight pence the pound. These statements are also appended to this chapter, and are minute and satisfactory in their details; and there can be no reason why tea should not be produced in India at the same cost as at Java.

Indeed, if tea can be manipulated and packed in China at its seat of growth, for seven or eight pence the pound, as now shown, it may fairly be assumed, so far as the price of labour is concerned, that the

* Parliamentary papers on the Cultivation of Tea in India, printed February, 1839.

$\dagger$ This statement is made from an account of the quantity sold in Holland. 
same quality of tea ought to be shipped from India at four or five pence the pound.

Thus, it appears, from the habits and wants of the two people - Chinese and Hindoo, - from the rate of wages in the two countries, and from actual experiments, _ so far as these afford certainty of result in conjunction with concurrent testimony to the success of the cultivation of tea at Java, that India possesses an undoubted power of competing with China in the European and American markets in the cultivation of tea.

It, therefore, only remains for the enlightened Government of Bengal, now enjoying the fruits of peace, and turning its thoughts once more to the moral and physical improvements of the people, to extend its fostering help and encouragement, as it has hitherto done, until the native population shall have adopted and established the cultivation of the tea-tree as a native product; nothing doubting, that it will thereby be administering to the comfort, happiness, and sobriety of the people of India; as well as to the increase of the wealth and commercial prosperity of the mother country and her cherished colony. 


\section{$\mathrm{N} O \mathrm{O} \mathrm{T} \mathrm{E}$.}

\section{Cost of Cultivation and Manufacture of Tea in Java.}

Mr. JACOBson at Java has arranged his ground into plantations, each consisting of one million bushes, planted in squares of four feet. These he divides into ten gardens of 100,000 each, subdivided into parks or sections, regulated by the num. ber of days in which the planter determines to establish his gatherings. The calculation adopted by him is grounded on a subdivision into 35 sections, each containing 2857 bushes; and that each gathering should continue 35 days during a season of four gatherings.

Thus, a garden consisting of 100,000 bushes will yield $37,000 \mathrm{lbs}$. of fresh leaves, or 10,000 lbs. of tea. This is equal to one pound of tea from ten bushes; and $3 \frac{3}{4} \mathrm{lbs}$. of fresh leaves to $1 \mathrm{lb}$. of tea.

'The total cost, including rent of manufactories, planting, remuneration, and cost of transport to the ship, would amount to 4000 florins, which, at $1 s .8 d$. the florin, on $10,000 \mathrm{lbs}$. of tea would be less than $8 d$. the pound, Rhine (which is about the same as English) weight. But if the gatherers are skilful, and gather ten catties the day, which they can easily do, then the cost would be 3,500 florins, or less than $7 d$. the $1 \mathrm{~b}$. And if the planter can stimulate his workmen to diligence, he may make one pound of tea from five instead of ten bushes, and thus diminish his cost from 30 to 40 per cent.

In fact, the cultivation of tea at Java is a certain source of gain ; on middling lands ten bushes will yield one pound of tea ; but on good lands the same quantity may be procured from five bushes. And, in another part ( $\$ 186$.), the author distinctly states " That it may be taken for granted that 142 Amsterdam lbs. may be made from ten bushes, which is equal to $1 \mathrm{lb}$. from 
five bushes." Farther, that a skilful gatherer may gather sixteen catties the day; though his calculations are grounded on the supposition that each person gathers only seven catties the day. One pound of tea requires for furnace drying 3lbs. of wood, and $1 \mathrm{lb}$. of charcoal.

At the same time this author observes that, unless attention and skill be exercised in every part of the cultivation and manipulation, the teas will be found deficient in weight, and inferior in quality. Thus, a plantation ill-pruned, which would otherwise yield 100,000 lbs. of tea, reckoning $1 \mathrm{lb}$. to ten bushes, would produce only $85,000 \mathrm{lbs}$; and, if badly manipulated, only $70,000 \mathrm{lbs}$; and this quantity would also be reduced in value 20 per cent., together making a loss of $4 d$. the $\mathrm{lb}$. In fact, the plantation would not pay. The planter might ascribe the failure to many chimerical fancies, but in truth it could only be attributed to unskilfulness and indolence. (Par. 324.)

$\$ 173-4$. In the second year the topping or stopping must be frequently repeated, so that the regular harvest may commence the third year, and many implements made, as well as the manufactories built. All this work is to be done by twelve families which have been hired the first year, aided by the women and children of another twelve families which have to be engaged the second year. Thus, these people must be employed in the service of the planter one year before the harvest. It is highly important to the successful growth of the plant that the stopping and pruning should not be neglected. This occupation, while it affords an opportunity of instructing the gatherers in the mode of gathering, and of exercising the manipulators on the leaves gathered, also furnishes to the planter the means of testing and appreciating the skill and character of his people. [Here follow excellent observations on the regulation and management of the labourers.]

$\S 174$. For a garden of 100,000 bushes, 26 families are required the second year :-

1 foreman and 12 able men for the labour of the soil.

1 foreman and 12 able men for the manipulation.

26 women and 52 children for the gathering of the leaves and other assistance. Total 104.

With respect to the women and children, three fourths of 
these are not obliged to labour. They are supported by the wages of the men. But when they are employed they ought to be paid full wages, since they do the work equally well with the men; and it is the interest of the planter to encourage them to work.

$\S 175$. [Observations on the beneficial effects produced on the women by liberal treatment.]

$\S 176$. Every encouragement should be given to settlers. A cottage with a garden attached, may be let for four or five florins the year., The cultivation of coffee should be encouraged; and, for the cultivation of rice, the planter should lend a buffalo for the ploughing, \&c.

$\$ 180 .-1$. Those who keep the gardens and embankments in order should be paid by daily wages; the gatherers by the pound of fresh leaves; and the manipulators by the weight of tea they make; the rate per pound must be regulated relatively to the wages paid to the gatherers and other labourers. The payment for the erection of the buildings, and construction of implements must be settled by agreement.

$\S 186$. Supposing one park to consist of 2857 bushes, and the garden to produce seventy-one Amsterdam pounds of tea for each day's gathering, then the division of labour would be:

For keeping up the garden daily carriage of fire-wood making boxes and baskets pinning together bamboo leaves

$$
\text { for tea canisters }
$$

the gathering of the leaves carriage of leaves to the sheds the manipulation of the tea foremen
- 12 men.

- 2 men.

- 2 men.

- 2 women.

- 14 women and 28 children. 4 boys.

- 8 men and 4 boys.

- 2

Thus leaving 10 women and 16 children to complete the total number of 104 .

$\S 187$. The expense of a plantation of ten gardens, containing one million bushes would be, for the two first years, as follows: 

12 families, 5 florins for the men the month is 60 florins, or for 24 months 1440

1 family, 6 florins for a garden foreman the month, or for 24 months 144

12 families, 5 florins for the men the month, or for 12 months - 720

1 family, 6 florins for the foreman of the manufactory, or for ditto - 72

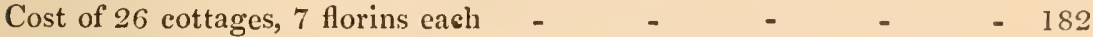

1 manufactory for green tea, 110 florins, or for black 160 florins, say

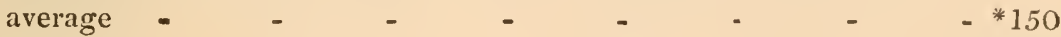

Implements, iucluding roasting vessels; tea boxes; lead and fuel sheds 232 Agricultural implements for maintenance of the garden - $\quad$ - 30 Unforeseen expenses -

For one garden $\quad-\quad \quad-\quad-\frac{1}{3,670}$

At the above rate of expense for one garden, the total expense for a plantation of ten gardens, would be florins 36,700

1 superintendent, 12 fl. the montl, for 24 months - 288

1 packing house, with iron implements and scales - 512

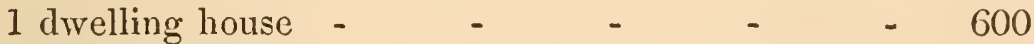

Allowance to the planter, or the paid planter, $300 \mathrm{fl}$. the month, for 24 months - - - $\quad$ - 7,200

Though "families" is the term employed in the above statement, yet it is only the head of each family which enters into the calculation of the number of persons employed. (Abstracted from the Handboek v. d. Kult. en Fab. v. Thee.)

\section{Cost of Cultivation and Manufacture of Tea in Kamaon and} Gurhwal.

Dr. Jameson, observes:- "The number of acres now in cultivation in Kamaon, may be estimated at 118; which I

* For a plantation consisting of ten gardens and one million plants 3 green tea manufactories are required, at a cost of - 330 Florins.

And 7 black, at

Or 4 green, at -

And 6 black, at

- 1190

$-{ }_{440} 1520$

- 1020

thus giving an average of 150 florins for eacl manufactory as already stated. 
trust will be raised this season to 165 , which will yield, when all the plants come into full bearing as estimated, 165 maunds of tea. This being sold at 3 rupees per seer, will realise 21,600 rupees. The present expenditure in Kamaon is as follows :-

\section{Tea Cultivation.}

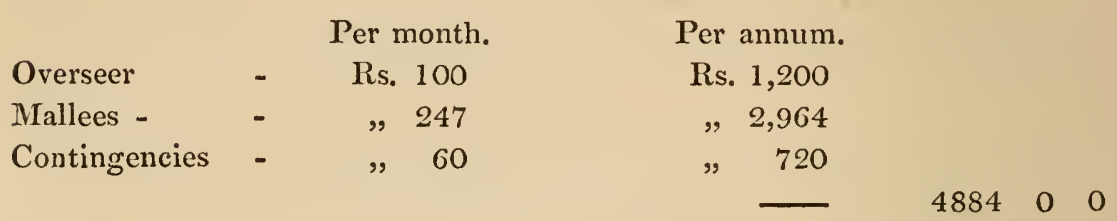

\section{Tea Making and Packing.}

10 Chinese teal makers Rs. 33140

Rs. 3,975

2 Chinese tea-box makers - $\quad " 6440$

4 Sawyers - $\quad$ \% 2400

Present rent per anuum

Rent of additional 50 acres, at 3 rupees per acre

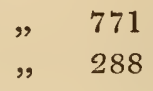

$5034 \quad 0 \quad 0$

\section{Land Rent.}

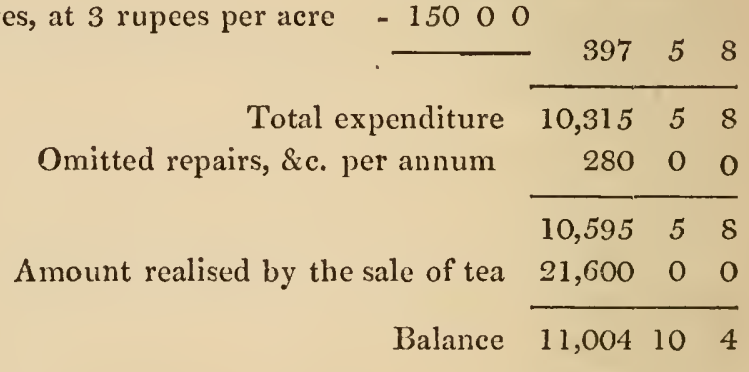

This balance, though good, is very far short of the amount which would be realised were the establishments better adjusted.

The following is a calculation showing the rate at which six thousand acres of land can be cultivated, the expense of carriage, $\& c$. and the return.

\section{Cultivation of Tea.}

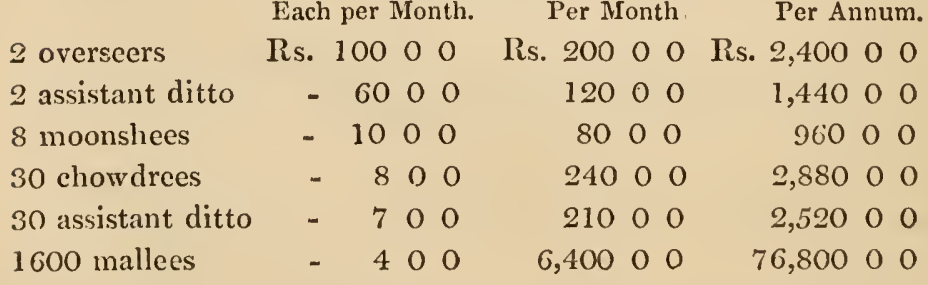

* Some of the land is government land, and therefore free of rent. 
Making Tea.

10 Chinese manufac- Per Month. Per Month. Per Annum. turers - Rs.3320 Rs. $33140 \quad$ Rs. 000003,97500

Packing Tea.

2 Chinese tea-box makers. - - 3320

1 chowdree carpenter 000

1 assistant - - 000

6640

79500

12 carpenters - $\quad 600$

1000

12000

800

9600

8 sawyers - $\quad 400$

7200

86400

$3200 \quad 38400$

\section{Carriage.}

Carriage of 6000 maunds of tea to Bhamoree at 1 rupee per maund -

Carriage of 6000 maunds of tea to Ghurmuk6,00000 tissur Ghaut at 25 maunds, to each 4 bullock hackery, it being 8 stages, at 1.8 rupees per stage $=12$ rupees and of these 240 will be required, $240 \times 12=$

Hire of eleven 600 maund boats to transport the tea to Calcutta, 220 rupees each, $220 \times 11$

Extraordinary contingent Expenses.

Wood for boxes, repairs, additional coolies, \&c.

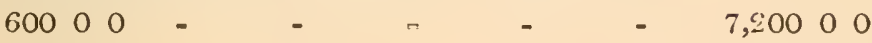

I.and Rent.

Land-rent of 6000 acres at 3 rupees per annnm 18,00000

Total expenditure $1,29,734$ o 0

To value of 6000 maunds of tea, or 2,40,000 seers, at 2 rs. per seer 4,80,000 00

Or say that the tea is sold at 1.8 rupees per seer,

$$
\text { Balance } \overline{3,50,26600}
$$

Balance 2,30,266

This estimate is as accurately calculated as our data will admit; and not overrated. There would be no difficulty in procuring the requisite numbers of labourers. Moreover, the natives, by encouragement and by making advances, will be induced to undertake the cultivation of the plant; a certain sum per seer for kutcha leaves being paid them on liberal 
terms at the manufactory, they would receive five or six times the amount procured elsewhere for any other produce. The plant is thriving over about $4^{\circ}$ of latitude and about $3^{\circ}$ of longitude. It is a great mistake to suppose, that the quantity of land available and adapted to tea cultivation in the hills is small. The tea sold at Almorah from $3 \cdot 2$ rupees to $5 \cdot 1$ rupees per seer. The quantity sold was small, amounting to 173 seers. There are now three Chinese engaged in manufacturing tea in Deyra." (Journal of the Agricultural and Horticultural Society of India, Part IV. vol. iv. pp. 181-196.)

\section{Brazils.}

With respect to the green tea manufactured at Rio de Janiero, it is simply necessary to state that the cost of manufacture in that settlement is so great that its importation into England would be attended with considerable loss. The cost of Hyson tea is stated at prices varying from $3 s .4 d$. to $6 s .5 d$., for teas valued by respectable parties to be worth only from $1 s$. $6 d$. to $2 s$. $6 d$. the pound in the ordinary state of the market. 


\section{A P P E NDIX.}

\section{Climate-Canton and Macao.}

THE quantity of rain recorded by Kerr (a respectable and intelligent gardener and botanist sent out by Sir Joseph Banks) in his Meteorological Journal, which fell on the 10th of May, 1810, at Macao, is $12 \cdot 10$ inches; but this I consider an error. I have, consequently, corrected it by forming an average out of the quantity which fell for a few days before and after. The quantity, then, which fell in inches for each month, from 1808 to 1811, say from the middle of October to the middle of April at Canton, and the remaining portion of the year at Macao (dividing the year into monsoons), may be stated as follows:-

S. W. Monsoon.

\begin{tabular}{|c|c|c|c|c|c|c|c|}
\hline $\begin{array}{l}\text { Kerr } \\
\text { Beal Macao }\end{array}$ & $\begin{array}{l}\text { May. } \\
11.88 \\
11.85\end{array}$ & $\begin{array}{lr}\text { June. July } \\
10^{\circ} 19 & 14.35 \\
11 \cdot 10 & 7 \cdot 75\end{array}$ & $\begin{array}{l}\text { Aug. } \\
11 \cdot 30 \\
9 \cdot 90\end{array}$ & $\begin{array}{lr}\text { Sept. } & \text { Oct. } \\
12.5 & 6.54 \\
10.92 & 5.50\end{array}$ & $\begin{array}{ccc}\text { Nov. Dec. } & \text { Jan. } \\
1.32 & 0.19 & 0.65 \\
2.42 & 0.97 & 0.67\end{array}$ & $\begin{array}{ll}\text { Feb. } & \text { Mar. } \\
1 \cdot 20 & 3 \cdot 14 \\
1 \cdot 70 & 2 \cdot 15\end{array}$ & $\begin{array}{l}\text { Mean. } \\
78 \cdot 96 \\
7062\end{array}$ \\
\hline $\begin{array}{l}\text { etterman's } \\
\text { Macao. }\end{array}$ & s $\}$ Total & & & 30 & 30. $1814,95 \cdot 70$. & $1815,54 \cdot 50$ & $77 \%$ \\
\hline
\end{tabular}

\section{Temperature and its Monthly Variations.}

I am induced here to give an extract of Mr. Bletterman's Journal of the highest and lowest range of the thermometer for each month during eleven years, from 1806 to 1808 , and 1810 to 1817 , as exhibiting a remarkable coincidence with the daily mean temperature as given by Kerr, from 1807 to 1811 ; also the monthly variation of temperature as exhibited in these Journals. 


\begin{tabular}{|c|c|c|c|c|c|c|c|c|c|c|c|c|c|}
\hline & $\begin{array}{c}\text { May } \\
\text { o }\end{array}$ & $\begin{array}{c}\text { June. } \\
\circ\end{array}$ & $\begin{array}{c}\text { July. } \\
0\end{array}$ & $\begin{array}{c}\text { Augt. } \\
0\end{array}$ & $\begin{array}{c}\text { Sept. } \\
0\end{array}$ & $\begin{array}{c}\text { Oct. } \\
\circ\end{array}$ & $\begin{array}{c}\text { Nov. } \\
0\end{array}$ & $\begin{array}{c}\text { Dec. } \\
\circ\end{array}$ & $\begin{array}{c}\text { Jan. } \\
0\end{array}$ & $\begin{array}{c}\text { Feb. } \\
0\end{array}$ & $\underset{0}{\text { Mar. }}$ & $\begin{array}{c}\text { Apr. } \\
0\end{array}$ & $\begin{array}{l}\text { Annual } \\
\text { Mean. }\end{array}$ \\
\hline $\begin{array}{l}\text { Lowest } \\
\text { Highest }\end{array}$ & $\begin{array}{l}70 \\
86\end{array}$ & $\begin{array}{l}76 \\
88\end{array}$ & $\begin{array}{l}78 \\
88\end{array}$ & $\begin{array}{l}77 \\
89\end{array}$ & $\begin{array}{l}73 \\
89\end{array}$ & $\begin{array}{l}68 \\
86\end{array}$ & $\begin{array}{l}54 \\
83\end{array}$ & $\begin{array}{l}44 \\
75\end{array}$ & $\begin{array}{l}44 \\
73\end{array}$ & $\begin{array}{l}48 \\
72\end{array}$ & $\begin{array}{l}53 \\
76\end{array}$ & $\begin{array}{l}62 \\
82\end{array}$ & \multirow{3}{*}{$72^{\circ}$} \\
\hline Mean & 78 & 82 & 83 & 83 & 81 & 77 & 68 & 59 & 58 & 60 & 65 & 72 & \\
\hline $\begin{array}{l}\text { Variation } \\
\text { Kerr's variation }\end{array}$ & $\begin{array}{l}16 \\
17\end{array}$ & $\begin{array}{l}12 \\
13\end{array}$ & $\begin{array}{l}10 \\
12\end{array}$ & $\begin{array}{l}12 \\
13\end{array}$ & $\begin{array}{l}15 \\
13\end{array}$ & $\begin{array}{l}18 \\
16\end{array}$ & $\begin{array}{l}29 \\
29\end{array}$ & $\begin{array}{l}31 \\
27\end{array}$ & $\begin{array}{l}29 \\
24\end{array}$ & $\begin{array}{l}24 \\
26\end{array}$ & $\begin{array}{l}23 \\
23\end{array}$ & $\begin{array}{l}20 \\
24\end{array}$ & \\
\hline Kerr's mean - & 77 & 82 & 82 & 82 & 80 & 77 & 68 & 59 & 60 & 59 & 65 & 70 & 71 \\
\hline
\end{tabular}

Mean variation N. E. Monsoon, Kerr's Journal 25०.5. Mr. Bletterman's, 11 years, $25^{\circ} .9$. S. W.

\section{Temperature at Japan.}

The following accounts of the temperature of the seasons at Nangasacki in Japan are extracted from:-

1. French edition of Thunberg's Japan, edited by E. Langles, vol. iii. pp. $174-178$.

2. Ib. vol. iii. pp. 188 - 193, taken from the Memoirs of the Batavian Society, in the year 1779 .

3. Von Siebold's Voyage au Japan, p. 326.

\begin{tabular}{|c|c|c|c|c|c|c|c|}
\hline & Winter & Spring. & Summer. & Autumn. & $\begin{array}{l}\text { Lowest } \\
\text { Range. }\end{array}$ & $\begin{array}{l}\text { Highest } \\
\text { Range. }\end{array}$ & $\begin{array}{l}\text { Mean } \\
\text { of } \\
\text { Year. }\end{array}$ \\
\hline 1 & $51^{\circ}$ & $63^{\circ}$ & $81^{\circ}$ & $71^{\circ}$ & January, $35^{\circ}$ & August, $96^{\circ}$ & $66^{\circ}$ \\
\hline 2 & 42 & 57 & 83 & 74 &,$\quad 27$ &,$\quad 98$ & 61 \\
\hline 3 & 44 & 57 & 79 & 66 & & & 61 \\
\hline
\end{tabular}

Von Siebold also observes, that "The rains in the Japanese Islands are more frequent in June, July, and November, than at other times of the year. The rainy season takes place during the first two of these months; and in April and May a dense fog, common to these islands, not unfrequently envelopes them for days together."

It may be advisable here to state, that a certain correction must be made in the results extracted from the Canton and Macao Meteorological Journals, the general temperature being somewhat too high. I have not quoted M. Richnet's Journal, but to show the errors to which such 
observations are exposed, it is therein stated, that at Macao on the 31st of December, 1811, the thermometer, standing in its usual place in his room at Macao, marked $53^{\circ}$; while another thermometer, placed in the open air against a window, stood at $38^{\circ}$; and, though at $38^{\circ}$, yet ice was found on the terrace of a neighbouring house, and other terraces in the town. Both thermometers were also placed with a south-east aspect, and therefore in a situation to favour a high temperature.

Again, in Kerr's Journal on the night of the 29th of Jamuary, 1811, the thermometer at Canton in its usual place on the ground floor, with a northern aspect and in the open air, stood at $41^{\circ}$; while another thermometer placed on a platform elevated not more than thirty feet, in the same pile of buildings, and not otherwise more exposed, marked only $30^{\circ}$, and the next morning ice was carried through the streets for sale.

Also, in Mr. Bletterman's Journal, the thermometer which marked the greatest heat was placed in the upper story of his house at Macao, the roof of which was directly exposed to the influence of the sun's rays: and the one by which the greatest cold was observed, was placed in a room on the ground floor. Thus, both thermometers favoured extremes of temperature.

Further, the Rev. Vicar-General Carpina of Folien, observes, that when the thermometer stood at $37^{\circ}$ in the vestibule of his house at Fogan, it froze in the fields; and speaks of having seen ice an inch thick. Now, if we estimate $27^{\circ}$ as the lowest range of the thermometer, and $95^{\circ}$ as the highest, this would give a mean of $61^{\circ}$; and even taking $32^{\circ}$ as the lowest, still that would furnish a mean of $63 \frac{1}{2}^{\circ}$, whereas the mean of his journal is stated at $70^{\circ}$.

Taking $29^{\circ}$ as a mean latitude of the tea districts connected with foreign supply (as correctly estimated by Dr. Falconer), $61^{\circ}$ may then, perhaps, be received as the mean of the temperature. 
Again, there is a difference of $5^{\circ}$ between Thunberg's Journal; and the one furnished by the Memoirs of the Batavian Society and that of Von Siebold.

Thus, it is obvious that these Journals must be considered as imperfect records of the true temperature of the atmosphere. Those of Canton and Macao were nevertheless kept with care, and are deserving of equal attention with the ordinary Journals of this description not kept by scientific observers.

\section{Elevation of the Tea Districts above the Sea Level.}

I have not attempted to estimate the height of the tea country above the level of the sea, because we have too little data upon which any such calculation can be grounded. But, as observed by Dr. Royle, as the barometer stands at about $30^{\circ}$ in the Yang-cse-kiang, it may be assumed that the green tea district does not rise much above the level of the sea. The same remark holds good as regards the southern part of the province in which the tea districts are situated; for we see that as Lord Macartney's embassy skirted this part of the province, the barometer stood at about the same height. Further, Du Halde states, that at Kieu-kiang-fu, situated on the south banks of the Yangcse-kiang, in Kiang-sy, the tide regularly ebbs and flows at the full and change of the moon, although the distance from the sea is computed to be 100 French leagues, or 280 British miles; which circumstance equally marks the low level of the entire province of Kiang-nan, as well as the slow current of this great river beyond the ordinary influence of the tide.

With respect to the black tea district, calculating the distance by the river Min at 270 miles from the sea, and the current at even four miles the hour, which is a rapid current, this might give (I am informed on very good authority) an inclination of two and a half feet the mile; thus making the elevation of the Bohea district 675 feet 
above the level of the sea. And it has been shown that some of the finest teas are produced on the plains. But if we estimate the elevation of the hills, on which the teas of commerce are grown, and which are said to be not remarkable for their height, at from 700 to 800 feet more, this would give an elevation of 1500 feet. For the highflavoured teas, the reader may indulge his fancy at any height above this.

Now, if we examine a good map in which the mountains are indicated, we shall find that a continuous and somewhat lofty range extends nearly from the Yang-cse-kiang to the western extremity of the empire, separating the provinces of Kiang-soo, Che-kiang, Fokien, Quong-tong, Quong-sy, and Yun-nan, from the rest of the empire. Then, if we imagine this great and extensive range, heaved and raised up to irregular heights, varying perhaps from 4000 to 8000 feet above the sea, and examine the course of the rivers, we shall find that all west and north of this range discharge their waters into the great river, the Yang-cse-kiang; and all east and south disembogue into the sea, thus indicating an inclination in opposite directions on either side of this range. The province of Kiang-soo, however, is almost a dead level from the mountains to the sea. The green tea district is situated near the western base of this range; and the black tea districts, also, at the base, but on the east. Then, if we imagine two other ranges forking off from the principal range, running in a direction east of north, and dividing the provinces of Kiang-sy and Hu-quong, and the latter from Szu-chuen, with inclinations inwards, as well as towards the Yangcse-kiang, we shall then, I believe, have some general, though imperfect, idea of the face and inclination of that part of the country, where the tea plant has been found indigenous in all ages. The provinces of Szu-chuen, Kiangsy, Fokien, and Che-kiang are classed among the most mountainous provinces of the empire. 
Sifting and Winnowing of Hyson and Twankay Teas,

The following is Mr. Reeves's account of the sifting and winnowing of Hyson and Twankay teas, to form Hyson; Gunpowder; Hyson Skin; and Young Hyson: also Twankay; and Twankay Hyson; Gunpowder; Skin; and young Hyson.

The tea as taken from the chest was put, by a catty or two at a time, into a sieve, which the Chinese called the fifth sieve; so fine that only dust and very small leaves could pass through; and, as this will be the subject of further operations, let us call it sample A.

The returns of the fifth sieve, or that which would not pass through, was sifted in the fourth sicve, and passed the sample $B$.

The returns of this sieve put into No. 3. passed the sample $\mathrm{C}$, and

The returns of this sieve sifted through No. 2. the sample $\mathrm{D}$, and

The remainder, which would not pass the sieve, formed the sample E.

The samples B, C, and D, being tossed in large flat baskets (as is done by the seedsmen in England), threw off light leaves or skin of inferior quality; and by giving the baskets a circular motion, other leaves were brought up to the middle of the sieve, whence they were skimmed off; and the samples were then hand-picked to separate the irregularly formed leaves too heavy to be separated by the former processes, which form Skin of the better quality, and the Hyson only.

The skin of $\mathrm{E}$ is also hand-picked, as it is in general too heavy to be separated by other means.

B, C, D, and E, are now Hyson tea, differing only in size, according to the sieve which each has passed through; but requiring, on account of this difference, a longer or a 
shorter time in the following processes: the larger leaf requiring the longer firing or roasting.

A sample of $\mathrm{C}$ from one and a half to two catties was put into an iron pan, set orer a charcoal fire, and kept constantly stirred with the hand; the fire being kept at an equable degree of heat by occasionally slipping a tile between it and the pan. This operation is called Chao, and lasted fifty-eight minutes. The leaf by this operation becomes closer in the twist, and paler though brighter in colour; the proper degree being determined by the eye, according to the judgment of the manufacturer.

When $13, \mathrm{C}, \mathrm{D}$, and $\mathrm{E}$, have been each separately roasted and sifted, to clear them from the dust occasioned by friction against the sides of the pan, they are mixed to form Hyson according to fancy or sample; then roasted again in their mixed state and packed hot into the chests. The Chinese say it is necessary to pack it hot to preserve the smell: the leaves also are not so apt to break as when cold; and they say the colour gets darker in a few days.

The constant friction keeps the inside of the kuo clean, and it is said, those long in use become as bright as silver.

The sample $A$ is put into a very fine sieve, which separates the extreme fine dust, which is sold to the manufacturers of china-ware in Kiang-sy and Ho-nan, the poorer class of whom use it by putting some into a tea cup and pouring boiling water upon it, as is done with other tea leaf at Canton. When this fine dust is separated, the remainder is passed through a winnowing machine, the supply being regulated by a sliding board at the bottom of the hopper; and the fanner being set in motion, the smallest broken leaf is blown out at the end, near which the larger broken leaf falls: and the other is delivered, according to the respective degrees of gravity, in young 
Hyson and Gunpowder, at the side orifices. This process, however, does not so completely divide the Gunpowder and young Hyson, but it is necessary to separate them afterwards by hand, or rather with the end of a feather.

The Gunpowder and young Hyson are then separately roasted to give them a lighter twist and to bring out the colour. This requires the roasting to be repeated, and the pan to be made much hotter; so that three men took their turns in stirring the tea, relieving each other on account of the heat. This roasting continued ten minutes, during the whole of which the tea was kept stirred about with a constant quick motion, and examined frequently to see when done enough.

The Gunpowder consists of such young leaves as on the original drying at the tea-farms take the round twist: the young Hyson of such young leaves as take the long twist, and, therefore, when truly made should consist of whole leaves; but very little is now made in this manner. The demand for the Americans, who consume large quantities of these teas, is so great that the manufacturers cannot supply them, except by cutting up the leaves before drying, and making imitations.

\section{Twankay Tea.}

The Twankay tea was passed through the same sieves as the Hyson, but the roasting was done with a quicker fire; so that the leaf of the same size as the Hyson required only ten minutes instead of fifty-eight. The tea was tossed hot to throw off the skin, as the makers say the Twankay skin will not fly off when cold.

The tea from the second sieves was roasted separately as the Hyson; the larger leaf requiring the longer roasting. After being mixed to fancy, it is roasted again and packed hot.

The same process as in the Hyson forms the Twankay 
Gunpowder, and Twankay young Hyson; and the dust is sold to the porcelain manufacturers, as is the Hyson dust also.

The manufacturer who showed this process has about 100 pans (kuo) at work; and employs 300 women during the tea season, who can perform all the various operations, even the roasting. Women are employed, as their pay is cheaper, being only four or five candareens a day, whereas the men charge one quarter of a dollar (say eighteen candareens). Charcoal is used.

In the manufacturing of the finest Hyson tea, 100 catties of rough tea (Mao Cha, or as purchased of the farmers,) will produce about,

35 to 36 catties of fine Hyson.

20

25 to 26 good Hyson.

10

5 of large $\}$

5 of small $\}$

Hyson Skin.

young Hyson.

Gunpowder.

\section{Second Quality.-100 Catties.}

50 catties of good and fair.

11 to 12 inferior, below Company's quality.

20 Hyson Skin.

10 to 14 young Hyson.

5 or $6 \quad$ large and small Gunpowder.

Third Quality.-100 Catties.

45 to 46 catties, if picked clean, quality below Company's.

35 to 36 Hyson Skin.

16 to 17 young Hyson.

3 to 4

Gunpowder.

In Twankay teas, 100 Catties.

10 catties Twankay Hyson, that is, leaf regular enough to look like Hyson.

50

Twankay.

20 Skin.

10 young Hyson.

4 to 5 Gunpowder. 
Second Quality Twankay.-100 Catties.

10 catties 'Twankay Hyson.

60 Twankay.

10 Skin.

10 young Hyson.

4 to 5 Gunpowder.

Von Siebold's Botanical Classification of the Tea Tree. (Nippon, p. vi. s. 12.)

\section{THEA SINENSIS, Linn.}

System. Artific. Linn. Class Monadelphia, Ord. Polyandria. Famil. Natural. Camelliarum De Cand.

\section{Character Generis.}

Calyx pentasepalus; Corolla hexa-seu enneapetala, petalis basi cohærentibus, bi-seu triserealibus; Stamina numerosa, monadelphia, androphoro cum petalorum unquibus subcohærente; antheræ subrotundæ; Germen subrotundum ex ovariis 3-6- ovulatis compositum, 3loculare; stylus e tribus coalitis, apice ad medium usque trifidis formatus; stigmata tria linearia reflexa. Capsula tricocca, trilocularis, loculis abortu monospermis, dorso (loculicide) dehiscentibus. Semina nuculiformia.

\section{Character Speciei.}

Thea sinensis Linn. Foliis elliptico-oblongis, acutis vel obtusis, serratis; floribus in foliorum axillis binis vel solitariis breve pedunculatis.

\section{VARIETATES JAPONICE.}

Foliis minoribus, saturatius viridibus. (Thea Bohea aliorum.)

a) Thea sinensis, strricta ; foliis elliptico-oblongis, subrugosis, latitudine duplo longioribus, acutis; ramis strictis, erectis. 
ß) Thea sinensis, Rugosa ; foliis ellipticis obovalibusve, rugosis, latitudine vix duplo longioribus, obtusis; ramis erectis.

Foliis majoribus latius viridibus. (Thea viridis aliorum.)

$\gamma$ ) Thea sinensis, diffusa ; foliis lanceolatis, planis, latitudine triplo longioribus, utrinque acuminatis; ramis diffusis.

ס) Thea sinensis, macrophylla; foliis ellipticis, magnis, latitudine triplo longioribus; ramis erectis.

In addition to the above description, the botanist will find in the original work many notes and observations which may be useful: and, among the plates, the four varieties here described are well figured in outline.

\section{Cost of Tea in the Bohea District.}

The teas which the Chinese class as Paochong and Souchong are said to sell from 42 to 92 tales the pecul, or from $2 s .1 d$. to $4 s .7 d$. the 1 b. Such as the Chinese class as Kong-fu or Congou, sell from 22 to 32 tales the pecul; and the teas known to us as Congou, sell from 7 to 13 tales the pecul. These are the prices after the usual allowances of trade have been deducted.

On teas selling above 20 tales the pecul, an allowance is made from the seller to the buyer of 7 per cent.; and below 20 tales, the allowance is 20 per cent. A further allowance is also made, on payment in cash, of 5 per cent. There is also a gain to the Canton merchant on the dollar, the value of the dollar being reckoned at Canton, at 7 mace, 2 candareens; and in Fokien, at 8 mace, 2 candareens. There is, moreover, a gain of 10 per cent. in the weight of tea. The fine teas are sold in quantities of from 2 to 30 chests at a time; and other teas from 5 to 130 , or more chests. The first gatherings of these latter 
teas sell from 11 to 21 tales the pecul: the second gatherings from 12 to 13 : and the third gatherings from 10 to 11 tales the pecul; from which the preceding allowances have to be made. I shall now give one or two examples of the mode of calculating these accounts: there may be some little discrepancy in them, which I may not now be able to reconcile, still they may be considered sufficiently near approximations to truth; and in China it is only by comparison of such data furnished by different parties, and at remote periods of time, that accurate accounts can be established.

Say that a chop of tea of 1000 chests, weighing 66,000 catties,

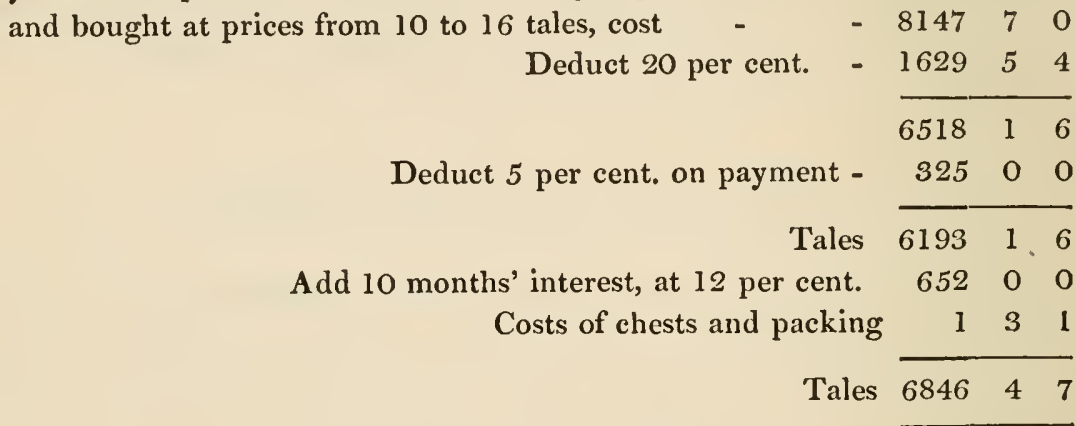

Tales. m. c.

The above example supposes that the Hong merchant sends his own agent to the tea country, with ample funds at his command, and that he buys with every advantage. This would make the cost of Congou tea, of the best quality, after packing, about $10 \cdot 3$ tales the pecul, or about $6 d$. the pound, at its seat of growth.

Tales. m. c.

Another chop of 600 chests, or 396 peculs, bought at prices

varying from 16 to 21 tales, cost -

Deduct 20 per cent. $\quad \begin{array}{lll}6102 & 1 & 0\end{array}$

Tales $\overline{4881 \quad 6 \quad 8}$ 
Tales 488168 at 8 mace, 2 candareens $=5953 \frac{20}{100}$ dollars.

Dollars $5953 \frac{20}{100}$ at 7 mace, 2 candareens

Tales. m. c.

Net weight

- 321 peculs.

Gain on weight

- 325

Part of a former chop

3535 Ta. m. c.

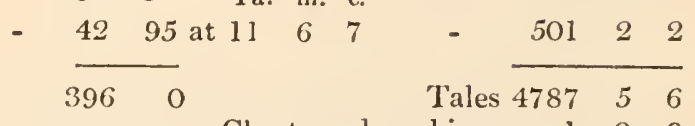

Chests and packing $\quad 1 \quad 0 \quad 9$

Tales $4788 \quad 6 \quad 3$

Thus making the pecul of tea 12 m.

In this statement the 5 per cent. is not deducted.

The contracts with tea-men were said to be effected by the Hong merchants, in the season 1824-6, on the following terms.

$\left.\begin{array}{l}\text { Puiqua, advanced } 4200 \text { tales on account } \\ \text { Mowqua ditto ditto }\end{array}\right\}$

Tales. m. Tales. m. Tales. m.

$\begin{array}{llllll}16 & 5 & 17 & 5 & 18 & 5\end{array}$

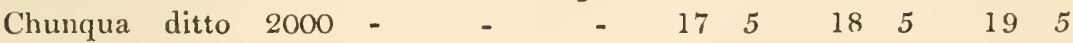

No advances $\quad-\quad$ - $\quad$ - $\quad$ - $\quad \begin{array}{lllllll}18 & 5 & 19 & 2 & 20 & 5\end{array}$

The several items of the account may be thus explained.

Contract prices -

T. m. c. T. m. c.

Cost of chests and packing

- $2050 \quad 1850$

Interest at 18 per cent. for 10 months, on 400

peculs of tea, at 14 tales the pecul, or on 5600

tales

Cost of transport and duties to Canton, the

$$
\text { pecul }
$$

Interest 6 months on the above 1600 tales

Tea-factors' profit

Cost of tea previously to packing $\begin{array}{rlllll}- & 2 & 4 & 0 & 1 & 4\end{array}$

$\begin{array}{llllll}- & 392 & & & & \end{array}$

- $036 \quad 036$

- 060006

- 11911083

* Interest at 12 per cent. for ten months, on 4200 tales, T. m. c. advanced

Interest at 18 per cent. for 8 months, on difference between money advanced, and cost of tea, at 14 tales the pecul - 048 
Further, I have a statement of the cost of 12 chops of tea, varying in price from 10.2 to 14.4 tales, and furnishing an average of $12 \cdot 1$ tales. The cost of chests is stated at $1 \cdot 1$ tales, together making the cost of tea packed, $13 \cdot 2$ tales the pecul.

Mr. Pigou states, that the first gathering when brought to

Canton, commonly costs the Hong merchant

The second gathering

And the third gathering * -

T. m. c.

In this account, I presume Mr. Pigou does not include the cost of transports to Canton. I am disposed to think, also, that the cost of chests is not included; and, moreover, by first, second, and third gatherings, the merchant who furnished the statements meant Congou teas of first, second, and third qualities. These terms are not unfrequently so used; so explained the account does not differ essentially from the statements herein given.

The inference, then, to be drawn from the preceding statements is, that Congou tea, equal in quality to such as the East India Company formerly received as contract teas, cost on an average 12 tales the pecul in the tea country previous to packing, or $7 d$. the pound avoirdupois. So there is no reason to suppose that the statements of cost made at Java and in India are underrated. In fact, they are too high. All new undertakings involve extraordinary expenses, but if teas can be made in China for $7 d$. the pound, the greater cheapness of labour in India ought to enable the Hindoo cultivator, when he has become familiarised with the cultivation, and equals the Chinese in skill, to furnish the same description of tea at $4 d$. the pound.

* Oriental Repertory, vol. ii. p. 287.

THE END. 


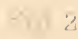

$F_{1}=1$

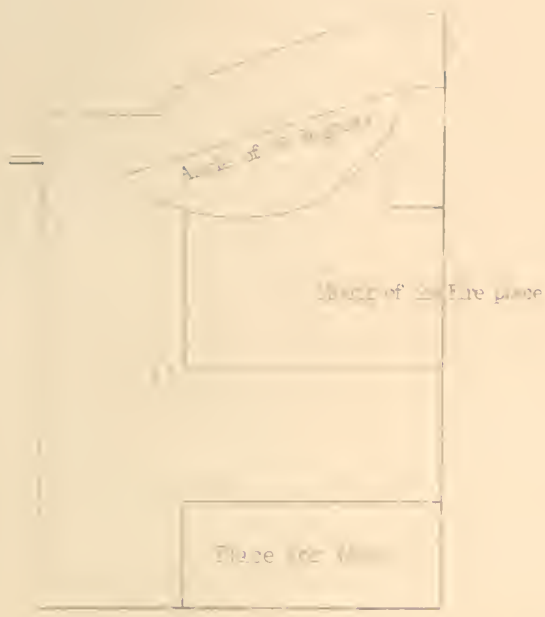

Whith in $=$ and

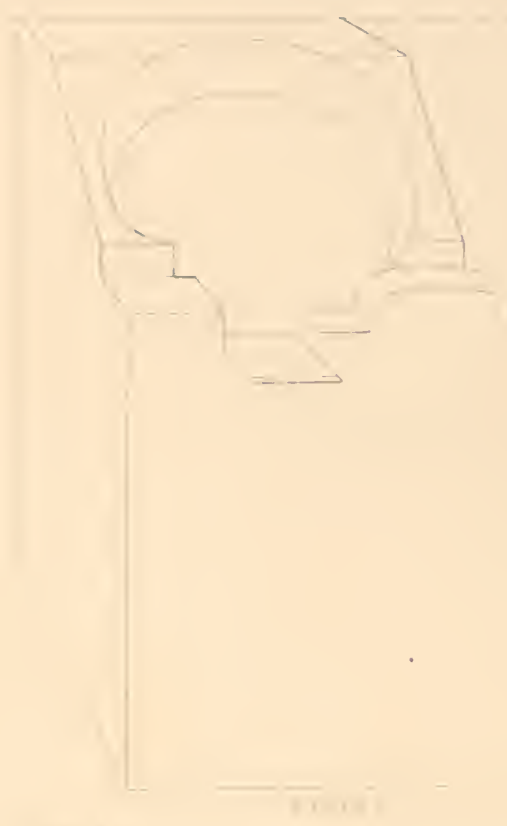

1. - sul

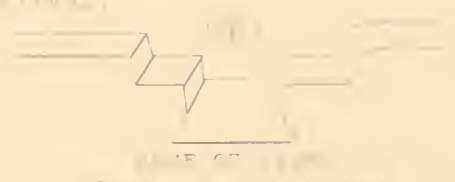

H $5, \ldots+\infty+1+1+\omega$

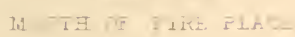

Pig $=$

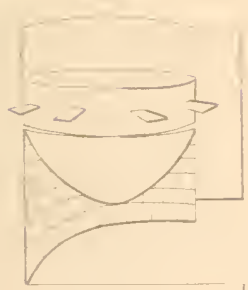

Fach Im thod

$2+1 \ldots+\ldots+\cdots$

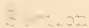
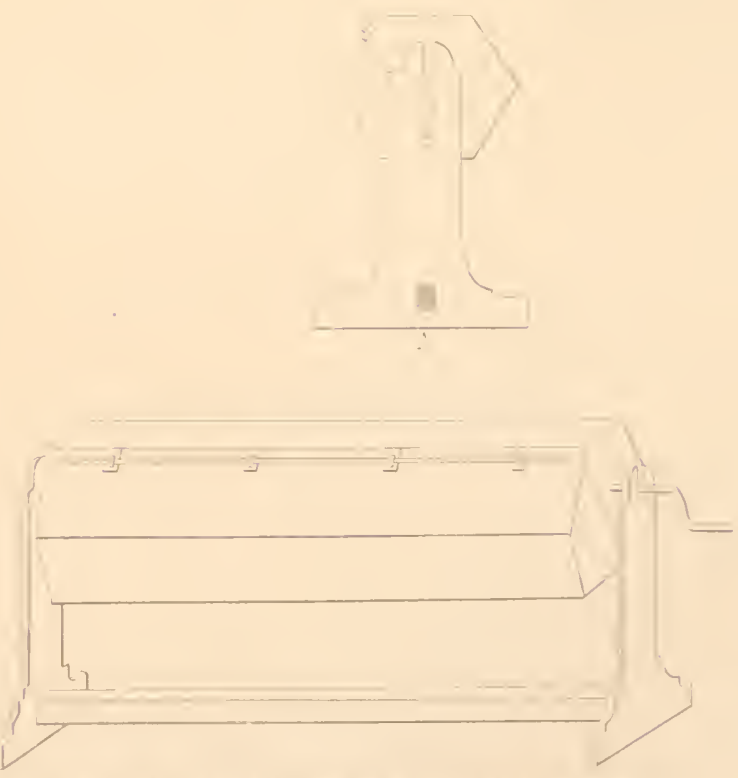

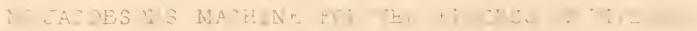





\section{DIRECTIONS TO THE BINDER.}

Chinese gathering Tea-leaves - - - Frontispiece.

View of a part of the "Inner Range" of the

Bohea Mountains _ - - _ To face page 43

Sections of Stoves - _ _ _ _ At the end. 

39 Pateryoster Row, E.C. Loxnox, July 1865.

\section{GENERAL LIST OF WORKS,}

\section{NEW BOOKS AND NEW FDITIONS,}

\section{PCBLISHED BY \\ Messrs. LONGMANS, GREEN, READER, and DYER.}

Arts, Minufictures, \&e Astronomy, Mistronologr, Populat Geography, \&e.

Biographi and Megroirs ............... Cimmistri, M[edicine, Sergiri; AN1) the Aldied Sciences ................ Comyerce, Naygatiox, axd MrercaxTILE AFF.Mrs Criticisir, Philology, \&c.............. 4 Fine Arts and Ilaustratrid Editions 10 Gexterde .19d School Atrases......... Historical Works. INDEX
.... 1

$21-24$

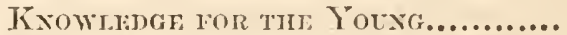
20

Miscrilangers and Popetan MetaPHY YSIC.I. Works.

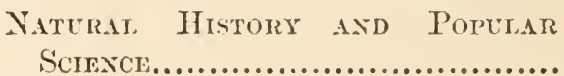

Penonical, Pubilchtoxs ................

Poetry a.d tith: Dr.anc.................

Remigiers Works

Rural Sports, \&e.

Traveis, Yoyagis, \&e. ................. 1.

Works of Fiction ...................... 16

Works of Utility AND Gevelzal IxFORMATIOX
The History of England from the Fall of Wolsey to the Death of Elizabeth. By James Antuony Frovde, M.A. late Fellow of Exeter College, Oxford.

\section{Vols. I. to IV. the Reign of Henry} VIII. Third Edition, $54 s$.

Vols. V. and VI. the Reigns of Edward VI. and Mary. Second Edition, 28s.

Vors. VII. and VIII. the Reign of Elizabeth, Vous. I. and II. Thirl Edition, $28 s$.

The History of England from the Accession of Janes II. By Lord Maciul.1Y. Three Elitions, as follows.

Libratix Edition, 5 vols. 8 vo. $£ 4$.

Carinet Enition, 8 vols. post 8 vo. $48 s$.

People's Edition, 4 vols. crown 8 ro. 16 s.

\section{Revolutions in English History.}

By Ronert Vaughan, D.D. 3 vols. 8 vo. 45 s.

Vor. I. Revolutions of Race, $15 s$.

VoI. II. Revolutions in Religion, 15 s.

Vor. III. Revolutions in Government, 1 s.
An Essay on the History of the Fnglish Gorernment and Constitution, from the Reign of IIenry VIl. to the P'resent Time. By Jour liner Russend. Third Edition, revised, with Jew Introduction. Crown 8 ro. $6 s$.

The History of England during the Reign of George the Third. By Willitar Mlassey, M.P. 4 rols. 8vo. 48s.

The Constitutional History of England, since the Accession of George III. 1760-1860. By Thomis Erskixe MaY, C.B. Second lidition. 2 vols. 8 vo. $33 s$.

Historical Studies. I. On some of the Precursors of the French Revolution; II. Studies from the History of the Serenteenth Century"; III. Leisure Hours of a Tourist. By Henus Merivide, M.A. 8ro. 12s. 6d.

\section{Lectures on the History of Eng-} land. By Willian Loxgmax. Yol. I. from the Earliest Times to the Death of King Edward II. with 6 MInps, a coloured Plate, and 53 Woodeuts. 8vo. 15 s. 
A Chronicle of Fingland, from B.c. 55 to A.D. 1485 ; written and illustrated by J. E. Doyle. IVith 81 Designs engraved on Wood and printed in Colours by E. Evans. 4to. $42 s$.

History of Civilization. By Henry 'THOMAS BUCKLE. 2 vols. $£ 117 s$.

VoL. I. England and France, Fourth Edition, $21 s$.

Vou. II. Spain and Scotland, Second Edition, 16 s.

Democracy in America. By Arexis De Toceueville. Translated by Henry ReEve, with an Introductory Notice by the Translator. 2 vols. 8 vo. $21 \mathrm{~s}$.

\section{The Spanish Conquest in}

America, and its Relation to the History of Slavery and to the Government of Colonies. By Artilur Helps. 4 vols. 8vo. £3. Vols. I. \& II. 28s. Vols. III. \& IV.16s, each.

History of the Reformation in Europe in the Time of Calvin. Ey J. H. Merle D'Aubigné, D.D. Vols. I. and II. 8 ro. $28 s$. and VoL. III. $12 s$.

Library History of France, in 5 vols. 8ro. By Eyre Evans Crowe. Vol. I. 14s. VoL. II. 15̃s. YoL. III. 18s. VoL. IV. nearly ready.

Ieetures on the History of France. By the late Sir James Stephen, LL.D. 2 vols. 8 vo. $24 s$.

The History of Greece. By C. ThrrLWALL, D.D. Lord Bishop of St. David's. 8 vols. 8 vo. $£ 3$; or in 8 vols. fep. $28 s$.

The Tale of the Great Persian War, from the Histories of Herodotus. $\mathrm{By}$ George W. Cox, M.A. late Scholar of Trin. Coll. Oxon. Fep. 7 s. $6 d$.

Ancient History of Egypt, Assyria, and Babylonia. By the Author of 'Amy Herbert.' Fep. 8vo.6s.

\section{Critical History of the Ian-} suace and Literature of Ancient Greece. By Wrldan Mure, of Caldwell. 5 vols. 8vo. $£ 39 s$.

History of the Literature of Ancient Greece. By Professor K O. MI ÜLLER. Translated by the Right Hon. Sir George Connewali. Lewis, Bart. and by J. W. DoNaLDSOr, D.D. 3 vols. 8 ro. 36 s.
History of the Romans under the Empire. By Crarles Merivale, B.D. Chaplain to the Speaker.

Cabinet Edition, 8 vols. post 8 ro. 48 s. Library Edition, 7 vols. 8vo. £5. $11 s$.

The Fall of the Roman Republic : a Short History of the Last Century of the Commonwealth. By the same Author. 12mo. 7s. $6 d$.

\section{The Conversion of the Roman}

Empire: the Boyle Lectures for the year 1864, delivered at the Chapel Royal, Whitehall. By the same. 2nd Edition. 8ro. 8s.6d.

\section{Critical and Historical Essays} contributed to the Edinburgh Review. By the Right Hon. Lord Macaulay.

Librany Edition, 3 vols. 8vo. $36 s$.

Traveller's Edition, in 1 vol. $21 s$.

In Pocket Volunes, 3 vols. fep. $21 s$.

People's Edition, 2 vols. crown 8 vo. $8 s$.

\section{Historical and Philosophical} Essays. By Nassau W. Senior. 2 vols. post Svo. 16 s.

History of the Rise and Influence of the Spirit of Rationalism in Europe. By W. E. H. Leckr, M.A. Second Edition. 2 vols. 8 vo. 25 s.

The Biographical History of Philosophy, from its Origin in Greece to the Present Day. By George Henry Lewes. Revised and enlarged Edition. 8ro. $16 s$.

\section{History of the Inductive Sciences.} ByWilliair IV heweli, D.D. F.R.S. Master of Trin. Coll. Cantab. Third Edition. 3 vols. crown $8 \mathrm{vo} .24 s$.

\section{Egypt's Place in Universal His-} tory; an Historical Investigation. $\mathrm{By}$ C. C. J. Bussex, D.D. Translated by C. H. Cotrrelu, M.A. With many Illustrations. 4 vols. 8 ro. $£ 58 s$. VoL. V. is nearly ready, completing the work.

Maunder's Historical Treasury; comprising a General Introductory Outline of Universal Histnry, and a Series of Separate Histories. Fep. $10 s$.

\section{Historical and Chronological En-}

cyclopædia, presenting in a brief and convenient form Chronological Notices of all the Great Events of Universal History. By B. B. Woodwari, F.S.A. Librarian to the Queen.

[In the press. 
History of the Christian Church, from the Ascension of Christ to the Conversion of Constantine. By E. Burton, D.D. kate Regius Prof. of Divinity in the University of Oxford. Eighth Edition. Fep. $3 s .6 d$.

Sketch of the History of the Church of Englancl to the Revolution of 16Ss. By the Right Rev. '1. Y. SuonT, D.D. Lord Bishop of St. Asaph. Sixth Edition. Crown 8ro. 10 s. $6 d$.

History of the Early Church, from the First Preaching of the Gospel to the Council of Nicra, A.D. 325. By the Anthor of 'Amy' Herbert.' Fep. 4s. $6 a$.

The Finglish Reformation. By F. C. Massirgberd, M.A. Chancellor of Lincoln and Rector of South Ormsby. Third Edition, revised and enlarged. Fep. $6 s$.
History of Wesleyan Methodism. By Glorge Surtri, F.1.S. Fourth Edition, with numerous l'ortraits. 3 ro's. crown 8ro. 7s. each.

Villari's History of Savonarola and of his Times, translated from the Italian by Leovarn Horxer, F.R.S. with the cooperation of the Author. 2 rols. post Ero. with Medallion, 18 s.

Lectures on the History of Modern Arasic, delivered at the Royal Institution. By Jornv Hullail, Professor of Vocal Mlusic in King's College and in Queen's College, London. Iirst Course, with Chronological Talbles, post 8ro. 6s. Gd. Second Counse, on the Transition Period, with 26 Specin:ens, 8ro. $16 s$.

\section{Biography and Memoirs.}

\section{Letters and Iife of Francis} Bacon, including all his Occasional Works. Collected and edited, with a Commentary, by J. Spedding, Trin. Coll. Cantab. Vols. I. and II. $8 \mathrm{ro} .24 \mathrm{~s}$.

Passages from the Life of a Philosopher. By Cirarles BabBage, Esq. M.A. F.R.S. \&c. 8vo. $12 s$.

\section{Life of Robert Stephenson, F.R.S.}

By J. C. JeAfFleson, Barrister-at-Law, and Willian Pole, F.R.S. Memb. Inst. Civ. Eng. With 2 Portraits and 17 Illustrations. 2 vols. 8 ro. $32 s$.

Life of the Duke of Wellington. By the Rev. G. R. Gleig, M.A. Popular Edition, carefully revised; with copious Additions. Crown Svo. with Portrait, 5 s.

Erialmont and Gleig's Life of the Duke of Wellington. 4 vols. 8 ro. with Illustrations, £2 $14 s$.

Life of the Duke of Wellington, partly from the French of M. BrIALsont, partly from Original Documents. By the Rev. G. R. Gleig, M.A. 8vo. with Portrait, 15s.

History of my Religious Opinions By J. H. Newria, D.D. Being the Substance of Apologia pro Vitâ Suâ. Post 8ro. $6 s$.

Father Mathew: a Biography. By John Fraxcis MAguire, M.P. I'opular Edition, with Portrait. Crown 8vo. 3s. $6 d$.

Rome; its Rulers and its Institutions. By the same Author. New Edition in preparation.
Memoirs, Miscellanies, and Letters of the late Lncy Aikin; includiug these addressed to Dr. Channing from 1826 to 1842. Edited by P.H. Le Breton. Post Sro. 8s. Gd.

Iife of Amelia Wilhelmina Sieveking, from the German. Edited, with the Author's sanction, by Catherive IVINKworth. Post Sro. with Portrait, 12s.

Louis Spohr's Autobiography. Translated from the German. 8vo. $14 s$.

Felix IMendelssohn's Letter's from Italy and Switzerlund, and Letters from 1833 to $184 \pi$, translated by Lady WALLice. New Edition, with Portrait. 2 vols. crown 8ro. 5s. each.

Diaries of a Lady of Quality, from 1797 to $184 t$. Edited, with Totes, by A. Hayward, Q.C. Post 8vo. 10s.6d.

\section{Recollections of the late William} Wilberforce, M.P. for the County of York during nearly 30 Years. By.J. S. HARFord, F.R.S. Second Edition. Post 8ro. 7 s.

\section{Memoirs of Sir Henry Havelock,}

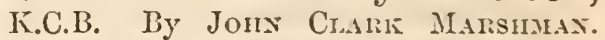
Second Edition. 8ro. with Portrait, 12s. $6 d$.

\section{Thomas Moore's Memoirs, Jour-} nal, and Correspondence. Edited and abridged from the First Edition by Earl Russele. Square crown 8ro. with 8 Portraits, 12s. $6 d$. 
Memoir of the Rev.Sydney Smith. By his Daughter, Lady Holuaxd. With a Selection from his Letters, edited by Mrs. Austin. 2 vols. 8 ro. 28 s.

Vicissitudes of Families. By Sir Bersard Burke, Ulster King of Arms. First, Second, and Tinrd Serizs. 3 vols. crown 8 vo. $12 s .6 d$. each.

Essays in Ecclesiastical Biography. By the Right Hon. Sir J. STErHeN, LL.D. Fourth Edition. 8ro. 14s.
Biographical Sketches. By Nassau

W. Srivior. Post 8vo. 10 s. $6 d$.

Biographies of Distinguished Scientific Mell. By lirançors Arago. Translated by Admiral W. H. Ssiririr, F.R.S. the Rev. B. Powell, M.A. and R. Grant, M.A 8ro. $18 s$.

Maunder's Biographical Treasury : Memoirs, Sketches, and Brief Notices of above 12,000 Eminent Persons of All Ages and Nations. Fcp. 8ro. 10s.

\section{Criticism, Philosophy, Polity, \&.c.}

Papinian: a Dialogue on State Affairs between a Constitutional Lawyer and a Country Gentleman about to enter Public Life. By Georie Atrisson, B.A. Oxon. Serjeant-at-Law. Post 8vo. 5s.

\section{On Representative Government.}

By Joln Stuair Mrl.. 'I hird Edition 8 vo. $9 s$. crown 8 vo. $2 s$.

On Liberty. By the same Author. Third, Edition. Post 8ro. 7s. 6d. crown 8ro. 1s. $4 d$,

Principles of Political Economy. By the same. Sixth Edition. 2 vols. 8vo. 30 s. or in 1 vol. crown 8 ro. $5 s$.

A System of Logic, Ratiocinative and Inductive. By the same. Fifth Edition. 2 vols. 8 vo. 25 s.

Utilitarianism. Bythe same. 2d Edit. Sro. $5 s$.

Dissertations and Discussions. By the same Author. 2 rols. 8 ro. $24 s$.

Examination of Sir W. Hamilton's Philosophy, and of the Principal Philosophical Questions discussed in his Writings. By the same Author. 8ro. 14s.

Lord Bacon's Works, collected and edited byR. L. ELLIs, M.A. J. SreDDing, M.A. and D. D. Heatir. Vols. I. to V. Philosoplical Works, 5 vols. 8 vo. $£ 46 s$. VoLs. VI. and VII. Literary and Professional Works, 2 vols. $£ 116 s$.

Bacon's Essays, with Annotations. By R. Whately, D.D. late Archibishop of Dublin. Sixtlı Edition. Sro. 10s. $6 d$.

Elements of Logic. By R. WhateLY, D.D. late Archbishop of Dublin. Ninth Edition. 8ro. 10s. $6 d$. crown Sro. $4 \mathrm{~s} .6 d$.

Elements of Rhetoric. By the sanc Author. Seventh Edition. Svo. 10s. 6d. crown 8 vo. $4 s .6 d$.

English Synonymes. Edited by Archbishop Whately. 5th Edition. Fep. $3 s$.
Miscellaneous Remains from the Common-place Book of Riciraid Winters, D.D. late Archbishop of Dublin. Edited by Miss E. J. Wirntely. Post 8 vo. $7 s, 6 d$.

Essays on the Administrations of Great Britain from 1783 to 1830 . By the Riglit Hon.'Sir G. C. Lewis, Bart. Edited by the Right Hon. Sir E. Hean, Bart. Sro. with Portruit, $15 s$.

\section{By the same Author.}

A Dialogue on the Best Frorm of Government, $4 s .6 d$.

Essay on the Origin and Formation of the Romance Languages, $7 s .6 d$.

Historical Survey of the Astronomy of the Ancients, $15 s$.

Inquiry into the Credibility of the Early Roman History, '2 rols. 30s.

On the Methods of Observation and Reasoning in l'olitics, 2 vols. $28 s$.

Irish Disturbances and Irish Church Question, 12s.

Remarks on the Use and Abuse of some Political Terms, $9 s$.

On Foreign Jurisdiction and Extradition of Criminils, $2 s .6 d$.

The Fables of Babrius, Greek Text with Latin Notes, PAn' I. 5s,6 . PAR'T II. 3s. 6d.

Suggestions for the Application of the Fyyptological Method to Modern History, 1s.

\section{An Outline of the Necessary} Laws of Thought: a Treatise on Pure and Applied Iogic. By the Most Rev. WV. Thomson, D.D. Archbishop of York. Crown 8 vo. 5s $6 d$. 
The Elements of Logic. By Troms Sneudex, M.A. of St. Peter's Coll. Cantab. 12mo. $4 s .6 d$.

\section{Analysis of Mr. Mill's System of} Logic. By W. Stenbivg, M.A. Fellow of Worcester College, Oxford. 12mo. 3s. $6 d$.

\section{The Election of Representatives,} Parliamentary and Municipal; a Treatise. By Tiromas Hare, Barrister-at-Law. Third Edition, with Additions. Crown Svo. $6 s$.

Speeches of the Right Hon. Lord MACAULAY, corrected by Himself. 8vo. 12s.

Lord Macaulay's Speeches on Parliamentary lieform in 1831 and 1832. $16 \mathrm{mo} .1 s$.

\section{A Dictionary of the English} Language. By- I. G. Lathan, M.A. M.D. F.R.S. Founded on the Dictionary of Dr. S. Jornsov, as edited by the Rev. H. J. Tond, with numerous Emendations and Additions. Publishing in $36 \mathrm{P}$ arts, price $3 s .6 \mathrm{~d}$. each, to form 2 vols. 4 to.

\section{Thesaurus of English Words and}

Phrases, classified and arranged so as to facilitate the Expression of Ideas, and assist in Literary Composition. By P. M. IlogET, M.D. 14th Edition, crown 8ro. 10s。 $6 d$.

\section{Lectures on the Science of Lan-} guage, delivered at the Royal Institution. By Max Müllekr, M.A. Taylorian Professor in the University of Oxford. First Skries, Fourth Edition, 12s. Second Sertes, 18s.

The Debater; a Serics of Complete Debates, Outlines of Debates, and Questions for Discussion. By F. Rowrox. Fep. 6s.

\section{A Course of English Reading,} adapted to every taste and capacity; or, How and What to Read. By the Rev. J. Prcroet, B.A. Fourth Edition, fep. 5 s.

\section{Manual of English Literature,} Historical and Critical: with a Chapter on English Metres. By Tironas Arixold, B.A. Post 8 vo. $10 \mathrm{~s} .6 d$.

Southey's Doctor, complete in One Voiume. Edited by the Rer. J.W. W Writer, B.D. Square crown 8 vo. 12 s. $6 d$.

\section{Historical and Critical Commen-} tary on the Old Testament; with a New Trauslation. By M. M. Kaliscur, I'h. D. Vol. I. Genesis, 8ro. 18s. or adipted for the General lieader, 12s. Vou. II. Exodus, 15s. or alapted fur the General Iieader, 12s.

A Hebrew Grammar, with Exercises. by the sanne. P'AnT l. Outlines with Exercises, 8ro. 12s. Grl. Kixy, js. PAlt II. Frtceptional Forms and Constructions, 12s.6d.

A Latin-English Dictionary. By J. T. Whits, M.A. of Corpus Christi Cullege, and J. E. LinnLE, M.A. of St. Edmund Ilall, Oxford. Imp. 8ro. pp. 2,128, 42s.

A New Latin-English Dictionary, abridged from the larger work of White and Riddle (as above), by J.'1. Wutrs, M.A. Joint-Autliur. Meclium 8vo. pp. 1,018, 18s.

A Diamond Latin-English Dictionary, or Guide to the Meaning, Quality, and Accentuation of Latin Classical Words. By J. E. RIDDLE, M.A. $32 m o .2 s .6 d$.

An English-Greek Lexicon, containing all the Greek Words used by Writers of good authority. By C. D. YONGE, D.A. Fifth Edition. 4to. $21 s$.

Mr. Yonge's New Lexicon, English and Greek, abridged from his lar.rer work (as above). Square 12mo. 8s. 61.

A Greek-English Lexicon. Compiled by H. G. Lindisti, D.D. Dean of Christ Church, and R. Scotr, D.D. Master of Balliol. Fiftl Edition, crown 4to. 31 s. $6 d$.

A Lexicon, Greek and English, abridged from LIDDELL and ScorT's GreckEnglish Lexicon. Eleventh Edition, square 12mo. $7 s .6 d$.

A Practical Dictionary of the French and Einglish Languages. By L. Contansenu. Sth Edition, post Sro. 10s.til.

Contanseau's Pocket Dictionary, French and Englisl, abridged from the above by the Author. Jew Edition. 1Smo. 5s.

New Practical Dictionary of the German Language; German-English, and English-German. By the lier. W. I. Blackler, M.A., and Dr. Calit Mantin Friedlaxder. Post 8 ro. [In the press. 


\section{Miscellaneous Works and Popular Metaphysics.}

Recreations of a Country Parson: being a Selection of the Contributions of A. K. II. B. to Fraser's Magazine. SEcond Serirs. Crown 8vo. $3 s .6 d$.

The Commonplace Philosopher in Town and Country. By the same Author. Crown 8 ro. $3 s 6 d$.

Leisure Hours in Town; Essays Consolatory, Esthetical, Moral, Social, and Domestic. By the same. Crown 8vo. 3s. $6 d$.

The Autumn IDolidays of a Country Parson : Essays contributed to Fraser's Magazine and to Good Words, by the same. Crown 8ro. 3s. $6 d$.

The Graver Thoughts of a Country Parson, Second Series. By the same. Crown 8vo. 3s. $6 d$.

Critical Essays of a Country Parson, selected from Essay's contributed to Fraser's Magazine, by the same. Post 8vo. 9s.

A Campaigner at Home. By SurnLEY, Author of 'Thalatta' and 'Nugæ Critica.' Post 8vo. with Vignette, 7s. 6d.

Friends in Council: a Series of Readings and Discourses thereon. 2 vols, fcp. $9 s$.

Friends in Council, Secord Series. 2 vols. post 8 vo. $14 s$.

Essays written in the Intervals of Business. Fep. $2 s .6 d$.

\section{Lord Macaulay's Miscellaneous Writings.}

Libraliy Edition, 2 vols. 8 ro. Portrait, $21 s$. Peoples Edrtox, 1 vol. crown 8 vo. $4 s .6 d$.

The Rev. Sydney Smith's Miscellaneons Works; including his Contributions to the Edinburgh Review.

Library Edition, 3 vols. 8 vo. 36 s.

Traveller's Edition, in 1 rol. $21 \mathrm{~s}$.

In Pochet Volumes, 3 vols. fep. $21 s$.

Peorle's Edition, 2 vols. crown 8 vo. 8 s.

Elementary Sketches of Mroral Philosophy, delivered at the Royal Institution. By the same Author. Fep. $7 s$.

The Wit and Wisdom of the Rev. SydneY Surtu: a Selection of the mast memorable Passages in his Writings and Conversation, $16 \mathrm{mo} .7 \mathrm{~s} .6 \mathrm{~d}$.
The History of the Supernatural in All Ages and Nations, and in All Churches, Christian and Pagan ; remonstrating a Universal Faith. By WrLlida HowitT. 2 vols. post 8 vo. 18 s.

The Superstitions of Witchcraft. By Howard Williams, M.A. St. John's Coll. Camb. Post 8ro. 7s. $6 d$.

Chapters on Miental Physiology. By Sir Henky Holland, Bart. M.D. F.R.S. Second Edition. Post 8vo. 8s. 6d.

Fssays selected from Contributions to the Edinburgh Review. By Hevry Rogers. Second Edition. 3 vols. fcp. 21 s. The Eclipse of Faith; or, a Visit to a Religious Sceptic. $B y$ the same Author. Tenth Edition. Fcp. $5 s$.

Defence of the Eclipse of Faith, by its Author; a Rejoinder to Dr. Newnan's Reply. Third Edition. Fcp. 3s.6d.

Selections from the Correspondence of R. E. H. Greyson. By the same Author. Third Edition. Crown 8vo. 7s.6d.

Fulleriana, or the Wisdom and Wit of Thomas Fulder, with Essay on his Life and Genius. By the same Author. 16mo. 2s.6d.

The Secret of Hegel: being the Hegelian System in Origin, Principle, Form, and Matter. By JAmes Hutchisun StirLivG. 2 vols. 8 vo. $28 s$.

An Introduction to Mental Philosophy, on the Intuctive Method. By J. D. Moreli, M.A. LL.D. 8vo. $12 s$.

Elements of Psychology, containing the Analysis of the Intellectual Powers. By the same Author. Post 8vo. 7s.6d.

Sight and Touch: an Attempt to Disprove the Received (or Berkeleian) Theory of Vision. By Timmas K. Aвbott, M.A. Fellow and Tutor of Trin. Coll. Dublin. 8vo. with 21 Woodcuts, 5s. $6 d$.

The Senses and the Intellect. By Alexander BaIs, M.A. Prof. of Lugic in the Univ. of Aberdeen. Second Edition. 8 vo. $15 s$.

The Imotions and the Will, by the same Author; completing a Systematic Exposition of the Human Mind. 8vo. 15s.

On the Study of Character, including an Estimate of Phrenology. By the same Author. 8ro. $9 s$. 
Time and Space: a Metaphysical Essay. By Shadworth H. Hovgson. 8 vo. pp 588, price $16 s$.

Hours with the Mystics: a Contribution to the History of lieligions (opinion. By Robert Alfrei) Vavghin, B.A. Second Edition. 2 vols. crown sto. $12 \%$

Psychological Inquiries. By the late Sir BexJ. C. Brovie, Bart. 2 vols. or SERIEs, fup. 5 s. each.
The Philosophy of Necessity; or, Natural Law as applicable to Mental, Moral, and Socia! science. By Charles Bray. Second Edition. 8vo. $9 s$.

The Education of the Feelings and Affections. By the same Author. Third Edition. 8vo, 3s. 6 d.

Christianity and Common Sense. by sir Whllougher Joses, Bart. M.A. Trin. Coll. Cantab. 8vo. 6s.

\section{Astronomy, Meteorology, Popular Geography, \&ce.}

\section{Outlines of Astronomy. By Sir} J. F. W. Herschel, Bart, Ml.A. Seventh Edition, revised; with I'lates and Woodcuts. 8 ro. 18 s.

\section{Arago's Popular Astronomy.} 'Translated by Admiral W. H. SHYTi, F.R.S. and R. Graxt, M.A. With 25 Plates and 358 Woodcuts. 2 vols. 8 ro. $£ 25$ s.

Arago's Meteorological Essays, with Introduction by Barmi Hewlicotot. 'Translated under the superintendence of MajorGeneral E. SAbine, R.A. 8vo. $18 s$.

Saturn and its System. By RichArd A. Procurur, B.A. late scholar of St. John's Coll. Camb. and King's Coll. London. Sro. with 14 Plates, 14 s.

The Weather-Book; a Manual of Practical Meteorolugy. By Rear-Admiral Ionert Frtz Roy, R.N. F.R.S. Third Edition, with 16 Diagrams. 8vo. $15 s$.

Saxby's Weather System, or Lunar Intluence on Weather. by S. M. SAXBY, R... N. Instructor of Naval Engineers. Second Edition. Post Svo. 4 s.

Dove's Law of Storms considered in connexion with the urduary MIovements of the Atmusphere. Translated by R. H. ScotT, M1.A. T.C.D. 8 vo. 10 s. $6 d$.

\section{Celestial Objects for Common} 'Telescopes. By'T. W. W енв, Mi.A.F.R.A.S. With Map of the Noon, and Woodeuts. 16mo. $7 s$.

\section{Physical Geography for Schools} and General Readers. By.M. F. MAURY, LL.D. Fcp, with 2 Charts, $2 s, 6 d$.
A Dictionary, Geographical, Statistical, and Historical, of tle various Countries, Places, and principal Natural Objects in the World. By J. R. M'Culloch. With 6 Maps. 2 vols. 8 ro. 63 s.

\section{A General Dictionary of Geo-} graphy, Descriptive, Physical, Statistical, and Historical ; forming a complete Gazetteer of the World. By A. KeIth Johsstox, F.R.S.E. Svo. 31 s. $6 d$,

A Manual of Geography, Physical, Industrial, and Political. By W. Hugires, F.R.G.S. P'rof. of Geog. in King's Coll. and in Queen's Coll.Lond. With 6 Maps. Fcp. $7 s .6 d$.

The Geography of British History; a Geographical Description of the British Islinds at Successive Periods. By the same. With 6 Maps. Fcp. $8 s .6 d$.

Abridged Text-Book of British Geography. By the same. Fcp. 1s.6d.

The British Empire; a Sketch of the Geography, Growth, Natural and Political Features of the United Kingdom, its Colonies and Dependencies. By Caroline Bray. With 5 Maps. Fep. 7s, $6 d$.

Colonisation and Colonies : a Series of Lectures delivered before the University of Oxford. By Hermax Merivale, M.A. Prof. of Polit. Econ. Svo. 18s.

\section{Maunder's Treasury of Geogra-} phry, Physical, Historical, Descriptive, and Political. Edited by WV. Hugres, F.R.G.S. With 7 Maps and 16 Plates. Fcp. 10 s. 


\section{Natural History and Popular Science.}

The Elements of Physics or Natural Philosophy. By Neic ArNott, M.D. F.R.S. Physician Extraordinary to the Queen. Sixth Edition. PART I. 8vo. 10 s. $6 d$.

\section{Heat Considered as a Mode of} Motion. By Professor Jorrs Trxp.luL, F.R.S. LL.D. Second Edition. Crown svo. with Woodcuts, 12s. $6 d$.

Volcanos, the Character of their Phenomena, their Share in the Structure and Composition of the Surface of the Globe, \&c. By G. Poulett Scrope, MI.P. F.R.S. Second Edition. 8ro. with Illustrations, $15 s$.

\section{A Treatise on Electricity, in} Theory and Practice. By A. DE LA Rrve, Prof. in the Acalemy of Geneva. Translated by C. V. WALKER, F.R.S. 3 rols. Sro. with Woolcuts, £3 $13 s$.

\section{The Correlation of Physical} Forces. By W. R. Grove, Q.C. V.P.R.S. Fourth Edition. 8vo. $7 s .6 d$.

\section{The Geological Magazine; or,} Monthly Journal of Geology. Edited by Henry Woodward, F.G.S. F.Z.S. British Museum; assisted by Professor J. MInRris, F.G.S. and R. ETIIELIDGE, F.R.S.I. F.G S. 8 vo. price $1 s$. monthly.

A Guide to Geology. By J. Phillyps, M.A. Prof. of Geol. in the Univ. of Oxford. Fifth Edition; with Plates and Diagrams. Fcp. $4 s$.

A Glossary of Mineralogy. By H.W. Bristow, F.G.S. of the Geological Survey of Great Britain. With 486 Figures. Crown 8vo. 12 s.

\section{Phillips's Elementary Introduc-} tion to Mineralogy, with extensive Alterations and Addlitions, by H. J. Brooke, F.R.S. and W. H. MInLLir, F.G.S. Post 8 vo. with Woodcuts, $18 s$.

\section{Van Der Hoeven's Handbook of} ZooLoGY. Translated from the Second Dutch Edition by the Rev. W. Cuark, M.D. F.R.S. 2 vols. 8 vo. with 24 Plates of Figures, 60s.

\section{The Comparative Anatomy and} Physiology of the Vertebrate Animals. By Richani) Owin, F.R.S. D.C.L. 2 vols. 8 ro. with upwards of 1,200 Woodeuts.

[In the press.

Homes without Hands: an Account of the Habitations constructed by various Animals, cliassed according to their Principles of Construction. By Rev. J. G. Woon, M.A. F.L.S. Illnstrations on Wood by G. Pearson, from Drawings by F. W. Keyl and E. A. Smith. In 20 Parts, 1 s, each.

\section{Manual of Corals and Sea Jellies.}

By J. R. Greense, B.A. Edited by the Rev. J. A. Galbraitri, MI.A. and the Rev. S. Haugiton, M.D. Fep. with 39 Woodcuts, $5 s$.

Manual of Sponges and Animalculæo; with a General Introduction on the Principles of Zoology. By the same Author and Editors. Fcp. with 16 Woodcuts, $2 s$.

Manual of the Metalloids. By J. Аруопr, M.D. F.R.S. and the same Editors. Fep. with 38 Woodcuts, $7 s .6 d$.

The Sea and its Living Wonders. By Dr. G. Hartwig. Second (English) Edition. 8vo. with many Illustrations, $18 s$.

The Tropical World. By the same Author. With 8 Chromoxylographs and 172 Woodents. 8vo. $21 s$.

Sketches of the Natural History of Ceylon. By Sir J. Eumerson Tennerst, K.C.S. LL.D. With 82 Wood Engravings. Post 8vo. 12s.6d.

Ceylon. By tho same Author. 5th Edition; with Maps, \&re. and 90 Woorl Engratings. 2 vols. 8 vo. $£ 210 s$.

A Familiar History of Birds. By E. STanler, D.D. F.R.S. late Lord Bishop of Norwich. Seventh Edition, with Woodcuts. Ficp. $3 s .6 d$.

Marvels and Mysteries of Instinct; or, Curiosities of Animal Life. By G. Garisatt. Third Edition. Fep. Ts.

Home Walks and Holiday Rambles. By the Rev. C. A. Jonss, B.A. F.L.S. Fep. with 10 Illustrations, $6 s$. 
Kirby and Spence's Introduction to Entomology, or Elements of the Natural History of Insects. Seventh Edition. Crown 8 ro. $5 s$.

\section{Maunder's Treasury of Natural}

History, or Popular Dictionary of Zoolozy. Revised and corrected by T.S. Conior.t, M.D. Fep. with 900 Woodeuts, 10s.

\section{The Treasury of Botany, on the} Pian of Miunder's Treasury. L'y J. LisidLEY, MI.D. and 'L'. MLORR, F.L.S. assisted by other Practical Botanists. With 16 l'lates, and many Woodcuts from designs by W. H. Fitch. Fip. [In the press.

T.he Rose Amateur's Guide. By Thomas Rivers. Sth Edition. Fep. $4 s$.

The British Flora; comprising the Phanogamons or Flowering Plants and the Ferns. By Sir W. J. Hookek, K.II. and G. A. Walker-ArsotT, LL.D. 12 mo. with 12 Plates, 14 s. or coloured, $21 s$.

Bryologia Britannica; containing the Mosses of Great Britain and Ireland, arranged and deseribed. By W. Wilsox. 8vo. with 61 l'lates, $42 s$. or coloured, $£ 44 s$.

The Indoor Gardener. By Miss MALING, Fep. with Frontispiece, $5 s$.
Loudon's Encyclopædia of Plants; comprising the Specific Character, Descrip)tion. Culture, History, \&.c. of all the Plants found in Great Britain. With upwards of 12,000 Woodcuts. 8ro. £3 13 s. Gd.

Loudon's Encyclopædia of Trees and Shrubs; containing the IIardy Trees and Shrubs of Great Britain scientifically and popularly described. Witt 2,000 Woodcuts. Svo. 50s.

Maunder's Scientific and Literary 'lreasury; a Popular Encyclopadia of Science, Literature, and Art. Fep. 10s.

\section{A Dictionary of Science, Litera-} ture, and Art. Fourtl Edition. Edited by IV. 'T. Braxde, D.C.I. and George IV. Cox, M.A., assisted by gentlemen of emineut Scientific and Literary Acquirements. In 12 Parts, each containing 240) pages, price 5 s. forming 3 vols. medium 8 vo. Irice 21 s. each.

Essays on Scientific and other subjects, contributed to lieviews. By Sir II. Hollaxd, Bart. M.D. Second Edition. 8 ro. 14s.

Essays from the Edinburgh and Quarterly Revieu's; with Adtresses and other Pieces. By Sir J. F. W. Herschl:L, Bart. M.A. Sro. 18s.

\section{Chemistry, Medicine, Surgery,}

A Dictionary of Chemistry and the Allied Branches of other Sciences. By Hevry IVATts, F.C.S. assisted by eminent Contributors. 5 vols. medium 8vo. in course of publication in Parts. VoL. I. $3 s$. 6d. VoL. II. 26s. and VoL. III. 31 s. $6 d$. are now ready.

\section{Handbook of Chemical Analysis,} adapted to the Unitary System of Notation: By F. T. Conington, M.A. F.C.S. Post 8ro. 7s. 6d. - Tamles of Qualitative Axalisis adipted to the same, $2 s .06$.

\section{A Handbook of Volumetrical} Analysis. By Robelit H. Scott, M.A. T.C.D. Post 8ro. 4s. Gd.

Elements of Chemistry, Theoretical and Practical. By Wrulasr A. Miller, M.D. LL.D. F.R.S. F.G.S. Professor of Chemistry, King's College, London. 3 vols. 8 ro. £2 13s. Part I. Chemical Pirsics, Third Edition, 12s. Part II. Inorganic Cinemistry, 21s. Part III. Orgaxic Cumurstry, Second Edition, 20 s.
A Manual of Chemistry, Descriptive and Theoretical. By Willtas OnLxis, M.B. F.R.S. Lecturer on Chemistry at St. Bartholomew's Hospital. P.urr I. 8 ro. $9 s$.

A Course of Practical Chemistry, for the use of Medical Students. By the sinne Author. Second Edition, with 70 new Woodcuts. Crown 8ro. 7 s.6d.

The Diagnosis and Treatment of the Diseases of Women; including the Diagnosis of Pregnancy. By GidIL Hewrt, M.D. Physician to the British Lying-in Hospital. Sro. $16 s$.

Lectures on the Diseases of Infancy and Childhood. By Chariss WEs, 11.D. \&. 5th Elition, revised and enlarged. 8vo. 16 s.

Exposition of the Signs and Syuntoms of Pregnancy : with other Papers on subjects connected with Midwifery. By W. F. Montgomery, M.A. M.D. M.R.I.A. 8vo. with Illustrations, 25s. 
A System of Surgery, Theoretical and Practical, in Treatises by Various Authors. Edited by T. Holires, M.A. Cantab. Assistant-Surgeon to St. George's Hospital. 4 vols. Sro. $\mathcal{1} 13 s$.

Vol. I. General Pathology, 21s.

Vol.II. Iuocal Injuries: Grin-shot Wounds, Injuries of the Head, Back, Face, Neck, Chest, Abdomen, Pelvis, of the Upier and Lower Extremities, and Diseases of the Eye. $21 s$.

Vol. III. Operative Surgery. Diseases of the Organs of Circulation, Locomotion, \&c. 21 s.

Vol. IV. Diseases of the Crgins of Digestion, of the Genito-Urinary System, and of the Breast, Thyroid Gland, and Skin; with Appendix and Generil Index. 30s.

Lectures on the Principles and Practice of Physic. By Tromas Watson, M.D. Physician-Extraordinary to the Queen. Fourth Edition. 2 vols. 8ro. 31 s.

\section{Lectures on Surgical Pathology.} By J.PAGET, F.R.S. Surgeon-ixtritordinnry to the Queen. Edited by W. Turxer, M.B. 8vo, with 117 Woodcuts, $21 s$.

\section{A Treatise on the Continued} Fevers of Great Britain. By C. Míurcuison, M.D. Senior Physician to the London Ferer Hospital. Sro. with coloured Plates, 18 s.

\section{Anatomy, Descriptive and Sur-} gical. By Inexry Gray, F.R.S. With 410 IVood Engravings from Dissections. Third Edition, by T. Hownes, M.A. Cantab. Royal 8ro. 28s.

\section{The Cyclopædia of Anatomy and}

Physiology. Edited by the late R. B. Tond, M.D. F.R.S. Assisted by nearly all the most eninent cultivators of Fhysiological Science of the present age. 5 vols. Sro. with $2,8 \check{3} 3$ Woodcuts, $£ 66 s$.
Physiological Anatomy and Physiology of Man. By the late R. B. Tond, M.D. F.R.S. and W. Bownis, F.R.S. of King's College. With numerous Illustrations. Vol. II. 8 ro. $25 s$.

\section{A Dictionary of Practical Medi-} cine. By J. Coplaxd, M.D. F.R.S. Abridged from the larger work by the Author, assisted by J. C. CopLAvd, M.R.C.S. 1 vol. 8 vo.

[In the press.

Dr. Copland's Dictionary of Practical Medicine (the larger work). 3 rols. 8 ro. $£ 511 s$.

The Works of Sir B. C. Brodie, Bart. collected and arranged by Craduss Hawkins, F.R.C.S.E. 3 vols. 8vo. with Medallion and Facsimile, 48 s.

Autobiography of Sir B. C. Brodie, Bart. printed from the Author's materials left in MS. Fcp. $4 s .6 d$.

Medical Notes and Reflections. By Sir H. Hollaxd, Bart. M.D. Third Edition. Svo. 18s.

\section{A Manual of Materia Mectica} and Therapeutics, abridged from Dr. Pereira's Elements by F. J. Farile, M.D. Cantab. assisted by R. Bentley, MI.R.C.S. and by R. Warisgton, F.C.S. 1 rol. 8 ro.

[ In October.

Dr. Pereira's Elements of Materia Medica and Therapentics, Third Edition, by A. S. TAYLOR, M.D. and G. O. ReEs, M.D. 3 vols. 8 vo. with Woodcuts, £3 $15 s$.

Thomson's Conspectus "of the British Pharmacopocia. Twenty-fourth Edition, corrected and made conformable throughout to the New Pharmacopœia of the General Conncil of Merlical Education. By E. Lloud birkett, M.D. 18mo. $5 s .6 d$.

\section{Manual of the Domestic Practice} of Medicine. By W. B. KFsteres, F.R.C.S.E. Second Elition, thoronghiy revised, with Additions. Fcp. ə̃s.

\section{The Fine Arts, and Tlustrated Editions.}

The New Testament, illustrated with Wood Engravings after the Early Nasters, chiefly of the Italian School. Crown 4to. 63.s. cloth, gilt top; or $£ 55 s$. elegantly bound in morocco.
Lyra Germanica; Hymns for the Sundays and Chief Festivals of the Cluristian Year. Translated by CATHKLLIs WiskwokTr; 125 Illustrations on Wood drawn by J. Leiguton, F.S.A. Fep. 4to. 21 s. 
Cats' and Farlie's Moral Emblems; with Aphorisms, Adages, and Proverbs of all Nations: comprising 121 Illustrations on Wood by J. Leighton, F.S.A. with an appropriate Text by R. PIgot. Imperial 8vo. 31s. $6 d$.

\section{Bunyan's Pilgrim's Progress:} with 126 Illustrations on Steel and Wood by C. BennetT ; and a Preface by the Rev. C. KivgsLex. Fer. 4to. $21 s$.

Shakspeare's Sentiments and Similes printed in Black and Gold and illuminated in the Missal style by Hexry NonL HumphreYs. In massive covers, containing the Medallion and Cypher of Shakspeare. Square post 8ro. $21 s$.
The History of Our Lord, as exemplified in Works of Art; with that of $\mathrm{His}$ Types in the Old and New Testament. By Mrs. Jameson and Iady Eastlake. Being the concluding Series of 'Sacred and Legendary Art;' with 13 Etchings and 281 Woodcuts. 2 vols. square crown 8 ro. $42 s$.

In the same Series, by Mrs. JArreson.

Jegends of the Saints and IMartyrs. Fourth Edition, with 19 Etchings and 187 Woodcuts. 2 vols. $31 \mathrm{~s} .6 d$.

Legends of the Monastic Orders. Third Edition, with 11 Etchings and 88 Woodcuts. $1 \mathrm{vol} .21 \mathrm{~s}$.

Legends of the Madonna. Third Elition. with 27 Etchings and 165 Woodcuts. 1 vol. $21 s$.

\section{Arts, Manufactures, \&'c.}

Encyclopædia of Architecture, Historical, Theoretical, and l'ractical. by JoSEPI GwILT. With more than 1,000 Woodcuts. 8vo. $42 s$.

Tuscan Sculptors, their Lives, Works, and Times. With 45 Etchings and 28 Woodcuts from Original Drawings and Photographs. By Churies C. Perkiss 2 vols. imp. 8 vo. $63 s$.

The Engineer's Handbook; cxplaining the Principles which should guide the young Engineer in the Construction of Machinery. ByC. S. Lowndes. Post 8ro.5s.

The Elements of Mechanism. By T. M. Gooneve, M.A. Prof. of MLchanics at the $\mathrm{R}$ M. Acad. Woo' fricls. Second Edition, with 217 Woodcnts. Post 8 vo. 6s. 6d.

\section{Ure's Dictionary of Arts, Manu-} fictures, and Hines. Rie-written and enlarged by Rober Huxr, F.R.S., assisted by numerous gentlemen eminent in Science and the Arts. With 2,000 Woodcuts. 3 rols. 8 ro. £4.

\section{Encyclopædia of Civil Engineer-} ing, Historical, Theoretical, and Practical. By E. Cresr, C.E. With abore 3,000 Woodeuts. 8 ro. $42 s$.
Treatise on Mills and Millwork. BY IV. Fairnains, C.E. F.R.S. With 18 Plates and 322 Woodcuts. 2 vols. 8 vo. 3 ?s.

Useful Information for Engineers. By the same Author. Frust and SEcovin Series, witl many Plates and Woodcuts. 2 vols. crown 8 vo. 10 s. $6 d$. each.

The Application of Cast and Wrought Iron to Building Purposes. By the sanse Author. Third Edition, with 6 Plates and 118 Woodcuts. Sro. 16 s.

The Practical Mechanic's Journal: An Illustrated Fecord of Mechanical and Engineering Science, and Epitome of Patent Inventions. 4to. price 1s. monthly.

\section{The Practical Draughtsman's}

Book of Industrial Design. By WT. Jonxsox, Assoc. Inst. C.E. With many hundred Illustrations. 4to. 28s.6d.

The Patentee's Manual: a Treatise on the Law and Practice of Letters Patent for the use of Patentees and Inventors. By J. and J. H. Jomssox. Post Sro, 7s. 6d.

The Artisan Club's Treatise on the Steam Engine, in its various Apylications to Mines, Mills, Steam Navigation, Railways, and Agrienlture. By J. Boune, C.E. Sixth Edition; with $3 i$ Plates and 546 Woodcuts. 4to. $42 s$. 
Catechism of the Steam Engine,

in its various Applications to Mines, Mills, Steam Navigation, Railway's, and Agriculture. By J. Bourse. C.E. With 199 Woodcuts. Fcp.9s. The Istroducrios of 'Recent Improvements' may be had separately, with 110 Woodcuts, price $3 s .6 d$.

Handbook of the Steam Engine, by the same Author, forming a KEY to the Catechism of the Steam Engine, with 67 Woodcuts. Fep. $9 s$.

\section{The Theory of War Illustrated} by numerous Examples from History. By Lieut.-Col. P. L. MacDovgall. Third Edition, with 10 Plans. Post 8ro. 10s. $6 d$.

Collieries and Colliers; A Handbook of the Law and leading Cases relating thereto. By J. C. Fowler, Barrister-atLaw, Stipendiary Magistrate. Fep.6s.

The Art of Perfumery ; the History and Theory of Olours, and the Methods of Extracting the Aromas of Plants. By Dr. Puesse, F.C.S. Third Edition, with 53 Woodcuts. Crown 8 ro. $10 s .6 d$.

Chemical, Natural, and Physical Magic, for Juveniles during the Holidays. By the same Author. Third Edition, enlarged, with $3 \delta$ Woodeuts. Fcp. 6 s.

The Iaboratory of Chemical Wonders : A Scientific Mélange for Young People. By the same. Crown 8 ro. $5 s .6 d$.

Talpa; or, the Chronicles of a Clay Farm. By C. W. Hoskras, Esq. With 24 Woodcuts from Designs by G. CruikSIIANK. $16 \mathrm{mo} .5 \mathrm{s.} 6 d$.
H.R.H. the Prince Consort's Farms; an Agricultural Memoir. By Jous Cinaliers Morton. Dedicated by permission to Her Majesty the QueEN. With 40 Wood Engravings. 4to. 52s. $6 d$.

\section{Loudon's Encyclopædia of Agri-} culture: Comprising the Laying-out, Improvement, and Management of Landed Property, and the Cultivation and Economy of the Productions of Agriculture. With 1,100 Woodcuts. 8vo. 31s. $6 d$.

Loudon's Encyclopædia of Gardening: Comprising the 'Theory and Practice of Horticulture, Floriculture, Arboriculture, and Landscape Gardening. With 1,000 Woodcuts. 8ro. 31s.6d.

Loudon's Encyclopædia of Cottage, Farm, and Villa Architecture and Furniture. With more than 2,000 Woodcuts. 8vo. $42 s$.

\section{History of Windsor Great Park} and Windsor Forest. By Wizliam MrezIEs, Resilent Deputy Surveyor. With 2 Maps and 20 Pliotographs. Imp. folio, £S 8s.

T'he Sanitary Management and Utilisation of Sewage: comprising Details of a System applicable to Cottages, J)wellingHouses, Public Buildings, and 'Towns; Suggestions relating to the Arterial Drainage of the Country, and the Water Supply of Rivers. By the same Author. Imp. 8ro. with 9 Illustrations, $12 s .6 d$.

\section{Bayldon's Art of Valuing Rents} and Tillages, and Claims of Tenants upon Quitting Farms, both at Michaelmas and Lady-Day. Eiglith Edition, revised by J. C. Mortox. 8ro. 10s.6d.

\section{Religious and Moral Works.}

\section{An Exposition of the 39 Articles,} Historical and Doctrinal. By E. HArol.D Brovne, D.D. Lord Bishop of Ely. Sixth Edition, Sro. 16s.

The Pentateuch and the Elohistic Psalms, in Reply to Bishop Colenso. By the same. Second Edition. 8vo. $2 s$.

Examination Questions on Bishop Browne's Exposition of the Articles. By the Rer. J. Gorler, M.A. Fep. 3s. $6 d$.

\section{Five Lectures on the Character} of St. Paul; being the IIulsean Lectures for 1862. By the Rev. J. S. IIowson, D.D. Second Edition. Sro. 9s.
The Iife and Epistles of St. Paul. By W. J. Conyeeare, M.A. late Fellow of Trin. Coll. Cantab. and J. S. Howson, D.D. Principal of Liverpool Coll.

Limrary Editron, with all the Original Illustrations, Maps, Landscapes on Steel, Woodcuts, \&.c. 2 vols. 4 to. 48 s.

Intermediate Edrtion, with a Selection of Maps, Plates, and Woodcuts. 2 rols. square crown 8vo. 31 s. $6 \mathrm{~d}$.

People's Edition, revised and con. densed, with 46 Illustrations and Maps. 2 vols. crown 8 vo. $12 s$ 
The Voyage and Shipwreck of St. Paul; with Dissertations on the Ships and Navigation of the Ancients. By James Surth, F.R.S. Crown 8vo. Charts, 8s. $6 d$.

\section{A Critical and Grammatical Com-} mentary on St. Paul's Epistles. By C. J. EllicotT, D.D. Lord Bishop of Gloucester and Bristol. 8ro.

Galatians, Third Edition, $8 s .6 d$.

Ephesians, Third Edition, $8 s .6 \%$.

Pastoral Epistles, Third Edition, 10 s. 6d.

Philippians, Colossians, and Philemon, Third Elition, 10s.6d.

Thessalonians, Sccond Edition, $7 s .6 d$.

Historical Lectures on the Life of Our Lord Jesus Christ: being the Hulsean Lectures for 1859. By the same Author. Fourth Edition. Sro. $10 s .6 d$.

The Destiny of the Creature ; and other Sermons preached before the University of Cambridge. By the same. Post 8ro. $5 s$.

The Broad and the Narrow Way; Two Sermons preached before the University of Carnbridge. By the same. Crown Sro. $2 s$.

\section{Rev. T. H. Horne's Introduction} to the Critical Study and Knowlentge of the Holy Scriptures. Eleventh Edition, corrected, and extended under careful Editorial revision. With 4 Maps and 22 Woodcuts and Facsimiles. 4 vols. 8 vo. $£ 313 s .6 d$.

Rev. T. H. Horne's Compendious Introduction to the Study of the Bible, being an Analysis of the larger work by the same Author. Re-edited by the Rev. JoIr AYre, M.A. With Maps, \&c. Post 8 ro. $9 s$.

\section{The Treasury of Bible Know-} ledge, on the plan of Maunder's Treasuries. By the Rev. Jorr Arre, M.A. Fcp. Svo. witl Maps and Illustrations. [In the press.

\section{TheGreek Testament; with Notes,}

Grammatical and Exegetical. By the Rev. IV. Wenster, M.A. and the Rev. W. F. Wirkisson, M.A. 2 rols. 8 ro. £2 $4 s$.

Vor. I. the Gospels and Acts, 20 s.

VoL. II. the Epistles and Apocalypse, $24 \mathrm{~s}$.

The Four Experiments in Church and Stute; and the Conflicts of Churches. By Lord Robent Montagu, M.P. 8ro. 12s.

\section{Every-day Scripture Difficulties} explained and illustrated; Gospels of St. Mattlew and St. Mark. By J. E. Prescott, M.A. 8 ro. $9 s$.
The Pentateuch and Book of Joshua Critically Examined. By the Right Tier. J. W. Colksso, D.D. Lord Bishop of Xiatal. People's Edition, in 1 vol. crowu 8 ro. 6s. or in $\bar{J}$ Parts, 1 s. each.

The Pentateuch and Book of Joshua Critically Examined. By Prof. A. Kuexes, of Leyden. Translated from the Duteh, and edited with Notes, by the light Rev. J. W. Colfi:o, D.D. Bishop of Natul. 8ro. 8s. 6d.

The Formation of Christendom. Pait I. By' T. W. Alimzs. Sro. 12s.

Christendom's Divisions; a Philosophical Shetch of the Divisions of the Christian Family in Last and West. Hy Ensurd S. FFoulkes, formerly Fellow and Tutor of Jesus Coll. Oxford. Post 8ro. 7s. Gd.

The Life of Christ, an Eclectic Grospel, from the Old and New Testaments, arranged on a New l'rinciple, with Analytical Tables, \&e. By Charles De la Prime, M.A. 'Trin. Coll. Camb. Revised Edition. Sro. ǔs.

The Hidden Wisdom of Christ and the liey of linowledge; or, History of the Apocrypla, By Lisxest dE Buxsix. 2 vols. 8 vo. $28 s$.

Hippolytus and his Age; or, the Beginnings and Prospects of Christianity. By Baron Buxsex, D.D. 2 vols. 8 ro. 30 s.

Outlines of the Philosophy of Universal History, applied to Language and Religion: Containing an Account of the Alphabetical Conferences. By the same Author. 2 vols. Sro. 33 s.

Analecta Ante-Nicæna. By the same Author. 3 vols. 8 ro. $42 s$.

Essays on Religion and Literature. By various Writers. Eilitel by II. E. MAxisg, D.D. 8 ro, 10s, Gd.

Essays and Reviews. By the Rer. IV. 'Teniple, D.D. the Rer. R. Whelasis, B.D. the Rer. B. Power., M.A. the lier. H. B. Wilsos, B.D. C. W. Goodwix, M.A. the Rer. M. Pattisos, B.D. and the lier. B. Jowetr, MI.A. 12th Edition. Fep. Svo. $5 s$.

Mosheim's Ecclesiastical History. Murdock and SoAMes's Translation and Notes, re-edital by the Rer. W. Stunes, I.A. 3 rols. 8 ro. 45 s. 
Bishop Jeremy Taylor's Entire Works: With Life by Bishop HeBer. Revised and corrected by the Rev. C. P. EDEN, 10 vols. £5 $5 \mathrm{~s}$.

\section{Passing Thoughts on Religion.} By the Author of 'Amy Herbert.' 8th Edition. Fep. 5 s.

Thoughts for the Holy Week, for Young Persons. By the same Author. 3d Edition. Fep. Sro. $2 s$.

Night Lessons from Scripture. By the same Author. $2 \mathrm{~d}$ Edition. $32 \mathrm{mo} .3 \mathrm{~s}$.

Self-examination before Confirmation. By the same Author. 32mo. 1s.6d.

Readings for a Month Preparatory to Confirmation from IV riters of the Early and English Church. By the same. Fep. $4 s$.

Readings for Every Day in Lent, compiled from the Writings of Bishop JeremY TAYLOR. By the same. Fep. 5s.

Preparation for the Hoiy Communion; the Devotions chiefly from the works of Jereny Taylor. By the same. $32 \mathrm{mo} .3 s$.

Morning Clouds. Second Edition. Fcp. $5 s$.

Spring and Autumn. By the same Author. Post 8vo. 6s.

The Wife's Manual; or, Prayers, Thoughts, and Songs on Several Occasions of a Matron's Life. By the Rev. W. CaLverT, M.A. Crown 8vo. 10s. 6d.

\section{Spiritual Songs for the Sundays} and Holidays throughout the Year. By J. S. B. MoNsELI, LL.D. Vicar of Egham. Fourth Edition. Fcp. $4 s .6 d$.

The Beatitudes: Abasement before God: Sorrow for Sin; Meekness of Spirit ; Desire for Holiness; Gentleness; Purity of Heart ; the Peace-makers; Sufferings for Christ. By the same. 2 d Idition, fep. 3s.6d.

Hymnologia Christiana; or, Psalms and Hymns selected and arranged in the order of the Christian Seasons. By B. H. Kennedy, D.D. Prebendary of Lichtield. Crown 8vo. 7 s. $6 d$.

Lyra Domestica; Christian Songs for Domestic Edification. Translated from the Psaltery and Harp of C. J. P. SpItTA, and from other sources, by Richard Massie. First and Second Series, fep. $4 s .6 d$. each.

Lyra Sacra; Hymns, Ancient anı Modern, Odes, and Fragments of Sacred Poetry. Edited by the Rev B. W. Savile, M.A. Fcp. 5 s.
Lyra Germanica, translated from the German by Miss C. IVLNkworti. First SERIEs, Hymns for the Sundays and Chief Festivals; Second Series, the Christian Life. Fcp. כ̌s. each Series.

Hymns from Lyra Germanica, 18mo. 1s. Historical Notes to the 'Iyra Germanica:' cuntaining brief Menoirs of the Authors of the Hymns, and Notices of Remarkable Occasions on which some of them have been used; with Notices of other German Hymn Writers. By Tneodore Kübler. Fip. $7 s .6 d$.

Lyra Eucharistica; Hymns and Verses on the Holy Communion, Ancient and Modern; with other Poems. Edited by the Rev. Orby Shipley, M.A. Second Edition. Fep. 7 s. $6 d$.

Iyra Messianica; Hymns and Verses on the Life of Christ, Ancient and Modern; with other Poems. By the same Editor. Fcp. $7 s .6 d$.

Lyra Mystica; Hymns and Verses on Sacred Subjects, Ancient and Modern. I3y the same Editor. Fip. $7 s .6 d$.

\section{The Chorale Book for England;}

a complete Hynın-Book in accordance witlı. the Services and Festivals of the Church of England : the Hymns translated by Miss C. Wiskwortir ; the Tunes arranged by Prof. W. S. Bensett and OtTo Goldschmidt. Fep. 4 to. 12 s. bid.

Congregational Edition. Fep. $2 s$.

The Catholic Doctrine of the Atonement; an Historical Inquiry into its Development in the Church : with an Introduction on the Principle of Theological Developments. By H. N. Oxennum, M.A. formerly Scholar of Balliol College, Oxford. 8 vo. 8 s. $6 d$.

From Sunday to Sunday; an attempt to consider fumiliarly the Weekday Life and Labours of a Country Clergyman. By R. GFa, M.A. Vicar of Abbott's Langley and Rural Dean. Fcp. $5 s$.

First Sundays at Church; or, Familial Conversations on the Morning and Fvening Services of the Church of England. By J. E. Rinile, M.A. F.p. 2s. 6d.

The Judgment of Conscience, and other Sermons. By Richakd Wnatedr, D.D. late Archbishop of Dublin. Crown 8 vo. $4 s .6 r l$.

Paley's Moral Philosophy, with Aumutations. liy Ricirard WHATELY, D.D. late Archbishop of Dublin. 8vo. 7 s. 


\section{Trarels, Voyages, \&c.}

\section{Outline Sketches of the High} Alps of Dauphiné. By T. G. Bonver, M.A. F.G.S. M.A.C. Fellow of St. Jolnn's Coll. Camb. With 13 Plates and a Coloured Map. Post 4to. $16 s$.

\section{Ice Caves of France and Switzer-} land; a narrative of Subterranean Exploration. By the Rer. G. F. Irowne, M.A. Fellow and Assistant-Tutor of St. Catherine's Coll. Cambridge, MI.A.C. With 11 Woodcuts. Square crown Sro. $12 s .6 d$.

\section{Village Life in Switzerland. By} Śopira D. Delumard. Post 8ro. 9s.6d.

\section{How we Spent the Summer; or,} a Voyage en Zigzag in Switzerland and Tyrol with some Members of the Alpixe Club. From the Sketch-Book of one of the Party. In oblong 4to. with about 300 Illustrations, 10 s. $6 d$.

Map of the Chain of Mont Blane, from an actual Survey in 1863-1864. By A. Adans-Reilly, F.R.G.S. MI.A.C. Published uncler the Authority of the Alpine Club. In Chromolithography on extra stout drawing-paper $28 \mathrm{in}$. $\times 17 \mathrm{in}$. price $10 \mathrm{~s}$. or mounted on canvas in a folding case, 12s. $6 d$.

\section{The Hunting Grounds of the Old} World; Frnst Sernes, Asia. By H. A. L. the Old Slsekarry. Third Edition, with 7 Illustrations. 8ro. $18 s$.

Camp and Cantonment; a Joumal of Life in India in 1857-1859, with some Account of the Way thitler. By Mrs. LEopold PAget. To which is added a Short Narrative of the Pursuit of the Rebels in Central India by Major PAget, li.H.A. Post 8ro. 10s. 6d.

\section{Explorations in South - west} Africa, from Walvisch Bay to Lake Ngami and the Victoria Falis. By Tromis Barses, F.R.G.S. 8vo. with MIaps and Illustrations, 21s.

\section{South American Sketches; or, a}

Visit to Rio Janeiro, the Organ Mountains, La Plata, and the Paranà. By Tiromas W. Hinchlif, M.A. F.R.G.S. Post 8vo, with Illustrations, $12 s .6 d$.

\section{Vancouver Island and British} Columbia ; their History, Resources, and Prospects. By Mattheiv MAcrie, F.R.G.S. With Maps and Illustrations. 8ro. $18 \mathrm{~s}$.
History of Discovery in our Australasian Colonies, Australia, Tasmania, and Now Zealand, from the Earliest Date to the Present Day. By Whilian Howite. With 3 Maps of the Recent Explorations from Official Sources. 2 vols. 8ro. $28 s$.

The Capital of the Tycoon; a Narrative of a 3 Years' Residence in Japan. By Sir Ruthlerford Alcock, K.C.B. 2 vols. Svo. with numerous Illustrations, $42 s$.

Last Winter in Rome. By C. R. WELD. With Portrait and Engravings on Wood. Post 8ro. 14s.

\section{Autumn Rambles in North} Africa. By Jonn Orussi, of the Middle Temple. With 16 Illustrations. Post 8 ro. 8s. $6 d$.

The Dolomite Mountains. Excursions through Tyrol, Carinthia, Carniola, and Friuli in 1861, 1862, and 1863. By J. Gileert and G. C. Churchill, F.R.G.S. With numerous Illustrations. Square crown 8ro. $21 s$.

A Summer Tour in the Grisons and Italian Valleys of the Bernina. By Mrs. Hexry Freshifield. With 2 Coloured Maps and 4 Views. Post 8vo. 10s. 6d.

Alpine Byways; or, Ljght Leaves gathered in 1859 and 1860 . By the same Authoress. Post 8 vo. with Illustrations, $10 s .6 d$.

A Lady's Tour Round Monte Rosa; including Visits to the Italian Valleys. With Map and Illustrations. Post 8vo.14s.

Guide to the Pyrenees, for the use of IIountaineers. By Cratrles Packe. With Maps, Sc. and Appendlix. Fep. $6 s$.

The Alpine Guide. By Jorr Ball, II.R.I.A. late President of the Alpine Club. Post 8vo. with Maps and other Illustrations.

Guide to the Western Alps, including Nont Blane, Monte Rosa, Zermatt, \&c. Ts. $6 d$.

Guide to the Oberland and all Switzerland, excepting the Neighbourhood of Monte Rosa and the Great St. Bernard; with Lombardy and the adjoining portion of Trrol. $7 s .6 d$. 
Christopher Columbus; his Life, Voyages, and Discoveries. Tievised Edition, with 4 Woodcuts. 18 mo. $2 s .6 d$.

Captain James Cook; his Life, Voyages, and Discoveries. Revised Edition, with numerous Woodcuts. $18 \mathrm{mo} .2 \mathrm{~s} .6 d$.

Narratives of Shipwrecks of the Royal Navy between 1793 and 1857 , compiled from Official Documents in the Admiralty by W. O. S. GiLLY; with a Preface by W. S. Grus, D.D. 3rd Edition, fcp. $5 s$.
A Week at the Iand's End. By J. T. BLIIGHT; assisted by E. H. RoDd, R. Q. Couci, and J. Ralfs. With Map and 96 Woodeuts. Fep. $6 s .6 d$.

\section{Visits to Remarkable Places :} Old Halls, Battle-Fields, and Scenes illustrative of Striking Passages in English History and Poetry. By Winliay Howiț. 2 vols. square crown 8 vo. with Wood Engravings, $25 s$.

The Rural Life of England. By the same Author. With Woodcuts by Bewick and Williams. Medium Svo. 12s. $6 \dot{d}$.

\section{Works of Fiction.}

Late Laurels : a Talc. By the Author of ' Wheat and 'Tares.' 2 vols. post 8 ro. 15 s.

A First Friendship. [Reprinted from Fraser's Mragazine.] Crown 8vo. $7 s .6 d$.

Atherstone Priory. By L. N. Coмrș. 2 vols. post 8 ro. $21 s$.

Ellice : a Tale. By the same. Post 8vo. 9s.6d.

\section{Stories and Tales by the Author} of 'Amy Merbert,' uniform Edition, each 'Tale or Story complete in a single volume.

Amy Heirert, $2 s .6 d$. Katirarine Asiton, Gertrude, $2 s .6 d$.

Earl's Daughter, $2 s .6 d$. $3 s .6 d$.

Margaret PerciVAL, $5 s$.

Experiexce of Life, Laneton Parson$2 s .6 d$. $\mathrm{AGE}, 4 s .6 d$.

Cleve Hale, 3s. 6d. Ursula, 4s.6d.

Irons, $3 s .6 d$.

A Glimpse of the World. By the Author of 'Amy Herbert.' Fcp. 7s. $6 d$.

Essays on Fiction, reprinted chiefly from leviews, with Additions. By Nassau W. Sexior. Post 8ro. 10s.6d.

Elihu Jan's Story; or, the Private Life of an Eastern Queen. By William KNignton, LL.D. Assistant-Commissioner in Oudh. Post 8vo. $7 s .6 d$.

\section{The Six Sisters of the Valleys:} an Historical Romance. By W. BranleyMoore, M.A. Incumbent of Gerrard's Cross, Bucks. Third Edition, with 14 Illustrations. Crown 8vo. 5s.
The Gladiators : a Tale of Rome and Judiea. By G. J. WIITE Melville. Crown 8vo. 5s.

Digby Grand, an Antobiograply. By the same Author. 1 vol. 5 s.

Kate Coventry, an Autobiography. By the same. 1 vol. $5 s$.

General Bounce, or the Lady and the Locusts. By the same. 1 vol. $5 s$.

Holmby House, a Tale of Old Northampton. shire. 1 vol. 5 s.

Good for Nothing, or All Down Hill. By the same. 1 vol. $6 s$.

The Queen's Maries, a Romance of Holyrood. 1 vol. $6 s$.

The Interpreter, a Tale of the War. By the same. 1 vol. $5 s$.

\section{Tales from Greek Mythology.} By George IV. Cox, M.A. late Scholar of Trin. Coll. Oxon. Second Edition. Square $16 \mathrm{mo} .3 s .6 d$.

Tales of the Gods and Heroes. By the same Author. Second Edition. Fep. ós.

Tales of Thebes and Argos. By the same Author. Fcp. 4s. $6 d$.

The Warden : a Novel. By Axthox 'Trollore, Crown 8ro. 3s. $6 d$.

Barchester Towers: a Sequel to 'The Warden.' By the same Author. Crown 8 vo. 5 s. 


\section{Poeting and the Diama.}

Select Works of the British Poets ; with Biographical and Critical Prefices by Dr. AIkin: with Supplement, of more recent Selections, by LuC'Y A Ikı. Mellum 8 vo. 18 s.

Goethe's Second Faust. Translated by Joms Axs'rer, LL.D. M.R.I.A. Regius Professor of Civil Law in the University of Dublin. Post 8ro. 15s.

\section{Tasso's Jerusalem Delivered,} translated into Euglish Verse by Sir J. Kingston Jimes, Kt. M.A. 2 vols. fep. with Facsinile, $14 s$.

\section{Poetical Works of John Edmund}

Reade; with final lievision and Additions. 3 vols. fcr. 18 s. or each vol. separately, 6 s.

Moore's Poetical Works, Cheapest Editions complete in 1 vol. including the Autobiographical Prefaces and Author's last Notes, which are still copyright. Crown 8vo. ruby type, with Portrait, 7s. 6rl. or People's Edition, in larger type, $12 s .6 d$.

Moore's Poetical Works, as above, Library Edition, medium 8ro. with Portrait and Vignette, $14 s$, or in 10 rols. fep. $3 s .6 d$. each

\section{Tenniel's Edition of Moore's} Lalla Rookh, with 68 Wooll Engravings from Original Drawings and other Illustrations. Fep. 4to. $21 s$.

Moore's Lalla Rookh. 32mo. Plate, Is. $16 \mathrm{mo}$. Vignette, $2 s .6 d$.
Maclise's Edition of Moore's Irish Meloclies, with 161 Steel Plates from Origrina! Drawings. Super-royal 8vo. 31s.6d.

Moore's Irish Melodies, 32mo. Portrait, 1s. 16mo. Vignette, 2s. bid.

Southey's Poetical Works, with tho Author's last Corrections anci colyright Additions. Library Edition, in i vol. medium 8vo. with Portrait and Yisnette, $14 s$ or in 10 vols. fep. $3 s .6 d$. each.

Lays of Ancient Rome; witl I vry and the Armada. By the Right Hon. Lonn MLACallat. 16mo. 4s. Gd.

Lord Macaulay's Lays of Ancient Rome. With 90 Illustrations on Wool, Original and from the Antique, from Drawings by G. Scilarl. Fip. 4to. $21 s$.

Poems. By Jeax Ixgelow. Ninth Edition. Fep. 8vo. 5s.

Poetical Works of Letitia Elizabeth Lancion (L.E.L.) 2 vols. 16 mo. 10s.

Playtime with the Poets : a Selection of the best English Poetry for the use of Children. By a LADY. Crown 8vo. כs.

\section{Bowdler's Family Shakspeare,} cheaper Genuine Edition, complete in 1 vol. large type, with 36 Woodcut Illustrations, price 14s. or, with the same IrLustr.tTioss, in 6 pocket rols. $3 s .6 d$. each.

Arundines Cami, sive Musarum Cantabrigiensium Lusus Canori. Collegit atque edidit II. DrunY. M.A. Editio Sexta, euravit H. J. Hodisos, M.A. Crown 8ro. 7s. $6 d$.

\section{Rural Sports, se.}

Encyclopædia of Rural Sports ; a Complete Accuunt, Historical, Practical, and Descriptive, of Hunting, Shooting, Fishing, Racing, \&e. By D. P. Butixe. With above 600 Woodcuts (20 from Designs by JoIIY LEECH). 8vo. $42 s$.

Notes on Rifle Shooting. By Captain Heatos, Adjutant of the Third Man. chester Rifle Volunteer Corps. Fep. $2 s .6 d$.
Col. Hawker's Instructions to Young Sportsmen in all that relates to Guns and Shooting. Revised by the Author's Sox. Square crown Sro. with Illustrations, $18 s$.

The Dead Shot,or Sportsman's Complete Guide; a Treatise on the Use of the Gun, Dog-breaking, Pigeon-shooting, \&c. Bt Marksulax. Fep. 8vo, with Plates, 5 . 
The Fly-Fisher's Fntomology. Ry Alfred Fonalds. With coloured Representations of the Natural and Artificial Insect. 6th Edition; with 20 coloured Plates. 8vo. 14s.

Hand-book of Angling: Teaching Fly-fishing, Trolling, Bottom-fishing, Salmon-fishing; with the Natural History of River Fish, and the best modes of Catching them. By Epmenera. Fop. Woodcuts, $5 s$.

The Cricket Field; or, the History and the Science of the Game of Cricket. By James Prchoft, B.A. Trin. Coll. Oxon. 4th Edition. Fep. $5 s$.

The Cricket Tutor; a Treatise exclusively Practical. By the same. 18mo.1s.

Cricketana. By the same Author. With 7 Portraits of Cricketers. Fcp. 5 s.

The Horse : with a Treatise on Draught. By IVIldiam Youatr. New Edition, revised and enlarged. 8vo. with numerous Woodcuts, 10s. $6 d$.

The Dog. By the same Author. 8vo. with Inumerous Woodcuts, $6 s$.
The Horse's Foot, and how to keep it Sound. By W. MrLes, Esq. 9th Edition, with Illustrations. Imp. 8vo. 12s. 6d.

A Plain Treatise on Horse-shoeing. By the same Author. Post 8vo. with Illustrations, $2 s .6 d$.

Stables and Stable Fittings. By the same. Imp. 8vo. with 13 Plates, $15 s$.

Remarks on Horses' Teeth, addressed to Purchasers. By the same. Post 8vo. 1s.6d.

On Drill and Manœuvres of Cavalry, combined with Horse Artillery. By Major-Gen. Michaer, W. Smith, C.B. Conmanding the Poonah Division of the Bombay Army. 8vo. 12s. $6 d$.

\section{The Dog in Health and Disease.}

By Stonenenge. With 70 Wood Engravings. Square crown 8vo. 15s.

The Greyhound in 1864. By the same Autlior. IVith 24 Portraits of Greyhounds. Square crown 8vo. 21s.

The $O x$, his Diseases and their Treatment; with an Essay on Parturition in the Cow. By J. R. Douson, M.R.C.V.S. Crown 8vo. with Illustrations, $7 s .6 d$.

\section{Commerce, Navigation, and Mercantile Affairs.}

The Law of Nations Considered as Independent Political Communities. By Travers Twiss, D.C.L. Regius Professor of Civil Law in the University of Oxford. 2 vols. 8 vo. 30 s. or separately, PArt I. Peace, 12s. Part II. War, 18s.

\section{A Nautical Dictionary, defining} the Technical Language relative to the Building and Equipment of Sailing Vessels and Steamers, \&c. By Artiun Young. Second Edition; with Plates and 1 õ $\mathrm{W}$ Woodcuts. 8 vo. $18 s$.
A Dictionary, Practical, Theoretical, and Historical, of Commerce and Commercial Navigation. By J. R. M'CuLLOCH. 8vo. with Maps and Plans, 50s.

The Study of Steam and the Marine Engine, for Young Sea Otficers. By S. M. SAxby, R.N. Post 8 vo. with 87 Diagrams, $5 \mathrm{~s} .6 \mathrm{~d}$.

A Manual for Naval Cadets. By J. M'NerL Boyn, late Captain R.N. Third Edition; with 240 Woodcuts, and 11 coloured Plates. Post 8vo. 12s. 6d.

\section{Works of Utility and General Information.}

Modern Cookery for Private Families, reduced to a System of Easy Practice in a Series of carefully-tested Receipts. By Eliza Acton. Newly revised and enlarged; with 8 Plates, Figures, and 150 Woodcuts. Fep. 7 s. 6 d.
The Handbook of Dining; or, Corpulency and Leanness scientitically considered. By Brillat-Savarin, Author of 'Plysiologie du Goût.' Translated by L. F. Sinpsox. Revised Edition, with Additions. Fep. 3s. $6 d$. 
On Food and its Digestion; an Introduction to Dietetics. By IV. Brixros, M.D. Physician to St. Thomas's Hospital, \&c. Witl 48 Woodeuts. Post 8 ro. $12 \mathrm{~s}$.

Wine, the Vine, and the Cellar. By Tromas G. Shaw. Second Edition, revised and enlarged, with Frontispiece and 31 Illustrations on Wood. Svo. 16 s.

\section{A Practical Treatise on Brewing;} with Formulie for Public Brewers, and instructions for Private Families. By W. Black. 8vo. 10s. 6d.

Short Whist. By Maror A. The Sixteenth Elition, revised, with an Essay on the Theory of the Modern Scientitic Game by Prof. P. Fep. 3s. $6 d$.

Whist, What to Lead. By Casr. Second Edition. 32mo. 1 s.

\section{Hints on Ftiquette and the} Usages of Society; with a Glance at Bad Habits. Revised, with Additions, by a LADY of RANir. Fep. 2s.6d.

The Cabinet Lawyer; a Popular Digest of the Laws of England, Civil and Criminal. 20th Edition, extended by the Author; including the Acts of the Sessions 1863 and 1864 . Fcp. 10s. $6 d$.
The Philosophy of Fiealth; or, an Exposition of the Phy'siological and Sanitary Conditions conducire to Human Longerity and Happiness. By Soutnimood Surtir, M.D. Eleventh Elition, revised and enlarged; with 113 Woodents. 8ro. 15 s.

\section{Hints to Mother's on the Manage-} ment of their Health during the Period of Preguancy ant in the Lying-in Room. By T. Bull, M.D. Fep. 5 s.

The Maternal Management of Children in Kealth and Disease. By the same Author. Fep. 5s.

Notes on Hospitals. By Florexce Nigitivgale. Third Edition, enlarged; with 13 Plans. Post 4to. 18 s.

\section{II. Willich's Popular Tables} for Ascertaining the Value of Lifehold, Leasehold, and Church Property, Renewal Fines, \&:c.; the Public Funds; Annual Average Price and Interest on Consols from 1731 to 1851; Chemical, Gengraplical, Astronomical, Trigonometrical Tables, \&c. Post Sro. 10s.

Thomson's Taわles of Interest, at Three, Four, Four and a IIalf, and Fire per Cent, from One Pound to Ten Thousand and from 1 to 365 Days. $12 \mathrm{mo}$. 3s. $6 d$.

Maunder's Treasury of Knowledge and Library of lieference: comprising an English Dictionary and Grammar, Universal Gazetteer, Classical Dietionary, Chronology, Law Dictionary, Synopsis of the Peerage, ușeful Tables, \&e. Fep. 10s.

\section{General and School Atluses.}

An Atlas of History and Geography; representing the Political state of the World at suecessive Epochs from the commencement of the Christian Era to the Present Time, in a Series of 16 coloured Maps. By J. S. Brewer, MI.A. Third Edition, revised, \&c. by E. C. Brewer, LL.D. Royal Sro. 15 s.

Bishop Butler's Atlas of Modern Geography, in a Series of 33 full-coloured Maps, accompanied by a complete Alphabetical Index. New Edition, corrected and enlarged. Royal Sro. 10s. 6el.

\section{Bishop Butler's Atlas of Ancient} Geography, in a Series of 24 full-coloured Maps, accompanied by a complete Accentuated Index. New Edition, corrected and enlarged. lioyal sro. 12s.
School Atlas of Physical, Political, and Commercial Geography, in 17 full-coloured MIaps, accompanied by descriptive Letterpress. By E. HuGHes F.R.A.S. Loyal Sro. 10s. 6d.

\section{Middle-Class Atlas of General} Geography, in a Series of 29 full-coloureci Naps, containing the most recent 'Territorial Changes and Discoveries. PyiWaLter? II TrEon, F.R.G.S. 4to. js.

\section{Physical Atlas of Great Britain} and Ireland; comprising 30 full-colourel Maps, with illustratire Letterpress, forming a concise Synopsis of British Physical Geographr. By Walter MI'LEod, F.R.G.S. Fep. 4 to. $\overline{i s} .6 d$. 


\section{Periodical Publications.}

The Edinburgh Review, or Critical Journal, published Quarterly in January, A pril, July, and October. 8ro. price 6s, each No.

\section{The Geological Magazine, or}

Monthly Journal of Geology, edited by Henry Woodward, F.G.S.; assisted by Prof. J. Morris, F.G.S. and R. Etneridge, F.R S.E. F.G.S. 8vo price 1 s, each No.
Fraser's Magazine for Town and Country, published on the 1st of each Month. 8vo. price $2 s, 6 d$. each No.

The Alpine Journal: a Record of Mountain Adventure and Scientific Observation. By Members of the Alpine Club. Edited by H. B. Geonge, M.A. Published Quarterly, May 31, Aug. 31, Nov. 30, Feb. 28. 8ro. price 1s. $6 d$. each No.

\section{Knowledge for the Young.}

The Stepping Stone to Knowledge: Containing upwards of Seven Hundred Questions and Answers on Miscellaneous Subjects, adapted to the capacity of Infunt Minds. By a Mothrs. New Edition, enlarged and improved. $18 \mathrm{mo}$. price $1 \mathrm{~s}$.

'The Stepping Stone to Geography: Containing several Hundred Questions and Answers on Geographical Subjects. 18 mo. 1 s.

The Stepping Stone to English History : Containing several Hundred Questions and Answers on the History of England. $1 s$.

The Stepping Stone to Bible Knowledge: Containing sereral Hundred Questions and Auswers on the Old and New 'Testaments. $18 \mathrm{mo} .1 \mathrm{~s}$.

The Stepping Stone to Biography: Containing several Hundred Questions and Answers on the Lives of Eminent Men and Women. 18mo. $1 s$.

Second Series of the Stepping Stone to Knowledge: containing upwards of Eight Hundred Questions and Answers on Miscellaneous Subjects not contained in the Finst Series. 18 mo. $1 s$.

The Stepping Stone to French Pronun. ciation and Conversation: Containing several Hundred Questions and Answers. By Mr. P. SAdLier. 18 mo. $1 s$.

The Stepping Stone to English Grammar: containing several Hundred Questions and Answers on English Grammar. By Mr. P. SADLER. 18 mo. $1 s$.

The Stepping Stone to Natural History: Venthisate or backBoned Animals. Pan' I. Mammalia; Pan'T II. Birds, Reptiles, Fishes. 18 mo. 1s, each Part.
The Instructor; or, Progressire Lessons in General Knowledge. Originally published under the Direction of the Committee of General Literature and Education of the Society for Promoting Christian Finowledge. 7 vols. 18 mo, freely illustrated with Woodcuts and Maps, price 14 .

I. Exercises, Tales, and Conversations on Familiar Subjects; with Easy Lessons from History. Revised and improved Edition. Price $2 s$.

II. Lessons on Dwelling-Houses and the Materials used in Building Them; on Articles of Furniture; and on Food and Clothing. Revised and improved Edition. Price $2 s$.

III. Lessons on the Universe; on the Three Kingdoms of Nature, Animal, Vegetable, and Mineral ; on the Structure, Senses, and Habits of Man; and on the Preservation of Health. lievised and improved Edition. $2 s$.

IV. Iessons on the Calendar and AIminack; on the 'Twelve Months of the Iear; and on the appearances of $\mathrm{Na}$ ture in the Four Seasons, Spring, Summer, Autumn, and Winter. Revised and improved Edition. Price $2 s$.

V. Descriptive Geography with Populin Statistics of the various Countries and Divisions of the Globe, their People and Productions. Revised and improved Edition. With 6 Maps. $2 s$.

VI. Elements of Ancient History, from the Formation of the First Great Monarchies to the Fall of the Roman Simpire. Revised and improved Edition. Price $2 s$.

VII. Elements of [Mediveval and] Modern Iistory, from A.D. 406 to A.D. 1862 : with brief Notices of European Colonies. Revised and improved lidition. Price $2 s$. 
Edinburgh Review (The) $\ldots \ldots \ldots \ldots \ldots \ldots$ Ellice, a Tale.

EllicotT's Broad and Narrow Way........ - Commen tary on Ephesians.... - Destiny of the Creature........ Lectures on Life of Christ ..... 13 Commentary on Galutians .... 13 - Pastoral Epist. 13 Philippians, \&c. 13 Thessalonians 13

Essays and Reviews ................. 13 on Religion and Literature, edited by

MANING

- written in the Intervals of Business

Fairbairn's Application of Cast and Wrought Iron to Building.............. Information for Engineers .. Treatise on Mills \& Millwork FFoulkes's Christendom's Divisions ......

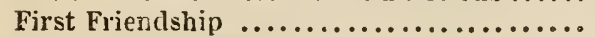

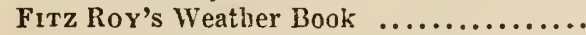
Fowlen's Collieries and Colliers ......... Fraser's Magazine ................... Freshaield's Alpine Byways ........... Tour in the Grisons ........ Friends in Council ..................... Froude's History of́ England...........

GARratT's Maryels and Mysteries of Instinct GeE's Sunday to Sunday .............. 1t Geological Magazine ............... 8, 20 Gilbert and ChuRchill's Dolomite Moun-

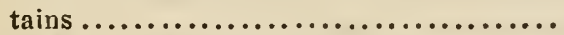

GiLly's Shipwrecks of the Navy ......... Goethe's Second F a ust, by Anster........

Goodeve's Elements of Mechanism........

Gorle's Questions on Brow NE's Exposition

of the 39 Articles ...................

Graver Thoughts of a Country Parson ......

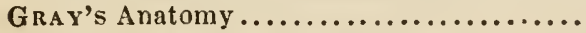
Greene's Corals and Sea Jellies ......... - Sponges and Animalculae ...... Grove on Correlation of Physical Forces .. Gw ILT's Encyclopadia of Architecture ....

Handbook of Angling, by Epheutera..... Hare on Election of Representatives...... HARTw I $Q$ 's Sea and its Living iVonders.... - Tropical Worid .............. HAWKER's Instructions to Young Sports-

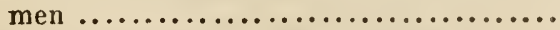

HEaton's Notes on Rifle Shooting ........ Helps's Spanish Conquest in America .... HERSCHEL's Essays fiom the Elimburgh and Quarterly Reviews .................. Q Outlines of Astronomy ........ HewitT on the Diseases of Women ........ H I ссн LIFF's South American Sketches....

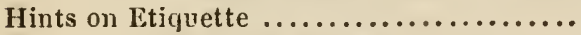
Hodgson's Time and Space............. Holland's Chapters on Men!al Physiology Essays on Scientific Suhjects.. Medical Notes and Reflections

HoLMes's System of Surgery .............

HOOKER and WALKER-ARNOTT'S British

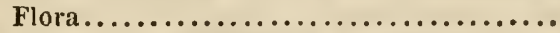

Horne's Introduction to the scriptures....
Horve's Compendium of the Scriptures .. 13 Hoskyns's Talpa .................. 12 How we Spent the Summer................ 15 How rtw's Australian Discovery .......... 15 - History of the Supernatural .... 6

- Rural Life of England .......... 16
- Visits to Remarkable Places .... 16

Howson's Hulsean Lectures on St. Paul.... 12

Hughes's (H.) Atlis of Physical, Political, and Commercial Geograpby .......... 13

- (W.) Geography of British His-

tory $\ldots \ldots \ldots \ldots \ldots \ldots \ldots \ldots \ldots \ldots, 7$

Hutanual of Geography ......

HuLlah's History of Modern Music ...... Transition A! usical Lectures ....... Huм PH Ri.ys' Sentiments of Shakspeare.... Hunting Groundis of the Old World ........ Hymns from Lyra Germanica.............

INGe Low's Poems ................ I7

Instructor (The) $\ldots \ldots \ldots \ldots \ldots \ldots \ldots \ldots \ldots, 20$

JAMESON's Legends of the Saints and Martyrs ......................... 11 - Legends of the Madonna ...... I1

- Legends of the Munastic Orders 11

JAMESON and EASTLAKE'S History of Our Lord .......................... 11

Jон ns's Home Walks and Holiday Ramules JoHnson's Patentee's Manual ............ Practical Draughtsman ........

Johnston's Gazetteer, or Geographical Dic-

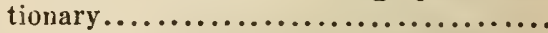
Jones's Christianjty and Comnon Sense ..

KaLISCH's Commentary on the Old Testa-

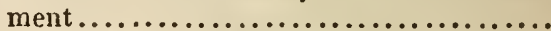

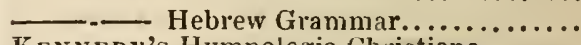
Kennedy's Hymnologia Christiana ....... Kesteven's Domestic Medicine ............. KiRBY and SPENCE's Entomology ....... KNightoN's tory of Elihu Jan ......... KïBLER's Notes to Lyra Germanica........ KUENEN on Pentateuch and Joshua.......

Lady's Tour round Monte Rosa .......... 15

LANDon's (L. E. L.) Poetical Works....... 17 Late Laurels ..................... 16 LATHA u's English Dictionary ......... 5 LECKY's History of lRationalism ........ 2 Leisure Hours in 'Town ................ 6 LEwes's Bingraphical History of Philosophy LEwis oll the Astronomy of the Ancients .. L_ on the Credibility of Early Roman

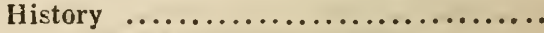
- Dialogue on Government......... - on Eiryptological Method.......... - Essays on Arministrations........

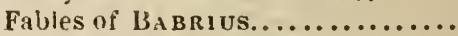
on Foreign Jurisdiction .......... on Irish Disturbances ............ on Observation and Reasoning in

Politics............................ $-\longrightarrow$ on Political Terms ............... _ - on the Romance Languages ...... LI DDELL andScotr's Greek-English Lexicon - Abridged ditto ......

LiNDLEY and Mioore's Treasury of Botany. 11 15 14 (1) . 1 8 11 11

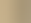

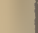

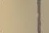

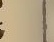

.

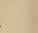

5

6


LoxguAx's Lectures on the History of Eng-

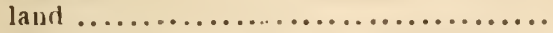
Loudox's Encjclopæedia of Agriculture.... Loudox's Encjclopadia of Agricuiture... and Villa Architecture .............. 12 Gardening .... 12 Plants ........ g Trees and Slirubs 9

Lowndes's Engineer's Handbook ....... 11

Lyra Womestica .................... 14

Encharistica................... It

Germanica .....................11, 14

Messianica .................... 14

Mystica...................... 14

Sacra ...................... 14

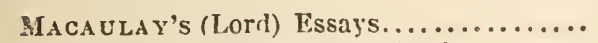
- History of England .......... Lais of Ancient k.ime....... -Miscellaneons Writings ...... S! eeches .................

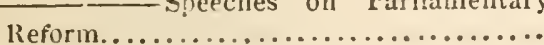
Macnougall's Theory of War ............ MARSHMAN's Life of Havelock............ MCLEOD's Middie-Class Atlas of General Geography ............................

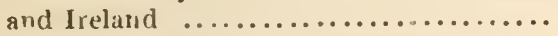
MlcCulloch's Dictinnary of Commerce.... Geographical Victionary ....

MaCfie's Vancouier Island .............. MarulRe's Life of Father Matiew ........ Rome and its Rulers .........

MALINa's Indloor Gardener.............. Massey's history of England............. MA SSINGBERD's History of the Reformation Ml A U v UER's Biographical Treasury ........ - Geigraphical Treasury ........ - Historical 'Treasury ........... Scientific and Literary Treasury - Treasury of kinowledge....... - Treasury of Narural Hilotory ..

Ma Uky's Plissical Geography............. May's Constitutional History of England.. M ELVILLE's Digby Grand .............. General Bounce............. Gladiators ................ Good for Nothing ........... Holmby House ............. Interpreter ................ Kate Coventry.............. Queen's Maries .............

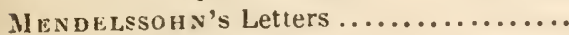
MENZıEs' II indsor Great Park ........... on sewage..................

Merivale's (H.) Colonisation and Colonies - Historival Sturies ......

(C.) Fall of the Koman Lepublic Romans uneles the Empire on Cunversion of Roman

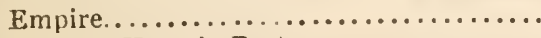
on Horse's Foot.................. on Horse Shoeing................ on Horses' 'Teeth ...............

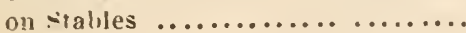

M11LL on Liberty ..................... on Representative Gorerninent ...... on Utilitarianism...............
IILL's Dissertations and Discussions....... Political liconomy ............... System of $\operatorname{Logic} . \ldots \ldots \ldots \ldots \ldots \ldots$ - Hamilton's Plilosopldy ............

MILLER's Elements of Chemistry.......... Monsell's Spiritual Songs............. - Beatitudes.....................

Montagu's Experiments in Cuurch and

State........................... 13

MoNTGo:HerY on the Signs and Symptoms

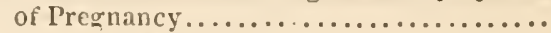

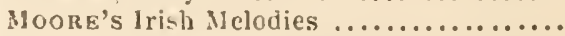

—_alla Rookh ............... 17

dence Merroirs, Journal, and Correspon-

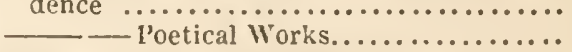

Morell's Elements of Psychology ........ Hental Philosophy............

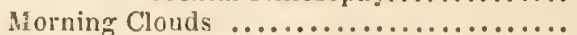

Mortos's l'rince Consort's Farms ........

Mosherm's Ecclesiastical History......... 13

MULLER'S (Max) Lectures on the Science of

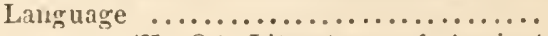

(K. O.) Litcrature of Ancient

Greece..........................

A U RCH Isox on Continued Ferers........ 10

MURE's Languare and Literature of Greecc

New Testament illustrated with Wood Engravings from the Old Mlastcrs ......... 10

NEWMAN's Histcry of his Religious Opinions 3

Nighticale's Notes on Hospitals ......

ODLing's Course of Practical Chemistry.... - Manual of Chemistry ...........

OrMsBr's Rambles in Algeria and Tunis .. OWEx's Comparative Anatomy and Plysiolowy of Vertevrate Animals .............

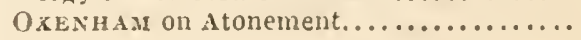
4 4 4 9 14 14

PACkE's Guide to the Pyrences......... 15 PAGET's Lectures on Surgical Pathology .. 10

Camp and Cantonment......... 15

PEREIRA's Ficments of Materia Medica.... I0

Manual of Materia Melica...... 10

Perkins's ']'uscan Sculpture ........... 11

PHilles's Guide to Geology ........... 8 - Introdnction to Mineralogy.... 8

Presse's Art of Perfumery .............. 12

- Chemical, Natural, and Physical

Magic ...................... 12

L Liburatory of Chemical Wonders 12

Playtine with the Poets............... 17

Practical Mechanic's Journal ........... 11

Prescotr's scripture Difficulties .......... 13

Proctok's Saturn ................. 7

PycroFt's Course of English Reading .... 5

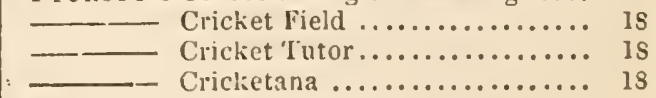

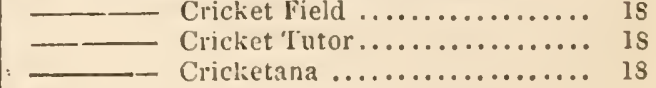

READE's Poetical Works ............... 17

Recreations of a Country Parson, SEcoxn

SERIES ........................ 6

RElLLY's Miap of Mont Blanc........... 15

RIDDLE's I Iiamond Latin-English Dictionary 5

- First sundays at Church ....... It

Rivers's Rose Amateur's Guide ........ 9 
Rogers's Correspondence of Greyson...... liclipse of Faith................ Defence of ditto ............... Essays from the Edinburgh Review Fulleriana ...................

Roaer's Thesaurus of English Words and

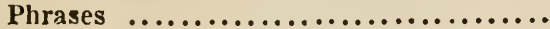

Ronalds's Fly-Fislier's Entomology ......

Rowton's Debater......................

RUSSELL on Government and Constitution.

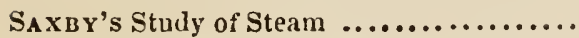
Weather System................ Scotr's Handbook of Voluinetrical A nalysis

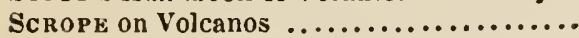
SENIOR's Biographical Sketches ......... Historical and Philosoplical

Essays........................

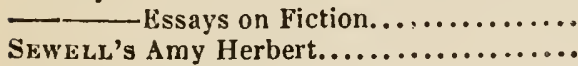

Ancient History...............

Cleve Hall ...................

Earl's Daughter................

Experience of Life .............

Gertrude....................

Glimpse of the World...........

History of the Early Churcli......

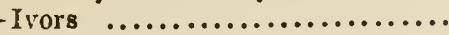

Katharine Ashtor..............

Laneton Parsonage.............

Margaret Percival .............

Night Lessons from Scripture....

-Passing Thouglits on Religion....

Preparation for Communion......

Readings for Confirmation ......

Readings for Lent..............

Self-Examination before Confir

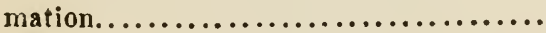

Stories and Tales ..............

Thoughts for the Holy Week......

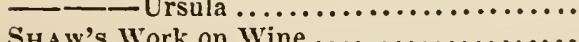

SHEDDEN's Elements of Logic ............

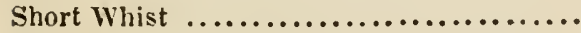

SHoRT's Church History ................

SIEVEKING's (AMELIA) Life, by Wixk-

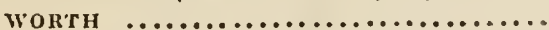

Simpson's Handbook of pining...........

SMITH'S (Southwood) Philosopliy of Health

(J.) Voyage and Shipwreck of St

Paul .

(G.) Wesleyan Methodism ........

(SY DNEY) Memoir and Letters.... Miscellaneous Works .. Sketches of Moral Plilo.

sophy

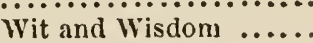

Surti on Cavalry Drill and Mancuvres....

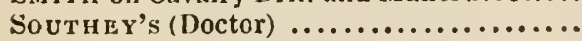
Poetical Works...............

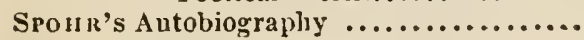

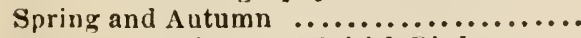
STANLEY's History of British Birds........ Strbitan's Analysis of MILL's Logic...... STEPHENSON'S (R.) life by JEAFFnESON

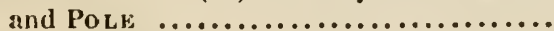
STEPHEx's Essays in Ecclesiastical Biography ...........................
Strephex's Lectures on the History of

France........................... 2

Stepping Store to Knowledge, \&c......... 20

Stirlina's Secret of Hege 1............ 6

Stonehenae on the Dog.............. 18

on the Greyhound ......... is

TAsso's Jerusalem, by Ja M Es.......... 17

TAYLOR's (Jeremy) Works, edited by EDEN 14

Tennent's Ceylon .................. 8

Natural History of Ceylon ....

TuIRLwall's History of Greece .........

Thonson's (Archbishop) Laws of Thought

(J.) Tables of Interest .........

Conspectus, by B I R KET'......

ToDd's Cyclopadia of Anatomy and Pliysio-

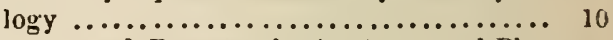

and Bowman's Anatomy and Phy-

siology of $\operatorname{Man} . \ldots \ldots \ldots \ldots \ldots \ldots \ldots \ldots . . . .10$

Trowlope's Barchester Towers.......... 16

Warden .................. 16

Twiss's Law of Nations .............. 13

TYNDALL's Lectures on Heat........... 8

URE's Dictionary of Arts, Manufactures, and

Mines ............................

ViN DER Horven's Handbook of Zoology

VAUGHAN's (R.) Revolutions in English

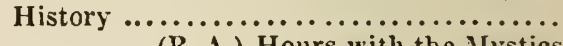

(R. A.) Hours with the Mystics

Villari's Savonarola ...............

Watson's Principles and Practice of Plysic

WatTs's Dictionary of Chemistry..........

WeвB's Celestial Objects for Common 'iele. scopes ......................... 7

WEBSTER \& WILKINSON's Greek Testament I3

WeLD's Last Winter in Rome........... 15

WELLINOTON's Life, by brialmont and

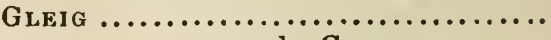
by GLEIo ............

West on the Diseases of Infancy and Child-

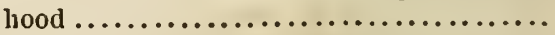
WhateLy's English Synonymes ........

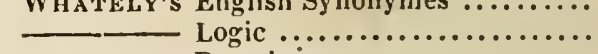
Lemains......................

- Rhetoric ................. - Sermons................... - Paley's Moral Phylosophy ....

WHEWELL's History of the Inductive Sci-

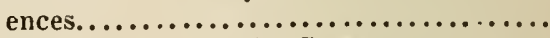

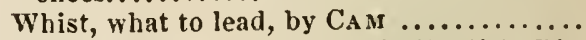

WHITE and RIDDLE's Latin-Englislı Dictionary .......................... WILBERForce (W.) Recollections of, by

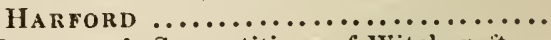
WiLlaAs's Superstitions of Witcherait .. Willich's Popmlar Tables ............... Wilson's Bryologia Britannica........... Wood's Honjes without Hands ........... WooDWARD's Historical and Chronological

Encyclopxdia .....................

YoNoE's English-Greek Lexicon ......... Abrilged ditto ...............

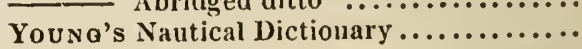

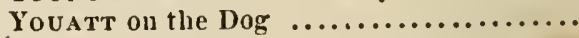
4 10

11

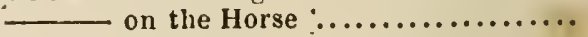

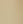
政

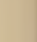
7 8 2 19 0

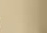
(

8



HD9195

$$
\begin{gathered}
B 72 B 36 \\
1848
\end{gathered}
$$



